\title{
LA FRONTERA DEL ESTADO INCA
}

Tom D. Dillehay y Patricia Netherly, compiladores

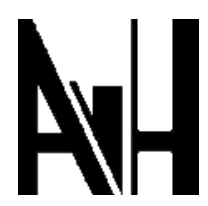

FUNDACION ALEXANDER

VON HUMBOLDT

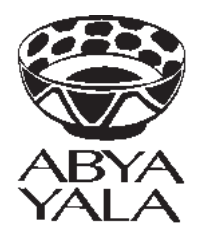

EDITORIAL ABYA-YALA 


\section{SEGUNDA EDICION REVISADA}

Los artículos presentados en La Frontera del Estado Inca fueron expuestos como ponencias en la sesión del mismo nombre en el 45 Congreso Internacional de Americanistas, realizado en Bogotá, Colombia en 1985.

La primera edición fue publicada por B.A.R. de Oxford, Inglaterra, como el No. 442 de su International Series.

(C) Por los autores individuales

Todos los derechos reservados

Coedición de la Fundación Alexander von Humboldt y Editorial Abya-Yala.

Pedidos a Fundación Alexander von Humboldt, Casilla 17-21-1202, Quito, Ecuador o Abya-Yala, Quito.

Precio al Exterior: US\$15.00 más US\$5.00 franquicia

Precio Nacional: S/.65,000.

Foto de la carátula: Byron Camino P., Callanca de Carangui.

Plano del dorso: Max Uhle (1925). Plano de Tambo Blanco.

Asistentes de Producción: Cecilia Ríos

Marcela Facchinci

Diagramación: Oswaldo Dávila

Rocío de Dávila 


\section{CONTENIDO}

Páginas

Colaboradores

Prefacio a la segunda edición.

Patricia J. Netherly,

Tom Dillehay

Introducción

Tom D. Dillehay,

Patricia J. Netherly

Las fronteras estatales extremas del Tawantinsuyu

John Hyslop

Frontera aborigen y dualismo inca en el Ecuador prehispánico:

Pistas onomásticas

Frank Salomon

Tomebamba: Primera fase de conquista incásica en los Andes septentrionales.

Los cañaris y la conquista incásica del Austro ecuatoriano Jaime Idrovo

El reino de Chimor y el Tawantinsuyu Patricia J. Netherly

Más allá de las fronteras de Chincha

Patrones de asentamiento incaicos en el Norte Grande de Chile.

Hans Niemeyer F.,

Virgilio Schiappacasse F.

Red vial incaica en los términos meridionales del imperio: Tramo Valle

del Limari-Valle del Maipo.

Rubén Stehberg,

Nazareno Carvajal

La actividad prehispánica de los incas y su influencia en la Araucania

Tom D. Dillehay,

Américo Gordon

Los diaguitas y el Tawantinsuyu: Una hipótesis de conflicto

Ana María Lorandi

Comentario: Las fronteras del estado inca Richard Schaedel

Epílogo

Tom D. Dillehay,

Patricia J. Netherly 


\section{Colaboradores}

Nazareno Carvajal

Universidad de Chile, Santiago.

Tom D. Dillehay

University of Kentucky, Lexington, Kentucky

Universidad Austral de Chile, Valdivia.

† Américo Gordon

Sociedad Arqueológica de Chile, Temuco.

† John Hyslop

Institute of Andean Studies, New york.

Ana María Lorandi

Instituto de Ciencias Antropológicas

Buenos Aires, Argentina.

Jaime Idrovo

Museo Etnográfico

Banco Central de Ecuador, Cuenca.

Craig Morris

American Museum of Natural History, New York.

Patricia J. Netherly

Plácido Caamaño N25-62 y Colón. Casilla 17-21-1202, Quito, Ecuador.

Hans Niemeyer

Museo Nacional de Historia Natural, Santiago.

Richard P. Schaedel

Department of Anthropology

University of Texas

Austin, Texas

Virgilio Schiappacase

Sociedad Arqueológica de Chile, Santiago

Ruben Stehberg

Museo Nacional de Historia Natural, Santiago 


\section{PREFACIO \\ A LA SEGUNDA EDICION}

Luego de un lapso de diez años, nos es grato poner en manos de los especialistas y el público en general una segunda edición de La frontera del estado inca. El presente texto ha sido revisado por infelicidades de traducción y redacción, y errores tipográficos, pero no hubo oportunidad de enviar los trabajos a los autores para su actualización. En realidad, como nos comentó un colega amigo, los trabajos presentados aquí aún son innovadores y corrientes. Lo cual indicaría que estuvieron bastante adelantados para la época de la publicación original.

Los motivos que nos impulsaron a sacar nuevamente el libro fueron la poca circulación que tuvo la primera edición, publicada por B.A.R. en Inglaterra justo antes de la desaparición del director de esa editorial desktop. Los investigadores sudamericanos, sobre todo, habían quedado sin acceso a los resultados de sus propios colegas. Fue difícil obtener copias individuales y el precio, moderado en dólares, estaba fuera del alcance de muchos de la comunidad universitaria latina. Hemos tomado esta oportunidad para rediagramar el texto y buscar la mejor reproducción posible para las figuras.

Ahora la Editorial AbyaYala de Quito, de difusión continental y la Fundación Alexander von Humboldt, también de Quito, por medio de su programa de publicaciones que aspira una difusión continental, han unido esfuerzos en la coedición de la segunda edición de La frontera del estado inca. Esta edición está patrocinada por la Fundación Alexander von Humboldt y la Universidad de Kentucky, Estados Unidos.

Es nuestro deseo que los interesados en adquirir el libro tengan solo que dirigirse a uno de los coeditores, cuyas direcciones se encuentran al dorso de la página titular.

Las ideas y los resultados obtenidos por los autores lucen perennes por sus propios méritos. Las investigaciones continúan y se espera que en un futuro las interrogantes planteadas en el presente volumen reciban respuestas, algunas de las cuales serán sorprendentes.

Quisiéramos recordar a dos colegas fallecidos después de la publicación de la primera edición: John Hyslop, desaparecido muy joven y en plena actividad, y Américo Gordon, lleno de años pero de mente y espíritu jóvenes. Ambos dejaron una obra digna de emular.

Quito, diciembre de 1997

Patricia J. Netherly

Tom D. Dillehay 


\title{
INTRODUCCION
}

\author{
Tom D. Dillehay \\ Patricia J. Netherly
}

El estudio de las fronteras del estado inca está vinculado con la gran diversidad de situaciones y relaciones que resultaron de la expansión y conquista de grupos culturalmente distintos. De estos contactos surgieron complejas interacciones que deben ser entendidas dentro del marco del intercambio de información y recursos, de las relaciones entre conquistador y conquistado, así como del esfuerzo por establecer el control político y económico. Cada una de estas relaciones tenía características particulares. Sin embargo, hasta el momento, poco se ha logrado en cuanto a la identificación y comprensión de las distintas formas de interacción a lo largo de las fronteras estatales.

La expansión incaica creó numerosos estados de frontera, sin embargo, nuestro conocimiento del territorio del imperio, tanto interior como fronterizo, es en algunos casos nulo y en otros solo parcial. La etnohistoria brinda un panorama general de los eventos y organización del estado a lo largo de las fronteras donde estaban establecidos diferentes grupos étnicos que habían o no habían caído bajo el control del Tawantinsuyu. De esta información, podemos inferir que en algunos casos la actividad del estado y la manera en que se organizó en las zonas de frontera fue incompleta, requiriendo formas de control social, político y económico distintas a las aplicadas en el interior del imperio. Aunque la naturaleza general de la actividad incaica al norte, sur $\mathrm{y}$, en menor escala al este, puede ser trazada a través de documentos etnohistóricos, un entendimiento del proceso de la acomodación cultural e institucional de los pueblos conquistados es bastante más difícil de lograr. La adaptación de las instituciones es de particular importancia dado que las formas de organización indígena que se encuentran en el presente entre los grupos indígenas, son parcialmente el resultado del proceso de adaptación ocurrido en la época de la dominación incaica. Aún cuando queda mucho trabajo por realizar al respecto, ya han sido señaladas amplias zonas en las cuales esta adaptación ocurrió.

Además, los límites del imperio inca fueron reforzados mediante el traslado de gobernadores y mitimaes, pueblos leales o subyugados, hacia territorios que habían sido colonizados y conquistados paulatinamente, intentando así integrar estas áreas y sus habitantes dentro de las esferas sociales y económicas del Tawuantinsuyu, al igual que otros aspectos de la cultura y la organización, la expansión y la colonización reflejan los principios y la complejidad de la organización de la sociedad inca. Tanto las justificaciones como la forma y magnitud de la expansión y colonización parecen variar según el nivel de integración sociocultural de la sociedad inca en desarrollo y su papel dentro del mayor escenario regional de interacción política y económica. Es probable que las regularidades observadas en la expansión inca indiquen causas y circunstancias paralelas a los límites. Los análisis comparativos de límites diferentes pueden revelar tales regularidades e identificar sus causas. El análisis de los límites 
incas debería identificar procesos tanto similares como diversos en la expansión del estado, la formación de esos límites y el cambio de los mismos. Esto podría ser útil a la investigación sobre el desarrollo del estado inca y en muchos aspectos de la formación del imperio.

Como los límites del estado inca casi siempre incluían la interacción de varios grupos, aparte del inca, todo estudio debería considerar la organización de los incas y de los habitantes locales. La mayoría de los estudios científicos sobre el estado inca están enfocados principalmente en la evolución del estado conquistador. Sin embargo, los efectos de la expansión y colonización en los grupos ya existentes en las zonas conquistadas son también dignos de investigar, si se quiere estudiar todos los elementos relevantes de un sistema de interacción dentro de un estado integrado.

En el 45 Congreso Internacional de Americanistas celebrado en Bogotá, Colombia, en el año de 1985, organizamos un simposio sobre los límites del estado inca con el fin de: 1) explorar algunos problemas de investigación identificables dentro del estudio de los límites incas; 2) reunir proyectos de investigación que se realizaban en las áreas de límites del estado; 3) evaluar los tipos de evidencia disponibles sobre esos límites e 4) intentar examinar las diferentes situaciones y procesos en la formación y cambio de tales límites, concentrándonos específicamente en la identificación arqueológica y etnohistórica de la forma en que el estado se organizó en situaciones diferentes.

El propósito del presente volumen es reunir los ensayos presentados por los participantes en el simposio, como una manera de enfocar la atención sobre el tema de las fronteras.

Señalamos desde un principio que estos ensayos no cubren todos los temas claves acerca del desarrollo del estado inca y sus principales áreas geográficas. Existen dos razones para este tratamiento desigual. Primero, son pocos los estudios arqueológicos e históricos en la mayoría de las áreas relacionadas con las fronteras. Este volumen incluye los trabajos de estudiosos que están activamente comprometidos con estas áreas. En segundo lugar, al invitar a los participantes de este simposio, intentamos incluir una amplia gama de investigadores dedicados al estudio de la expansión y las fronteras del estado inca a lo largo de los Andes. Particularmente notable es la ausencia de trabajos sobre Colombia y el norte del Ecuador, la mayor parte de Bolivia y algunas áreas de la sierra del Perú. Algunos colegas de diferentes países fueron invitados al simposio, pero, por una razón u otra, no pudieron estar presentes y tampoco enviaron su colaboración para ser incluida en este volumen.

\section{IMPRONTUS DE LA INVESTIGACION DE LAS FRONTERAS DEL ESTADO INCA}

Además, en general, los artículos no tratan los tipos de problemas que han preocupado a la mayoría de los estudiosos del estado inca, es decir, amplios aspectos de la organización social y económica. Como la investigación arqueológica e histórica 
previa ha sido insuficiente, la mayoría de los especialistas se han enfocado en aspectos específicos del desarrollo local y regional. En las últimas cuatro décadas muchas investigaciones han tocado el tema de la organización del estado inca, y la organización social, política y ritual de la sociedad andina bajo el dominio inca. Entre estos temas están: Murra presenta la organización administrativa del estado expansionista (1970a, 1972 , 1975, 1980), además de la organización y el rol de las poblaciones locales dentro del estado (Murra 1970a, 1972, 1980; Netherly 1977, 1984, Rostworowski Murra 1970, 1977, 1981; Watchel 1977; Zuidema en particular, ha dado énfasis a la organización sociopolítica y los ciclos rituales, 1964, 1982a, 1982b). Otros han tocado las variaciones y similitudes regionales de la geopolítica inca (Collier et al 1982; Espinosa Soriano 1971, 1972, Masuda et al. 1985; Rostworowski 1983; Salomon 1986). En cuanto al tema de la obtención de recursos para el mantenimiento del estado y el soporte de su expansión, la administración de la recolección de productos y del trabajo humano contribuidos por la población organizada en señoríos y, finalmente, los mecanismos de control para todas estas actividades (D'Altroy 1987, D'Altroy y Earle 1985; Murra 1975, 1980).

Hasta ahora no se ha prestado la debida atención a la política inca de expansión ni a la políticas involucradas en la conquista, la incorporación de grupos dentro del mismo imperio y la historia de las expresiones suscritas en la diversas fronteras del tawuantinsuyo. Los artículos en esta colección pretender esclarecer las fronteras, límites internos y externos del imperio inca.

Estos trabajos no presentan una unidad teórica o metodológica, se trata de enfoques muy diferentes y a veces incompatibles. No creemos que ésto sea una desventaja, al contrario, ésto ha constituido uno de los aspectos más productivos del simposio. Podríamos agregar que de este modo se refleja también la realidad de este campo de estudio en la actualidad. En esta etapa temprana de la discusión del desarrollo del estado inca, ha sido necesario y fructífero presentar los resultados de enfoques más amplios y puntos de vista muy diferentes.

Está fuera del alcance de este capítulo introductorio la entrega de un informe detallado de la historia y las consideraciones científicas del imperio inca, así como el desarrollo de sus límites internos y externos. Tal esfuerzo requiere un análisis teórico más riguroso y extenso. También queda fuera de la intención y propósito de esta introducción el desarrollo de métodos y modelos específicos derivados de la arqueología y la etnología para estudiar este fenómeno. No obstante, nuestro propósito es intentar una indagación metodológica y teórica muy general de estos aspectos importantes de la formación y desarrollo del estado inca. Para lograr este propósito, si es que pretendemos avanzar en su conocimiento, es necesario ir más allá del análisis de la frontera local como una entidad aislada para examinar el escenario más amplio en el cual ocurrió la expansión, con el fin de alcanzar un conocimiento más cabal de los cambios en los límites y su relación con el desarrollo del estado. La historia del desarrollo de los límites del estado inca no se puede entender adecuadamente sin recurrir al ámbito cultural más amplio en el cual las economías de todas las áreas afectadas están entrelazadas en una red de interdependencia mutua. 
Esta discusión empezará con un análisis breve de las fuentes escritas y las limitaciones de la información que proporciona sobre la extensión geográfica de las fronteras del estado inca para luego resumir brevemente los tipos de evidencia disponibles, los puntos más notables de cada artículo y su contribución al estudio sobre los límites. Después, se presenta un sumario breve de cada ponencia. Enseguida, se considera en forma más extensa los comentarios y enfoques más generales para el estudio de los límites y las orientaciones para investigaciones futuras.

\section{ANÁLISIS CRÍTICO DE LAS FUENTES ESCRITAS}

Los artículos incluidos en este trabajo examinan los diversos aspectos de la frontera inca, en base a documentos y evidencia arqueológica.

La información sobre la actividad del estado existente en las crónicas ha sido cuidadosamente presentada (véase Rowe 1942; Murra 1970b, 1972, 1975; para obtener una lista general con comentarios sobre la mayoría de estas fuentes). El contenido de estas relaciones revela el significado que tuvieron los eventos particulares, ocurridos en áreas específicas, para los cronistas españoles y los motivos que los llevaron a preservarlos. Como Murra y otros antropólogos e historiadores lo han señalado, el registro escrito puede contener prejuicios que son el resultado de estereotipos sociales, políticos, económicos, étnicos, religiosos, raciales y otros presentes en aquellos que lo compilaron. Para interpretar el registro documental, el investigador debe considerar su contenido a la luz de los prejuicios potenciales del autor, así como verificar la exactitud de la información observando la coherencia de ésta en relatos comparativos (Murra 1970b, 1972). Los documentos históricos, así como otros artefactos del pasado, también están sujetos a los propósitos de la gente que los produjo (Netherly 1988). Con estos antecedentes en mente, debería quedar claro que el registro documental histórico sobre los incas pueden contener muchas lagunas e información distorsionada.

Sin embargo, los documentos pueden ser muy útiles, proporcionando información sobre eventos regionales, circunstancias y cambios ocurridos. Los procesos de cambio, tales como los que están involucrados en la expansión del estado, son generalizaciones extraídas del análisis comparativo de situaciones registradas en documentos en las cuales las variables económicas, ecológicas y otras se mantienen constantes. Las características de tales procesos se manifiestan en eventos observados y registrados por extraños a la cultura y compilados posteriormente por otros. Las fuentes escritas incluyen documentos públicos, relacionados al estado o a la iglesia; y documentos privados, por ejemplo, cartas personales. Estas pueden proveer información directa y comparativa de gran utilidad para la discusión y ordenamiento de los eventos en secuencias que explican los procesos de cobertura más amplia. Esta información, de hecho, contiene los prejuicios de sus autores, pero también está sujeta a las limitaciones basadas en los intereses de los grupos étnicos y las instituciones españolas para las cuales fue redactada (Murra 1970b; Netherly 1977, 1988). 
Los datos relacionados con los procesos de desarrollo y cambio proporcionados por los estudios arqueológicos, constituyen una fuente de evidencia histórica muy diferente. Más que el resultado de un esfuerzo consciente para registrar hechos del pasado, los materiales arqueológicos son los subproductos de las actividades asociadas con tales eventos (Morris 1972). El registro arqueológico se formó, en su mayoría, como un resultado de las actividades diarias realizadas por toda la gente sujeta al estado. El registro material que no está disturbado, en contraste con las fuentes escritas puede entregar una expresión cultural sin sesgo porque carece del prejuicio inherente en estas últimas (Murra 1962; Murra y Morris 1976a; Morris 1984). Tanto la información arqueológica como la histórica están incompletas. Sin embargo, utilizadas en conjunto aumentarán nuestro entendimiento del estado inca.

La evidencia arqueológica, aunque es más extensiva y menos susceptible a la falsificación, presenta problemas de interpretación que son a menudo más complejos que aquellos que se encuentran en los registros históricos. Los modelos para la interpretación de los materiales arqueológicos frecuentemente se derivan del registro documental. El contenido y la distribución del material en los sitios arqueológicos se pueden usar como base para inferir los tipos de actividades, incluso estatales, que ocurrieron allí, y así para identificar la función de los asentamientos.

No obstante, la inferencia arqueológica no es ilimitada. Siguiendo a los arqueólogos es necesario desarrollar un conocimiento acerca de la dinámica de las actividades del estado involucradas en el sistema socio-cultural local, antes de poder interpretar la relación entre el modelo arqueológico y la organización del estado. Aquí es donde los documentos históricos juegan un papel importante para los arqueólogos. Entregan información específica acerca de las actividades del estado inca a nivel local, proveyendo así una información adecuada para que los arqueólogos puedan comprobar ciertas proposiciones acerca del registro arqueológico del mismo (véase Dillehay 1976; Hyslop 1984; Julien 1982; Morris 1967, 1972, 1978-80, 1984; Morris y Thompson 1974, 1985; Netherly 1977, 1984, 1988).

\section{LOS LÍMITES DEL ESTADO INCA}

Aunque nunca se ha hecho un estudio sistemático sobre los límites del estado inca, varios estudiosos han entregado una sinopsis detallada de los límites políticos y geográficos del imperio (entre otros, Baudin 1961; Hyslop 1984; Metraux 1969; Murra 1980; Rowe 1942, 1982; Schaedel 1978; Uhle, 1909; Zuidema 1964, 1982a, 1982b).

El primer investigador que observó un componente del proceso a nivel regional en la expansión del estado fue John H. Rowe (1942). Otros han hecho comentarios sobre el carácter del estado, a medida que se formaba, mediante la continua expansión fuera del Cuzco, hacia nuevos territorios por conquistar. Colectivamente estos trabajos han entregado una reconstrucción general de la extensión geográfica del estado inca y las relaciones entre el estado y los grupos étnicos locales. 
El Valle del Cuzco, la patria del imperio inca, en donde se concentró la población y los recursos durante la etapa inicial del desarrollo del estado en el siglo XV y la sociedad inca asumió sus características básicas, abarcó una porción relativamente pequeña del territorio total incluido dentro de los límites formales del estado. A través de la historia del imperio inca los gobernantes continuaron impulsando el estado fuera del centro hacia nuevas tierras, enfrentando serios desafíos por parte de diferentes grupos étnicos en el lejano norte, a lo largo de la frontera del bosque tropical al este y también en el sur. Al inicio del siglo XVI, las fronteras en expansión se extendían aproximadamente desde la región de los Ancasmayo en el norte del Ecuador y sur de Colombia hacia el Río Maule en la parte central de Chile, con varios puentes esparcidos en diferentes áreas de las selvas amazónicas del actual Ecuador, Perú y Bolivia, así como en las tierras áridas del noroeste y centro-occidente de Argentina (Figura 1. Según Hyslop 1984 y en este trabajo).

Aunque todos estos vastos y lejanos puestos de avance estaban técnicamente sujetos a la misma organización administrativa que regía en la patria del estado, aparentemente las fronteras lejanas dieron lugar a prácticas distintas de conquista y colonización.

En parte, estas diferencias se debieron simplemente a la distancia geográfica de los principales centros poblacionales en la costa y sierra de los Andes Centrales. Este aislamiento se puede haber agraviado, pues los chasquis y la provisión de materiales por medio de las obligaciones de productos y mano de obra requerida a las poblaciones locales, a pesar de todo, no franqueaban las grandes distancias entre el cuzco y las fronteras lejanas. Sin embargo, gran parte de la configuración distintiva de la organización y cultura limítrofe reflejó la naturaleza de los patrones étnicos que los incas encontraron en estas regiones.

En la zona central del imperio, que en gran medida coincidía territorialmente con las regiones agrarias y pastoriles densamente pobladas y altamente organizadas en el Perú Central y el norte de Bolivia y Chile, se lograba un control efectivo de la vasta población en forma bastante fácil después de un período de conquista inicial. La dominación inca fue lograda removiendo a las élites locales gobernantes de sus altos puestos de autoridad político-religiosa y reemplazándolas por una administración inca o permitiéndole al gobernante local continuar en el poder bajo el fuerte mandato de los administradores del estado (Menzel 1952; Murra 1980; Rowe 1942). Localmente, los miembros de las comunidades étnicas continuaron sirviendo a sus nuevos gobernadores por medio de tributos en mercaderías y servicios, tal cual habían servido a los gobernantes nativos. Así que los incas pudieron ejercer control sobre suficiente mano de obra nativa y recursos como para crear colonias bastante estables y sedentarias en la mayoría de las áreas (Rowe 1942). En este sentido, es claro que el estado fue mantenido por la mano de obra nativa y no por el tributo de bienes. La mano de obra fue convertida en bienes y servicios para la manutención del estado inca.

A medida que los incas se expandieron más allá de las áreas de alta cultura en los Andes Centrales, hacia el sur de Bolivia, el noroeste de Argentina y la parte central 


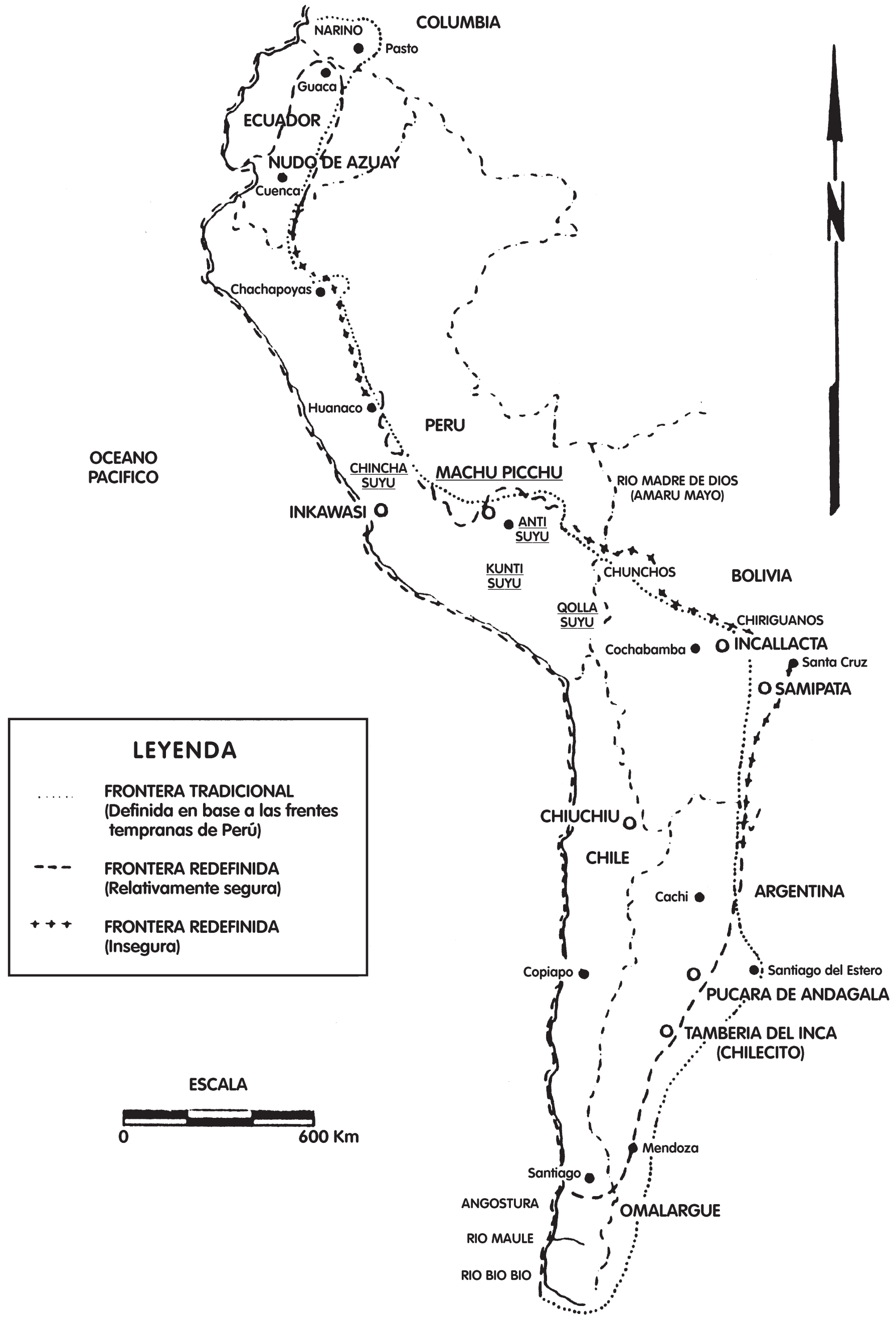

Figura 1.- Las fronteras del Tawantinsuyu (Según Hyslop este tomo). 
de Chile, no siempre encontraron señoríos densamente poblados con una experiencia previa de dominación por un imperio. Los pocos agricultores ubicados en las nuevas áreas conquistadas no podían ofrecer entregar productos de interés al estado inca. En las montañas orientales del Ecuador, al sureste de Colombia (Uribe 1975, 1977-78), al sur de Chile y las vastas mesetas y desiertos de las tierras altas del sur de Bolivia, el noroeste de Argentina, al igual que en los de la parte norte y central de Chile, habían pequeñas aldeas cuyos habitantes horticultores parciales, cazadores-recolectores eran más móviles (Rowe 1942). En muchas de estas áreas, los incas encontraron poblaciones móviles y belicosas organizadas en bandas esparcidas. Aunque los incas capturaron mucha gente en esta área para proveerse de mano de obra en las minas y proyectos del estado, no lograron el control absoluto de estas poblaciones étnicas por la forma dispersa de su organización social. Otras veces, la causa fue la retirada de estas bandas hacia áreas no conquistadas. También está presente el concepto de entregar productos y mano de obra para evitar la conquista. Parece que ésto es también lo que los incas hicieron con los señoríos huancavilcas de la costa del Golfo de Guayaquil y el valle del Guayas (Marcos y Norton 1984).

Si por un lado se pretendía asegurar estos territorios externos para los propósitos de colonización estatal y por otro, controlar a los grupos dispersos para incorporarlos de manera efectiva como trabajadores contribuyentes dentro de la estructura del estado, habría que conquistarlos. Aparentemente, esta tarea nunca se logró cabalmente a lo largo de los límites externos del estado en lo que es hoy Colombia, Ecuador, la mitad sur de Bolivia, el noroeste de Argentina y la parte central de Chile.

También es importante observar al respecto que la mayoría de los grupos étnicos residentes en las selvas orientales permanecieron separados de la influencia inca. Como lo ha señalado Rowe (1942), al parecer los incas tuvieron problemas de organización al enfrentar la conquista y control de los grupos que habitaban la selva. Fracasaron los esfuerzos militares para penetrar y someter estas áreas, sin embargo, el estado pudo haber intercambiado con estos grupos, o bien, tuvo otro tipo de relaciones con ellos.

Para concluir las observaciones anteriores, no deberíamos esperar que todas las regiones fronterizas, aún aquellas que presentan el mismo tipo de actividad estatal, sean idénticas, ya que cada una involucra una adaptación a las circunstancias encontradas en un específico ambiente natural y social. Sin embargo, la similitud general de sus adaptaciones, particularmente respecto a los tambos y sistemas de caminos estatales, parecen indicar la ocurrencia de procesos comunes en la colonización de las fronteras por parte del estado. Desafortunadamente todavía no ha sido explorado adecuadamente este aspecto de la diferenciación social y económica interna dentro del estado inca. Resta por considerar la probable importancia de las diferentes condiciones fronterizas en el desarrollo expansivo del estado inca y en los cambios ocurridos dentro del mismo como resultado de esta expansión. 


\section{LOS EXPOSITORES EN EL SIMPOSIO}

Los participantes en el simposio fueron Silvia Alvarez (Programa de Arqueología, ESPOL, Guayaquil, Ecuador); Pío Pablo Díaz (Museo Cachi, Argentina); Tom D. Dillehay (University of Kentucky, EE.UU. y Universidad Austral de Chile, Valdivia); Alberto Rex González (Consejo de Investigaciones, Argentina); John Hyslop (American Museum of Natural History, EE.UU.); Américo Gordon (Sociedad Arqueológica de Chile, Temuco); Virgilio Schiappacasse (Sociedad Arqueológica de Chile, Santiago); Jaime Idrovo (Museo de Arqueología, Banco Central del Ecuador, Cuenca), Ana María Lorandi (Universidad de Buenos Aires, Argentina); Jorge Marcos (Centro de Arqueología y Antropología, ESPOL, Ecuador); Craig Morris (American Museum of Natural History, EE.UU.); John V. Murra (Cornell University, EE.UU.); Hans Niemeyer (Museo Nacional de Historia Natural, Chile); Patricia Netherly (University of Massachusetts Amherst, EE.UU.); Frank Salomon (University of Wisconsin, EE.UU.); Nazareno Carvajal y Ruben Stehberg (Museo Nacional de Historia Natural, Chile). John V. Murra (Cornell University, EE.UU.), Richard Schaedel (University of Texas, EE.UU.) y R.Tom Zuidema (University of Illinois, EE.UU.) fungieron como comentaristas. Se presentará a continuación una reseña breve de los puntos más importantes de cada trabajo, al igual que algunos de los comentarios que suscitaron. A ésto le seguirá una breve discusión de los problemas de investigación y las tendencias identificadas durante el curso del simposio incluyendo, a la vez, recomendaciones para futuras investigaciones vinculadas al problema de los límites del estado inca.

\section{EXPOSICIÓN SUMARIA DE LAS PONENCIAS}

El trabajo presentado por Craig Morris bajo el título "Más allá de las fronteras de Chincha" se centra en las relaciones que los pobladores de Chincha mantuvieron con los de las regiones del Ecuador y del Cuzco. El autor discute la evidencia etnohistórica y arqueológica para el comercio marítimo establecido entre el reino costeño y la región norte del imperio, en base al intercambio de minerales como el cobre y la plata provenientes del sur, así como de la concha llamada Spondylus que se encontraba en la costa occidental del Ecuador. Al parecer, Cuzco alentó dicha relación reconociendo la importancia del grupo costeño como centro de intercambio, lo cual motivó la construcción de un complejo inca en el sitio capital de Chincha de La Centinela y también de un camino que unía la zona del litoral con la región alto-andina. Aunque el estudio se encuentra en una etapa preliminar, Morris cree posible sugerir, en base a la evidencia, que este tipo de relaciones indica la necesidad de imaginar el territorio incaico como un conjunto de vinculaciones establecidas entre las distintas regiones a lo largo de los Andes Centrales y no como un estado integrado y homogéneo. De allí, la importancia de señalar la manera como el Inca, desempeñando una serie de funciones políticas, sociales y económicas, logró integrar las zonas del interior y exterior del imperio.

En su estudio sobre "La frontera inca con el Reino de Chimor y el Tawantinsuyu", Patricia Netherly analiza la confrontación entre los estados chimor e inca y la mane- 
ra como los incas administraron el estado de la costa norte utilizando datos etnohistóricos y arqueológicos. En la administración de la zona norte del Perú los incas favorecieron a los pobladores de la zona alto-andina construyendo un importante centro administrativo en la Provincia de Cajamarca. Además, los incas construyeron otros centros de orden secundario en las tierras ubicadas en la parte definida por los habitantes andinos como chaupiyunga. Finalmente, la autora señala que la conquista y dominio de la Costa Norte parece haber alterado las divisiones existentes entre los grupos de altura y los de la costa.

Tomebamba, otro importante centro administrativo inca localizado en la ciudad de Cuenca en el Ecuador, es el tema desarrollado por Jaime Idrovo en su presentación "Tomebamba: Una primera fase de conquista incásica en los Andes septentrionales". Idrovo utiliza documentos históricos para reconstruir la ruta seguida por los incas en el proceso de la conquista de la región y, al mismo tiempo, identifica la secuencia del proceso administrativo empleado por los invasores en su esfuerzo por obtener el control de la región. En el período de Tupac Yupanqui, los incas conquistaron la parte central y occidental del territorio Cañari. Dos décadas más tarde, Huayna Capac completó la conquista. Dándose cuenta de la importancia social y económica de la región, los incas construyeron un importante centro administrativo: Tomebamba. Sin embargo, no fue hasta la construcción de numerosos templos que se consolidó el control sobre esa región. Finalmente, durante los primeros 25 años del siglo XVI, los incas construyeron otro importante centro militar y administrativo en Quito, el cual asumió un papel similar al de Tomebamba para el norte . Quito habría de convertirse en la base para la reanudación de las actividades de conquista en dirección norte.

Un breve trabajo presentado por Silvia Alvarez se centra en "El territorio de los Huancavilcas" en Ecuador. Utilizando un documento del Archivo General de Indias en Sevilla, la autora señala que Cuzco estableció un tratado con las poblaciones de la costa ecuatoriana a fin de evitar la invasión de esa región. Lo interesante del caso es que esta particular situación de "territorio libre" se prolonga prácticamente hasta nuestros días, dándonos una idea del carácter político que tuvo el establecimiento de los límites fronterizos en el área.

Jorge Marcos presenta un trabajo titulado "Los incas fuera de la costa central del Ecuador: la Isla de la Plata". Esta ponencia discute la manera como la llegada de los españoles interrumpió un antiguo sistema de intercambio que los incas habían manejado durante su dominio. El estado inca no solo sacaba ventaja de las estructuras políticas existentes, tal como muchos investigadores han señalado para otras áreas del Perú, sino que, como en el caso de los Huancavilcas y la Isla de la Plata, también obtenía beneficios explotando las redes de comercio existentes.

En su trabajo realizado sobre el Ecuador y titulado "Frontera aborigen y dualismo inca en el Ecuador prehispánico", Frank Salomon presenta un interesante enfoque metodológico en cuanto al análisis de la documentación etnohistórica y de los nombres utilizados en las lenguas indígenas. Este trabajo ofrece un novedoso e informativo tratamiento metodológico y conceptual aplicado al análisis de información correspon- 
diente al período cercano a 1559 en Quito. Con anterioridad había parecido factible rastrear el cambio cultural sufrido por el grupo aborigen después de la llegada de la cultura inca. Empleando el concepto de "cuantitativos onomásticos" y el método de la antroponimia (nombres de persona), el autor intenta establecer las diferencias entre los términos que eran de carácter aborigen y aquellos provenientes de la zona del Cuzco. De esta manera podría determinarse si Quito fue una provincia culturalmente homogénea ubicada dentro del estado inca o si fue el resultado de la unión de distintos grupos étnicos. Otro tópico de interés fue la aculturación y asimilación de los aborígenes dentro del estado. Su trabajo proyecta una imagen muy distinta de lo que fue la cultura en la etapa final del imperio inca y principios de la colonia, en comparación con la versión tradicional basada en la documentación española. Es así que se concluye que la región al este de Quito albergó una población culturalmente heterogénea. Las zonas del sur y norte poseían distintos nombres, lo que probablemente reflejaba diferencias en el lenguaje así como en los aspectos sociales. También se establece que la dominación incaica motivó la adopción de muchos nombres de origen inca por parte de un sector homogéneo de la población de ambas zonas. El autor sostiene, además, que las divisiones y diferencias existentes en el período preinca entre los grupos aborígenes cercanos a Quito, así como las existentes entre los pequeños grupos políticos y los mayores grupos lingüísticos y culturales, fueron reordenadas por el Tawantinsuyu de acuerdo al sistema de las mitades anan y urin aplicado en el interior de una "provincia". Este ordenamiento significa, al menos en el caso de la zona alto-andina ecuatoriana, la reevaluación del carácter de las relaciones políticas y organizativas establecidas entre el centro de poder y los territorios preincas. Salomon analiza estas relaciones considerando el grado de complementaridad de las unidades duales y el papel que dicha relación jugó en la transformación de una "cruda" frontera militar a una frontera civilizada.

En su trabajo "Los yunga de Coca: Una frontera interna del Tawantinsuyu", John V. Murra centra su atención en un grupo étnico ubicado en la parte oriental de los Andes en la frontera norte con Bolivia. Basándose en el análisis de una visita realizada a unos cocales estatales en la zona de La Paz y en el trabajo de R. Romano y G. Tranchand, Murra examina de una manera profunda las relaciones del estado con un grupo local dedicado a la producción de la coca.

Hans Niemeyer y Virgilio Schiappacasse analizan principalmente la evidencia arqueológica sobre las actividades del estado en la parte norte de Chile. Su propósito es el de interpretar las distintas estrategias políticas y económicas empleadas por los incas conforme iban tomando control de la región. En el norte grande el estado inca ejercía un control político vertical por medio del cual el gobernante establecía representantes en las poblaciones sometidas. Nuevos asentamientos eran construidos en áreas estratégicas donde no habían centros poblados. Económicamente los incas ejercían el control sobre diferentes centros dedicados a la producción especializada de ciertos bienes, como era el caso de las guaneras. Las regiones ubicadas más hacia el sur, en la zona llamada "Norte Chico" y en la parte central de Chile, fueron controladas mediante ocasionales incursiones militares. Dicha zona era de gran importancia para el Tawantinsuyu por ser una fuente de recursos minerales, en especial de oro. El trabajo de Niemeyer y Schiappacasse es particularmente interesante porque documen- 
ta la capacidad organizativa del estado inca para establecer y mantener el control sobre zonas ecológicas y étnicas adyacentes a su área de dominio.

El trabajo "Red vial incaico en los términos meridionales del imperio" presentado por Ruben Stehberg y Nazareno Carvajal trata el establecimiento de caminos y edificios incas en la zona de Alicahue en la región central de Chile, entre los Ríos de Choapa y Putaendo. Previo al descubrimiento de este camino se pensaba que mucha de la actividad del imperio inca al sur del Valle de Elqui (La Serena) era canalizado desde la Argentina a través de la región del Uspallata hacia la zona del Aconcagua en dirección este-oeste. Esa ruta por los Andes era prácticamente intransitable en los períodos de invierno crudo. Nuevas evidencias revelan que, con la construcción del camino de Alicahue, los incas intentaban reconstruir y modificar un camino que habría unido la costa norte y sur desde el Río Elqui hacia el área correspondiente a Santiago en la región central. Es importante señalar que en esta zona se ha encontrado cerámica inca asociada con material diaguita. Stehberg y Carvajal, por otro lado, describen los típicos patrones incas de conquista: 1) uso de vías de transporte previamente establecidas; 2) colaboración y control de etnias locales y 3) emplazamiento selectivo de fortalezas y asentamientos en zonas estratégicas.

Más hacia el sur de la región araucana, Tom D. Dillehay y Américo Gordon, analizan datos arqueológicos, etnohistóricos, etnográficos y lingüísticos referentes al carácter económico, político y social de las fronteras del imperio. En su trabajo "La actividad prehispánica de los incas y su influencia en la Araucania", los autores delimitan la parte sur del imperio utilizando dos tipos de frontera: 1) una frontera geopolítica exclusiva que delimitaba la ocupación territorial en alguna parte entre la ciudad de Santiago y el Río Maipo o el Río Maule, en cuyas orillas los araucanos detuvieron el avance inca y 2) una frontera geoeconómica inclusiva, sin ocupación militar y no incluida dentro de las fronteras formalizadas del imperio inca. Esta región se extendía en forma de islas dispersas unos 500km al sur del Río Maipo o Maule en el territorio araucano. Dillehay y Gordon examinan la organización institucional del estado en el contexto de estos dos tipos de frontera, poniendo particular atención en las transacciones sociales y económicas realizadas en los límites formalizados del imperio ubicados en la región sur. El principal aporte de Dillehay y Gordon consiste en haber señalado la conveniencia de distinguir con claridad entre la frontera política formalizada y la extensa frontera no formalizada. Así, numerosas instituciones incas fueron introducidas a lo largo del Río Maule (o Maipo) a medida que las actividades del estado iban penetrando la frontera no formalizada a través de emisarios, mercaderes o exploradores que al parecer llegaron hasta Valdivia.

La ponencia de Alberto Rex González y Pío Pablo Díaz, titulada "Excavaciones Arqueológicas en la Casa Morada de La Paya, N.O.A.: La vivienda y el inventario patrimonial de un curaca inca en una provincia marginal del imperio", se ocupa del estudio del material recogido en la "ciudad" aborigen de La Paya en el Valle de Calchaquí en el noroeste de Argentina. La investigación se centra particularmente en una estructura: La Casa Morada. Recientes excavaciones en dicha construcción revelaron que había sido utilizada por un curaca local impuesto por el inca para la jefatura 
y administración de la "ciudad" de La Paya. Los autores apoyan sus hipótesis en las evidencias arqueológicas y arquitectónicas que encontraron en el lugar. Este trabajo es un claro ejemplo de la importancia de la investigación arqueológica comparada.

En otro trabajo vinculado al noroeste argentino, Ana María Lorandi hace referencia a la región del Tucumán. Basándose en la evidencia histórica Lorandi documenta la existencia de una larga frontera que actuó a manera de "colchón" defensivo entre los pobladores de las zonas de altura y los de las zonas bajas de "hondas de lule", quienes pretendían extender sus territorios hacia el oeste. Ese límite defensivo, llamado Tucumán por los españoles, estaba habitado por una población que al parecer compartía rasgos culturales tanto de las zonas bajas como de las zonas de altura. Lorandi postula que la población de Tucumán recibió el encargo del estado inca de defender esta parte de Argentina, a cambio de un conjunto de privilegios especiales dentro del estado. Más aún, algunos pobladores fueron desplazados como mitmakuna hacia otros centros artesanales del noroeste argentino. La autora define la frontera del Tucumán como un asentamiento multiétnico que existió desde antes de la conquista inca y que fue utilizado posteriormente como una frontera interna del Tawantinsuyu en esa parte del imperio.

John Hyslop analiza "Las fronteras estatales extremas del Tawantinsuyu". Juntando una serie de evidencias históricas y arqueológicas, el autor procura evaluar qué tan lejos llegó la dominación real del estado inca en 1555. Analizando los límites en el norte, este y sur Hyslop discute la información disponible para la reconstrucción de tales fronteras, las limitaciones de esa información y el grado en que las instituciones incas fueron introducidas en cada área. Apoyandóse fundamentalmente en la presencia de cerámica inca y de rasgos arquitectónicos, el autor realiza una serie de precisiones y reajustes a los límites geográficos establecidos tradicionalmente. Por ejemplo, hace hincapié en que la elaboración de un mapa de límites para los Andes Orientales en la parte norte del Perú y sur de Bolivia, podría no reflejar la realidad debido a la falta de información precisa para tal efecto. Considera, además, que la investigación arqueológica habría de jugar un importante papel en la definición de dichos límites fronterizos. Finalmente, señala que se ha tenido la tendencia de incluir dentro del imperio inca ciertos territorios que éste nunca controló y en los que su presencia solo fue ocasional a través de enviados especiales o por medio de acciones de guerra que no implicaron el establecimiento de institución alguna.

Debido al gran número de ponencias presentadas en el simposio se dispuso de poco tiempo para hacer preguntas y discutir prolongadamente cada trabajo. No obstante, los comentaristas John V.Murra, Richard Schaedel y R.Tom Zuidema aportaron algunas observaciones de gran utilidad. Murra centró sus observaciones en la necesidad de utilizar la evidencia histórica y arqueológica en forma complementaria con el propósito de elaborar preguntas adecuadas para la investigación, al igual que modelos que faciliten la detección y estudio de las diferencias y similitudes de las instituciones estatales en los sitios de frontera. También indicó la importancia de vincular dichas instituciones con las de carácter local. Schaedel, a su vez, señaló que los investigadores deberían estar más conscientes de la dinámica política y económica de las zonas de frontera en oposición a las zonas internas donde el control era más esta- 
ble. Mencionó, además, que la mayoría de los especialistas en la cultura inca ponían demasiada atención en las tendencias expansionistas del estado, descuidando el conflicto que surgió del proceso de conquista y dominación de las poblaciones locales. Schaedel subrayó, finalmente, que algunas ponencias se habían enfocado más en los problemas generales del estado inca que en el tratamiento específico del tema sobre los estados fronterizos. Zuidema se mostró particularmente interesado en que los arqueólogos trabajen con todos los aspectos e implicaciones socioeconómicas contenidas en los registros etnohistóricos y antropológicos. Anotó, además, que los asentamientos fronterizos deberían ser vistos a la luz de la organización y planeamiento del estado interesado en utilizar dichas áreas como el punto de partida para futuras actividades de expansión.

Es de hacer notar que las presentaciones del Dr.Pío Pablo Díaz, Dr.Jorge Marcos, Lcda. Silvia Alvarez, Dr. John Murra, Dr.R.Tom Zuidema y Dr. Alberto Rex González no aparecen en este trabajo.

\section{HACIA UN ENFOQUE MAS AMPLIO EN EL ESTUDIO DE LAS FRONTERAS DEL ESTADO INCA}

Como se observó anteriormente, nunca se ha estudiado cabalmente la organización social y económica en los límites del estado. Existen investigaciones arqueológicas en algunas áreas acerca de la distribución de los asentamientos. Los etnohistoriadores e historiadores han escrito sobre la territorialidad pero se han concentrado en las divisiones mayores del estado. Ejemplos de ésto son la combinación de los trabajos sobre arqueología y ethnohistoria de los nichos ecológicos aprovechados en el área del Lago de Titicaca (Hyslop 1976, 1977, 1979; Murra 1964, 1966-67, 1970a) así como sobre la actividad inca en el área de Huánuco (Murra 1962, 1966-67, 1972c; Morris 1967, 1978-80; Morris y Thompson 1974, 1985; Ortíz de Zúñiga 1967-72). Los pensadores estructurales, tales como Zuidema $(1964,1982 a)$ y otros han hecho comentarios sobre los aspectos simbólicos del espacio social aunque sin extenderlos al estudio de la sociedad inca como un todo.

Hay unas pocas generalizaciones claves que deberían ser consideradas en el estudio de la organización del estado inca. La presentación que se ofrece aquí, así como la totalidad de este capítulo, es preliminar, pero esperamos que sirva como base para la discusión y motivación de trabajos futuros. Estas generalizaciones se centran en torno a la organización política y económica de las fronteras del estado y a los diversos tipos de situaciones limítrofes posibles de encontrar.

\section{LA ECONOMÍA Y LOS TIPOS DE FRONTERAS}

La mayoría de las investigaciones sobre los incas han demostrado que los asentamientos son representaciones institucionales del sistema político y económico del estado en el cual jugaron un papel preponderante, así como una adaptación al medio social y económico de las áreas conquistadas (Morris 1972; Murra 1972c, 1975, 1978; 
Watchel 1977). Como consecuencia, estos asentamientos y las áreas limítrofes en donde pueden estar ubicados, exhiben un grado mayor de uniformidad arquitectónica y de sus conjuntos de artefactos, a pesar de los medioambientes variados en que se encuentran. Esto significa que la uniformidad se mantuvo a través de la participación en las actividades comunes del estado y por medio de la ubicación y construcción de asentamientos dirigidos por el estado. Aún siendo políticos de carácter y en la forma de control, estos asentamientos y actividades funcionaban esencialmente para obtener recursos y, en especial, mano de obra para el estado. Estos son los términos en que se les debe entender.

Una clave para relacionar los procesos económicos con el carácter y la distribución de los asentamientos fronterizos es la relación entre la producción y el transporte. La tecnología del transporte fue una variable económica importante para mantener la expansión del espacio. La red de almacenamiento y redistribución y los lazos de comunicación que ésta desarrolló fueron los factores principales en la unificación de las áreas de colonización y el mantenimiento de sus nexos con el área central del estado. Como D'Alstroy y Earle (1985), Hyslop (1984) y Morris (1972) lo han demostrado, las redes camineras guiaron la expansión del estado mediante la construcción de asentamientos a lo largo de las rutas por las cuales los recursos eran transportados hacia las áreas interiores o hacia otras fronteras del estado. En este sentido, el patrón de asentamiento en las áreas limítrofes fue generalmente el resultado directo de la necesidad de instalar sitios para controlar militarmente a las poblaciones locales y el deseo de situarse en lugares con mayores recursos, accesibles al comercio y con vías de comunicación locales y regionales. Claramente, un aspecto del desarrollo del estado inca que no ha sido tratado plenamente y que requiere de atención inmediata es la relación entre la expansión y los recursos limitados, incluyendo la mano de obra de cada área de colonización.

La relación entre los patrones de asentamiento y los papeles económicos en una sociedad inca en expansión también ha sido discutida anteriormente (Hyslop 1984 y Morris 1972, 1984, en este trabajo). Implícitamente, ambos se adhieren a dos tipos de expansión o fronteras estatales que se distinguen por la distancia a la capital, Cuzco. El primero es el período de subyugación, la duración y naturaleza de los nexos de interacción con el área de Cuzco y las áreas del estado insular en la parte central del Perú. El segundo, la distancia, duración y naturaleza de la interacción se manifiestan en el nivel de subyugación y el cambio que ha sufrido una sociedad conquistada. Las fronteras internas y externas representan diferentes fases de la expansión y desarrollo del estado. Ambas pueden ser caracterizadas por diferentes situaciones limítrofes internas y externas.

Las fronteras internas se encuentran ubicadas en los Andes Centrales. Por ser las primeras establecidas, son económicamente diferentes y de larga duración en cuanto a su naturaleza. Su éxito requirió una adaptación más extensiva del estado a las condiciones locales, promoviendo nexos con el sistema socio-económico del área del Cuzco que llegarían a ser mayores y más directos a través del tiempo. Este tipo de 
frontera se hace presente en los estudios de Morris, Netherly, Niemeyer \& Schiappacasse y Salomon.

Las fronteras externas representan la forma inicial de la interacción entre la patria y la nueva frontera colonizada. Esta se desarrolla en una frontera interna en la medida en que se prolonga y se ensancha la expansión más allá de los límites del estado. Posteriormente, podremos encontrar que algunas fronteras externas estaban económicamente especializadas, en forma de un asentamiento económico o de un puesto de avanzada militar. Estos eran a menudo de corta duración y su éxito dependía, en gran parte, de las necesidades económicas y la política de los incas. Como resultado de la manipulación directa en las actividades de los asentamientos, podríamos esperar un escaso nivel de compromiso estatal y poca oportunidad para el desarrollo económico local. Es posible encontrar ejemplos de fronteras externas especializadas en las tierras de grupos marginales, como los araucanos en el sur de Chile, los numerosos grupos de la selva tropical, sobretodo de la "ceja de la selva" en las colinas del este de los Andes y varios grupos en Colombia y Ecuador. Desde el punto de vista arqueológico, podríamos encontrar sitios de explotación especializada a lo largo de cierta frontera externa, con poca o ninguna arquitectura, cerámica u otros rasgos pertenecientes al estado. Dillehay \& Gordon e Idrovo \& Lorandi presentan algunos casos que se ajustan a este tipo de frontera.

El desarrollo de cada tipo de frontera está basado en los requerimientos de adaptación según el tipo y propósito de la expansión del estado en el área. Considerados a la luz de la función principal de las fronteras en la política y economía del estado, los procesos de cambio que acompañan la expansión tienen que ser considerados como procesos de desarrollo regional. Probablemente, estos procesos estaban condicionados por la función que tenía el asentamiento en la frontera y en el sistema socioeconómico mayor del estado inca, así como por la naturaleza de los vínculos de la región con la población local y con la patria en el centro del sistema. Gran parte de la variedad observada en el desarrollo de las fronteras individuales, tanto internas como externas, puede explicarse por su grado de adaptación sociocultural y por medio de su función particular como regiones limítrofes internas y externas. Debido a las diferencias fundamentales entre los diferentes tipos de subordinación y colonización, la evolución de cada una probablemente tuvo lugar a lo largo de sendas diferentes. La naturaleza temporal y restringida de la frontera externa y la cercanía de sus vínculos con el estado también pueden haber retardado el desarrollo y cambio local. Por otra parte, las fronteras internas generalmente se convertían en sociedades permanentes con un nivel de integración comparable a la del área central del estado.

También parecería que los procesos de expansión del estado están relacionados con la adaptación de los asentamientos estatales al ambiente económico de las regiones fronterizas creadas únicamente para la explotación de sus recursos. Inicialmente, los personeros del estado llegaron con un conjunto de materiales y un definido plan de organización adaptado a las condiciones de la patria y áreas internas del estado o basado en experiencias anteriores en otro lugar (por ejemplo, fronteras externas anteriores en Perú). Si los asentamientos del estado se mantuvieron por un lar- 
go período de tiempo, deberíamos encontrar un conjunto de artefactos específicamente adaptados a la situación presente. En el caso del desarrollo de las fronteras externas, podemos imaginar que la estrecha gama de actividades iniciales asociadas con el papel especializado de conquista de un área, unido al establecimiento de un sistema caminero, puede haber restringido el registro arqueológico observable en un grado mucho mayor que en la frontera interna, económicamente diferente, en donde el desarrollo cubre un período de tiempo más extenso. Esto también debería resultar en una uniformidad mayor del material representativo del estado que es característico de la mayoría de las regiones, tal como Hyslop (1984) lo ha descrito refiriéndose a los caminos y tambos.

Aunque la frontera externa puede estar caracterizada por la uniformidad cultural que surge de una función especializada, ya sea económica o militar, ésta no debería ser completamente homogénea. Cada tipo de frontera externa se adaptó en forma diferente a las otras, puesto que estaba organizada en una forma que permitiera la explotación más eficiente de un área con recursos particulares. En consecuencia, probablemente allí mismo se desarrolló modificando su propio ambiente cultural como un medio para cumplir con la tarea. Así, la variación en el conjunto de artefactos dentro de un tipo determinado de frontera puede resultar de la necesidad de adaptar una tecnología uniforme a los requerimientos del medio ambiente local. La necesidad de tal adaptación podría depender del grado en que la tecnología disponible se permitió el control ambiental y del grado que alcanzó la integración dentro de la economía del estado.

En resumen, es posible plantear la hipótesis de que las fronteras externas del estado inca pueden ser visualizadas como un territorio insular fraccionado (véase Morris en este trabajo) constituido por sitios militares, sitios mineros, asentamientos urbanos y sitios de extracción de recursos en general. Pudiera darse el caso de que el estado no haya controlado las áreas que separaban los territorios fraccionados de este imaginario archipiélago, de modo que no deberíamos esperar encontrar bienes representativos del estado en todas estas áreas. Muchos factores deben haber afectado la capacidad del estado para incorporar territorios. Estas incluyen la variabilidad, tamaño del territorio y de la población local, así como también la eficiencia tecnológica utilizada en la explotación, el control político y los intereses del estado en la región.

Por último, deberíamos ser muy cautos en la correlación entre la expansión del estado y el verdadero control estatal en las fronteras externas. A pesar de la uniformidad impuesta por la política limítrofe del estado y el papel económico del asentamiento fronterizo, probablemente se dio un proceso de diferenciación local que debe haber entrado en acción permitiendo una variación de la respuesta adaptada a condiciones particulares enfrentadas en la región fronteriza. Podemos hipotetizar que la naturaleza y duración de tales adaptaciones indican el grado de control tecnológico y político en el medio local y la integración de la región con el estado. 


\section{TIPOS DE FRONTERAS Y PATRONES DE ASENTAMIENTO}

A pesar de la escasez de datos empíricos sobre el estado inca, con el fin de investigar los diferentes tipos de fronteras y su organización dentro del marco de consideraciones de la variación regional mencionada antes, es necesario considerar diseños de investigación que tengan en cuenta el desarrollo del estado. Como se señaló anteriormente, el desarrollo de modelos está fuera de los marcos de esta introducción. Sin embargo, podemos explorar los aspectos plausibles de los diferentes tipos de organización fronteriza por medio de la evidencia arqueológica y etnográfica. Una forma de lograr ésto requiere que nos concentremos en ciertos aspectos generales de la expansión y colonización del estado, susceptibles de evidenciarse en la naturaleza y distribución del registro arqueológico. Debido a que las fronteras son, en su mayor parte, un producto de los procesos políticos, económicos y demográficos que gobiernan su existencia, su estructura y organización son susceptibles de reflejar su función básica como productoras y administradoras de recursos especializados o como supervisoras de nuevos territorios u otras actividades del estado. A partir del conjunto de trabajos presentados en este trabajo y en base a la gran cantidad de literatura disponible sobre el estado inca, podemos concluir que, aún cuando todas las fronteras son económicas y políticas por naturaleza, probablemente existieron diferentes tipos. Las hubo representadas por asentamientos militares, de transporte, agrícolas, de pastoreo, de intercambio, de extracción de recursos especiales y posiblemente otras más.

¿Cómo podrían haberse identificado arqueológicamente estas diferentes fronteras? Nos parecería obvio que la arquitectura y los tipos de artefactos asociados con estos asentamientos reflejarían su función especializada. Sin embargo, al ir más allá de la evidencia material, debemos considerar también las diferencias conceptuales y funcionales involucradas en los diferentes tipos de fronteras y la forma como estas diferencias determinan el registro material.

En contraste con otros tipos de fronteras, las fronteras militares generalmente no surgen en respuesta a un interés por explotar los recursos económicos de un área periférica. Estas probablemente siempre se establecen para conquistar, proteger, regular o mantener los nexos en cuanto a transporte y comunicación se refiere, además del control político en otras áreas. Las fronteras militares fueron seguidas por las fronteras económicas y socio-políticas. Así, las fronteras favorecen la expansión del estado participando activamente en su producción primaria. A causa de su función de apoyo, la estructura de las fronteras militares y de transporte está probablemente ligada a factores distintos de aquellos que afectan a otros tipos de asentamientos y fronteras.

En otras palabras, las fronteras militares fueron creadas por los incas para establecer el control militar en una región de asentamientos periféricos. (El control político era ejercido a través de señoríos locales subordinados a inspectores estatales). Así, los asentamientos fueron establecidos para controlar las rutas de transporte y otros lugares estratégicos que vigilaban el acceso hacia tales regiones y fuera de ellas. El pa- 
trón de asentamiento arqueológico puede variar en respuesta a los factores ambientales y la naturaleza de los problemas políticos locales. Debido a sus tareas protectoras y reguladoras, los asentamientos militares generalmente estaban ubicados en lugares estratégicos a lo largo de las principales rutas de transporte de la región (Hyslop 1984). También sería posible localizar fronteras militares coincidiendo con otros tipos de asentamientos fronterizos.

Por otro lado, las rutas de transporte y los asentamientos, como cada uno de los otros tipos de asentamiento, estaban compuestos por lugares de actividad especializada cuyas funciones probablemente estaban ligadas directamente al control de la mano de obra y a la producción de bienes localizados. Ellos mantenían el flujo de información y productos dentro y entre regiones limítrofes. Así, no es de esperar que las fronteras de transporte exhiban evidencia arqueológica de las actividades de producción especializada observada en otros asentamientos fronterizos. En lugar de ésto, deberían contener materiales que reflejen su papel determinado por los medios de transporte y comunicación y mostrar solo aquellas actividades asociadas con el movimiento de bienes, personas, representantes de estado e intercambio de información. Como lo ha mostrado el trabajo de Hyslop, los patrones de asentamiento y los asentamientos de transporte parecen ser lineales en su ordenamiento, siguiendo el curso de las redes que unían las áreas fronterizas internas y externas entre sí y también con el mundo externo.

Otro tipo de frontera que no ha sido formalmente reconocida en la literatura, pero cuya existencia se ha demostrado, es la frontera de intercambio exploratorio (véase Dillehay y Gordon en este trabajo). La organización de las fronteras de intercambio requeriría una mínima presencia del estado y una estructura bastante simple. Esto incluiría los sitios en donde los bienes de intercambio y los productos nativos podrían haber sido almacenados en chullpas antes y después del intercambio. El patrón de asentamiento resultante podría consistir en sitios ampliamente separados, con una función económica especializada, ubicados dentro o bordeando los límites del estado, en los Andes del norte, este, sur o más allá de los componentes estatales en sitios locales.

Las actividades en estos sitios deberían revelar la función más bien restringida de los asentamientos y estar limitados, en su mayor parte, al intercambio de productos. $\mathrm{Si}$ es que esos asentamientos existieron, probablemente fueron pequeños y ofrecían las construcciones necesarias para almacenar bienes de intercambio y hospedar a personeros del estado. En algunas áreas, las funciones económicas pueden haberse combinado con las funciones militares u otras. Las funciones especializadas de estos sitios deberían reflejarse en una frecuencia relativamente baja de artefactos entregados por el estado o tal vez en una mezcla de diversos bienes provenientes de varias áreas del estado.

Por ejemplo, las fronteras de pastoreo y de los asentamientos del altiplano debieron ser geográficamente extensas demandando un gran número de personal y viviendas. A diferencia del intercambio, el pastoreo de camélidos estaba centrado en la 
producción real de animales y subproductos animales como la lana y el charqui; y hasta cierto punto en el intercambio de los mismos. Dado el tamaño del imperio inca, el patrón de asentamiento debería estar caracterizado por varias formas de transporte, tales como las estaciones de control, tambos, redes camineras y corrales (Hyslop 1984; Núñez y Dillehay 1979). Cada una de estas instalaciones debería representar el componente de control de una actividad dispersada tanto por el espacio como por el pastoreo.

Los asentamientos agrícolas estaban caracterizados por un uso intensivo de la tierra y el empleo de una gran cantidad de mano de obra. Estos asentamientos estaban dedicados a la producción de bienes especializados para el estado. Debido a su intensa actividad, el sitio agrícola involucraba procesos más complejos de producción que los que ocurrían en las fronteras de intercambio o pastoreo. Allí se sembraban los cultivos, se recolectaban y se procesaban. Los yanakona y mitmaqkuna del estado y otros trabajadores laboraban en los campos y unidades de almacenamiento. Se realizaban actividades de apoyo especializadas y la administración de toda la operación se planeaba y se coordinaba. Aparte de todo ésto, se construían y mantenían terrazas agrícolas y canales de riego.

La ubicación de estos asentamientos está ambientalmente confinada a los valles costeros del Perú y a los valles de tierra alta de los Andes, desde el Ecuador hasta el sur del Perú y norte de Bolivia, incluyendo el Lago Titicaca. Estos sitios debían contener también algunas de las dependencias de almacenamiento más grandes en el imperio. Aquí los ejemplos son Huancayo Alto en la chaupiyunga de los declives occidentales de los Andes Centrales (Dillehay 1976, 1979, 1987) y las instalaciones estatales en la ceja de la selva en Ecuador, Perú y Bolivia, específicamente en Cochabamba (Byrne de Caballero, 1977; Hyslop 1984; Watchel 1977, 1982).

Por último, las fronteras para extracción de recursos especiales fueron creadas para explotar las riquezas no agrícolas de una región. Allí las actividades estaban enfocadas en recursos particulares. La producción se impulsaba en aquellos lugares en donde los recursos se obtenían en forma natural. Se supone que el asentamiento se ubicaba con el fin de convertir la materia prima en bienes transportables. Un ejemplo de ésto puede ser la explotación para el beneficio del estado de ciertos recursos (especialmente el oro) en los bosques orientales de la ceja de la selva.

La distinción entre estas dos últimas fronteras no es siempre clara. Parece que siempre que fue posible, los incas combinaron la explotación agrícola con las actividades no agrícolas. Sin embargo, también parece haber casos en los cuales el estado instaló mitmaqkuna en algunas áreas, artesanos para la producción especializada de bienes, tales como los olleros de Milliraya en Qollasuyu (ver Murra 1978). Es mucho más probable, sin embargo, que algunas clases de explotación no agrícola solo se encontraran donde la producción agrícola no era posible. Un ejemplo es la frontera araucana en el sur de Chile, donde los incas aparentemente explotaban oro, plata y probablemente otros minerales con ausencia de asentamientos estatales. 
A diferencia de otros tipos de asentamientos que aparentemente estaban orientados hacia el control y explotación de una región, incluyendo sus recursos y su población, los asentamientos de extracción especial involucraban la explotación de recursos en sitios específicos. En consecuencia, el patrón de asentamiento de estas fronteras se organizaría en torno a la ubicación de estos sitios. El conjunto de artefactos debería reflejar los requerimientos tecnológicos de extracción y procesamiento de los recursos, así como la necesidad de mantener y abastecer la fuerza laboral necesaria para asegurar la producción. Su registro material debería estar caracterizado, por un lado, por un componente tecnológico y, por otro dedicado a la vivienda y manutención de los personeros del estado y los trabajadores. Además, cada uno debería presentar una estructura de organización manifiesta en la distribución y composición de sus asentamientos. Estos fenómenos deberían ser perceptibles tanto en el registro material como en el documental.

\section{DISCUSION}

Los asentamientos de frontera del estado inca debieron representar ocupaciones especializadas cuyas funciones estuvieron estrechamente relacionadas con el desarrollo político y económico del mismo. Este estrecho contacto favoreció la retención de las instituciones sociales, políticas y económicas ya existentes, como lo han señalado Menzel (1952), Murra (1972c, 1980), Dillehay (1977), Netherly $(1984,1988)$ y otros. La variación en el tipo de actividades económicas asociadas con las diferentes regiones indicaría la existencia de distintos tipos de asentamientos fronterizos. Cada uno estaría caracterizado por una estructura de organización manifiesta en la distribución y composición de los asentamientos.

También debería quedar claro que la expansión del estado debió estar asociada con una variedad de estrategias de adquisición diseñadas para obtener, en forma de tributo, una diversa gama de recursos y servicios humanos. Estas estrategias incluirían medios de producción que eran apropiados para la recolección y procesamiento de bienes particulares, previo a su explotación fuera del área.

Deberíamos también tener presente que el patrón de asentamiento se ve directamente afectado por los requerimientos impuestos para la obtención de estos recursos. El asentamiento asociado con la adquisición de determinados recursos se propagó por una extensa área, tal como es el caso de los camélidos en la puna, que requieren de pequeños procesamientos previos al transporte hacia otras áreas. Este asentamiento tendía a distribuirse a lo largo de un gran territorio o establecerse en una ubicación central dentro de él. Los asentamientos de pastoreo e intercambio fueron de este tipo. Por otro lado, la adquisición de recursos que requieren más procesamiento, tales como los minerales, la coca y los cultivos en general, se encontraban solo en ciertos lugares, lo que podía haber resultado en un patrón de asentamiento compacto o centrado en aquellas áreas en donde los bienes deseados se obtenían más fácilmente.

Los sitios agrícolas exhiben una distribución de asentamientos de este tipo. Los sitios asociados con aspectos no productivos de fronteras externas probablemente involucraban la necesidad de proteger o mantener el orden dentro del área de colonización y efectuar el movimiento de recursos desde estas regiones hacia el estado cen- 
tral. Consecuentemente, los sitios militares fronterizos estaban estratégicamente ubicados para propósitos de control, mientras que los sitios de transporte emplearon un patrón de asentamiento diseñado para apoyar el flujo de bienes y el abastecimiento fuera y dentro de otras áreas fronterizas internas y externas.

La composición de las fronteras externas también debería reflejar la naturaleza de los sitios de control y extracción de recursos. Probablemente, éstos eran más extensos y más diversos que aquellos asociados con medios de adquisición relativamente simples. Entre los tipos descritos en este trabajo, las fronteras agrícolas de pastoreo en el Perú y norte de Bolivia y Chile aparentemente se caracterizan por ser unos asentamientos más extensos y más elaborados en relación a aquellos que se encuentran dentro de otros tipos (cf Hyslop 1984; Morris 1972). En ambos casos estos asentamientos incluían actividades de adquisición de múltiples etapas que, a menudo, implicaban una tecnología compleja y en donde al menos el procesamiento preliminar era completado antes del almacenamiento o el transporte fuera del área.

Por otro lado, los tipos de fenómenos recurrentes y los cambios culturales que podrían haber ocurrido dentro de la población local se desconocen por la poca duración del estado inca. Se espera que estos fenómenos recurrentes pongan de manifiesto un patrón que esté relacionado con la estructura de organización de cada tipo de frontera. Puede ser difícil observar patrones de cambio temporal en el registro arqueológico de un período tan corto. Puede ser que confiemos más en las fuentes documentales para obtener este tipo de información. Además, parece probable que si las fronteras estatales se desarrollaron en etapas, como lo implican varios autores en este trabajo, especialmente Netherly, entonces algunas de ellas tendrían instalaciones militares, instalaciones relacionadas con la red de caminos, otras instalaciones relacionadas con el control de los mitmaqkuna y las poblaciones locales. La función y secuencia de este desarrollo podrían detectarse arqueológicamente.

En base a estas consideraciones, creemos que es muy difícil enfocar el examen del estado inca desde la perspectiva de un modelo expansionista único. Hemos considerado brevemente diversos aspectos de la expansión del estado y, al mismo tiempo, hemos intentado considerar un patrón material y espacial relacionado con la naturaleza de las diversas estrategias de adquisición involucradas y del desarrollo histórico de fronteras internas y externas. Se observaría ésto tanto en los registros arqueológicos como en los documentales.

Además, el desarrollo de modelos de las fronteras internas y externas en la organización del estado está en sus inicios. Es necesario realizar más investigaciones para aislar todas las variables que afectan a cada uno de los tipos de asentamientos fronterizos en nuestras discusiones. Otras investigaciones y estudios comparativos de cada uno de estos tipos, proveerán un cuadro más claro acerca de la estructura de la organización del estado inca y también acerca de la interrelación entre esa estructura y el papel de cada área dentro de la economía mayor del estado. 
También tuvieron lugar variaciones dentro de cada tipo de asentamiento. Sus causas deben ser clarificadas en términos de la interacción de variables tales como la tecnología de adquisición, las condiciones ambientales, la autonomía política y la diversidad étnica (véase Hyslop 1984 para ejemplos de esta variación regional). Solo cuando se conozcan estos factores será posible predecir con exactitud la distribución, ordenamiento y contenido de los asentamientos fronterizos internos y externos. El desarrollo de estas fronteras a través de las pocas décadas de duración del estado inca se conoce muy poco, lo mismo sucede con las variables que influyeron en su cambio. Finalmente, el desarrollo de modelos adecuados requiere de un conocimiento sobre la interrelación de los diferentes tipos de fronteras, particularmente aquellas que cumplieron con una función secundaria en el control de la mano de obra y en la producción de bienes. Los nexos entre las áreas fronterizas individuales y su conexión con las áreas fronterizas internas y semiperiféricas pueden contribuir en la definición de su función dentro del sistema económico del estado y ofrecer una base para la formulación de una hipótesis acerca del desarrollo del estado inca.

Nuestra capacidad para derivar información con respecto al proceso acaecido en las fronteras sobre la base de la evidencia documental y material, demuestra también la utilidad del método arqueológico, especialmente de los estudios espaciales, en la obtención de una base de información independiente. Las hipótesis arqueológicas basadas en las características de los cambios fronterizos internos y externos requieren ser formuladas tanto con referencia a las fuentes históricas que pertenecen directamente a áreas específicas como sin ellas. De igual manera, las analogías utilizadas para probar estas hipótesis tienen que ser desarrolladas independientemente a estas fuentes. Estas analogías constituyen el tipo de investigación hecha por la mayoría de los etnohistoriadores en el pasado.

En el análisis del estado inca, es inútil considerar la expansión y organización fronteriza sin referencia al aspecto espacial de estos procesos. Como elemento de un sistema político y económico en expansión, un sitio cumplía una función dictada por su posición dentro de un diseño más amplio en relación al centro de poder del estado. Así también la función de los asentamientos estaba determinada por su posición política y geográfica dentro de la red económica de la región. Estas funciones deben haber variado a medida que se expandía el área de control, crearse nuevos asentamientos o cambiarse las rutas de transporte.

Otro tópico que no se ha tratado es el de los mecanismos de integración utilizados por el estado para entrelazar las fronteras al centro o área de núcleo. Salomon y Netherly aluden a este asunto en sus trabajos incluidos en este trabajo y Zuidema se refirió a él brevemente en su comentario en Bogotá, pero no fue considerado formalmente por ninguno de los participantes.

El sistema político inca era ciertamente un estado, pero la forma de organización de las funciones a nivel estatal y de integración de las diferentes fronteras internas y externas eran diferentes de las encontradas en los estados del mundo o aún los de Mesoamérica (ver D'Altroy 1987:4-5 para una opinión ligeramente diferente). Los esta- 
dos pueden tener funciones comunes, pero la manera en que éstas se integran puede variar mucho. El trabajo de Murra $(1955,1970 a, 1972 c, 1980)$ y Rowe $(1942,1982)$ y sus estudiantes sobre la organización económica y política del estado inca, así como de numerosos estructuralistas (por ejemplo Watchel 1977; Zuidema 1964, 1982a) y otros investigadores que trabajan en los Andes, ha mostrado cómo las funciones y responsabilidades de las comunidades locales fueron adjudicadas e integradas de acuerdo a la ideología del estado inca. No obstante que el trabajo de estos investigadores ha aportado un conocimiento invaluable de los asuntos locales y regionales del estado, se requieren mucho más estudios etnohistóricos y arqueológicos; igualmente se necesita más análisis teórico de la política estatal antes de que podamos proponer modelos empíricos sobre la organización e integración del estado.

A la luz de las anteriores consideraciones se advierte la necesidad de un enfoque regional para estudiar la expansión e integración del estado, arqueológica e históricamente. Las áreas o partes fronterizas, como zonas de poblamiento humano y extracción de recursos, constituyen una porción de la periferia en el sistema estatal, pero no todas las áreas periféricas permanecen necesariamente como fronteras. Las fronteras representan una región periférica durante el tiempo en que ésta evoluciona de una nueva área ocupada a una caracterizada por una adaptación políticamente estable. Por cierto, no todas las fronteras evolucionan hacia esta meta.

Los diferentes tipos de fronteras considerados aquí representan etapas diferentes de incorporación y estabilización dentro del estado con áreas que siguen un curso diferente. La evolución de una región colonizada, que va desde una frontera externa a una frontera interna, es un proceso complejo de cambio, algo que no se puede medir fácilmente en el corto período de duración del estado inca. El proceso de cambio de lo externo a lo interno incorporado dentro de una sola región revelará los diversos tipos de asentamiento de una región fronteriza en el desarrollo progresivo del estado.

En fin, al comienzo de esta introducción se señaló que los artículos contenidos en este trabajo representan una amplia gama de temas acerca de los límites internos y externos del estado. Aún cuando puedan parecer desarticulados desde el punto de vista teórico y conceptual, tienen coherencia en el sentido de que su diversidad probablemente refleja la realidad de la situación del estado inca. Estos ensayos también muestran que los estudios sobre las fronteras incas están apenas en sus comienzos. Las investigaciones potenciales, tanto arqueológicas como históricas sobre el estudio de su expansión y colonización, solo están comenzando a vislumbrarse. Esto probará ser una principal fuente de información acerca de un proceso que jugó un papel tan importante en la formación del estado inca.

Agradecemos a la Dra. Gloria Lara-Pinto de Haseman por la redacción gramatical de los manuscritos y a la Sra. Lillian Palmer por escribirlos a máquina. 


\section{BIBLIOGRAFIA}

Baudin, Louis

1961 A Socialist Empire: The Incas of Peru. Compilado por Arthur Goddard, traducido por Katherine Woods. Van Nostrand, Princeton, New Jersey, Estados Unidos.

Byrne de Caballero, $\mathrm{G}$.

1977 Comentario al repartimiento de tierras por el inca Huayna Capac. Departamento de Arqueología, Museo Arqueológico, Universidad Boliviana Mayor de San Simón, Cochabamba, Bolivia.

Collier, G.A., R.J. Rosaldo, y J.D. Wirth (compiladores)

1982 The Inca and Aztec States, 1400-1800. Academic Press, New York, Estados Unidos.

D'Altroy, Terrence y Timothy Earle

1985 Stable Finance, Wealth Finance, and Storage in the Inka Political Economy. Current Anthropology 25(2):187-206.

D'Altroy, Terrence (compilador)

1987 Inka Ethnohistory. Ethnohistory, edición especial 34(1).

Dillehay, Tom D.

1976 Competition and Cooperation in a Multi-Ethnic System in the Central Andes. Tesis de doctorado. University of Texas, Austin, Texas, Estados Unidos.

1977 Tawantinsuyu: Integration of the Chillón Valley, Peru: A Case of Inca Geo-political Mastery. Journal of Field Archaeology 4:397-405.

1987 Estrategias políticas y económicas de las etnias locales del valle del Chillón durante el período prehispánico. Revista Andina 5(2):407-456.

Espinoza Soriano, W.

1971-72 Los huancas aliados de la conquista: tres informaciones inéditas sobre la participación indígena en la conquista del Perú, 1558, 1560 y 1561. Anales Científicos de la Universidad del Centro del Perú 1:9-407. Huancayo, Perú.

Hyslop, John

1976 An Archaeological Investigation of the Lupaqa Kingdom and its Origin. Tesis de doctorado. Columbia University. New York, Estados Unidos.

1977 Chulpas of the Lupaqa Zone of the Peruvian High Plateau. Journal of Field Archaeology 4:149-170.

1979 El área lupaqa bajo el dominio incaico. Un reconocimiento arqueológico. Historia 3(1):53-79. Lima.

1984 The Inka Road System. Academic Press, New York, Estados Unidos. 
Julien, Catherine

1982 Inca Decimal Administration in the Lake Titicaca Region. The Inca and Aztec States, 1400-180 G.A. Collier, R.I.Rosaldo, y J.D.Wirth, compiladores. pp.153-71. Academic Press, New York, Estados Unidos.

Marcos, Jorge y Presley Norton

1984 From the Yungas of Chinchaysuyo to Cuzco: The Role of La Plata Island in Spondylus Trade. Social and Economic Organization in the Prehispanic Andes. D.L.Browman, R.L.Burger y M.A.Rivera, compiladores. pp.7-20. British Archaeological Reports, International Series, No.194. Oxford, Inglaterra.

Masuda, S., Izumi Shimada, y Craig Morris (compiladores)

1985 Andean Ecology and Civilization. University of Tokyo Press, Tokyo.

Menzel, Dorothy

1959 The Inca Occupation of the South Coast of Peru. Southwestern Journal of Anthropology 15(2):125-142.

Metraux, Alfred

1969 The History of the Incas. Schocken, New York, Estados Unidos.

Morris, Craig

1967 Storage in Tawantinsuyu. Tesis de doctorado. University of Chicago, Chicago, Illinois, Estados Unidos.

1972 State Settlements in Tawantinsuyu: A strategy of Compulsory Urbanism. En Contemporary Archaeology. M.Leone, compilador. pp.393-401. Southern Illinois University Press, Carbondale, Illinois, Estados Unidos.

1978-80 Huánuco Pampa: nuevas evidencias sobre el urbanismo inca. Revista del Museo Nacional (Lima) 44:139-152.

1984 Architecture and the Structure of Space at Huanuco Pampa. En Tecnología, urbanismo y arquitectura de los incas. G.Gasparini y L.Margolies, compiladores. Ediciones Venezolanas de Antropología. Caracas.

Morris, Craig y Donald Thompson

1974 Huánuco Viejo: An Inca Administrative Center. En The Rise and Fall of Civilization. C.C.Lamberg-Karlovsky y Jeremy A.Sabloff, compiladores. pp.191-208. Cummings Publishing Co., Menlo Park, New Jersey, Estados Unidos.

1985 Hиаписо Pampa. Thames and Hudson, Londres.

Murra, Jonh V.

1962 An Archaeological "Restudy" of an Andean Ethno-historical Account. American Antiquity 28:1-4. 
1964 Una apreciación etnológica de la visita. En Visita hecha a la provincia de Chucuito, por Garci Diez de San Miguel en el año 1567. pp.421-442.

Casa de la Cultura de Perú, Lima.

1967 La visita de los chupachu como fuente etnológica. En Visita en la Provincia de León de Huánuco en 1562, John V. Murra, compilador. T.1.pp.381406. Universidad Nacional Hermilio Valdizán. Huánuco, Perú.

1970a An Aymara Kingdom in 1567. Ethnohistory 15:115-151.

1970b Current Research and Prospects in Andean Ethnohistory. Latin American Research Review S (1):3-35.

1972 El "control vertical" de un máximo de pisos ecológicos en la economía de las sociedades andinas. En Visita en la provincia de León de Huánuco en 1567.John V. Muna compilador T.2:pp.429-476. Universidad Nacional Hermilio Valdizán. Huánuco, Perú.

1975 Formaciones económicas y políticas del mundo andino. Instituto de Estudios Peruanos, Lima.

1978 La organización económica del estado-inca. Traducido por Daniel R.Wagner. Siglo Veintiuno, México.

1980 The Economic Organization of the Inca State. JAI Press. Greenwich, Connecticut, Estados Unidos.

Murra, John V. y Craig Morris

1976 Dynastic Oral Tradition, Administrative Records, and Archaeology in the Andes. World Archaeology 7(3):269-279.

Netherly, Patricia J.

1977 Local Level Lords on the North Coast of Peru. Tesis de doctorado. Cornell University.

1984 The Management of Late Andean Irrigation Systems on the North Coast of Peru. American Antiquity 49(2):227-254.

1988 From Event to Process: The Recovery of Late Andean Organizational Structure by Means of Spanish Colonial Written Records. An Overview of Peruvian Prehistory. Londres y New York. Richard Keatinge, compilador. Cambridge University Press.

Núñez, Lautaro y Tom D. Dillehay

1979 Movilidad giratoria, armonía social y desarrollo en los Andes meridionales: patrones de tráfico e interacción económica. Universidad del Norte. Antofagasta, Chile.

Ortiz de Zúñiga, Iñigo

1967,1972 Visita en la provincia de León de Huánuco en 1562. Documentos para la historia y etnología de Huánuco y la selva central. John V.Murra, compilador. T.2. pp.8-266. Universidad Nacional Hermilio Valdizán. Huánuco, Perú. 
Rostworowski, de Diez Canseco, María

1970 Mercaderes del valle de Chincha en la época prehispánica: Un documento y unos comentarios. Revista Española de Antropología Americana 5.

1977 Etnia y sociedad: Costa peruana prehispánica. Instituto de Estudios Peruanos. Lima.

1981 Recursos naturales, renovables, y pesca, siglos XVI y XVII. Instituto de Estudios Peruanos. Lima.

1983 Estructuras andinas del poder. Instituto de Estudios Peruanos. Lima.

Rowe, John H.

1942 Inca Culture at the Time of the Spanish Conquest. Handbook of South American Indians. T.2. Julian Steward, compilador. Bureau of American Ethnology, Bulletin 143:183-330. Washington, DC.

1982 Inca Policies and Institutions Relating to the Cultural Unification of the Empire. The Inca and Aztec States, 1400-1800. G.A.Collier, R.J.Rosaldo, y J.D.Wirth, compiladores. pp.93-118. Academic Press, New York, Estados Unidos.

Salomon, Frank

1986 Native Lords of Quito in the Age of the Incas. Cambridge University Press. Cambridge.

Schaedel, Richard P.

1978 Early State of the Incas. The Early State. H.M.Claessen, G.P.Skalnik, compiladores. pp.289-320, Mouton Press. La Haya, Países Bajos.

Uhle, Max V.

1909 La esfera de influencias del país de los incas. Revista Histórica 415-40.

Uribe, María Victoria

1975 Documentos del Siglo XVIII referentes a la provincia de los pastos: Problema de interpretación. Revista Colombiana de Antropología 19:84-101. Bogotá.

1977-1978 Asentamientos prehispánicos en el altiplano de Ipiales, Colombia. Revista Colombiana de Antropología 21:57-196. Bogotá.

Watchel, Nathan

1977 The Vision of the Vanquished. Traducido por Beny Sian. The Harvester Press. Hassocks, Sussex, Inglaterra.

1982 The Mitimaes of the Cochabamba Valley: The Colonization Policy of Huayna Capac. En The Inca and Aztec States, 1400-1800. G.A.Collier, R.I.Rosaldo, y J.D.Wirth, compiladores. pp.199-235. Academic Press. New York, Estados Unidos. 
Zuidema, R. Tom

1964 The Ceque System of Cuzco. Brill. En Leiden, Países Bajos.

1982a Bureaucracy and systematic knowledge in Andean Civilization. En The Inka and Aztec States, 1400-1800. A.Collier, R.J.Rosaldo, y J.D.Wirth, compiladores. pp.419-458. Academic Press, New York, Estados Unidos.

1982b The Sidereal Lunar Calendar of the Incas. En Archaeology in the New World. A.F.Aveni, compilador. Cambridge University Press. Cambridge, Inglaterra. 


\title{
LAS FRONTERAS ESTATALES EXTREMAS DEL TAWANTINSUYU
}

\author{
John Hyslop
}

No se ha dedicado mucho tiempo al estudio de los límites externos o extremos del Imperio Incaico y no existen dos mapas del Tawantinsuyu que coincidan en su demarcación. Nuestro magro conocimiento del concepto de fronteras que tenían los incas causa más confusión en torno al problema. A medida que avance la investigación nos daremos cuenta, sin duda, de los varios tipos de fronteras incaicas, definidas en parte por el grado de subyugación de los pueblos fronterizos y el grado en que se introdujeron las instituciones incaicas. Bien pudo haber pueblos que guardaban una lealtad simbólica a los incas, pero que de hecho eran relativamente independientes en términos políticos y económicos. Está claro que algunas regiones limítrofes podrían ser más adecuadamente consideradas "en disputa" o "en transición", especialmente aquellas en las que los ejércitos incas se mantenían en actividad, aunque no necesariamente con éxito. Será necesario realizar un estudio más detallado en base a las fuentes históricas tempranas y al reconocimiento arqueológico, antes de hacer distinciones precisas entre las zonas que se encontraban parcialmente dentro de la esfera de influencia inca y aquellas que se hallaban bajo un control incaico razonablemente efectivo.

El propósito de este artículo es hacer una evaluación a grosso modo del área geográfica seguro dominio inca hacia el año 1525 cuando el imperio había alcanzado su máxima extensión. Por "dominación segura" me refiero a que una gama de instituciones incas habían sido introducidas con éxito, tales como el culto al sol, el uso de mit$m a q$, el sistema de trabajo de la mita y el sistema de caminos y de tampu. Las zonas bajo una efectiva dominación inca son definibles arqueológicamente puesto que se encuentran en esos lugares restos arquitectónicos y artefactos incaicos que van más allá de ser simples hallazgos casuales. Este trabajo empezará definiendo las fronteras extremas del imperio incaico tal como han sido presentadas tradicionalmente por algunos estudios. Luego se sugerirán ciertos reajustes a dichas fronteras a la luz de las recientes investigaciones. Finalmente, se tratará sobre el papel especial que juega la evidencia arqueológica, particularmente en cuanto a la cerámica y a las fortalezas incaicas se refiere, en la definición de las fronteras del imperio.

\section{LAS FRONTERAS ESTATALES EXTREMAS DESCRITAS EN LOS ESTUDIOS TRADICIONALES}

Durante más de medio siglo, el estudio de los caminos incaicos ha ido de la mano con el estudio de las fronteras incaicas debido a que el trazo del sistema de caminos está íntimamente ligado a la delimitación de las fronteras geográficas del imperio. Algunos de los primeros mapas del imperio incaico fueron hechos por aquellos que también trabajaban en la definición del sistema de caminos (Hyslop, 1984:218219). Estudiosos como Urteaga, Levellier, Regal y Strube Erdmann se basaron prin- 


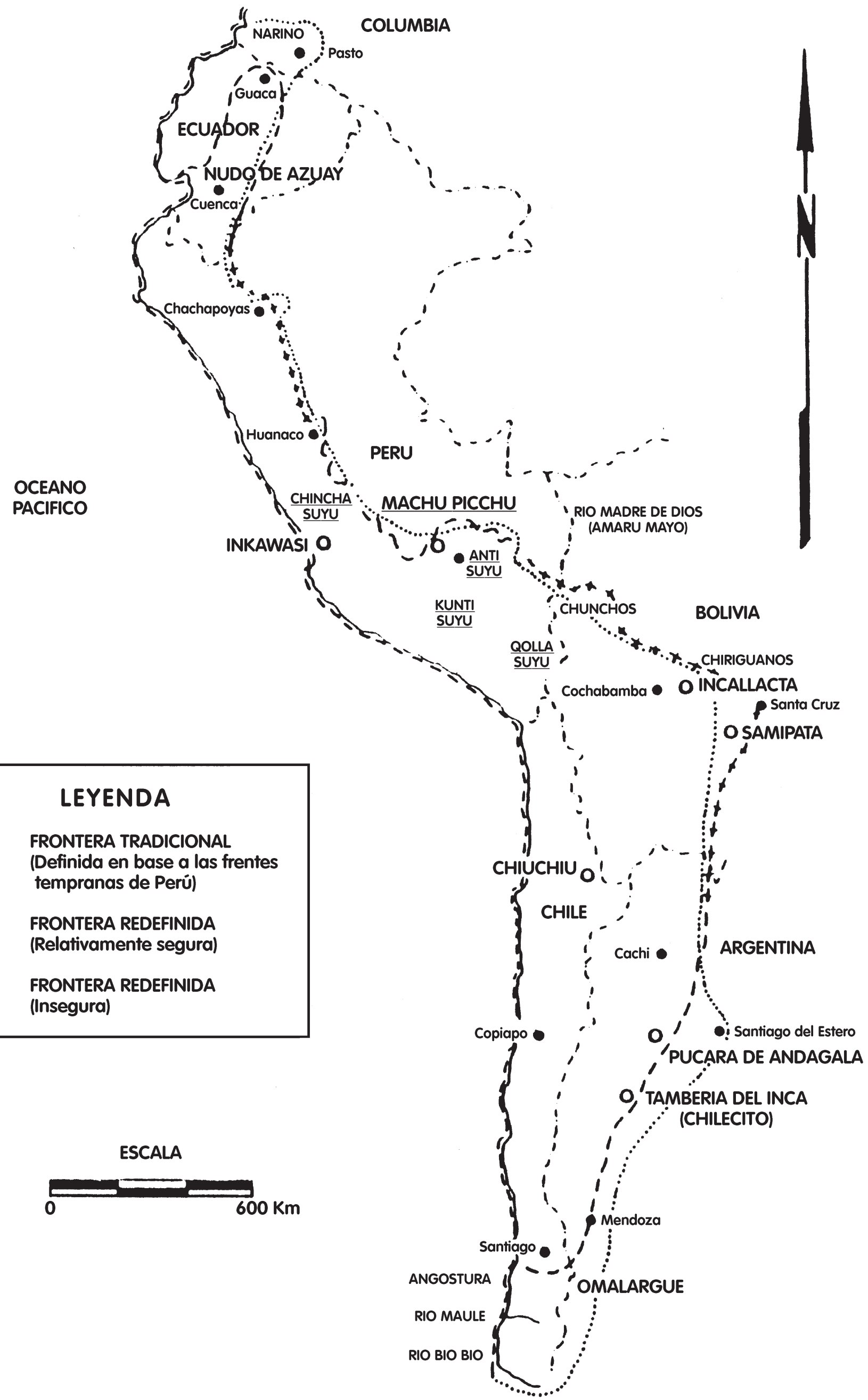

Figura 1.- Mapa general de los caminos principales de los incas. 
cipalmente en los tempranos datos históricos para identificar a los caminos y fronteras. Todos sus estudios (línea de puntos en la figura 1), con la excepción de los de Regal (1936), sitúan los límites más septentrionales en la provincia occidental de Nariño, en Colombia, y los límites más meridionales hacia los Ríos Bío Bío o Maule, varios cientos de kilómetros al sur de Santiago, en Chile. Los mapas varían con respecto a si el imperio controlaba la costa del Ecuador. Los mapas de Urteaga (1926), Levellier (1942) y Rowe (1945:272-273) sitúan esta costa dentro de los dominios incai$\cos$.

Todo el límite oriental del Imperio Inca, desde la frontera colombiana-ecuatoriana hasta la boliviana-argentina, constituye un tremendo enigma. Con la posible excepción de las zonas del Cuzco y Cochabamba en Bolivia, la información arqueológica sobre esta frontera incaica es escasa, incoherente o históricamente tardía. Por falta de información, se ha asumido que la frontera incaica era además una frontera ecológica (Bonavía 1979). En consecuencia, los entendidos tendían a situarla en sus mapas en aquellos puntos en que las faldas de los Andes se unen con las tierras bajas de las selvas amazónicas. Los mapas tradicionales no sitúan la frontera del imperio más al este del área alrededor de la ciudad de Cochabamba, en Bolivia. Levellier (1942), cuyo mapa presenta el límite oriental incaico a lo largo del flanco andino oriental, reconoció la dificultad de localizar dicha frontera en Bolivia y Perú. Levellier ubica el límite de la "esfera de influencia" inca a más de $200 \mathrm{~km}$ al este.

De la frontera argentina-boliviana hacia el sur, los mapas del imperio incaico generalmente concuerdan en que la frontera sigue las faldas orientales de los Andes. Aquí, la prueba es la distribución de muchos conocidos sitios arqueológicos incas (ver Schobinger 1982; Raffino 1981). Ciertos mapas (Urteaga [1926], Regal [1936], Hagen [1955]) extienden el imperio hasta Santiago del Estero. Si ésto es cierto, sería la extensión más oriental del imperio.

En resumen, de acuerdo a las fuentes tradicionales, los límites extremos del imperio incaico abarcarían la costa ecuatoriana, parte de Nariño, Colombia y todo el flanco oriental de los Andes hasta las tierras bajas selváticas. La extensión más oriental del imperio, por su parte, atravesaría la provincia de Santiago del Estero, en Argentina y la frontera sur estaría localizada cerca de la ciudad de Concepción, bastante al sur de Santiago, en Chile. No hay dos autores que concuerden en cuanto a los citados límites, pero existen razones, por cierto discutibles, para trazarlos tal como se ha hecho. No obstante ésto, la lectura cuidadosa de las primeras fuentes escritas y un estudio de la distribución espacial de los artefactos incaicos dejan en claro que, cuando menos, algunas de estas fronteras están imprecisamente trazadas sin precisión y no delimitan el territorio sujeto al efectivo dominio inca. El intento por extender el Estado Inca desde Bogotá al Estrecho de Magallanes (García R. 1962) no se tomará en consideración. 


\section{REAJUSTES EN ALGUNAS DE LAS FRONTERAS INCAS}

El conocimiento que se tiene sobre las fronteras extremas del imperio incaico es generalmente tan pobre que cualquier intento por definirlas, con un probable margen de error de 50 a $100 \mathrm{~km}$, es un logro considerable. Esta sección discutirá un trazado distinto de algunos segmentos de las fronteras incas, particularmente en áreas donde los recientes trabajos arqueológicos y etnohistóricos han colaborado en la aclaración del asunto que nos ocupa (Figura 1, línea interrumpida).

\section{La costa ecuatoriana}

La tendencia a incluir esta planicie tropical costera dentro de los dominios del imperio inca, proviene de una serie de tempranos relatos históricos sobre el estado inca que describen las campañas militares incaicas y los progresos imperiales en esa región. Es importante observar que dichas fuentes no registran victorias sino más bien derrotas incas. Además, el hecho de que por lo menos dos emperadores, Thupaq Yupanki y Wayna Qhapag, viajaron hasta allá, no significa que el estado inca controlara la costa. La experiencia de los primeros conquistadores españoles en Centro y Sudamérica, es prueba suficiente de que ejércitos pequeños pueden recorrer distancias considerables a través de territorios que no controlan y encontrar poca resistencia, por lo menos al principio. De manera similar, las operaciones militares incaicas fueron llevadas a cabo efectivamente más allá de los límites del control del estado. La mejor ilustración de este punto es el ejército inca que conquistó el área de Cajamarca, la cual se encontraba a gran distancia del entonces pequeño estado inca. Si acaso ejerció un control sobre los territorios intermedios, éste era muy débil.

El asunto del control inca sobre la costa ecuatoriana fue estudiado detalladamente por Cieza de León ([1533a] 1962:149-156), quien tenía un interés especial en él. Cieza escribió que algunos grupos costeños enviaban "resales" al emperador inca, pero que no existían gobernadores, viviendas o almacenes incaicos en esos lugares. Más aún, había gente que no se encontraba de modo alguno bajo la influencia inca.

Ya en 1946 John Murra (1946:809) escribía que los incas no controlaban la costa. Una investigación completa de la distribución de la cerámica inca en el Ecuador (Meyers, 1976) ha confirmado la observación de Murra. Todavía no existen pruebas de un conjunto cerámico inca o de áreas habitacionales incaicas en la costa. Los datos sobre el hallazgo ocasional de una vasija o fragmentos de cerámica incaica en la costa (Meyers 1976; Levellier 1946:181), no son prueba suficiente de la existencia de un control por parte del estado inca.

La ausencia de cerámica incaica es un tipo de evidencia negativa de la teoría acerca de la presencia inca. Sin embargo, ésta no puede ser ignorada dado que existe una estrecha correlación entre las localidades de las tierras altas ecuatorianas donde se ha hallado cerámica inca y la segura evidencia histórica de la presencia en ellas del estado inca. En suma, las pruebas que proporcionan las diversas fuentes son un fuerte argumento para sostener que el imperio inca no ejerció su control sobre la costa ecuatoriana. 


\section{La frontera en el extremo septentrional}

Las guerras más reñidas del reino de Huayna Capac fueron sostenidas en la región situada al norte de Quito. La mayoría de las tempranas relaciones escritas sobre las campañas militares incaicas hacen mención a incursiones en la región del Río Angasmayo o Pasto, cerca de la actual frontera entre Colombia y Ecuador. Existen pocas razones para dudar que se realizaron actividades militares incas en el área occidental de Colombia, pero sí hay buenos motivos para poner en duda que el estado incaico haya controlado efectivamente el área (Lunardi 1935). K. Romoli (197778:14-16) ha presentado convincentes evidencias históricas, lingüísticas y geográficas de que la presencia del Imperio Inca en Colombia es una interpretación incorrecta de los hechos.

Una prueba adicional es que Cieza de León ([1533a] 1962:121-249), quien conocía bien las tierras altas colombianas y ecuatorianas, escribió que el camino inca empezaba en Guaca (Huaca), una localidad de Ecuador cercana a la frontera con Colombia. La idea de que no existió un control fuerte de la parte occidental de Colombia por parte del estado inca, se ve reforzada por la ausencia de cerámica incaica y de sitios arqueológicos incas (M.V. Uribe, 1977-78 y comunicación personal, 1982). Esta observación significa que el estado inca abarcaría de 100 a 200 km menos de lo que generalmente se propone como su frontera norte. Ahí, como en el caso de la costa ecuatoriana, las zonas de actividad militar o donde el emperador realizó viajes fueron confundidas con áreas bajo el control inca. Parecería que los historiadores de la tradición oral del Cuzco asumieron que cualquier zona militar era (o sería pronto) inca y es ésta la impresión que da la historia del estado inca, la que, a su vez, ha sido propagada por muchos estudiosos modernos.

\section{La frontera este desde el Ecuador hasta Bolivia}

Esta región, generalmente desconocida, de las cordilleras andinas del este y noreste, requiere mucho mayor estudio si se busca definir alguna vez esta frontera inca. Bonavía (1979) hace una revisión de cierta parte de la información que existe sobre los sitios arqueológicos incas en esta área. El resumen de Strube Erdmann (1963:24-26, 33-38,51-54) sobre posibles caminos incas que conducían a las selvas orientales, sugiere que la frontera inca no puede ser definida como la división ecológica entre los flancos andinos y las bajas tierras amazónicas. Los caminos incas pueden haber penetrado las tierras bajas de la selva en Chachapoyas, Huánuco y cerca del Cuzco, pero todavía faltan pruebas fehacientes. Los relatos históricos de las conquistas incas en los afluentes del Madre de Dios (Amarumayo) son particularmente sugerentes (Raimondi 1874-79; Hassel 1905). La conclusión de Strube respecto a que la expansión incaica en la selva tropical es mucho mayor de lo que generalmente se admite, constituye una observación importante a la espera de investigación.

Se ha señalado que los incas consideraban incivilizados a los indios de las tierras bajas tropicales. Estos andaban desnudos, pintados y comían carne humana. Es bien sabido que el imperio construyó fortalezas en algunas partes de la frontera oriental pa- 
ra resguardarla de los "bárbaros" de las tierras bajas. Estas fortalezas son bien conocidas en la provincia de Cochabamba, Bolivia, donde un gran número fue cartografiado por primera vez por Nordenskiöld (1924). No hay certeza de si una serie de fortalezas caracterizaba toda la frontera este con las tierras bajas selváticas. Todavía no se ha localizado ninguna fortaleza en la frontera oriental en el territorio del actual Perú (partiendo del entendido que se excluyen sitios como Ollantaytambo y Machu Picchu). La visita de Ortiz hace mención de tres o cuatro fuertes incas al este del actual Huánuco (Murra 1968:400-402), los cuales estaban guarnecidos por mitmaq del Cuzco y, a pesar de que no han sido localizados, son prueba de que en lo que es el Perú actual existió, por lo menos, un segmento fortificado en la frontera oriental incaica.

Es razonable la hipótesis de que la frontera inca entre Colombia y Argentina fue bastante irregular, incorporando en algunos puntos tierras bajas, y sin incorporar en otros siquiera el control de todos los flancos de las montañas. También estaba tipificada, cuando menos, por dos áreas (las tierras altas septentrionales del Ecuador y el área de Chachapoyas en el Perú) que cayeron bajo el control inca dos o tres décadas antes de la caída del imperio, desconociéndose hasta qué grado las instituciones incaicas fueron implantadas en ellas con éxito. La delimitación de esta frontera se complica más aún debido a la posible existencia (tal como en la costa ecuatoriana) de esferas de influencia constituidas por los territorios de grupos sumisos y leales al imperio, pero donde no se habían introducido instituciones incas.

La obra titulada Marcas Orientales del Tawantinsuyu (1981), reúne un grupo de artículos que ayudan a definir la frontera oriental del estado inca en partes del Perú y en el sur del Ecuador (Mapa General I y Mapa Preliminar IV). Estos estudios se basan principalmente en información histórica y representan un serio intento por definir y localizar los grupos étnicos y el territorio que se encontraban bajo control incaico o fuera de éste (Romoli 1977-1978; Renard-Casevitz 1981; Saignes 1981; Taylor y Descola 1981). La identificación de la esfera geográfica de los grupos étnicos andinos del siglo XVI, permitirá el avance de los estudios de las fronteras incaicas, puesto que las tempranas fuentes históricas a menudo las definen en términos de los grupos que estaban dentro o fuera de ellas.

Los investigadores del Museo Arqueológico de Cochabamba, Bolivia, son los únicos que han hecho un continuo reconocimiento de los sitios arqueológicos incas en la frontera oriental que se extiende de Colombia a Argentina. Ellos (Byrne de Caballero $1975,1976,1978$ a) han ampliado el trabajo de Nordenskiöld y demostrado que la frontera inca en esa zona aparentemente es sinónimo de una cadena de fortalezas. Aún más al este, cerca de Santa Cruz, Bolivia, se encuentra Samaipata (Trimborn 1959,1967; Pucher 1945) con su curioso y monumental afloramiento rocoso labrado. Samaipata puede ser el punto más oriental hasta ahora conocido que alcanzó el imperio (aproximadamente $64^{\circ}$ longitud oeste). La crónica de Alcaya (1962) confirma la presencia inca en ese lugar. El reconocimiento de la región es pobre y es probable que se halle ocupación inca en lugares todavía más al este. 
Un trabajo particularmente detallado sobre los Andes orientales de Bolivia (Sainges 1985), pone de manifiesto que un grupo guaraní había traspasado un segmento considerable de esta frontera inca fortificada, poco antes de la conquista española. Se trata de un caso único, de una zona aparentemente alguna vez bajo firme dominio inca, donde se había perdido el control imperial.

La frontera inca al sur del Departamento de Santa Cruz en Bolivia, constituye otro misterio. Se conocen muy pocos sitios arqueológicos incas en el área de Chuquisara y Tarij (Nordenskiöld 1924; Walter 1959a, 1959; Schmeider 1924), principalmente porque no se ha hecho ningún esfuerzo prolongado para localizarlos.

\section{La frontera en la región noroccidental de Argentina}

Los argentinos han encontrado igual o más número de sitios arqueológicos incas en su país que cualquier otro grupo nacional de arqueólogos de los países andinos. Esto se debe a que han contado con un número mayor de investigadores. Además, en Argentina los sitios incas son frecuentemente mucho más fáciles de localizar e identificar puesto que los caminos modernos pasan cerca de ellos; también debido a que a menudo, estos sitios no se encuentran mezclados con los restos de sitios más grandes y antiguos que hacen más complejo el hallazgo, tal como sucede en Perú.

En consecuencia, la frontera inca en Argentina puede ser trazada con cierta seguridad, teniendo en cuenta la distribución de los sitios arqueológicos incas conocidos. Strube (1963:49-54,87-91), Raffino (1981) y Schobinger (1982) han presentado resúmenes sobre esta distribución. En estos trabajos pueden encontrarse omitidos asentamientos incas conocidos en donde no existe arquitectura inca y sólo poca cerámica incaica. Por lo tanto, será necesario levantar un registro más completo de los sitios con componentes incaicos antes de que la frontera llegue a conocerse con precisión en Argentina.

Gran parte de esta extensa frontera inca yace en puntos entre las faldas de los Andes y las áridas llanuras con zonas irrigadas por los ríos que descienden de la sierra. Algunos sitios incas (por ejemplo, Fock 1961) son prueba de que el imperio también tuvo asentamientos en las planicies de las tierras bajas, y no solo en las montañas o las faldas de las mismas. Una evidencia adicional de la penetración inca en áreas de las tierras bajas la brindan las referencias históricas acerca de que el imperio promovió sistemas de irrigación en el área próxima a las ciudades de Mendoza y San Juan (Canal Frau 1946:63,65,140-142). Algunos artículos de comercio incas bien pueden haber llegado hasta el centro y oriente de América del Sur (Uhle 1909).

Ciertos estudiosos (Regal 1936, Hagen 1955, Urteaga 1926) han situado esta frontera del estado inca tan al oeste como Santiago del Estero, en Argentina. Ello se debe a que durante los primeros años de la época colonial esta región fue una zona hablante de quechua, ya que el itinerario de Matienzo ([1567] 1967:280-281), que sigue un camino inca, conduce hasta ella. Levellier (1946:9) ha señalado que la lengua quechua de la zona fue introducida temprano en la colonia por los misioneros españoles. 
El itinerario de Matienzo conduce por cierto a Santiago del Estero, pero antes se aparta del camino inca. Por lo tanto, Santiago del Estero no puede ser considerado inca.

La frontera inca en Argentina será probablemente mejor definida en base a los datos arqueológicos, puesto que no se cuenta con suficientes fuentes históricas tempranas que se refieran a la presencia inca. Una de las razones para ésto es que existe una brecha de varias décadas entre la caída del imperio y el establecimiento de la mayoría de los primeros asentamientos europeos en la zona. Esto ha resultado en una escasez de información escrita temprana sobre los incas. Las primeras fuentes escritas solo proliferaron después de que el imperio había sido destruido y ya no quedaba allí una huella fresca de su presencia.

\section{La frontera en el extremo meridional}

La evidencia obtenida por el Proyecto de Caminos Incas en las áreas de Santiago en Chile, y Mendoza en Argentina, indica más bien que el imperio inca nunca las tuvo bajo un dominio completo, como tampoco logró introducir sus instituciones en las regiones más al sur. Esto contradice las informaciones aportadas por las relaciones históricas tempranas del estado inca y algunas evidencias arqueológicas de dudoso origen presentadas en Argentina durante las décadas pasadas.

La opinión más frecuente respecto a la frontera incaica en el extremo meridional, es que llegaba hasta los Ríos Bío Bío (cerca de Concepción) o Maule (cerca de Talca), bien al sur de Santiago. Los estudiosos chilenos, Medina (1952:328-335) y Silva G. (1977-78:211-212 y 1983) han refutado esta opinión y tienen amplias pruebas obtenidas de tempranas fuentes históricas locales. Los cronistas chilenos, Valdivia ([1545]1960:13), Bibar ([1558]1966:137-138) y Mariño de Lobera ([1580]1960:254) ubican el firme control inca en el Valle de Maipo, exactamente al sur de Santiago. Hasta la fecha los restos arqueológicos incas más meridionales en el centro de Chile se encuentran en San José de Maipo: el cementerio de Nos (Stehberg 1975:48) y la fortaleza de Chena (Stehberg 1976), ambos ubicados a menos de $20 \mathrm{~km}$ al sur de Santiago ( $33^{\circ}$ latitud sur aproximadamente). Los incas realizaron infructuosas incursiones más al sur dentro de la región de los Ríos Maule y Bío Bío (Medina 1952: 328$355)$, y probablemente ello explica que varias historias sobre el estado incaico incluyan esta área dentro del dominio imperial.

En el flanco oriental de los Andes (Argentina), el límite sur, de segura presencia inca, se encuentra en el Río Mendoza ( $32^{\circ} 50^{\prime}$ latitud sur aproximadamente). Algunos estudiosos argentinos han sugerido que el imperio inca se extendía $200 \mathrm{~km}$ o más hacia el sur, hasta el Río Diamonte o inclusive más allá de éste. Sin embargo, ha sido señalado (Strube Erdmann 1963:55-56; Raffino 1981:81) que las pruebas sobre el control inca en la zona son débiles y sin segura evidencia arqueológica. Actualmente se reconoce que la evidencia sobre la presencia inca (e incluso de Tiwanaku) en esta área, y particularmente en el sitio de Malargüe, es dudosa. 
De hecho, no existe confirmación arqueológica de sitios o caminos incas al sur del Río Mendoza, en el Valle de Uspallata. Schobinger (1971:83, 1975:35), la autoridad más reconocida sobre la presencia inca en la región centro-occidental de Argentina, ha escrito que el Río Mendoza es el límite más meridional de la zona en donde existe evidencia arqueológica de la dominación incaica en Argentina. Así como en la región central chilena, es probable que los ejércitos incas hayan incursionado en el sur, en áreas que nunca estuvieron en capacidad de controlar. Esto es señalado por el cronista Bibar ([1558]1966:165) quien escribió que los incas que conquistaron a los indios de Cuyo, erigieron un monumento en el Río Diamonte y "desde allí regresaron".

En resumen, los límites incas más meridionales, en los flancos chilenos y argentinos de los Andes, se encuentran a varios cientos de kilómetros más al norte de lo que generalmente se ha propuesto en la mayoría de las descripciones tradicionales del imperio. Sin embargo, existe poca duda acerca de que las campañas militares incas avanzaron más al sur de Santiago y Mendoza puesto que existe evidencia histórica al respecto.

\section{Las más tempranas fronteras incaicas}

La delimitación de las fronteras incaicas se complica por el hecho que el Tawantinsuyu era un imperio en expansión y los límites antes discutidos fueron fijados alrededor de 1525, año en que falleció el emperador Huayna Capac. Levellier (1942: mapa) y Rowe (1945:273) han trazado la expansión de las fronteras incas bajo los reinados de los diferentes emperadores. Ambos atribuyen la mayor expansión del imperio a los reinados de Pachacuti, Tupac Yupanqui y Huayna Capac (1438-1525), durante los cuales fueron incorporados casi todos los dominios del imperio.

El incremento en el uso de las fuentes históricas tempranas, administrativas y legales, así como una evaluación más crítica de los cronistas "clásicos", ha permitido a los entendidos discutir la expansión del imperio como una sucesión de etapas durante los reinados de determinados emperadores (Salomon 1978; Wedin 1963; Pease G.Y. 1978:31-112). Es posible que este importante enfoque del estudio de las fronteras incas despierte un nuevo interés en el crecimiento del estado inca. Es importante que la evidencia arqueológica sea usada en coordinación con la investigación etnohistórica, ya que las instalaciones militares incas, ubicadas dentro de los límites extremos del imperio pueden arrojar evidencia sobre las más antiguas fronteras, anteriores a la subsiguiente expansión del estado. Se sabe que las instalaciones militares incaicas situadas dentro de las fronteras del imperio se encuentran sobre las planicies costeras en los valles peruanos, cerca de Cachi en la provincia argentina de Salta; en el valle de Copiapó en Chile y cerca del Nudo de Azuay en Ecuador. Existe razón para pensar que en todas estas áreas, los sitios arqueológicos representan fronteras incas temporales, es decir, una etapa de la expansión del Tawantinsuyu.

En la medida en que progresen las investigaciones es de esperar que se logre una definición más precisa de estas fronteras temporales. 


\section{RELACION ENTRE LAS FRONTERAS INCAICAS Y LAS FORTIFICACIONES MILITARES}

Llama la atención que solo una fortaleza inca (excluyendo la ya discutida de Sacsahuaman) haya sido objeto de investigación arqueológica intensiva. Se trata de la fortaleza de Chena, situada cerca de Santiago en Chile (Stehberg 1976). Se han descubierto y levantado planos de muchas otras fortalezas, pero faltan investigaciones de campo detalladas con excavaciones tal vez en parte porque son de difícil acceso. Es por ello que se sabe muy poco acerca de las instalaciones militares del imperio conquistador más elogiado y sofisticado de la América precolombina.

Una serie de importantes interrogantes rodea la naturaleza de las instalaciones militares y las fronteras incaicas. Aún no se sabe con certeza hasta qué grado las fortificaciones, sitios para guarniciones, etc., tipifican los límites incas. Polo de Ondegardo ([1571] 1916:98) escribió específicamente sobre las fortalezas situadas en la región central de Chile; en Bracamoros (la región de Chachapoyas en Perú); cerca de Quito y en el límite de Charcas con los indios chunchos y chiriguanos (en Bolivia). A excepción del área de Chachapoyas, todas estas regiones son conocidas por la presencia de fuertes incas. Otros extensos tramos de las fronteras incaicas son mucho menos conocidos. Parecería que no se necesitaban fortalezas a lo largo de la mayor parte de aquellas, de otra manera ya se habrían descubierto algunos de esos sitios arqueológicos. Es remarcable que no se hayan localizado fortalezas a lo largo de los flancos orientales andinos del Perú, a pesar de que existen pruebas históricas tempranas de la existencia de, por lo menos, unas cuantas en Huánuco (Murra 1968:400-402). Probablemente, algunos límites no estaban fortificados. Ejemplos de ello son las zonas de fronteras incas en las provincias argentinas de San Juan y Mendoza, propias para la localización de fortalezas de haber existido. La dinámica de la política que decidía si una frontera sería fortificada, sin duda aclara mucho sobre la expansión, los pueblos vecinos y las metas del estado inca. Sin embargo, aún no se tiene una idea precisa, a base de las fuentes históricas o arqueológicas, sobre cuáles fronteras incaicas estaban protegidas militarmente.

En la medida en que se conozca más acerca de lo que constituía una fortificación incaica, progresará la identificación arqueológica de las fronteras incas. Generalmente, se llama fuertes a aquellos sitios ubicados en alturas, en emplazamientos fácilmente defendibles, algunas veces rodeados de murallas. Todavía no se cuenta con evidencia suficiente proveniente de excavaciones que podría definir un conjunto de artefactos indicativos de actividades militares (ver Urteaga 1920). Se sabe aún menos acerca de los emplazamientos de estacionamiento militar, desde donde se organizaron o recibieron apoyo las operaciones militares, que no fueron fortalezas como los de Inkawasi (Hyslop 1985) en Cañete y Londres en Argentina. Otro problema importante en la identificación de las fortalezas incaicas está relacionado con la reocupación de los fuertes o poblaciones preincas por el imperio. Los Andes abundan en sitios fortificados preincaicos. La ocupación inca de muchos de ellos (por ejemplo, Ungará y Cañete en Perú; Tilcara y Jujuy en Argentina; Paramonga y Fortaleza en Perú; Marca Huamachuco en Perú) no significó en cada caso que el imperio necesitara una posi- 
ción fortificada en un punto determinado, sino únicamente que había conquistado y luego utilizado tal sitio. Es curioso que el más famoso de los sitios incaicos, Machu Picchu, fuera considerado por Bingham (1930) y Uhle (1917) como un sitio fortificado. Su ubicación próxima a una frontera inca refuerza esta interpretación. A pesar de ello, actualmente no se acostumbra sugerir que es un fuerte.

Queda mucho por aprender acerca de cómo identificar la arquitectura y los artefactos militares incas. Incluso si se identificaran fortalezas incas en muchas áreas nuevas, quedaría por determinar si se usaron para proteger una zona limítrofe de los pueblos no conquistados o para proteger los intereses del imperio en las poblaciones "conquistadas" que lo rodeaban. La distinción es sumamente importante, ya que en el primer caso un fuerte probablemente identificaría con considerable precisión la frontera, mientras que en el segundo caso quizás no. Los numerosos puntos fortificados al norte de Quito pueden haber sido más utilizados contra poblaciones circunvecinas que contra los enemigos que acechaban al norte (Plaza Schuler 1976). Las ciudadelas fortificadas incas de Lascana y Chiu Chiu en la región de Atacama en Chile (Uhle 1917; Mostny 1949), pueden haber jugado un papel similar dado que las poblaciones enemigas habrían estado muy alejadas. El papel de los fuertes tanto para proteger al imperio de los intrusos como para proteger los intereses incaicos de rebeliones por parte de las poblaciones locales, puede ser estudiado mediante el análisis de la proximidad geográfica de esos sitios a las áreas no conquistadas, su ubicación y la defensa de las rutas hacia y desde aquellas áreas, así como por medio del conocimiento histórico sobre la lealtad o belicosidad de propios y extraños.

En resumen, los estudios existentes sobre la expansión, fronteras y operaciones militares incaicas (Bram 1977; Urteaga 1919-20; Quiroga Ibarrola 1962) no han ampliado o utilizado mucha de la información arqueológica relativa a las instalaciones militares incaicas. Estos sitios no son simplemente fuertes, sino que son ciudadelas amuralladas (por ejemplo, Chilecito, Chiu Chiu), o centros militares de apoyo (por ejemplo, Inkawasi en Cañete o Londres en Catamarca). Algunas de las fortalezas más grandes como Incallacta en Bolivia (González y Gravoto 1977), o la de Pucará de Andagalá en Argentina (Lange 1982; Brunch 1911; González y Núñez 1958-59), todavía necesitan de minuciosas investigaciones que comprendan excavaciones, estudios etnohistóricos complementarios, y reconocimientos de los patrones de asentamiento. Los caminos incas conectaban, indudablemente, los fuertes y sus centros de apoyo con las principales arterias del imperio. En donde estos caminos han desaparecido o no se puede seguir su huella, lo cual ocurre muchas veces en gran parte de la frontera inca oriental, las instalaciones militares a las cuales conducen pueden representar la mejor prueba de esta frontera. 


\section{LA CERAMICA INCA Y SU RELACION CON LAS FRONTERAS}

Es evidente hoy en día que en aquellos lugares en donde existen firmes pruebas históricas de dominación y control inca, la investigación arqueológica ha encontrado cerámica incaica o cerámica relacionada con el imperio inca. Ningún indicador arqueológico de presencia inca es más frecuente en cualquier lugar de los Andes que su cerámica. Las cerámicas incaicas se encuentran, no necesariamente en abundancia, incluso en áreas donde no se observa arquitectura inca o no hay prueba histórica de su presencia. Los arqueólogos son afortunados en que este imperio se representaba a sí mismo con un estilo cerámico distinguible en todo momento. Este punto es de gran utilidad para los estudios futuros que tengan como objeto identificar las fronteras incas.

En cualquier zona fronteriza del imperio se puede obtener una idea general de la ubicación geográfica de los límites marcando los puntos en donde se ha encontrado cerámica inca. Esta puede ser identificada en recolecciones de superficie o provenientes de excavaciones, al igual que en las miles de pequeñas colecciones locales existentes en los Andes pertenecientes a particulares, escuelas y municipalidades. Toda pequeña ciudad cuenta con su colección. El trazo de la distribución de la cerámica incaica de procedencia conocida es, quizás, una táctica arqueológica más efectiva para localizar las fronteras incas, que ubicar los caminos o fortalezas incaicas. Tal táctica, sin embargo, ofrece mejores resultados conjuntamente con los otros dos métodos, ya que, donde uno dá a conocer poco, los otros pueden arrojar pruebas concretas.

Dado que la cerámica no se presta particularmente para ser transportada, existe muy poca evidencia en lo que respecta a la cerámica relacionada con el imperio inca más allá de las fronteras incaicas bien establecidas. En ocasiones, se puede encontrar fragmentos o aún vasijas completas, pero no conjuntos completos de vasijas o fragmentos. De este modo, la ausencia de la cerámica inca en una zona, como la parte occidental de Colombia o en Chile, al sur de Santiago, se torna en una evidencia negativa de importancia para definir las fronteras del estado.

\section{COMENTARIO FINAL}

En la medida en que continúe la investigación detallada en base a las tempranas fuentes locales escritas y al reconocimiento arqueológico regional, hemos de esperar que el tema de las fronteras incaicas se desarrolle en un fenómeno cada vez más complejo. Es particularmente difícil ver la frontera de firme dominio inca como una línea claramente definida en los puntos donde atraviesa áreas disputadas militarmente, zonas de amortiguamiento político, territorios en posesión de aliados de cuestionable lealtad o zonas en transición de un tipo de influencia inca a otro. Quizás algún día sea aceptable referirse a las fronteras extremas incas como a una simple línea en un mapa, aunque probablemente una línea tal nunca existió.

Dada la información histórica y arqueológica disponible actualmente, no se pueden definir con exactitud tramos considerables de las fronteras incas más extremas. 
En donde la información es particularmente escasa, como sucede en los flancos orientales de los Andes en el norte del Perú o en el sur de Bolivia, los mapas publicados pueden cometer grandes errores al ubicar las fronteras en base a conjeturas. La información existente sugiere que la frontera oriental inca no fue únicamente la división ecológica entre los flancos andinos y las adyacentes tierras bajas, sino que la frontera inca pudo haber variado conforme al grado en que alcanzó y/o incorporó las áreas de las tierras bajas. Hoy parece ser que el territorio más oriental controlado por el imperio inca, no fue el área próxima a Santiago del Estero en Argentina, sino más bien el área cercana a Santa Cruz en Bolivia.

Anteriormente las fronteras incaicas fueron principalmente definidas a través de la evidencia aportada por las tempranas fuentes escritas. Esto continuará siendo importante, pero creemos que la evidencia arqueológica adquirirá un papel más importante en la definición de estas fronteras. Es claro, después de casi 70 años de actividad arqueológica en la mayoría de los países andinos, que la cerámica inca, cualquiera que sea la cantidad o el lugar en que se encuentre, es un indicador de la presencia del estado inca. De este modo, la presencia o ausencia de cerámica incaica en una zona es una evidencia decisiva en lo que concierne a las fronteras incaicas. Los fuertes y guarniciones incaicos, aunque no tan bien estudiados, ofrecen un útil y gran potencial para el estudio de las fronteras. Mientras más se localice e investigue, mejor se definirán (en algunas áreas) las fronteras extremas incaicas, así como las fronteras más antiguas antes de las subsiguientes expansiones.

Finalmente, ha habido una tendencia a incluir dentro de las fronteras incaicas algunos territorios que los incas nunca controlaron efectivamente. Esto se aprecia, en particular, en las fronteras incaicas norte y sur. En esos casos, lo que ha sido definido como territorio incaico son las zonas por donde viajaron los exploradores o incluso los emperadores o donde lucharon los ejércitos, pero donde las instituciones del estado nunca fueron introducidas. Una causa importante de esta confusión son las tempranas fuentes escritas basadas en información de segunda mano, proporcionada por devotos incas informantes, que supusieron que cualquier área de frontera en disputa perteneció al imperio. 


\section{BIBLIOGRAFÍA}

Ahlfeld, Friedrich

1933 Die inkaische Festung Cuticutuni. En der bolivianischen Ostkordillere Zeitschrift fur Etnologie. Tomo 64:260-262. Berlin, Alemania.

Bibar, Gerónimo de

1966 Crónica y relación copiosa y verdadera de los reynos de Chile. Transcripción paleográfica de Irving A. Leonard. Fondo Histórico y Bibliográfico José Toribio Medina. Santiago de Chile.

Bingham, Hiram

1930 Machu Picchu: A Citadel of the Incas. National Geographic Society and Yale University Press, New Haven, CN, Estados Unidos.

Bonavia, Duccio

1979 Ecological factors affecting the urban transformation in the last centuries of the pre-Columbian era. En Advances in Andean Archaeology, compilado por David L. Browman, pp.393-410. Aldine Press, Chicago, Estados Unidos.

Bram, Joseph

1977 Análisis del militarismo incaico. trans. de D. H. Tauro H., Universidad Nacional Mayor de San Marcos, Lima. (Doctoral dissertation, Department of Anthropology, Columbia University, New York. 1941).

Bruch, Carlos

1911 Exploraciones arqueológicas en las provincias de Tucumán y Cajamarca. En Biblioteca centenaria de la Universidad Nacional de La Plata, Tomo 5. La Plata, Argentina.

Byrne de Caballero, Geraldine

1975 Nuevas investigaciones arqueológicas en la Provincia de Ayopaya, Departamento de Cochabamba. Los Tiempos, Cochabamba, Bolivia.

1976 Los asentamientos precolombinos de Ayopaya. Los Tiempos, Oct. 24. Cochabamba, Bolivia.

1978 Arte y arqueología. Tomo 5-6:309-316. La Paz.

Canals Frau, Salvador

1946 Etnología de los huarpes: Una síntesis. Anales del Instituto de Etnología Americana. Tomo 8:9-147. Universidad Nacional de Cuyo, Mendoza, Argentina.

Cieza de León, Pedro de

1962 La Crónica del Perú (1ª Parte). Espasa Calpe, Madrid.

[1553] 
1967 El Señorío de los Incas (2ª parte de La Crónica del Perú). Instituto de [1553] Estudios Peruanos, Lima.

Fock, Nils

1961 Inka imperialism in north-west Argentina, and Chaco burial forms. En Folk. Tomo 3:67-90. Copenhagen, Dinamarca.

García Rosell, César

1962 Area y límites del Imperio de los incas. En Actas y trabajos del II Congreso Nacional de Historia del Perú. Tomo 2:121-132. Centro de Estudios Histórico-Militares del Perú, Lima.

Hagen, Víctor W. von

1955 Highway of the Sun: Duell, Sloan and Pearce. New York, Estados Unidos.

Hassel, Jorge M. von

1906 Ríos Alto Madre de Díos y Paucartambo. Boletín de la Sociedad Geográfica de Lima. Tomo 17:288-310. Lima.

Hyslop, John

1984 The Inka Road System. Academic Press. New York, Estados Unidos.

1985 Inkawasi: The new Cuzco. British Archaeological Reports, International Series 234, Oxford, Inglaterra.

Lange, Gunardo

1892 Las ruinas de la fortaleza del Pucará. Anales del Museo de La Plata, Arqueología III. Universidad Nacional de La Plata, La Plata, Argentina.

Levillier, Roberto

1942 Don Francisco de Toledo: supremo organizador del Perú. 3 tomos, Colección de publicaciones históricas de la Biblioteca del Congreso Argentino, Buenos Aires.

1946 El imperio incaico. Espasa Calpe. Buenos Aires.

Lunardi, Federico

1935 O Ancasmayo ou os verdadeiros limites septentrionaes du Imperio Incaico. Imprenta Nacional, Río de Janeiro, Brasil.

Marcas Orientales del Tahuantinsuyo 1500-1600.

1981 Boletín del Instituto Francés de Estudios Andinos. Tomo 10:Nos.3-4. Lima.

Mariño de Lobera, Pedro

1960 Crónica del Reyno de Chile. Biblioteca de Autores Españoles. Tomo 131: [1580] Autores Españoles. Tomo 131: 227-562. Atlas. Madrid. 
Matienzo, Juan de

1967 Gobierno del Perú, Travaux de l'I Institut Français d' Etudes Andines. Vol. II. París-Lima.

Medina, José Toribio

1952 Los Aborígenes de Chile. Fondo Histórico y Bibliográfico José Toribio [1882] Medina, Santiago de Chile.

Meyers, Albert

1976 Die Inka en Ekuador. Bonner Amerikanistische Studien. Compilado por Udo Oberem, No.6. Bonn, Alemania.

Mostny, Grete

1949 Ciudades Atacameñas: Norte de Chile. Boletín del Museo Nacional de Historia Natural 24: 125-204. Santiago de Chile.

Murra, John V.

1946 The historic tribes of Ecuador. En Handbook of South American Indians, Compilado por Julian H. Steward, Vol. 2, The Andean Civilizations, pp.785-821. Bureau of American Ethnology Bulletin 143, Smithsonian Institution, Washington.

1967 La visita de los chupachu como fuente etnológica. En Documentos para la Historia y Etnología de Huánuco y la Selva Central, Vol. 1, Compilado por J.V. Murra, pp. 381-406, Universidad Nacional Hermilio Valdizán. Huánaco, Perú.

1978 La guerre et les rébellions dans l'expansion de l'état inka. Annales: economies, sociétés, civilisations. 33(5/6):927-935. París.

Nordenskiold, Erland von

1915 Incallacta, eine befestigteund von Inca Tupac Yupanqui angelegte Stadt. Ymer 2:169-185. Stockholm.

1924 Forschungen und abanteuer in Südamerica. Strecker y Schroder. Stuttgart, Alemania.

Pease G.Y., Franklin

1978 Del Tawantinsuyu a la historia del Perú. Instituto de Estudios Peruanos. Lima.

Plaza Schuller, Fernando

1976 La incursión inca en el septentrión andino ecuatoriano. Instituto Otavaleño de Antropología. Serie de Arqueología No.2. Otavalo, Ecuador.

Polo de Ondegardo, Juan

1916 De los errores y supersticiones de los indios, sacados del tratado y

[1559] averiguación que hizo el Licenciado Polo. En Colección de libros y documentos referentes a la historia del Perú. Vol. 3, Compilado por Horacio H. Urteaga, pp. 1-44. Sanmartí. Lima. 
Pucher, Leo

1945 Ensayo sobre el arte pre-histórico de Samaypata. Museo Arqueológico, Universidad de San Francisco Xavier, Sucre, Bolivia.

Quiroga Ibarrola, César A.

1962 Ensayo monográfico de la organización del ejército y armas empleadas por los soldados del Tahuantinsuyo y por los conquistadores españoles. Actas y trabajos del II Congreso Nacional de Historia del Perú. Tomo 2. pp. 358-416. Centro de Estudios Histórico-Militares de Perú, Lima.

Raffino, Rodolfo A.

1981 Los Inkas del Illasuyu. Ramos Americana Editora, La Plata, Argentina.

Raimondi, Antonio

1874 El Perú: Historia de la Geografía del Perú. Tomo 3. pp. $76-79$ Imprenta del Estado. Lima, Perú.

Regal, Alberto

1936 Los caminos del Inca: en el antiguo Perú. Sanmartí, Lima.

Renard-Casevitz, France-Marie

1981 Las fronteras de las conquistas en el siglo XVI en la montaña meridional del Perú. Boletín del Instituto Francés de Estudios Andinos. Tomo 10, (34):113-140. Lima, Perú.

Rex González, Alberto y Antonio Cravotto

1977 Estudio arqueológico e inventario de las ruinas de Inkallajta. UNESCO Informe Técnico PP/1975-76/3.411.6. París.

Rex González, Alberto y V. Núñez Regueiro

1958-59 Apuntes preliminares sobre la arqueología de Campo de Pucará y alrededores (Depto. de Andagalá, Pcia. de Cajamarca). Anales de arqueología y etnología. Tomo 14-15:115-162. Universidad Nacional de Cuyo, Mendoza, Argentina.

Romoli, Kathleen

1977-78 Las tribus de la antigua jurisdicción de Pasto en el siglo XVI. Revista colombiana de antropología, Tomo 21:11-51. Bogotá.

Rowe, John H.

1945 Absolute chronology in the Andean area. American Antiquity. Vol.10, pp. 265-284. Salt Lake City, EU.

Salomon, Frank L.

1978 Ethnic lords of Quito in the Age of the Incas: The Political Economy of North Andean Chiefdoms. Tesis de Doctorado, Departamento de Antropología, Cornell University, Ithaca, NY, Estados Unidos. 
Saignes, Thierry

1981 El piedemonte amazónico de los Andes meridionales: Estado de la cuestión y problemas relativos a su ocupación en los siglos XVI y XVII. Boletín del Instituto Francés de Estudios Andinos. 10(3-4):141-176. Lima.

Schmieder, Oskar

1924 Condorhuasi: eine befestigte der Inkas im südlichen Bolivien. Mitteilungen aus Justus Perthes' Geographischer Anstalt. 70:229-230. Gotha, Suecia.

Schobinger, Juan

1971 Arqueología del valle de Uspallata: Provincia de Mendoza. Relaciones de la Sociedad Argentina de Antropología. Vol. 5, pp. 71-84, Buenos Aires, Argentina.

1975 Prehistoria y protohistoria de la región cuyana. Museo de Ciencias Naturales y Antropológicas, Compilado por J.C. Moyano. Mendoza, Argentina.

1982 Mapa: Ocupación incaica en el noroeste y oeste argentino y en el norte y centro de Chile. Estudios de Arqueología Sudamericana. Editorial Castañeda, San Antonio de Padua, Buenos Aires.

Silva Galdames, Osvaldo

1977-78 Consideraciones acerca del período inca en la Cuenca de Santiago (Chile Central). En Boletín del Museo Arqueológico de La Serena Chile. Edición Homenaje a Dn. Jorge Iribarren Charlin 16:211-243. La Serena, Chile.

1983 Detuvo la batalla del Maule la expansión inca hacia el sur de Chile. Cuadernos de Historia. 3:7-25. Departamento de Ciencias Históricas, Universidad de Chile, Santiago de Chile.

Stehberg L. Rubén

1975 Diccionario de sitios arqueológicos de Chile Central. Publicación ocasional del Museo Nacional de Historia Natural. No.17. Santiago de Chile.

1976 La Fortaleza de Chena y su relación con la ocupación incaica de Chile Central. Publicación ocasional del Museo Nacional de Historia Natural. No.23. Santiago de Chile.

Strube Erdmann, León

1963 Vialidad imperial de los incas. Instituto de Estudios Americanistas, Facultad de Filosofía y Humanidades, Universidad Nacional de Córdoba. Serie Histórica No.33. Córdoba, Argentina.

Taylor, Anne-Cristine and Philippe Descola

1981 El conjunto jívaro en los comienzos de la conquista española del alto amazonas. Boletín del Instituto Francés de Estudios Andinos. 10(3-4):754. Lima. 
Trimborn, Hermann

1959 Archaologische Studien in den Kordilleren Boliviens. Baessler Archiv, Beitrage zur Volkerkunde. n.b., Beiheft 2. Berlín, Alemania.

1967 Archaeologische Studien en den Kordilleren Boliviens. Baessler Archiv, Beitrage zur Volkerkunde. n.b., Beiheft 5. Berlín, Alemania.

Urteaga, Horacio H.

1919-20 El ejército incaico. Boletín de la Sociedad Geográfica de Lima. 35-36:283-331. Lima, Perú.

1926 Mapa del Tahuantinsuyu. Librería Armand Colin. París.

Uhle, Max

1909 La esfera de influencias del país de los incas. Revista Histórica. 4:5-40. Lima.

1917 Fortalezas incaicas: Incallacta-Machupichu. Revista Chilena de Historia y Geografía. 21:154-170. Sociedad Chilena de Historia y Geografía, Santiago de Chile.

Uribe, María Victoria

1977-78 Asentamientos prehispánicos en el altiplano de Ipiales, Colombia. En Revista Colombiana de Antropología. 21:57-196. Instituto Colombino de Antropología, Bogotá.

Valdivia, Pedro de

1960 Carta al Emperador Carlos V. Biblioteca de Autores Españoles. Vol. 131, pp. 3-74. Editorial Atlas, Madrid.

Walter, Heinz

1959a Die Ruine Pucara de Oroncota (Sudost-Bolivien). Baessler Archiv.

n.b.Band 7, Heft 2:333-340. Berlín, Alemania.

1959b Lakatambo, eine Inkaruine bei Mazque (Bolivien). Baessler Archiv. n.b., Band 7, Heft 2:319-332. Berlín, Alemania.

Wedin, Ake

1963 La cronología de la historia incaica. Instituto Ibero-Americano Gotemburgo Suecia. Insula, Madrid. 


\title{
FRONTERA ABORIGEN Y DUALISMO INCA EN EL ECUADOR PREHISPANICO: PISTAS ONOMASTICAS
}

\author{
Frank Salomon
}

\section{FRONTERA IMPERIAL Y FRONTERA ABORIGEN}

El presente ensayo aborda el problema de la relación entre las fronteras aborígenes líneas divisorias dinámicas cuyos perfiles reflejaron la pujanza de las fuerzas políticas locales y los linderos imperiales más estáticos y eregidos con la probable finalidad de organizar el juego político entre unidades aborígenes, en un sistema regional estable y susceptible de una administración centralizada. En la zona ecuatorial, la superposición de estas dos clases de líneas divisorias se detecta con relativa claridad, por haberse impuesto el régimen imperial en forma reciente y solo brevemente sobre una constelación aborigen todavía visible en el estrato temprano de la documentación colonial.

Dentro de este marco, podemos preguntarnos si algunas líneas divisorias incas reflejaron discontinuidades preexistentes en las sociedades autóctonas, y como éstas fueron reformuladas con el paso de la frontera inca a través del territorio quiteño en dirección norte. Utilizando un método onomástico modernizado, elaborado con Susan Grosboll de la Universidad de Wisconsin, sostenemos que las fronteras aborígenes preexistentes cerca de Quito, tanto entre pequeñas unidades políticas como entre las grandes agrupaciones lingüístico-culturales, se manifestaron, a veces, dentro de la nueva estructura del Tawantinsuyu transformadas no en linderos de "provincias", sino en líneas de mitad ana y urin dentro de una "provincia". Por lo menos en cuanto al Ecuador se refiere, este fenómeno permite cierta duda en cuanto a la ecuación, implícita en muchas descripciones, "provincia" inca y "grupo étnico" preinca. También sugiere nuevas pistas en la interpretación de los dualismos territoriales observados en las periferias del Tawantinsuyu.

\section{LAS FUENTES Y LA LOCALIZACIÓN DEL PROBLEMA}

Los datos del presente estudio provienen de la visita ejecutada en 1559 por Gaspar de San Martín y Juan Mosquera, en seis "pueblos de naturales" de la encomienda de Francisco Ruiz "el Contador": Uyumbicho, Ana Chillo, Urin Chillo, Puembo, El Ynga, y Pingolqui (AGI/S Justicia 683; Salomon 1985). En formato y contenido la visita es similar a las de Huánuco (Ortiz de Zúñiga [1562] 1967-1972) y de Chucuito (Diez de San Miguel [1567] 1964). Se trata de una "visita personal", hecha para modernizar una "visita de quipos" de 1549. Contiene datos acerca de los nombres aborígenes, residencia, rango social, afiliación política, estado civil, sexo, edad, posición dentro de la unidad doméstica, y salud de 3,258 indígenas. Los seis "pueblos de naturales" descritos en la visita se ubicaron en la cuenca interandina del Río San Pedro, Guayllabamba, al este de Quito (ver Figura 1). 


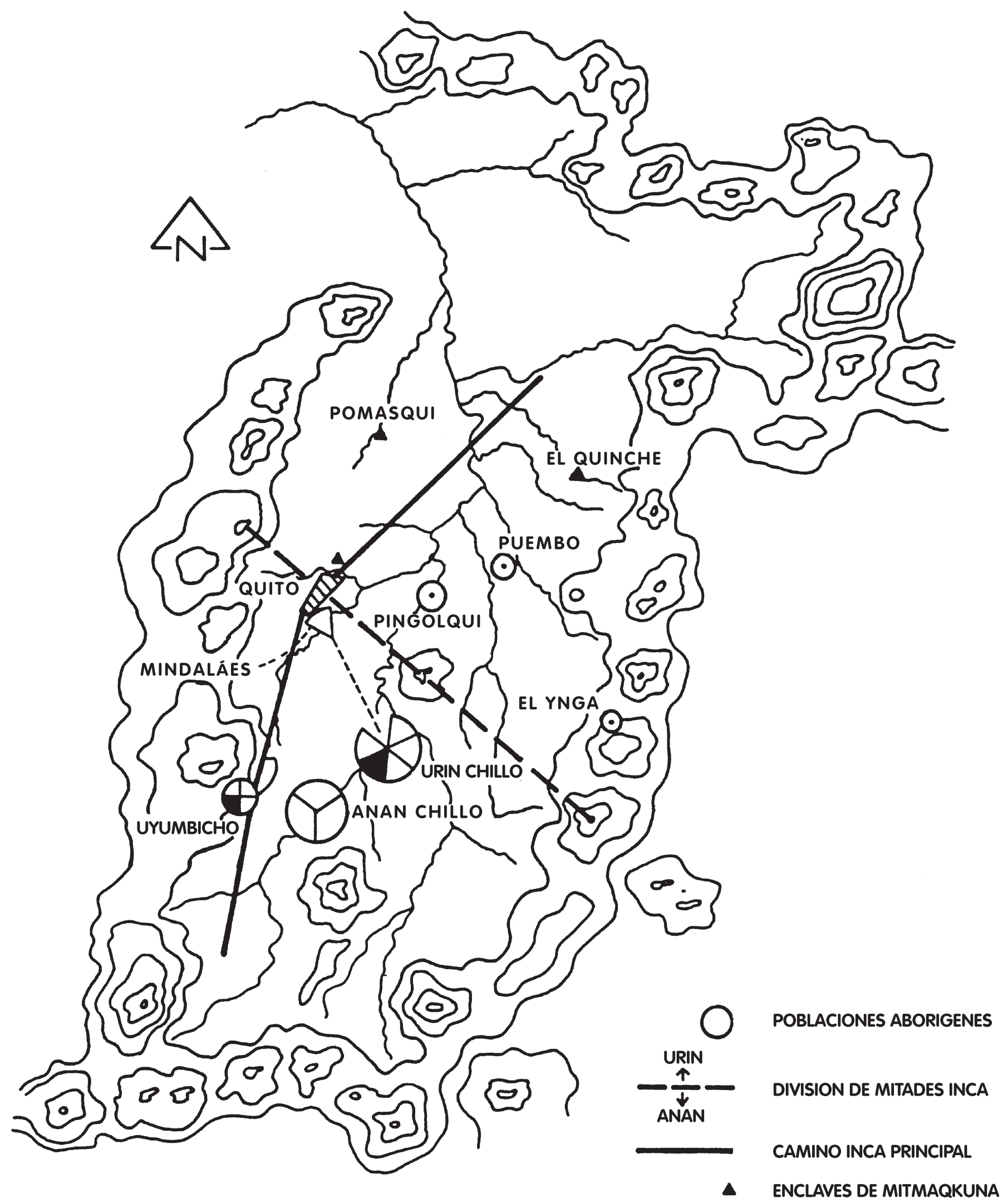

Figura 1.- Rasgos de organización social en seis comunidades indígenas de la cuenca de Quito alrededor de 1559 D.C. (simplificado). Los diámetros de los círculos que representan las poblaciones aborígenes corresponden aproximadamente a la relativa densidad demográfica. Los sectores de cada círculo corresponden a los sectores políticos de la población. 
Todos los pueblos están situados dentro de un radio de aproximadamente $30 \mathrm{~km}$ desde Quito. Debido a su posición cercana a la urbe inca, cayeron bajo el dominio español tempranamente. Sin embargo, en la fecha de la visita, seguían mostrando fuertes indicios de conservadorismo cultural. En 1559 fueron todavía organizados en categorías demográficas precolombinas y la gran mayoría de sus habitantes se autodenominaron con nombres pertenecientes no al quechua ni al español, sino a sus idiomas aborígenes.

\section{A PROPÓSITO DEL PROBLEMA QUITEÑO Y DEL MÉTODO ONOMÁSTICO UTILIZADO EN EL ECUADOR}

El régimen híbrido producido en la primera etapa de la invasión española, interpuso entre la pequeña minoría conquistadora y la mayoría aborigen una capa de ex-oficiales del Tawantinsuyu. Su presencia posibilitó el empleo del quechua como lengua administrativa y desincentivó a los españoles en el estudio de la lengua o lenguas autóctonas. El idioma supuestamente propio de Quito es mencionado en la literatura bajo la dudosa rúbrica de "Panzaleo" (Loukotka 1968:245-246; Murra 1946:795-796; Pérez 1962; Verneau y Rivet 1912-1922), todo a base de una única mención hecha por Cieza. Como las demás lenguas preincaicas de la sierra ecuatoriana, el "Panzaleo" fue desplazado por "la lengua general del Inca" durante la colonia. Hasta el momento actual no se ha encontrado ningún texto escrito en ella. Pérez $(1960,1962)$ sostiene acertadamente, según las evidencias a presentarse aquí, que la extinta lengua "Cara" de Imbabura también dejó su huella onomástica en la cuenca de Quito.

La "quechuización" colonial del Ecuador dificulta enormemente la reconstrucción de las sociedades no incas. La información, aún la de los mejores cronistas, nos viene a través de informantes hablantes de quechua y hasta los testimonios en visitas y procesos nos han llegado contaminados por la doble traducción. Debido a la influencia de los informantes incas sobre los cronistas, hemos heredado una visión inca de lo que fue el Quito preinca: caos de "behetrias", sojuzgado por el Tawantinsuyu y transformado en "provincia" con aspecto de "otro Cuzco". Para esta tradición, "los Quitos" (llamados por Cabello "los Quilacos" y por Jijón y Caamaño "los Panzaleos") figuran, con escasa claridad, como una "nación" (grupo cultural en términos modernos) aparentemente homogénea. Las fuentes narrativas del siglo XVI no ofrecen datos suficientes para esclarecer si esta aparente homogeneidad refleja la realidad cultural, o si es un espejismo resultado de la falta de interés por detectar diferencias entre los sectores de la población no inca.

Problemas de esta índole afectan a la casi totalidad de los estudios etnohistóricos relevantes para las periferias del Tawantinsuyu. En la búsqueda de datos que penetrasen la fachada imperial y que permitiesen ahondar en las sociedades sojuzgadas, los estudiosos ecuatorianos repetidas veces han intentado utilizar los perdurables restos onomásticos de los extintos idiomas preincas: nombres de personas (antropónimos) y de lugares (topónimos) abundantemente conservados en los archivos como en la realidad moderna. 
Tales investigaciones onomásticas parten de un axioma muy sencillo: El nombre es artefacto de la cultura que lo dio y, por lo tanto, la distribución de los nombres en el tiempo y el espacio ofrece pistas para la historia cultural. Este concepto ha sido empleado ampliamente en Europa y hasta cierto punto en América Latina. En el Ecuador los estudios onomásticos siguieron un rumbo algo especial, con el desarrollo del llamado "método etimológico" (por ejemplo, Buchwald 1921; Grijalva 1947; Jijón y Caamaño 1940-1941; Paz y Miño 1940, 1941a, 1941b; Pérez 1960). Los partidarios del "método etimológico" siguieron un proceder superado por la linguiística moderna. Partiendo de inventarios de nombres recopilados en cada una de las supuestas "provincias" o territorios "tribales", los descompusieron arbitrariamente en sus supuestas palabras o afijos componentes. Luego asignaron cada "palabra" al idioma, o mezcla de idiomas, que al investigador le pareció más plausible; más tarde ofrecieron una traducción y sintetizaron los resultados sumando porcentajes de "vocablos" atribuidos a cada idioma. Estas cifras fueron interpretadas como evidencia de grandes olas culturales y aún de migraciones en la América preincaica.

Estos estudios ya no son útiles puesto que sufren de irremediables defectos metodológicos. En primer lugar, utilizan como bases de la evidencia una mescolanza de datos recopilados sin sujeción a un control cronológico y ortográfico; en segundo lugar, no toman en cuenta los problemas estadísticos de representatividad, ni ofrecen pruebas de probabilidad que confirmen las supuestas tendencias estadísticas; en tercer lugar, no consideran los problemas de interferencia lingüística inherentes al registro levantado por los escribanos; en cuarto lugar, no usan métodos lingüísticamente coherentes para separar los nombres en componentes a nivel de palabra, morfema, o fonema; quinto, son netamente arbitrarios en la atribución de determinados elementos a diversos idiomas. En algunos casos los medios para evitar tales errores no existían en la época de auge del "método etimológico".

Sin embargo, el axioma central, es decir, la idea de utilizar los nombres y sus partes como índices del idioma y la cultura de sus portadores, no está errado. Proponemos retomar el proyecto iniciado por los "etimólogos" utilizando una metodología diferente (ver Salomon y Grosboll 1985; Salomón y Grosboll en prensa). A diferencia del "método etimológico", la "onomástica cuantitativa" moderna (Weitman 1981) exige: (1) un cuerpo de datos cronológicamente controlado y recopilado aplicando métodos uniformes o controlables; (2) controles sobre la interpretación de la ortografía colonial basados en la lingüística contrastiva (Lado 1957; Weinreich 1967); (3) segregación de morfemas y fonemas mediante principios lingüísticos (Nida 1949); (4) interpretación probabilística en el cotejo de los datos; (5) enfoque en la distribución de elementos dentro de la muestra, sin atribuciones de elementos a sistemas exteriores.

En el presente estudio, los datos de la visita de 1559 fueron preparados para la computación en la siguiente forma. Para cada persona visitada se elaboró un registro dividido en sectores reservados para variables específicas (nombre aborigen o inca, nombre de bautismo, lugar de residencia, estatus político, edad, etc.). Se identificaron ciertos fenómenos onomásticos cuyas distribuciones prometieron arrojar luz sobre la constelación socio-cultural de la zona circunquiteña: (1) distribución espacial y social 
de los nombres aborígenes más comunes; (2) distribución de los elementos más comunes constitutivos de los nombres, es decir, de morfemas y grupos de morfemas, con respecto a las mismas variables; (3) distribución de los grupos consonánticos potencialmente útiles como marcadores de discontinuidad entre sistemas fónicos, igualmente con respecto a las variables espaciales y sociales.

Para estudiar la distribución de nombres comunes, se aislaron a todos los individuos cuyos nombres se repitieron 12 veces o más. La ocurrencia de los nombres en esta lista (denominada COMUN) fue cotejada con las variables sociales. De una forma paralela, utilizando un método inventado por Eugene Nida para aislar morfemas aún en la ausencia de traducciones, se juntaron en la lista MORFEMA INICIAL los morfemas o grupos de morfemas que formaron las partes iniciales de los nombres repetidos 12 veces o más y éstas a su vez se cotejaron con las variables sociales. La lista MORFEMA FINAL fue compilada con un método análogo: identificando los grupos de letras (1 hasta 6 caracteres) con que finalizan los nombres indígenas, se seleccionaron los que se repitieron doce veces o más y que también funcionaron como morfemas o grupos de morfemas.

La lista "SHIBBOLETH" contiene todos los nombres con grupos consonánticos repetidos 12 veces o más. Para otras finalidades se segregaron los nombres incas, es decir, nombres de tipo quechua de Cuzco; ver Salomon y Grosboll en prensa. El presente ensayo se refiere exclusivamente a los nombres no incas.

\section{INDICIOS DE FRONTERAS PREINCAICAS: ECOLOGÍA, DEMOGRAFÍA, POLÍTICA, IDIOMA, CULTURA}

La visita de 1559, como tampoco las crónicas tempranas, no hace ninguna mención de líneas divisorias preincas entre unidades políticas o culturales dentro de la cuenca de Quito. Sin embargo, los testimonios de 1559, tomados en su conjunto, nos permiten vislumbrar ciertas discontinuidades significativas entre la parte septentrional y meridional de la región.

Estas discontinuidades en cierta medida se pueden describir en términos geográficos. Las partes bajas y sureñas de la cuenca (Uyumbicho, Anan Chillo, Urin Chillo), contienen terrenos casi ideales para el cultivo del maíz en chacras y en campos elevados (Knapp y Ryder 1983) algo debajo de los 3,000 msnm. Las partes norteñas (El Ynga, Pingolqui, Puembo), por su sequedad parecen menos aprovechables para esta técnica. En 1559, los aborígenes practicaban la siembra del maíz en secano. Pero en las profundidades de los cañones de los ríos atrincherados que atraviesan el distrito norteño, existen tierras tropicales irrigadas y excepcionalmente productivas (Gondard y López 1983:166; Salomon 1980:106). Estas eventualmente fueron aprovechadas por mitmaq incas.

¿Cuáles fueron las consecuencias de este panorama para el asentamiento humano? La arqueología todavía no tiene una respuesta, pero los datos demográficos son sugerentes. Por supuesto las cifras de 1559 reflejan bajas demográficas atribuibles a las 
epidemias post-colombinas y, por lo tanto, tienen solamente un valor relativo. Sin embargo, sugieren una desigualdad global entre las poblaciones de la parte norte y sur. Los pueblos norteños no irrigados descritos en la visita eran pequeños (con poblaciones entre 176 y 350 almas) y su régimen político simple. En cada "pueblo" regía un solo "señor natural", dotado de privilegios poligámicos y atendido por "yanaconas". En cambio, en los tres "pueblos" al meridión (Anan Chillo, Urin Chillo y Uyumbicho), existieron poblaciones más grandes (464-1,132 almas) organizadas de una forma más compleja. Cada localidad albergaba múltiples sectores políticos. Dentro de cada "pueblo" un curaca (cacique) tuvo dominio sobre su propio sector y también sobre los "principales" de los sectores subordinados. Entre caciques y principales hubo desigualdad de privilegios.

Características adicionales diferenciaron los pequeños "pueblos" norteños de los sureños: En el sur, dos pueblos (Urin Chillo y Uyumbicho) albergaron destacamentos de mitmaqkuna Wayakuntus instalados por el Tawantinsuyu. Estos pueblos eventualmente se mostraron dispuestos a militar por el Tawantinsuyu durante la crisis de la invasión española (Espinoza Soriano 1975; Salomon 1980:239-242). En las aldeas norteñas estaban ausentes los mitmagkuna incas. En ellas se produjeron incidentes de movilización anti-inca y en pro de los españoles.

Tales datos sugieren la hipótesis de una discontinuidad entre el norte (El Ynga, Puembo, Pingolqui) y el sur (Uyumbicho, Anan Chillo, Urin Chillo). Ahora bien, ¿en qué consistió la disyunción? Aparte de la intervención inca, los seis "pueblos" se conceptualizaron como soberanos. No mencionaron la existencia de fronteras políticas entre sí ni tampoco entre norte y sur; la interrogante tiene que dilucidarse por vías indirectas.

Los datos onomásticos fueron estudiados con la finalidad de detectar discontinuidades de orden cultural entre los pueblos. Para cada una de las listas (COMUN, MORFEMA INICIAL, MORFEMA FINAL y SHIBBOLETH) se formuló una hipótesis nula acerca de su relación con el factor geográfico. En el caso de la lista de nombres aborígenes más comunes (COMUN), los resultados, sin ser conclusivos (lambda=.36291), dañaron la verosimilitud de la hipótesis nula. En la casi totalidad de los nombres COMUN, la mayoría de las personas con un determinado nombre se concentró en las tres poblaciones chicas del norte o en las tres grandes del sur (ver cuadro 1).

Muy pocos fueron los nombres que se distribuyeron meramente de acuerdo con las cifras poblacionales. Para aclarar dicha tendencia se creó la variable dicótoma ZONA. La asociación entre COMUN y ZONA fue fuerte (Kramer v.73631, lambda 63).

Globalmente se detecta una discontinuidad entre las dos partes de la cuenca de Quito en cuanto a los inventarios de nombres: los nombres "comunes" eran los más generalizados en el norte como en el sur, pero no los mismos en ambas partes. Pero dicha discontinuidad es ambigua en ausencia de una aclaración ulterior. Por un lado, puede manifestarse así una discontinuidad en la organización social, sin señalar nin- 


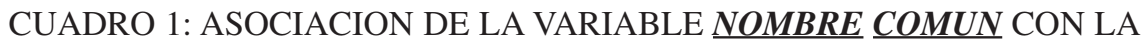

VARIABLE $\underline{\text { POBLACION }}$

\begin{tabular}{lrrrrrr}
\hline & EL YNGA & PINGOLQUI & PUEMBO & URIN & ANAN & CHILLO \\
CHILLO & UYMBICHO \\
\hline Amana & 0 & 1 & 1 & 19 & 15 & 2 \\
Angona & 0 & 0 & 0 & 19 & 7 & 0 \\
Axango & 22 & 9 & 10 & 1 & 0 & 0 \\
Axuan & 2 & 8 & 4 & 0 & 0 & 0 \\
Caxana & 0 & 0 & 0 & 11 & 26 & 0 \\
Çangoquica & 0 & 0 & 0 & 16 & 8 & 0 \\
Çicanazu & 0 & 0 & 5 & 18 & 6 & 0 \\
Çinalen & 0 & 0 & 0 & 21 & 35 & 5 \\
Collaguaco & 0 & 2 & 3 & 16 & 24 & 0 \\
Cugan & 1 & 5 & 8 & 3 & 0 & 0 \\
Guaña & 0 & 0 & 0 & 15 & 7 & 0 \\
Huña & 1 & 5 & 1 & 6 & 4 & 0 \\
Lucnango & 0 & 0 & 1 & 17 & 4 & 0 \\
Nahato & 0 & 0 & 0 & 16 & 13 & 0 \\
Nagaxa & 1 & 24 & 13 & 89 & 75 & 5 \\
Quiloguan & 14 & 2 & 2 & 0 & 0 & 0 \\
Quilunba & 8 & 4 & 12 & 0 & 0 & 0 \\
Tayango & 3 & 4 & 7 & 0 & 0 & 1 \\
Titoaçan & 0 & 2 & 0 & 9 & 6 & 0 \\
\hline
\end{tabular}

guna diferencia cultural. Por ejemplo, la diferencia de nombres podría reflejar grupos lingüísticos y culturales, hablantes de idiomas disímiles.

Esta pregunta fue sometida a dos pruebas onomásticas. La primera se realizó a nivel de la morfología y la segunda a nivel de la fonología.

De tratarse de una división únicamente organizacional, con ausencia de discontinuidades de orden cultural o lingüístico, sería probable que la diferencia entre los inventarios de nombres completos haya enmascarado una similitud en cuanto a los morfemas constituyentes de los nombres. (Por analogía: si encontramos en Barrio A únicamente las familias Herrera, Castillo, y Campos y en el Barrio B únicamente las familias Herradora, Castillejos, y Campoverde, es probable que los dos barrios hablen el mismo idioma a pesar de la ausencia total de nombres compartidos, puesto que comparten gran parte de sus respectivos inventarios morfémicos). En cambio, de tratarse de una división lingüístico-cultural, sería probable que la diferencia entre los inventarios de nombres haya reflejado también una diferencia en los inventarios morfémicos constituyentes de los nombres (Por analogía: Barrio A: Herrera, Castillo, Campos; Barrio B: Martinelli, Zanoletti, Borni).

Las pruebas estadísticas aplicadas a estas dos hipótesis favorecieron fuertemente a la segunda, o sea, la hipótesis de discontinuidad lingüística entre el septentrión y el 
CUADRO 2: MEDIDAS PROBABILISTICAS DE ASOCIACION ENTRE NOMBRES

(O MORFEMAS CONSTITUYENTES DE NOMBRES)

Y VARIABLES SOCIALES

\begin{tabular}{cccc}
\hline VARIABLE & Sexo & Población & Zona \\
\hline $\begin{array}{c}\text { Nombre común } \\
\text { No compensado }\end{array}$ & & \\
Cramer & Va .91343 & asimétrico & .74298 \\
Lambda & .87071 & .18699 & .55556 \\
Compensado & & & .73531 \\
Cramer V & .92080 & asimétrico & .63078 \\
Lambda & .87661 & .36291 & \\
Morfema Inicial & & & .78671 \\
No compensado & & & .65138 \\
Cramer V & .76340 & asimétrico & .78309 \\
Lambda & .65145 & .24060 & .68479 \\
Compensado & & & \\
Cramer V & .76306 & asimétrico & \\
Lambda & .66039 & .24523 & .85552 \\
Morfema Final (5-letter) & & & .76684 \\
Crampensado V & & & .87324 \\
Lambda & .87161 & asimétrico & \\
Compensado & .83548 & .32000 & \\
Cramer V no calculado no calculado & & \\
Lambda no calculado no calculado & & \\
\hline
\end{tabular}

a) Ninguna relación entre variables $=0$; relación perfecta $=1$.

b) Porcentaje de mejoramiento de la habilidad predictiva.

meridión. Tanto MORFEMA INICIAL como MORFEMA FINAL covariaron estrechamente con ZONA (Cramer V=.78309 y .83724, respectivamente; lambda $=.68479$, y .73322 , respectivamente; ver Cuadro 2).

Una segunda manera de averiguar la posible existencia de una frontera lingüística, se deriva del contenido fónico de los nombres. Claro está que esta averiguación no contribuye mucho a la reconstrucción de las desaparecidas lenguas autóctonas, porque los escribanos no formularon reglas grafofonémicas adecuadas ni uniformes para representar las fonemas aborígenes que oyeron. Lo que sí parece factible es estudiar la distribución de los sonidos que los caracteres gráficos representaron, sin juzgar el valor fónico de las representaciones mismas. Para esta finalidad los sonidos más útiles son los grupos consonánticos comunes, cuyos ejemplares se segregaron en la lista SHIBBOLETH.

Al tabular la relación entre los grupos consonánticos y la variable ZONA, se detectaron asociaciones entre ciertas combinaciones de sonidos y sectores de la región. Interpretadas en términos de reglas fónicas, los resultados parecen justificar dos con- 
clusiones. La primera se relaciona con los caracteres gráficos $\underline{\mathrm{CN}}$ o $\underline{\mathrm{CN}}$ (que parecen variar arbitrariamente) y $\underline{\mathrm{CCH}}$. Estos representan dos sonidos evidentemente extraños al oído del escribano. $\underline{\mathrm{CN} / \mathrm{CN}}$ posiblemente representa un nasal precedido por una oclusión glotal, y $\underline{\mathrm{CCH}}$ puede haber representado la $\underline{\mathrm{CH}}$ castellana modificada por una aspiración o una oclusión global. Los dos (¿o acaso tres?) sonidos así representados se produjeron en la onomástica sureña y rara vez en la norteña.

La segunda conclusión, en relación con el sistema de sonidos, se relaciona con el efecto de las nasales sobre las oclusivas. Los ejemplos de nasales seguidos por oclusivas pueblos "caranqui", el límite meridional de la distribución de "tolas". Este límite se sitúa cerca de Tumbaco, límite aproximado también entre las dos zonas detectadas mediante la antroponimia. Sin disponer de pruebas finales, nos parece probable que el centro de la cuenca de Quito no fue centro de una "provincia" o "nación" aborigen, sino zona fronteriza y posible teatro de conflicto entre dos grupos culturalmente disímiles.

\section{LA DIVISIÓN DUAL INCA Y LAS FRONTERAS ABORÍGENES}

La división entre las dos zonas antroponímicas cayó aproximadamente en el límite septentrional del Valle de los Chillos, marcado por el Cerro Ilhaló al sureste de la ciudad de Quito. De haberse establecido las unidades territoriales del estado inca en base a las unidades culturales preexistentes, sería de esperarse un lindero entre dos "provincias" incas aproximadamente coincidentes con este hito. Las evidencias documentales confirman la existencia de una línea divisoria en dicho lugar, pero falsifican la expectativa que sea una línea divisoria de unidades administrativas. Todo lo contrario. La división entre las dos zonas se expresó únicamente en términos de mitades dentro de un sistema dual.

El sistema dual a nivel regional en Quito (descrito con pormenores en Salomon 1980:258-266) tuvo por eje una línea N.O.-S.E. que pasó por el centro de Quito posiblemente por el barrio de la plaza colonial de San Francisco y por la cima del Ilhaló. Esto lo sabemos porque todos los "pueblos de naturales" al sur de esta línea hasta Riobamba, fueron clasificados como pertenecientes a Anan Quito en las actas de cabildo y demás documentos referentes a la administración de asuntos indígenas durante más de dos siglos. En forma similar las comisiones para Alcaldes de Naturales y demás documentos referentes al "mando indirecto" ejercido por miembros de la élite colonial inca y curaca, uniformemente califican a los pueblos del norte de dicha línea hasta Otavalo como pertenecientes a Urin Quito. En lengua castellana las mitades se llamaban respectivamente "partido de Riobamba" y "partido de Otavalo". La división dual quiteña tuvo su reflejo en la mención de dos curacas "de esta provincia de Quito" dentro de una nómina de la nobleza regional por categorías incas, hecha en 1563 (Salomon 1980:260-261). El sistema dual regional tuvo larga vigencia y sirvió para organizar la vida política interna indígena hasta fines del siglo XVII (Burgos 1975:244-257, 264-266). 
La simple existencia de una división en mitades macroregionales no comprueba, por supuesto, el origen inca de dicho sistema. Pero de haber existido una territorialidad dual preinca es probable que conoceríamos, por lo menos, su terminología, porque en general el Tawantinsuyu conservó tales terminologías locales (p.e. maa/alaa aymaras, ichoq/allawka centroperuanas). Entre los Puruháes ecuatorianos existió una dualidad local, al parecer territorial, con la terminología bat/tun que tampoco fue borrada por el régimen inca (Yánez 1979:4-5). En el caso quiteño, no se han encontrado señas de una terminología dual local. Además, existe otra indicación del carácter artificial de la dualidad regional inca. Los dualismos normalmente manifiestan su carácter de sistemas totales, no únicamente en la terminología dicótoma, sino también en las funciones o comportamientos sociales que los convierten en polos de movilización complementaria (reglas de privilegio entre líderes de ambas partes, combates rituales, organización de infraestructuras hidrológicas, etc.). Cuando nos apartamos de la capa inca y su quehacer administrativo, no encontramos en la sociedad aborigen ninguna evidencia de actuación dualista en torno a la línea quiteña. Finalmente, Rostworowski $(1983: 117,129)$ ofrece evidencias tendientes a corroborar la imposición incaica de dualismos artificiales. Creemos, por lo tanto, que en Quito se trató de una terminología importada y probablemente de una dualidad territorial impuesta.

¿Impuesta con qué finalidad? La terminología dualista conlleva fuertes implicancias ideológicas: las mitades en los sistemas propiamente incas se imaginaban como mutuamente complementarias, simétricas en forma y desiguales en rango. La complementación binaria normalmente se interpreta como emblema de la suficiencia y carácter total de una colectividad (Platt 1978), no obstante que tal representación se expresa mediante conflictos ritualizados, aún cuando se impone sobre realidades prácticas gravemente conflictivas (Skar 1982:98-99). En las cercanías de Quito hemos visto, sin embargo, indicios de una realidad diferente. Entre las dos partes calificadas como mitades incas, no encontramos funcionamiento conjunto, complementaridad, similaridad formalizada, ni reconocimiento mutuo de una jerarquía. Al contrario, las evidencias sugieren que la terminología inca encubrió una discontinuidad zonal y cultural con carácter de frontera entre grupos no complementarios. La representación de ellos como "partes" dentro de una sola organización global tiene todo el aspecto de ser artificial. El problema se reduce, por consiguiente, a la interpretación de un dualismo irreal superpuesto en una frontera real.

Para entender el dualismo inca quiteño es importante apreciar que la vasta categoría Anan Quito abarcó no solamente los tres pueblos inmediatamente al sur de la línea, sino numerosos pueblos y curacas de las actuales provincias de Cotopaxi, Bolívar y Chimborazo, diferentes entre sí en su afiliación lingüístico-cultural. Urin Quito también se extendió mucho más allá de los tres pueblitos que hemos denominado como norteños para abarcar a grandes poblaciones, en lo que ahora es la provincia de Imbabura. La política inca de clasificar estos dos grandes territorios, cada uno en sí heterogéneo, como "mitades" dentro de una totalidad política unificada, seguramente corresponde más bien a la ideología del proyecto planificador y no a la descripción de realidades preexistentes. Mediante la terminología se pretendió transformar la heterogeneidad en complementaridad. 


\section{CONCLUSIONES INTERPRETATIVAS}

Las evidencias examinadas aquí ponen en tela de juicio algunas ideas recibidas en cuanto a la inserción del establecimiento inca dentro de un ambiente no inca. Se propone replantear tres temas: la configuración de la "provincia" inca; el urbanismo inca; y, las bases funcionales del dualismo inca.

\section{1) La "provincia" inca}

En la literatura sobre el Chinchaysuyu se ha generalizado una ecuación implícita en términos geográficos, socio-culturales y políticos, de tal forma que por "provincia" inca (wamani) se sobreentiende una unidad a la vez hidrográfica, cultural y política: un "grupo étnico" radicado en una de las cuencas intercordilleranas, eventualmente redefinida como "provincia" inca. En la figura 2 se esquematiza esta imagen tradicional de la configuración de provincias incas: el Tawantinsuyu avanza sometiendo sucesivamente los grupos étnicos habitantes de las respectivas cuencas interandinas.

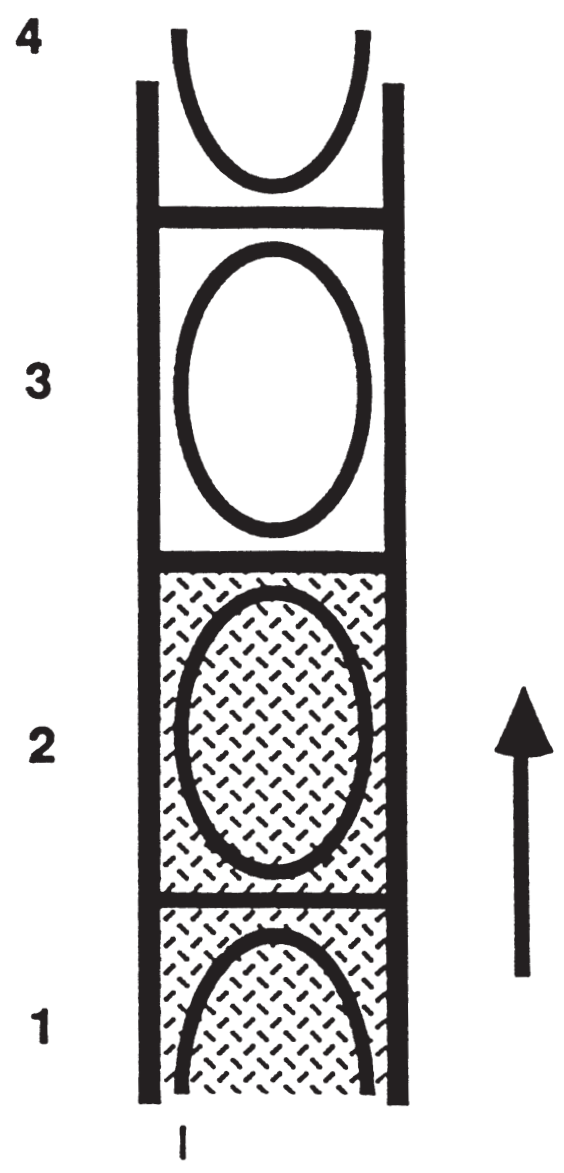

Figura 2.- Imagen tradicional de las provincias incas en el Chinchaysuyu septentrional. Los rectángulos simbolizan las cuencas interandinas. Los ovalos simbolizan los territorios de los grupos linguísticoculturales o étnicos. 
Como resultado se establecen unidades político-administrativas geográficamente cerradas y etnicamente homogéneas.

La imagen tradicional no es compatible con los datos obtenidos sobre el Quito incaico. Proponemos en su lugar un modelo algo más complejo, representado en la Figura 3.

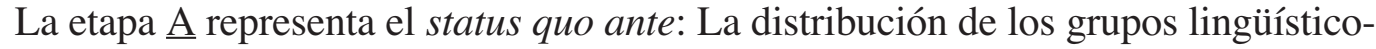
culturales rebasa los límites de las cuencas hidrográficas, de tal forma que los grupos a, b, etc., típicamente tienen asentamientos a ambos lados de los "nudos" divisorios de las cuencas hidrográficas. No se presupone ninguna forma de autoridad centralizada. Cada grupo lingüístico-cultural abarca múltiples curacazgos.

La etapa $\underline{B}$ representa una fase incipiente de la penetración inca de la cuenca $\underline{2}$. Las fuerzas incas avanzan hacia el norte, habiendo dominado ya a los miembros del grupo a habitantes de la cuenca 1 y agrediendo a los miembros del grupo a habitantes de la cuenca $\underline{2}$. La cuenca $\underline{2}$ en estos momentos es teatro de guerra, o frontera "cruda", con enclaves militares incas, pero con poca infraestructura administrativa. Esta fase se finaliza con la victoria sobre todas las fuerzas a , la cual permite un intervalo de estabilización, la construcción de un centro inca fortificado permanente en la cuenca $\underline{2}$, actividad diplomática con los curacas a y posibles tentativas para reclutar miembros del grupo a para la inminente campaña contra el grupo $\underline{b}$.

La etapa $\underline{\mathrm{C}}$ representa una fase avanzada de la invasión inca de la cuenca $\underline{2}$. Ya comienza a existir un centro político-militar inca en la cuenca $\underline{2}$, independiente de los curacazgos. Este centro comienza a organizar a los miembros del grupo a residentes en dicha cuenca de acuerdo a patrones imperiales: se instalan mitmaqkuna, se modernizan caminos y fortificaciones, se envían "dádivas" políticamente comprometedoras a los nobles aborígenes. La población más afectada es destinada a constituir el sector anan. Las fuerzas basadas en el enclave inca también someten en alguna medida a los miembros del grupo $\underline{b}$ residentes en la parte norte de la cuenca $\underline{2}$. En la medida que éstos se van sometiendo al dominio inca, su terreno comienza a funcionar como sector urin. El nuevo centro inca de la cuenca $\underline{2}$, al funcionar para imponer medidas articulatorias sobre las flamantes "mitades", adquiere un quehacer administrativo; se transforma la frontera "cruda" en frontera "civilizada".

Se inicia luego la campaña contra los miembros del grupo $\underline{b}$ residentes en la parte adyacente (meridional) de la cuenca $\underline{3}$. Cuando el combate con los miembros del grupo $\underline{b}$ rebasa los límites de la cuenca y comienza a afectar la cuenca $\underline{3}$, se reinicia el ciclo.

De ser correcto este modelo, podremos dejar a un lado el concepto de la frontera inca como un simple fenómeno militar y comenzar a interpretarla en sus términos políticio-culturales. El avance del perímetro militar no solamente tuvo la función de aumentar el imperio cuantitativamente, para los creyentes en la ideología inca, efectuó una transformación cualitativa. En sus periferias, el Tawantinsuyu enfrentaba un mundo simplemente heterogéneo, compuesto de diversos grupos aborígenes separados por linderos inestables y afectados por rivalidades y alianzas inestables. Al articular 


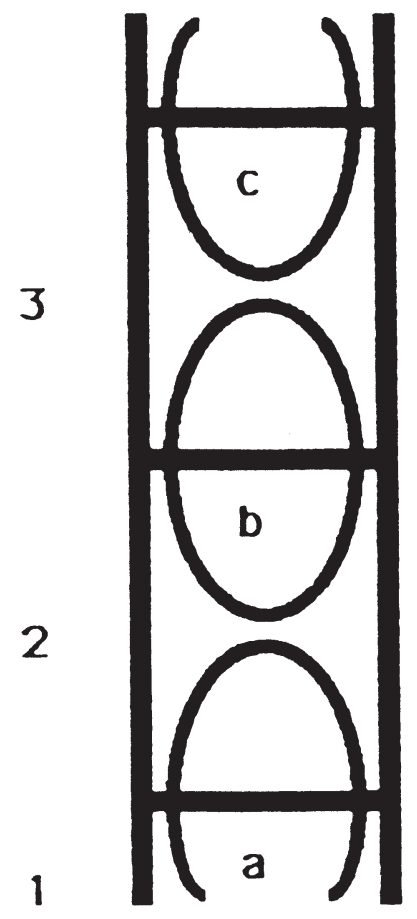

A. Status Quo Ante

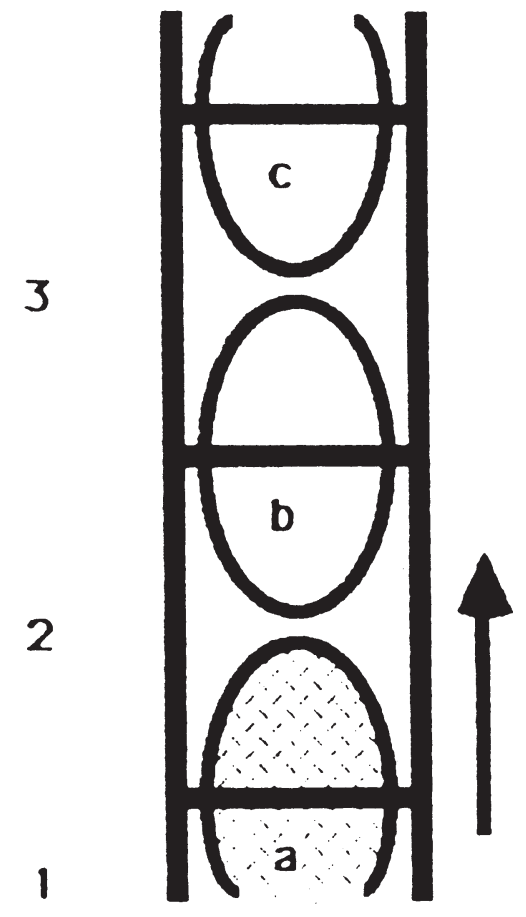

B. Fase incipiente

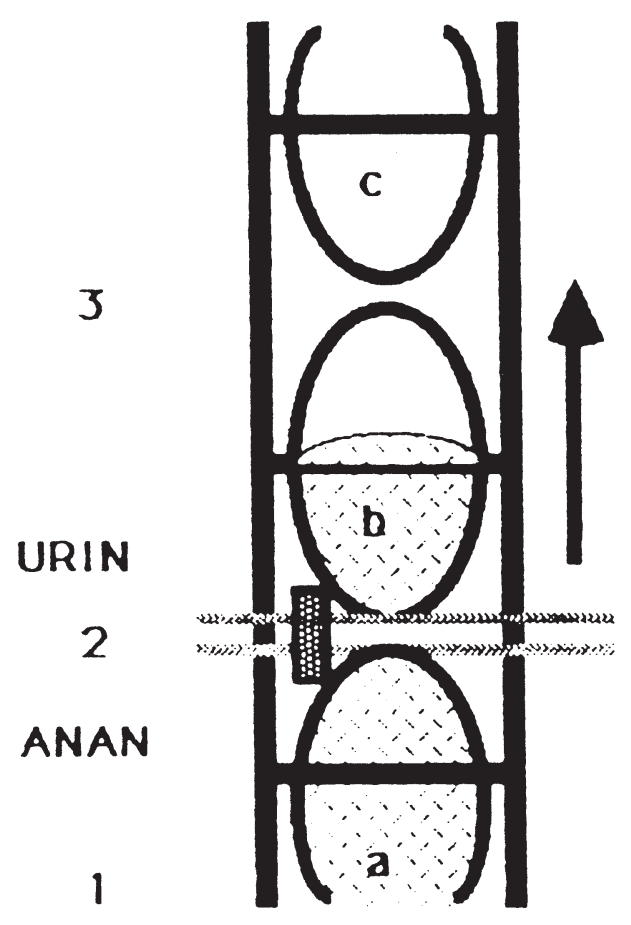

C. Fase Avanzada

Figura 3.- Modelo dinámico de las provincias incas en el Chinchaysuyu septentrional. Los rectángulos simbolizan las cuencas interandinas. Los ovalos simbolizan los territorios de los grupos linguístico culturales o étnicos. La línea doble simboliza la división en sayas o mitades incas. 
las nuevas "provincias" a través de las divisiones preexistentes, y al redefinir las unidades antes desconectadas u hostiles como "mitades" interdependientes, los incas iban "desarrollando" las interrelaciones simétricas latentes en un escenario superficialmente desordenado. Este proyecto ideológico conllevó, por supuesto, a la necesidad de radicar la simetría teórica en relaciones económicas y sociales concretas entre las supuestas mitades, proyecto no siempre realizable en la práctica.

\section{2) Urbanismo inca}

El esquema presentado aquí parece pedir una distinción entre dos tipos de centros o urbanizaciones incas. Por un lado, tenemos sitios cuyos nombres y cuyos restos arqueológicos sugieren una fuerte articulación inca con las diferentes sociedades no incas: Jatun Cañar (Alcina 1983; Fresco y Cobo 1978), Jatun Jauja (Espinoza Soriano 1973:43-84), Jatun Qolla (Julien 1983). Por otro, tenemos centros o urbanizaciones incas que no parecen pertenecer estrechamente a ninguna órbita "étnica", sino que aprovechan la ventaja de sus posiciones sobre las vías que conectaron varias zonas productivas y territorios "étnicos". Estos habrán sido los centros diseñados para hacer efectiva la interdependencia (económica, dinástica) de los grupos conquistados mediante intercambios. Estos parecen poseer un carácter más intensamente inca, aunque abarcaron también instituciones aborígenes conducentes al intercambio entre grupos (tiangueces, "mindaláes", etc.). En el Ecuador, Quito y Tomebamba parecen participar de este carácter.

\section{3) Bases funcionales del dualismo inca}

Cabe preguntar sobre la inserción funcional de los dualismos incas dentro de las sociedades aborígenes ya reorganizadas. Para esclarecerla, cabe recurrir a otro ejemplo del dualismo Anan/Urin ya mencionado antes sin comentario: la toponimia de Anan Chillo y Urin Chillo, los dos pueblos aborígenes de mayor población en el ámbito inmediato del presente estudio. Anan Chillo y Urin Chillo existieron lado a lado. De acuerdo a las evidencias onomásticas, parecen haber pertenecido a la misma comunidad de hablantes. En sus ecologías y formas de organización política se parecieron mucho. Estas similitudes parecen pronosticar una exitosa articulación dual. Pero la evidencia demuestra que, a pesar de la apariencia de pueblos parejados, las denominaciones ana y urin tuvieron poca vigencia. A diferencia de la terminología de Anan y Urin Quito, la de los Chillos se extinguió antes de 1600 a favor de topónimos no quechuas y no duales (Amaguaña/Sangolquí). ¿Cuáles fueron los factores relevantes para la implantación duradera del dualismo territorial presentes en la región grande de Quito y ausente en el escenario local de los Chillos? Difícilmente se puede extraer algún dato, porque no conocemos las ideas populares del período.

Sin embargo, no debe pasarse por alto dos hechos. Primero, la administración de los Chillos estuvo a cargo de los curacas locales y no de incas. Mientras la administración cuzqueña del Gran Quito definió un nuevo nivel del integración socio-política, con nuevas funciones, la de los Chillos únicamente pretendió redefinir las relaciones polí- 
ticas entre unidades preexistentes. Segundo, dicha redefinición conllevó a una conceptualización nueva y problemática: transformar la disyunción entre entidades similares y autosuficientes, en una conjunción de entidades disímiles e interdependientes. Es probable que Anan y Urin Chillo hayan sido demasiado similares en sus potenciales para pasar de una articulación simétrica formalizada a una duradera interdependencia.

\section{Hacia una interpretación global}

En todos los escritos que nos trasmiten testimonios sobre la ideología inca, salta a la vista el autoconcepto inca de héroes culturales. En una sociedad propensa a conceptualizar la organización social no como artefacto puramente utilitario, sino como manifestación e imagen de verdades sobrehumanas, la administración fronteriza adquiere un tremendo peso ideológico. Representa la transformación del caos exterior en un cosmos propiamente humano y sobrehumanamente inteligible. Por lo tanto, los incas no se habrán imaginado el cambio como un proceso acumulativo, incrementador, lineal; el simple movimiento de las fronteras militares en sí engrandece, pero no impone orden. Para constituirse en proceso cultural, tuvo que definirse de acuerdo a los patrones reconocidos en el Mundo Andino como civilizadores por excelencia: el despliegue de partes complementarias y discontinuas. Lo vemos en el avance de la frontera, que asume aspecto doble: la expansión inicial del dominio militar, proceso simplemente agregativo y condicionado por los azares del mundo exterior, inevitablemente cede el lugar al despliegue de una segunda frontera "interna", cuyo movimiento es determinado por las leyes de la cultura la discontinuidad, sobretodo y no por los hechos accidentales. El proceso inca comienza como historia encontrada y desemboca en historia diseñada.

\section{AGRADECIMIENTOS}

Agradezco sinceramente el trabajo de Susan Grosboll de la Universidad de Wisconsin, quien tuvo a su cargo la programación y computación del proyecto. Agradezco también la ayuda prestada por Almerindo Ojeda y David Peeler. Igualmente, doy las gracias por el apoyo monetario al Research Committee de la Universidad de Wisconsin.

\section{NOTAS}

1 Por "visita personal", se entiende una investigación en la cual el visitador se entrevistó cara a cara con los individuos censados. Las categorías empleadas en la visita son las mismas reflejadas en los quipu originales. El intérprete de la visita fue un natural de Cotocollao, probablemente hablante de castellano, quechua y uno o más idiomas aborígenes.

2 Las revistas europeas Onoma y Names contienen numerosos artículos sobre métodos para interpretar históricamente los datos onomásticos.

3 Los "etimólogos" utilizan como fuentes diccionarios de diversas lenguas autóctonas de Meso y Suramérica, sin estudiar sus características gramaticales. En el Ecuador, las ideas de Max Uhle propulsaron una tendencia a atribuir gran parte del léxico aborigen a raíces mayas, pero con ellas los etimólogos han mezclado fragmentos de Muchick, Arawaco, Aymara, Chibcha, etc., sin emplear criterios uniformes. 
4 El mínimo de 12 casos fue escogido para satisfacer las necesidades de las pruebas probabilísticas ji2, Kramer V, lambda, coeficiente de indeterminación. En muchos casos el escribano escribió sin uniformidad en la ortografía nombres cuya pronunciación probablemente era idéntica. Por ejemplo Zimbaña, nombre muy prevaleciente hasta en la actualidad, se escribe en la visita "Zimbaña", "Cinbaña", etc. En los casos que permitieron la ecuación entre ortografías distintas, se juntaron las variantes.

5 Los nombres comunes (sin enumerar sus variantes) son: Amaña, Angona, Axango, Axoan, Caxana, Cangoquiça, Cicanazu, Cinalen, Collaguazo, Cugan, Gualicicomen, Guaña, Hucña, Lucnango, Naato, Nachinba, Nagaxa, Nazinba, Oxina, Pallo, Pasña, Quiloguan, Quilumba, Tayango, Titoaca, Titoaña, Tubça, Uxingaxa, Xilimpazo, y Zinbaña. Con excepción de Pasña y, quizás, Pallo ninguno es quechua.

6 Se puede aislar un morfema si ocurre bajo cualquiera de las condiciones siguientes: "(1) aisladamente; (2) en combinaciones múltiples, siempre que una o más de las unidades con la cual vaya combinada, ocurra también aisladamente o en otras combinaciones; (3) en una sola combinación, siempre que el elemento con el cual vaya combinado ocurra también aisladamente o en otras combinaciones con constituyentes no únicos" (Nida 1949:58-59; traducción de F.S.).

7 Es decir, la hipótesis de una distribución al azar con respecto a la variable "pueblo".

8 La zonificación de algunos grupos consonánticos es lo suficientemente débil como para ser afectada por el tratamiento de los casos de los nombres con múltiples grupos consonánticos.

9 Montículos funerarios en forma de pirámide truncada.

10 Entre los curacas de Anan Quito (Salomon 1980) se enumeran varios cuya afiliación cultural probablemente fue Puruhá.

11 En la Audiencia de Quito la parte "anan" de cada pueblo generalmente se ubica en el sur. Este fenómeno se nota en Tomebamba (Cuenca actual), Quito y Otavalo. En la actualidad los términos "ana" y "uray", "alto" y "bajo", tiene el sentido de sur y norte, respectivamente. ¿Por qué se asignó el rango de Anan o "alto" al sur? Las razones aducidas para explicar la orientación de "alto" y "bajo" en sistemas locales hidrofrafía y astronomía (Sherbondy 1982), emulación del Cuzco (Albornoz 1948:44-45) no satisfacen mucho en este caso porque no aclaran el modo de dar un sentido ideológico a la topografía de un territorio con múltiples valles y cuencas como el Gran Quito de los incas. Sospechamos que al calificar la parte sur como "alta" y la parte norte como "baja", los incas atribuyeron el rango superior a la parte más extensa y completamente sometida: la parte más "civilizada" dentro de la óptica inca.

12 Utilizamos la palabra "desarrollar" para destacar la analogía entre el papel del concepto de simetría en el pensamiento inca y el concepto de progreso en el pensamiento occidental moderno. En ambos casos, se trata de una teología histórica; los actores creen que el "telos" ya está implícito en la constitución del mundo pre-existente (un territorio de "behetrías", un país "subdesarrollado") y que el oficio del individuo o grupo que "hace historia" es detectar, y luego manifestar en las obras, el patrón predestinado, siempre latente en el aparente caos de los acontecimientos humanos.

13 Probablemente correspondientes a las parroquias modernas de Amaguaña y Sangolquí, respectivamente.

14 Por ejemplo, en la coordinación de los ceques, líneas organizadoras de las corporaciones humanas, con los lineamientos naturales de la orografía y probablemente con los ritmos celestiales (Zuidema 1982).

15 Es interesante que la palabra awka significa a la vez persona extraña a la civilización, salvaje, y persona inca en pie de guerra, hostilidad, brujería, etc.; la actuación del combatiente significa una participación en el desorden que hierve fuera de la periferia política. 


\section{BIBLIOGRAFÍA}

AGI/S Justicia 683

1559 Visita de la encomienda de Francisco Ruiz hecha por Juan Mosquera y Cristobal de San Martin por mandado del gobernador Gil Ramirez Dávalos. ff.798r-874v. Archivo General de Indias, Sevilla, España-

Alcina Franch, José

1983 Tomebamba y el problema de los indios cañaris de la sierra sur del Ecuador. En Anuario de Estudios Americanos 37:403-433.

Albornoz, Víctor Manuel

1948 Cuenca: Monografía histórica. Casa de la Cultura Ecuatoriana, Núcleo de Azuay, Cuenca, Ecuador.

Buchwald, Otto von

1908 Vokabular der "Colorados" von Ecuador. Zeitschrift für Etnologie 40:7082 .

1921 La lengua de la antigua provincia de Imbabura. Boletín de la Academia Nacional de Historia 3(7-8):177-191. Quito.

Burgos-Guevara, Hugo

1975 El guaman, el puma, y el amaru: Formación estructural del gobierno indígena en el Ecuador. Tésis de Doctorado, Departamento de Antropología, Universidad de Illinois, Urbana, IL, Estados Unidos.

Diez de San Miguel, Garci

1964 Visita hecha a la provincia de Chucuito por Garci Diez de San Miguel en

[1567] el año 1567. Compilado por John V. Murra, Casa de la Cultura Peruana, Lima.

Espinoza Soriano, Waldemar

1973 La destrucción del imperio de los incas. Retablo de Papel. Lima.

1975 Los mitmas huayacuntu en Quito o guarniciones para la represión armada, siglos XV y XVI. Revista del Museo Nacional 41:351-394. Lima.

Fresco, Antonio y Wania Cobo

1978 Consideraciones etnohistóricas acerca de una tumba de pozo y cámara de Ingapirca (Ecuador). Revista Española de Antropología Americana 8:147-161. Ecuador.

Grijalva, Carlos Emilio

1947 Toponimia y antroponomia del Carchi, Obando, Túquerres e Imbabura. Editorial Ecuatoriana. Quito.

Gondard, Pierre y Freddy López

1983 Inventario arqueológico preliminar de los andes septentrionales del Ecuador. MAG/ORSTOM/Banco Central del Ecuador. Quito. 
Jijón y Caamaño, Jacinto

1940- El Ecuador interandino y occidental antes de la conquista castellana. Vol.

1941 3-4. Editorial Ecuatoriana. Quito.

Julien, Catherine

1983 Hatunqolla: A view of Inca rule from the Lake Titicaca region. University of California Publications in Anthropology. Tomo 15. University of California Press, Berkeley, CA, Estados Unidos.

Knapp, Gregory y Roy Ryder

1983 Aspects of the origin, morphology, and function of ridged fields in the Quito altiplano. Ecuador. En Drained Field Agriculture in Central and South America. Compilado por J. P. Darch. British Archaeological Reports, International Series, No.189. Pp.184-220. Oxford, Inglaterra.

Lado, Robert

1957 Linguistics across cultures. Applied Linguistics for Language Teachers. University of Michigan Press, Ann Arbor, MI, Estados Unidos.

Loukotka, Cestmir

1968 Classification of South American Indian Languages. UCLA Latin American Center, Los Angeles, CA, Estados Unidos.

Murra, John V.

1946 The historic tribes of Ecuador. En Handbook of South American Indians. Compilado por Julian Stewart. Vol. 2. Bureau of American Ethnology. Bulletin No.143:785-821. Smithsonian Institution, Washington, DC.

Nida, Eugene

1949 Morphology, The Descriptive Analysis of Words. University of Michigan, Ann Arbor, MI, EU.

Ortiz de Zuñiga, Iñigo

[1562] Visita a la provincia de León de Huánuco en 1562.2 tomos. Compilado por

1967 John V. Murra. Universidad Nacional Hermilio Valdizán, Huánuco,

1972 Perú.

Paz y Miño, Luis T.

1940 Lenguas indígenas del Ecuador: La lengua pasto. Boletín de la Academia Nacional de Historia. 20(56):161-178. Quito.

1941a Lenguas indígenas del Ecuador: La kito o panzaleio. Boletín de la Academia Nacional de Historia. 21(58): 145-170. Quito.

1941b Lenguas indígenas del Ecuador: La lengua kara. Boletín de la Academia Nacional de Historia. 21(57):28-52. Quito.

Pérez, Aquiles

1960 Quitus y caras. Instituto Ecuatoriano de Antropología e Historia. Llacta, No.10. Quito.

1962 Los seudo-Pantsaleos. Talleres Gráficos Nacionales. Quito. 
Rostworowski de Diez Canseco, María

1983 Estructuras andinas del poder: Ideología religiosa y política. Instituto de Estudios Peruanos, Lima.

Salomon, Frank

1980 Los señores étnicos de Quito en la época de los Incas. Instituto Otavaleño de Antropología, Serie Pendoneros, No.10. Otavalo, Ecuador.

Salomon, Frank, y Susan Grosboll

1985 A computer approach to a precolonial language problem. Computer-Assisted Anthropology News. 1(3):1-4.

sf Names and peoples in Incaic Quito: Retrieving Undocumented Historic Processes through Anthroponymy and Statistics. American Anthropologist. (En prensa)

Sherbondy, Jeannette

1982 El regadío, los lagos y los mitos de origen. Allpanchis. 20:3-32. Cuzco, Perú.

Skar, Harald O.

1982 The Warm Valley People: Duality and Land Reform among the Quechua Indians of Highland Peru. Universitetsforlaget, Oslo.

Verneau, R. y Paul Rivet

1912- Ethnographie ancienne de l'Equateur. Ministere de l'instruction, Francia,

1922 T. 6., 1899-1906. Mission de service géographique équatorial en Amérique de Sud sous le controle scientifique de l'Academie des Sciences.

Weinreich, Uriel

1967 Languages in Contact. Findings and Problems. Mounton Press. The Hague.

Weitman, Sasha

1981 Some Methodological Issues in Quantitative Onomastics Names. 29:181196.

Yánez Quirola, Francisco Gerardo

1979? Historia cuatrisecular del pueblo de San Andrés. Editorial Gallocapitán. Otavalo, Ecuador.

Zuidema, R. Tom

1982 Catachillay: The Role of the Pleiades and of the Southern Cross and Centauri in the Calendar of the Incas. En Ethnoastronomy and Archaeoastronomy in the American Tropics. Compilado por Anthony F. Aveni y Gary Urton. pp.203-229. New York Academy of Sciences, NY, Estados Unidos. 


\title{
TOMEBAMBA: PRIMERA FASE DE CONQUISTA INCASICA EN LOS ANDES SEPTENTRIONALES. LOS CAÑARIS Y LA CONQUISTA INCASICA DEL AUSTRO ECUATORIANO
}

\author{
Jaime Idrovo
}

La historia social y política del Perú y Ecuador antes de la llegada de los españoles tuvo muchos puntos de similitud y convergencia pero también diferencias. En el primer caso, el Perú prehispánico significó una geografía con posibilidades naturales no muy óptimas para acoger un crecimiento poblacional cada vez más denso; la organización política en sí misma se definió como un vasto sistema de estado, edificado sobre bases de fuerzas militares (Agro 1972:189). En el Ecuador existieron, por el contrario, mejores posibilidades de asentamientos humanos, sobretodo en la costa, cuyos centros administrativos aparecen como asociaciones de intercambio comercial.

En la sierra ecuatoriana, la gran concentración de restos culturales, especialmente cerámicos, demuestran también la existencia de una crecida población diseminada a lo largo de los extensos valles u hoyas. Estas sociedades que dominaron ampliamente su geografía, de la cual extrajeron los principales productos para su mantensión, desarrollaron, al mismo tiempo, una fuerte actividad comercial con otras regiones para el aprovechamiento de las materias faltantes.

Si bien estos grupos no llegaron a definirse como estados propiamente dichos, como en el caso del Perú, estuvieron mejor organizados en lo que se ha definido como señoríos cuyo modelo de asentamiento puede incluir comunidades de base parental, tanto de tipo poblado como caserío, con características como la aparición de centros religioso-administrativos y un crecimiento demográfico acelerado (Sanders y Merino 1973:15-16).

Según Godelier, los pueblos andinos anteriores a la invasión y conquista incásica mantenían la propiedad comunitaria de la tierra. Cada familia usufructuaba su parcela, la cual era distribuida en forma periódica pero sin llegar a la pertenencia de la misma. De esta forma, la producción reposaba en la cooperación de productores directos, entre los cuales había una suerte de obligaciones recíprocas de parentesco y vecindad (Godelier 1973:84,85). Pero claro, el derecho comunal de la tierra no excluyó la posición regente del curaca, depositario de un excedente económico que condicionó la existencia de una élite de control y dirección de la vida del grupo. De la región cultural cañari, en los Andes sur del Ecuador, sabemos que "En tiempos de su gentilidad cada parcialidad tenía señoríos, un Cacique sobre sus vasallos, de los cuales unos tenían más y otros menos... " (Gaspar de Gallegos 1965:275).

En este sentido el curaca disponía de un poder real frente a la comunidad, la misma que debía cultivar sus tierras o prestarse como fuerza de trabajo; el tributo, institución implantada durante la Colonia, parece haber estado ausente del sistema de organización social del mundo andino (Murra 1975:145). 
Una breve visión de las actuales provincias serranas del Azuay y Cañar, con amplias depresiones geográficas, especialmente en dirección Norte-Sur, dibuja un tipo de poblamiento disperso, a excepción de las dos ciudades: Cuenca y Azogues y sus cabeceras cantonales. Asimismo, una visión retrospectiva hacia el pasado testificada a través de los restos cerámicos conservados a lo largo de este territorio, sugieren el mismo panorama durante la época prehispánica, es decir, sobre lo que podríamos considerar como centros administrativos con una población dispersa en los alrededores.

Desgraciadamente, han quedado pocos ejemplos de estas áreas de concentración, al igual que de las huellas materiales de su existencia, testificada generalmente por la información que dejaron los cronistas castellanos. Del primer ejemplo citaremos un caso: Yaber junto al actual pueblo de Chordeleg. Se trata de una amplia zona que Matovelle describe, comprendida entre Jima, Sígsig y Gualaceo y donde "...hallánse las huellas de una extensa y muy poblada comarca de indios..." (1921:22,23); territorio que sin duda guarda relación con las ruinas cañaris de Yaber, constituidas por una enorme zona donde se descubren numerosas construcciones y murallas de contención, testimonio de un centro poblacional que dominó parte del sector oriental de la provincia del Azuay.

En cambio de Guapondélic, el primitivo asentamiento Cañari sobre el Valle de Cuenca, no han quedado vestigios de construcción alguna, salvo la presencia de abundante cerámica, sembrada literalmente en toda la extensión de esta unidad física. Nos han quedado asimismo algunas tumbas, pero sobretodo el testimonio de Hernando Pablos, quien en 1582 da a conocer el primitivo nombre de la parte baja del valle y que será luego reemplazado por el de Tomebamba en épocas del incario (1965:II:265).

Podríamos añadir otros ejemplos como Cañaribamba al occidente de Cuenca y Hatún Cañar o el actual Ingapirca al norte de Azogues. Todos ellos considerados como centros de concentración de poder político-religioso necesarios en la organización y relaciones de cada región.

Debemos, sin embargo, hacer una diferencia entre los centros administrativos que se manifestaron al mismo tiempo como plazas fortificadas o santuarios religiosos preurbanos y todo el desarrollo posterior, impuesto con el advenimiento de los incas. Entonces, los asentamientos cañaris como Guapondélic o Hatún Cañar se transformaron en términos físicos y organizativos hasta situarse en condiciones de verdaderas ciudades, con un esquema planificado de acuerdo a las necesidades de un estado en pleno proceso de expansión imperialista como fue el incásico.

González Suárez ha definido en su "Historia General de la República del Ecuador" la organización política de los Cañaris de la siguiente manera:

El Gobierno General de los Cañaris era, como el de sus vecinos los Puruháes, una Monarquía Federativa. Cada Curaca o Régulo gobernaba independientemente su propia tribu: pero en los casos graves, relativos al bien general, todos los jefes se juntaban a deliberar en asamblea común, presididos por el Señor o Régulo del Tomebamba, el cual ejercía indudablemente cierta jurisdicción sobre los demás... (Ariel s/f:I:88). 


\section{Por su parte Julio Matovelle agrega:}

Antes de la conquista llevada a cabo por los Incas no hubo ciudad alguna en la región; los habitantes de ella vivían en chozas diseminadas en todo el territorio azuayo, principalmente en las cumbres de las cordilleras y en los terrenos montuosos; a veces agrupados en villorios, entre los que los principales eran Hatún Cañar y Cañaribamba...

Allí seguramente reunían a los caciques subalternos y celebraban con ellos el Consejo indispensable para el buen régimen de la nación... (Matovelle 1921:81).

El criterio de los dos historiadores ecuatorianos, basado en el análisis de textos etnohistóricos dejados por cronistas y escritores del siglo XVI, ayuda a visualizar mejor el problema de la organización social de los cañaris. Con las dos citas presentadas apoyamos nuestro criterio acerca del tipo de asentamiento existente, pero resalta también otro aspecto tocante a la relación de cada grupo o región con los demás del conjunto del país cañari.

González Suárez supone una organización federativa que funcionaba en épocas de guerra o desgracias y sin duda no está lejos de la realidad, pues se trata de pueblos posiblemente marcados por diferencias considerables, pero dentro de una gran familia étnica que se identificó a través de un mismo idioma, tradiciones culturales más o menos similares, cerámica idéntica que, pese a las características o estilos que surgieron en cada región, tenía un mercado y consumo generalizado. Garcilaso de la Vega indica por otro lado que "había muchos señores de Vasallos, algunos de ellos aliados entre sí" (s/f:III:87) y es conocida la alianza concertada entre el cacique Duma con los caciques de Macas, Quizna y Pumallacta, a fin de oponer resistencia a la conquista incásica (Cordero Palacios 1981:141).

Sin embargo, este clima de colaboración parece haber estado interrumpido continuamente por una serie de guerras interiores pues

...los más pequeños se unían para defenderse de los mayores que como más poderosos querían tiranizar y sujetar a los más flacos..." Garcilaso (s/f:III:87).

Determinados así, los cañaris aparecen como una serie de parcialidades más o menos vecinas las unas de las otras, con una economía basada en la agricultura y el comercio con la costa y el norte peruano de manera preferencial. En suma, cacicazgos independientes económicamente, pero formando unidades regionales en torno a centros de cohesión organizativa, corrientemente afectados por enfrentamientos bélicos, pero asimismo prestos a unirse cuando un enemigo común se presentaba. En síntesis, “...una unidad cultural más no política cuando los incas venidos del sur toparon con ellos..." como afirma Udo Oberem (1976:264).

Trataremos de esbozar a continuación algunos puntos centrales de la conquista incásica del Austro Serrano del Ecuador, recalcando aquello de que todas las especificaciones de la región cañari, ya sean geográficas, de asentamientos humanos u organizativos, contrastan con aquellas que representaron Perú y Bolivia en épocas del incario. 
Con esta premisa, que bien puede generalizarse tanto para el centro y norte de los Andes septentrionales y que se radicaliza aún más en referencia a la costa ecuatoriana, estamos en condiciones de afirmar que la conquista de estos territorios diferió también de aquella que los incas realizaron en los Andes Centrales.

Los valles de Perú y Bolivia, menos extensos que los ecuatorianos, exigieron al hombre de esas latitudes una organización especial de control vertical de variadas economías (Murra 1975:59). Solo así se podían satisfacer íntegramente las necesidades básicas de las grandes concentraciones humanas que ocuparon los valles interandinos. El control de esas fuentes de subsistencia generaba, sin necesidad de guerras prolongadas, el pronto sometimiento de pueblos enteros que no pudieron soportar estas medidas, además de sobreponerse a ellas una enorme fuerza militar como fue la del incario. La costa desértica por otro lado, cuya vida es determinada por los ríos que bajan de la Sierra, fue aún más vulnerable pues siendo los incas un pueblo de montaña, el control de estas vertientes aseguró de manera más pronta y con menor esfuerzo la conquista y el sometimiento de los pueblos allí asentados. Leamos a este respecto el texto de Favre:

En efecto como todos los imperios "hidráulicos", el imperio Chimú fué singularmente vulnerable. Su pesada dependencia de la irrigación le puso al servicio de cualquiera que llegase a controlar las fuentes y recolectores de agua que le aseguraron su fastuosa opulencia. $\mathrm{Su}$ suerte estuvo jugada desde el día en que los incas, sólidamente implantados en las tierras altas del altiplano, podían determinar a su antojo el curso de los ríos, sustituyendo así los florescientes oasis de la costa por la aridez del desierto. (Favre 1980:22).

Este no fue el panorama de la geografía del Ecuador. Prueba de ello encontramos en el hecho de que en los mismos cañaris, si bien necesitaban desplazarse de sus sitios de vivienda permanente a otras áreas en busca de otros recursos como la sal, por ejemplo (Oberem 1981:45), el control vertical de nuevas zonas agrícolas o de abastecimiento no tuvo las características ni la intensidad que en Perú y Bolivia. A ello hay que añadir lo que hemos venido planteando: se trataba de pueblos que habían desarrollado ampliamente el comercio a tal punto que, según González Suárez, ...Si alguna de las antiguas naciones indígenas ecuatorianas conoció la moneda y la empleó en sus transacciones comerciales, esa fue, tal vez, la de los cañaris... considerables cantidades de conchas marinas, pequeñas de color rosado... eran tenidas como la moneda de que se valían; (s/f:I:108).

Así pues, cuando los incas ingresaron a esta zona, se enfrentaron a situaciones extrañas a las vividas anteriormente, puesto que un ejército poderoso basa generalmente sus acciones en el dominio de centros de importancia. La mobilidad es generalmente uno de los mayores problemas que tiene que enfrentar, dada la estructura misma que lo forma. La efectividad de estos ejércitos en territorios organizados del modo descrito anteriormente debió fracasar inicialmente pues, tratándose de pueblos auto-abastecedores y sin presiones ecológicas o dependencias esenciales de centros administrativos, imponían la desmembración de la fuerza invasora a fin de controlar toda la extensión poblada. Decimos inicialmente, tratando de concebir un tiempo que si bien nos 
será imposible determinar con exactitud, al menos podremos imaginarlo en las diferentes etapas de conquista que se sucedieron con la llegada de los incas a suelo cañari.

Planteamos de esta forma que la dominación militar incásica del territorio austral del Ecuador se dio por etapas, habiendo tenido los incas en los primeros años de campaña un fracaso importante, lo cual les obligó a detenerse durante mucho tiempo en los límites del actual Valle de Cuenca, a fin de planificar nuevas estrategias para la conquista del restante territorio cañari y de la Sierra Norte y Central ecuatoriana.

\section{LA CONQUISTA DE LOS CAÑARIS SEGUN LOS CRONISTAS DE INDIAS}

Varios y controvertidos son los criterios que se tejen, a través de los relatos dejados por los cronistas que se ocuparon de la conquista incásica de la zona cañari.

Un resumen de las principales fuentes etnohistóricas realizado por Manuel Miño Grijalbo, nos permite concluir a partir de sus observaciones que, si fue Huayna Capac el primero en conquistar Quito, debió ser también el encargado de la conquista en las regiones del Norte Cañari y Central de la sierra.

Sin embargo, a partir de Cieza de León, considerado el cronista más serio del siglo XVI, quien informó sobre la derrota y sometimiento de los cañaris por parte de Tupac Yupanqui (1967:189), la mayoría de cronistas españoles sostuvieron idéntico punto de vista, sugiriendo al mismo tiempo la idea de una ofensiva única y acelerada que al cabo de pocos años dio como resultado la anexión completa de los territorios meridionales de los Andes ecuatorianos dentro del Tawantinsuyu. En este sentido, solo Montesinos da cuenta de una corta resistencia local y el retiro de las tropas incásicas hasta Saraguro, en la región Palta (Cordero Palacios 1981:140), pero indica que el lanzamiento de una nueva ofensiva produjo la rendición completa de los cañaris.

Aquí conviene preguntarse si en realidad esta visión simplista de la historia no guarda en sí misma una serie de defectos tanto de información como de intereses tendientes a arreglar los eventos y presentar un cuadro coherente y arrollador de la conquista incásica.

Desde esta perspectiva, debe tenerse en cuenta sobretodo que la mayoría de informantes o los más importantes fueron gentes del Cuzco, quienes relataron los orígenes y epopeya incásica de la conquista con un sentido mesiánico, no siempre próximo a la verdad, sobretodo cuando se trataba de realizar las glorias pasadas, omitiendo los sucesos "menores" que podían empañar este objetivo.

Por esta razón hemos creído necesario revisar estas fuentes como auxiliares y basar los hechos, por el momento, sobre la opinión de cronistas menores incluidos en las Relaciones Geográficas de Indias. La causa de esta elección se apoya primeramente en la posición privilegiada que los doctrineros, autores de estos documentos, tenían dentro de las diferentes comunidades indígenas. Con esta ventaja, la recopila- 
ción de informaciones se realizó directamente de boca de quienes vivieron todo el proceso o por lo menos una parte del mismo, lo cual supone una visión mucho más próxima de los acontecimientos. Así, cada "relación" dirigida a una región particular, representa una brevísima síntesis histórica, que comienza con la conquista incásica, narrada por los más viejos de la comuna, kurakas y principales, cosa que no siempre sucedió con los cronistas encargados de rehacer, no la historia de una zona, sino de todo el imperio. En este caso, las informaciones venían muchas veces deformadas por versiones de segundas o terceras personas o simplemente era la versión oficial del incario, arreglada a fin de presentar un cuadro coherente de los sucesos donde naturalmente las etnias sometidas jugaban el simple papel de vencidas y servían para exaltar la grandeza del vencedor.

Debe también tenerse en cuenta que los curas doctrineros no solo conocían a los informantes, lo que les permitía realizar una cierta selección previa, sino que además, por el hecho de vivir en esa región, disponían de mayor tiempo para constatar las primeras notas, pudiendo considerarse los manuscritos presentados como documentos revisados. Procedamos pues a la lectura y análisis de estas fuentes.

En las relaciones del sector suroccidental de la provincia del Azuay, concretamente Cañaribamba a orillas del Jubones, Juan Gómez, doctrinero de ese sector recoge el criterio de que fue Tupac Yupanqui quien sometió esa región (Gómez 1965:II:282). Posteriormente en la zona de Girón o Pacaribamba, si bien no se especifica claramente el nombre del Inca conquistador, las referencias sobre la lealtad de los cañaris de ese sector para con los incas hacen suponer que fueron conquistados también por el citado monarca (Arias Dávila 1965:II:278).

Igual sucede en la relación de Cuenca, donde mejor se aprecia ya como referencia histórica la conquista de la región de Guapondélic "...Inga Yupanqui los conquistó... Después de muerto este Inga gobernó la tierra Topa Inga Yupanqui... [quién] vino a residir a este valle de Tomebamba que agora se llama Cuenca, en la cual estuvo diez años por ser tierra de mejor habitación" (Pablos 1965:266-67). Claro que Hernando Pablos confunde el nombre de Pachacútec con el de Inga Yupanqui. Para la relación de Azogues leemos:

Y después que vino el Inga Yupanqui que fué el primero que los conquistó...

... Y que no pagaban tributo ni otra cosa, hasta que después vino a tierra un nieto deste Inga Yupanqui que se llamaba Guaynacava y entonces fueron más trabajadores... (Gallegos 1965:275).

Este testimonio incluye también la misma confusión entre Inga Yupanqui y Pachacútec Inca. Se observan entonces hasta aquí dos aspectos principales: Fue Tupac Yupanqui quien conquistó la región del Jubones-Girón-Cuenca-Azogues, sin que por ello se deba confundir a Tupac Yupanqui, el que será emperador años más tarde y en este caso encargado de los ejércitos de Pachacuti, su padre, quien le confió el mando de sus tropas y la conquista de los territorios de la actual República del Ecuador (Metreaux 1983:42). 
Es, quizá, debido a este hecho que incluso Cieza afirma en la primera parte de la Crónica del Perú que los cañaris fueron conquistados por Pachacuti, aunque rectifica esta información en El Señorío de los Incas.

Por otro lado, hasta la región de Guapondélic o Cuenca, no se mencionan tampoco insubordinaciones, pero resulta evidente que en la zona de Azogues ocurre algo parecido pues "...estos indígenas no pagaban tributo ni otra cosa...", lo cual quiere decir que una vez conquistada la región central del país cañari, los pueblos localizados al norte del Valle de Cuenca recobraron su independencia y autonomía y solamente con Huayna Capac se evidencia el sometimiento definitivo de toda el área.

En la misma relación se lee además en referencia al monte de Cojitambo; localizado quince kilómetros al norte de Cuenca..." porque es cerro de peña viva y atajado y muy alto, que cuando el Inga andaba conquistando estas tierras, tenía allí su fuerte y su real y cuando los contrarios lo hostilizaban, se iba allí a hacer frente y descansaba allí..." (Gallegos 1965:276). Por lo tanto, la conquista no fue tan fácil ni arrolladora y en este punto los incas debieron levantar toda una infraestructura defensiva para soportar el embate de los cañaris. Parte de estos edificios existen aún en la actualidad, aunque al parecer bastante destruidos (Reinoso 1979:3).

Además, en la misma región habían otros sitios de defensa, como se desprende de las palabras de uno de los testigos en el Juicio de Nobleza de Don Juan Bistancela, cacique de Toctén," ...Porque en el dicho tiempo estaba en una fortaleza que llaman Pucára, en Guayay, cerca de Tatay [Taday] términos de la cibdad de Cuencia (Cuenca)... (Bistancela 1976:31). Solo así se comprende también porque el testigo Francisco Vilacutipa, cacique principal de la parcialidad de Anansaya de Ilave, declaró haber peleado junto con Guaynacana [Huayna Capac] contra los indios de Tumipampa, para lo cual dieron estos indios de la provincia de Chucuito "...Seis mil indios de los cuales murieron cinco mil... Y en otra ocasión tuvo que dar dos mil guerreros más de los que perecieron mil... (Diez de San Miguel 1964:106).

Resulta entonces lógico deducir que la empresa guerrera llevada a cabo por los incas costó mucha sangre y tiempo. Pero antes de seguir, vale aclarar el último texto en donde se sugiere que la guerra que enfrentó Huayna Capac y donde participaron tropas del sur del imperio, se realizó en Tomebamba. Esta parte debe ser interpretada, no como una guerra en la ciudad de Tomebamba, sino en la región de Tomebamba, por cierto al norte del Valle de Cuenca, generalizada bajo un mismo nombre, como es natural, por gente extraña al lugar. De estas batallas encarnizadas entre pueblos que defendían su independencia y las huestes de Huayna Capac han quedado asimismo algunos testigos. Miguel Durán visitó en 1930 lo que él llama ..." la piramidal colina de Guapán de más de 40 mts de alto... (al N.O.) había otro compartimento pequeño de piso más bajo, unos $0.75 \mathrm{~m}$, harto irregular y probablemente de fecha posterior que contenía un pozo de cenizas de cadáveres y otros pozos funerarios destituídos completamente de ajuar..." (Durán 1930:170). Junto a este pozo, Durán describe otros idénticos que contenían, según su apreciación, 160,000 cadáveres. En el mismo lugar se encontraron y fueron sacados veinte quintales de cobre en hachas y otros 
objetos de guerra. El autor interpretó este hallazgo como un templo de sacrificios maya, criterio con el cual no estamos de acuerdo, ni tampoco con el número de cadáveres calculados. Lo que importa en este caso son tres aspectos:

- La existencia de un número considerable de cadáveres incinerados;

- La gran cantidad de hachas y armas de cobre;

- La situación geográfica de Huapán, localizada junto a la ciudad de Azogues.

Con estas características no es difícil suponer que, en efecto, se trató de fosas comunes donde se incineraron los cadávares de una de las más grandes batallas de la "Resistencia Cañari" con sus armas como ofrenda. No debe tampoco extrañarnos el testimonio de Vilacutipa sobre el número de muertos que sufrieron las tropas de Huayna Capac, razón que obligó, además, a la construcción de varias fortalezas en Cojitambo, Taday y, sin duda, en otros sitios.

Siguiendo con el análisis de las Relaciones Geográficas en el documento correspondiente a Paute, al nororiente de Cuenca, Fray Melchor Pereira afirma de manera categórica que "...antes que Inga viniera quera Guaynacava... y que daban a Guaynacava y a Atagulpa de tributo todo lo que cogían de sus tierras..." (Pereira 1965:277) con lo cual se marcan tres zonas con diferentes períodos de conquista: Jubones-Cuenca, Azogues y el norte de la provincia del Cañar y finalmente las comarcas del sector Oriental del Azuay.

De estas tres regiones, la primera y segunda son conquistadas por Tupac Yupanqui bajo órdenes de su padre Pachacútec y, quizá, consolidada la primera ya bajo el reinado de Tupac Yupanqui. La segunda región, Azogues-Ingapirca (?), recobró prontamente su independencia y cayó definitivamente, junto con el sector de Paute, bajo el dominio incásico, solo con Huayna Capac. De las dos últimas etapas, nos ha quedado también el testimonio de Pedro Sarmiento de Gamboa que dice, "Y el Inga Huayna Capac tornose a Tomebamba donde descansó algunos días al cabo de los cuales movió su campo para conquistar a los Caranques, nación muy belicosa, en la cual entró conquistando los indios Macas [junto a Azogues] y los confines de los Cañaris..." (Sarmiento de Gamboa 1942:144).

Para sustentar de manera más sólida nuestras tesis sobre el sometimiento de la región Oriental, a más de la cita mencionada, tenemos el hecho de que se trataba de una zona muy rica, especialmente por la presencia de metales preciosos. Además, constituía una amplia franja de control de diferentes ecologías, como resulta ser el flanco Oriental de la Cordillera y, por último, ruta de ingreso a la Amazonía. Los incas no llegaron en ningún momento a levantar en este sector asentamientos urbanos de importancia, como los casos ya expuestos: Tomebamba, Hatún Cañar, Dumapara y Cañaribamba en el Centro, Norte y Suroccidental Cañari. Por otro lado, hay que tener en cuenta la red de pucáras que se extienden desde Gualaceo, pasando por Chordeleg y Sígsig hasta el Oriente y que posiblemente se trataron de fortalezas defensivas contra los jívaros porque "Las guerras que tenían [estos] antes que dieran obediencia a S.M. era con los indios Xibaros, por les quitar sus mugeres, y con los Zamoranos so- 
bre y en razón de defender las salinas." (Angeles 1965: II:270). Entonces, quizá, estos mismos Pucáras al momento de la conquista incásica tuvieron también como objetivo defender el flanco nororiental de la cordillera.

Por último, en las Relaciones de los Pueblos de San Antonio de Xunxi por Paz de Maldonado (1965, T.II:262) y en la de Chunchi por Martin de Guavira (1965:II:285) y Alausí por Hernando Haliuno (1965:II:288) situados al extremo norte del país Cañari, leemos que fue Huayna Capac quien llegó y sujetó primero estas tierras. Este argumento refuerza aún más nuestro punto de vista sobre la conquista incásica al norte del Valle de Cuenca realizada por Huayna Capac.

\section{MITMAG CAÑARIS}

El desplazamiento de poblaciones enteras de un lugar a otro del Imperio, práctica seguida por los incas, se desarrolló durante el reinado de Tupac Yupanqui, pero sobre todo con Huayna Capac. Este, a fin de consolidar la expansión del imperio hacia el norte, deportó masivamente a los habitantes de la actual República del Ecuador, reemplazando estas poblaciones por otras etnias de la región del Cuzco, leales a la estirpe imperial. Miño Grijalba quien estudió someramente el problema de los mitmag cañaris en el Perú, establece tres diversos momentos y circunstancias precisas en que se produjeron estas migraciones forzosas: la primera vez con Huayna Capac; la segunda con Quisquis y Calicuchima, capitanes de Atahualpa, durante la guerra civil del imperio; la última, con los conquistadores españoles (Miño Grijalba 1977:18).

Ahora bien, ¿cuál es el sentido mismo de esta institución? A juzgar por la forma en que fue practicada, tiene un carácter desmovilizador de los pueblos y etnias que presentaban problemas a la consolidación del imperio. Pachacuti, al iniciar los desplazamientos masivos de la región de Cuzco, consiguió el establecimiento definitivo de su etnia en ese lugar. Los resultados obtenidos permitieron su aplicación metódica en todas las tierras conquistadas (Favre 1980:55). El trasplante de los grupos a regiones donde el control político y militar era completo, evitaba las revueltas y aseguraba la estabilidad del Tawantinsuyu.

Dentro de este esquema, es importante el juicio de Miño Grijalba porque muestra justamente que los cañaris afectados por las deportaciones masivas pertenecen al período de conquista llevada a cabo por Huayna Capac y no por Tupac Yupanqui. Esto equivale a decir que aquel sector mantuvo una prolongada resistencia desde la primera campaña realizada por Tupac Yupanqui y finalmente al ser sometidos sus habitantes sufrieron la imposición de ser mitmag como castigo. Diseminados principalmente en lo que ahora es Perú y Bolivia, su papel como fuerza de resistencia cesó. Hubo en cambio otros que se fugaron al norte y que siguieron combatiendo. En efecto, según un texto que extractamos de Sarmiento de Gamboa, sabemos que luego de la Batalla de Yaguarcocha, donde se selló la victoria incásica contra los pueblos del norte, Pinto, el jefe local, "...se escapó con mil valientes cañaris..." (Sarmiento de Gamboa 1942:147). Seguramente se aliaron con las huestes imbayas y cayambes, a fin de evitar la muerte o deportación, luego de ser vencidos en su propio suelo. 


\section{ELEMENTOS ARQUEOLOGICOS A TENER EN CUENTA}

Existen diferencias sustanciales entre Tomebamba y Hatún Cañar o Ingapirca. Del análisis de la cerámica del primer lugar se puede convenir que cerca del $80 \%$ pertenece al estilo incásico. En Ingapirca, en cambio, el porcentaje de esta cerámica es mínimo. Antonio Fresco opina, por ejemplo, que "A pesar del hecho de que prácticamente todos los vestigios arquitectónicos descubiertos hasta ahora en Ingapirca corresponden al corto período de ocupación incásica (1500-1530 DC aproximadamente), la gran cantidad de fragmentos cerámicos y de objetos de otros materiales, así como enterramientos descubiertos en el lugar, demuestran que el sitio estuvo ocupado por los cañaris desde por lo menos el año 1,000 DC." (Fresco 1982:57).

Nosotros tuvimos asimismo la oportunidad de excavar en ese importante sitio arqueológico, en un espacio de terreno que consideramos exterior al área de ocupación urbana, ésto es, "La Quebrada del Intihuaico". Los porcentajes de cerámica localizados con filiación inca no pasaron del $4 \%$, considerando incluso estilos mixtos (Idrovo:1979:177). Igual sucedió en el sector de Pilaloma de ese mismo complejo excavado por Cueva, las muestras de alfarería incásica extraídas fueron mínimas y en nada proporcionales al conjunto de restos arquitectónicos de ese período (Cueva 1971:22).

Toda esta situación nos lleva justamente a pensar que la tendencia mayoritaria de la cerámica inca en Tomebamba es un afirmativo de que la ocupación, a más de haber sido densa, fue sobretodo prolongada, razón que explica que solo en Pumapungo, barrio de esa ciudad excavada actualmente por nosotros, se hayan recuperado hasta la fecha alrededor de dos millones de tiestos. En el caso de Ingapirca, la existencia de un porcentaje tan bajo de fragmentos incásicos, muestra que los incas apenas tuvieron tiempo de concentrar nuevas poblaciones, las cuales no dejaron mayores huellas de su vida doméstica y permanencia en el lugar. El desarrollo urbano, rápido y monumental, se debe, quizás a que Ingapirca se constituyó en plaza de avanzada en la conquista del Centro Andino, al norte del Nudo del Azuay. Otros lugares como Paredones, en las estribaciones de ese macizo montañoso, muestran vestigios incásicos constituidos esencialmente por kallankas (Hyslop,Idrovo y Guamán 1981) y una enorme cantidad de piedras labradas preparadas o en fabricación. Todo ésto muestra las necesidades materiales de contar con grandes depósitos o lugares de avituallamiento y, por otro lado, con un complejo religioso-militar de avanzada, el cual en pleno proceso de construcción quedó sin concluir, seguramente a causa de la guerra civil del Tawantinsuyu. (Idrovo y Almeida 1976).

\section{SINTESIS NECESARIA}

Según Carlos M. Larrea (1971:167), la conquista del Sur del Ecuador duró apenas cinco años, ésto es de 1460 a 1465 ó 1470, año en que nació Huayna Capac en Tomebamba. Nuevos estudios mejor documentados permiten reconsiderar estas fechas a partir de un esquema donde se observan diferentes etapas de avance y no simplemente una incursión general y única como pretenden los cronistas del siglo XVI. 
Es por lo tanto probable que la periodización de Larrea corresponda solamente a la región occidental de la provincia del Azuay, hasta los límites norte y oriental del Valle de Cuenca.

Apoyándonos en estas fuentes, sabemos por ejemplo que Tupac Yupanqui inició la expansión del Tawantinsuyu hacia el norte en el año de 1463, más o menos, y que la fecha de su muerte y, por lo tanto, el inicio del reinado de Huayna Capac sucede aproximadamente en 1493 (Favre 1980:21,25). En este lapso de treinta años, la guerra afectó los fastuosos estados de la Costa Norte peruana y de la Sierra hasta llegar a territorio Palta en la región ecuatoriana, desde donde se planificó y consumó la anexión de una parte del país cañari en los términos que hemos descrito.

Durante este tiempo es también probable que Tupac Yupanqui incursionara bien adentro en la provincia del Cañar, pero como indican los documentos que hemos revisado, muy pronto estos pueblos recobraron su independencia, concentrándose el grueso de efectivos en el área del Valle de Cuenca o más precisamente en Guapondélic, ahora convertida en Tomebamba. Desde aquí fortificados, buscaron los incas nuevos caminos de avanzada hacia el norte, esta vez por la costa, siguiendo la ruta de la Cordillera del Cajas o del Jubones. Por ello, se explica la conquista de la Isla Puná, centro de comercialización de Spondylus, cuyo valor económico-ceremonial ostentó una gran importancia entre todos los pueblos andinos. Pero incluso en este sector "Topa Inga no los sojuzgó enteramente hasta que lo hizo Guaynacaba" (Herrera 1960:366). Violentas rebeliones estallaron al parecer en las nuevas tierras conquistadas, obligando a las tropas incaicas a continuos repliegues sobre Tomebamba, fundada por Tupac Yupanqui como centro de operaciones militares y consecuentemente residencia prolongada del Inca y primera frontera real del expansionismo incásico en los Andes septentrionales. Desde aquí se incursionó y castigó los levantamientos (Garcilaso de la Vega s/f:125; Cobo 1956:187; Cabello Balboa 1951:150, 153), manteniendo un estado de guerra que, según Vilcacutipa, testigo y actor de las guerras de Tomebamba, duró veinte años (Diez de San Miguel 1964:105).

Huayna Capac reconquistó finalmente todo el territorio sublevado y anexó la parte oriental de las actuales provincias de Azuay y Cañar. A partir de este momento, el mismo Inca continuó hacia el norte venciendo después de una difícil y prolongada campaña militar a las etnias de las confederaciones del norte, entre las cuales estaban: Pastos, Cayambis e Imbayas. Aquí encontramos en alianza algunos cañaris escapados, sin duda, de la muerte o deportación luego de su derrota en las guerras de Tomebamba. 


\section{BIBLIOGRAFIA}

Agro, Roberto

1972 Algunas sugerencias ambientales determinantes que se relacionan con la geografía política del Perú pre-incásico y del sur del Ecuador. Cuadernos de Historia y Arquelogía. No.39. Guayaquil, Ecuador.

Angeles, Domingo de los

1965 San Francisco de Pacha y San Bartolomé de Atocxapa. En Relaciones geográficas de Indias.Vol. II, compilado por Marcos Jiménez de la Espada, pp.270-71. Ediciones Atlas, Madrid.

Arias Dávila, Pedro

1965 Pacaibamba y Leoquina. En Relaciones geográficas del Indias. Vol. II, compilado por Marcos Jiménez de la Espada, pp.278-80. Ediciones Atlas, Madrid.

Bistancela, Don Juan Cacique de Toctesi

1976 Probanza de Don Juan Bistancela cacique de Toctesi; de su noble y limpia sangre y de los servicios que prestó su padre al Rey. Cuadernos Guapondélic. Artes Gráficos, Quito.

Cabello Balboa, Miguel

1951 Miscelánea antártica. Universidad Nacional Mayor de San Marcos, Lima.

Cieza de León, Pedro

1967 El señorío de los incas. Instituto de Estudios Peruanos, Lima.

Cobo, Bernabé

1956 Historia del nuevo mundo. Biblioteca de Autores Españoles. Editorial Atlas, Madrid.

Cordero Palacios, O.

1981 El Azuay histórico; los cañaris y los inca-Cañaris. Consejo Provincial del Azuay, Cuenca, Ecuador.

Cueva, Juan

1971 Descubrimientos arqueológicos en Ingapirca. Informe preliminar de la primera etapa de trabajos en Ingapirca. Casa de la Cultura, Cuenca. Archivo del Museo del Banco Central del Ecuador, Quito.

Diez de San Miguel, Garci

1964 Visita hecha a la provincia de Chuicuito, por Garci Diez de San Miguel en el año de 1567. Casa de la Cultura del Perú, Lima.

Durán, Miguel

1930 Entierros en Guapán. Revista del Centro de Estudios Históricos y Geográficos de Cuenca. No.16. Cuenca, Ecuador. 
Favre, Henri

1980 Les Incas. Qué Sais-je?. París.

Fresco, Antonio

1982 La Cultura Cañari en Ingapirca. Editorial Andina, Quito.

Gallegos, Gaspar de

1965 Sant Francisco Pueleusi del Azogue. En Relaciones geográficas de Indias. Vol. III, compilado por Marcos Jiménez de la Espada. pp. 274-78. Editorial Atlas. Madrid.

Garcilaso de la Vega Inca

s/f Comentarios reales de los incas. Tomos I, II y III. Colección de Autores Peruanos. Lima.

Godelier, Maurice

1973 Horizon: trajets marxistes en anthropologie. Maspero. París.

Gomez, Juan

1965 Cañaribamba. En Relaciones geográficas de Indias. Vol. II, compilado por Marcos Jiménez de la Espada. pp. 281-286. Ediciones Atlas. Madrid.

González Suárez, Federico

1878 Estudio histórico de los cañaris, antiguos habitantes de la provincia del Azuay en la república del Ecuador. Quito.

s/f Historia general de la República del Ecuador. T.I. Editorial Ariel, Quito.

Guavira, Martín de

1965 Santo Domingo de Chunchi. En Relaciones geográficas de Indias. Vol. II, compilado por Marcos Jiménez de la Espada. pp. 285-287. Editorial Atlas. Madrid.

Herrera, Antonio de

1960 Historia de los hechos de los castellanos en las Islas y Tierras Firmes del Mar Océano. Cronistas Coloniales. Biblioteca Mínima. T.II. Puebla, México.

Hyslop, John, Jaime Idrovo y Jorge Guamán

1981 El camino del Inca. Informe Museo del Banco Central del Ecuador, Quito. Idrovo, Jaime y Napoleón Almeida

1976 Paredones en el contexto histórico y arqueológico del Cañar. Pucára \#1. Facultad de Filosofía de la Universidad de Cuenca, Cuenca, Ecuador.

Idrovo, Jaime

1979 Aspectos funerarios entre los Cañaris de Ingapirca. Maitrise de L'Université de Paris. Inédito. La Sorbonne, París.

Larrea, Carlos M.

1971 Notas de prehistoria ecuatoriana. Quito. 
Matovelle, Julio

1921 Cuenca del Tomebamba. Centro de Estudios Históricos y Geográficos del Azuay, Cuenca, Ecuador.

Metraux, Alfred

1983 Les Incas. Editorial Seuil. París.

Miño Grijalba, Manuel

1977 Los cañaris en el Perú. Pontificia Universidad Católica del Ecuador, Quito. Murra, John

1975 Formaciones económicas y políticas del mundo andino. Instituto de Estudios Peruanos, Lima.

1975 Control vertical de un máximo de pisos arqueológicos en la economía de las sociedades andinas. En Formaciones económicas y políticas del mundo andino. Instituto de Estudios Peruanos. Lima.

Oberem, Udo

1976 Los cañaris y la conquista española de la sierra ecuatoriana: Otro capítulo de las relaciones interétnicas en el siglo XVI. Journal de la Societé des Américanistes. París.

1981 El acceso a recursos naturales de diferentes ecologías en la sierra ecuatoriana (Siglo XVI). Pendoneros. No.20. Otavalo, Ecuador.

Pablos, Hernando

1965 Relación que enbio a mandar Su Magestad se hiziese desta ciudad de Cuenca y de toda su provincia. Relaciones geográficas de Indias. Vol. II, compilado por Marcos Jiménez de la Espada. pp. 265-270. Editorial Atlas, Madrid.

Paz Maldonado, Juan de

1965 Relaciones geográficas de Indias.Vol. II, compilado por Marcos Jiménez de la Espada. pp.261-64. Editorial Atlas, Madrid.

Relación del Pueblo de Sant-Andres Xunxhi para el muy ilustre Señor Licenciado Francisco Auncibay...

Pereira, Fray Melchor

1965 San Luis de Paute. Relaciones Geográficas de Indias.Vol. II, compilado por Marcos Jiménez de la Espada. pp. 271-274. Editorial Atlas, Madrid.

Reinoso, Gustavo

1979 Monumentales ruinas incásicas en Cojitambo. El Mercurio. 29 de Agosto 1979 . Cuenca, Ecuador.

Sanders, W. y J. Merino

1973 Prehistoria del nuevo mundo. Editorial Labor S.A., Barcelona, España.

Sarmiento de Gamboa, Pedro

1942 Historia de los incas. Buenos Aires. 


\title{
EL REINO DE CHIMOR Y EL TAWANTINSUYU
}

\author{
Patricia J. Netherly
}

\section{INTRODUCCION}

El surgimiento inicial del estado inca en los Andes sur-centrales no afectó mayormente al Reino de Chimor, que en el momento de su máximo auge se extendía a lo largo de la costa del Pacífico entre Tumbes y el Valle del Chillón. Por otra parte, sería ingenuo creer que mientras el imperio inca expandía sus fronteras, primero hacia el Collao en el sur y luego al norte, no había tomado conciencia del imperio costeño. Indudablemente, los gobernantes de Chimor veían con una preocupación creciente el avance inca sobre Cajamarca y Huamachuco.

La frontera entre Chimor y estos señoríos serranos tenía una larga historia de tensiones y fluctuaciones. Parece que en ningún momento contó el estado del litoral con territorio a más altura que la chaupiyunga, zona ecológica ubicada entre los $400 \mathrm{y}$ 1,400 msnm. Aún en épocas de avance serrano, no pasaron estos señoríos las tomas de las acequias costeñas entre los 200 y 300 msnm (Netherly 1977, sfb; Topic y Topic 1981). Durante el Período Intermedio Tardío, las zonas medias de los valles de la Costa Norte, las zonas chaupiyunga, quedaban dentro del ámbito de los señoríos del litoral (Netherly 1977, 1984; Netherly y Dillehay 1983; Dillehay y Netherly 1983; Topic y Topic 1981; Murra 1972; Rostworowski 1968-70; Dillehay 1976).

Esta frontera permitía una serie de relaciones recíprocas que fueron tipificadas por el conocido caso de los señores de Jayanca, quienes se obligaron a enviar sal, ají y algodón a Penachí en la sierra baja de Incahuasi a cambio de las aguas de la Quebrada de Canchachalá, un afluente del Río de la Leche, con que regaban las tierras de Jayanca (de la Gama [1540] 1974; Brüning 1923; Rubiños y Andrade [1782] 1936; Netherly 1977). En realidad no había manera por medio de la cual los serranos hubiesen podido cortar al agua en forma permanente. El "tributo" en productos típicamente costeños como la sal, el ají y el algodón, expresa más bién unas relaciones de dependencia mutua.

El gran reino del litoral, el estado chimú, fue el único rival del poderío del estado inca en el norte. Cuando convino al pequeño grupo real que formulaba la política inca emprender la conquista de Chimor, no le fue fácil. El estado chimú tenía la ventaja de un territorio que no dependía de los recursos serranos. Los valles-oasis estuvieron densamente poblados y ligados entre sí por múltiples caminos (Beck 1979), además de la gran vía que ofrecía el mar mismo. Tampoco conviene olvidar los recursos propios del litoral, no solo los frutos del mar, sino también el alto nivel freático que permitía el cultivo sin riego en hoyos más allá del término del sistema de riego y cuyo efecto fue aumentar la autosuficiencia ecológica de los valles costeños (Netherly 1977,1984,sfb). 


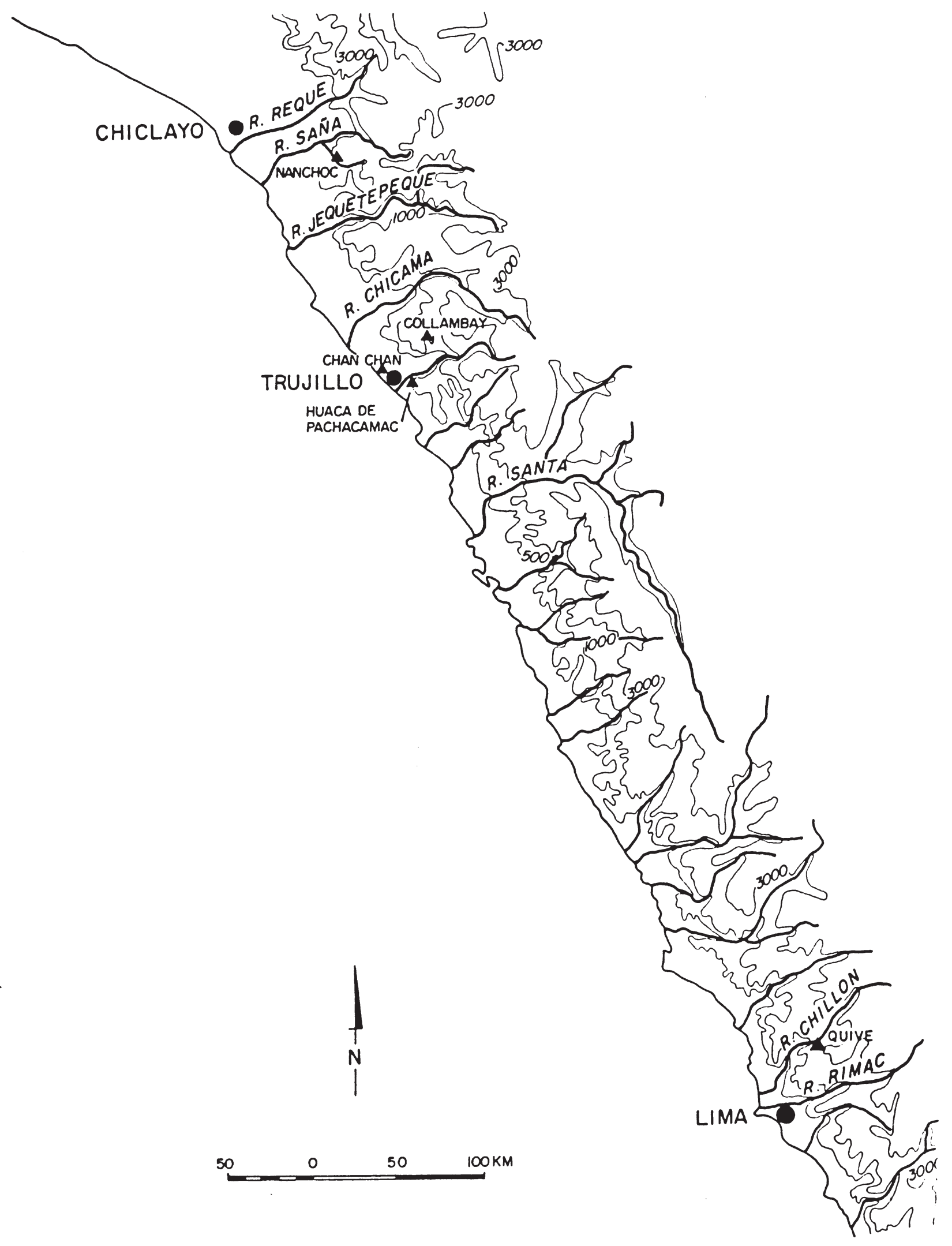

Figura 1.- Sitios mencionados en el texto. Los sitios arqueológicos están señalados por triangulos. 
No es, entonces, de extrañar que los señores de Chimor, en defensa de sus intereses en el intercambio con Cajamarca y Huamachuco a través de la frontera oriental, enviaran tropas para ayudar en la defensa de Cajamarca contra el precoz ataque inca. Como consecuencia de la conquista de Cajamarca por los incas, tienen que haber cambiado profundamente las condiciones en esta frontera norteña de tanta antigüedad (Cabello [1585] 1951, Caps.16,18). Por ejemplo, es seguro que aumentaron las tensiones y presiones serranas para mejorar el acceso a los recursos codiciados de la chaupiyunga, ya que los serranos tenían el respaldo latente o activo del estado inca. Además, en contraste con la situación en épocas anteriores, cuando la influencia serrana sobre las sociedades costeñas parece haber llegado por los señoríos cisandinos, esta vez no solo el estado inca se estableció en las gargantas de los valles del norte, sino también intervino directa e indirectamente en el aprovechamiento de los recursos de la costa y de la chaupiyunga.

\section{La conquista de Chimor según las tradiciones incas}

La relación de la conquista de Chimor por los incas es bien conocida pero también confusa y enigmática. Refleja el estado de tensión militar y cultural a través de la frontera entre la sierra y costa. También demuestra la compresión de acontecimientos y campañas (Cabello [1586] 1951, 3a Parte, Cap.16:319-333; Calancha 1638:550552; Cieza [1553] 1967, Caps.57-59:185-197; Pachacuti [1613] 1968:298).

Cabello describe lo que parece ser un primer intento o escaramuza por parte de los incas. Cuando la expedición militar bajo el mando del joven Topa Inga Yupanqui llegó a Cajamarca encontró

...sus soldados en buena orden, y por el Ynga, y en su obediencia la tierra, aunque auian sido molestados muchas veces de los Yndios yungas ...porque en el Valle de Chimo estaua un importuno contendor de sus disinios llamado Chimo Capac no menos poderoso en la tierra de los llanos que eran los Yngas en las tierras Serranas contra la pujanza de este valeroso Rey Chimo Capac embio Topay Ynga una buena parte de su Exercito, y bajando por la tierra de los Guamachucos, llegaron a los llanos, y tubieron grandes contiendas los Cuzcos y los de Chimo ...mas sabese por muy cierto que las armas de los Yngas pusieron en rebato á los del ancho y espacioso valle de Chimo, y tuvieron atemorizados a sus moradores, y hartos dias encerrados detras de sus empinados paredones de alli ( regada por el Ryo que llaman Pacaz mayo, y turbaron todos aquellos valles, y por el de Nepos arriba se bolvieron a Caxamarca... (Cabello Valboa [1586] 1951, 3a Parte, Cap.16:319-320).

Aquí se puede ver claramente la presión militar ejercida por los chimús, seguramente en forma de escaramuzas, contra la presencia inca en Cajamarca. Esta situación es posterior al envío de tropas chimús al abrupto terreno de Cajamarca en el momento de su conquista por los incas (Cabello Valboa [1586] 1951, 3a Parte, Cap.16:317). Como en esta instancia los ejércitos incas no podían tomar la capital de Chan Chan en el Valle de Chimor o Moche, pasaron al norte y subieron nuevamente a la sierra, utilizando el paso entre el Valle del Chamán y la Quebrada Nanchoc para luego tomar el camino a Cajamarca que pasa al sur de Niepos y por su territorio. 
La conquista de Chimor propiamente dicha parece haber venido del norte, realizada por el mismo ejército bajo Topa Inga, después de que conquistó la provincia de Quito y la costa del Ecuador. Luego de vencer a los Huancavilcas y Chonos, pasaron a Tumbes donde hicieron construir una "fortaleza", según Cabello. Este mismo cronista prosigue diciendo:

...y vinieron a Pohechos [en Piura] y allí descansaron algunos días, y fue determinado que el General y Señor Topa Yngayupangui se subiese a la Sierra con alguna parte de el exercito, y sus dos Tíos (con su nombre y boz) se fuessen por los llanos,...lleuando consigo los dos Capitanes las mas copia de la gente de guerra porque auian de pasar por unos valles de gente belicosa y mal sugeta al poder de Chimo capac, por esto y por la contienda que con este pujante enemigo se auia comenzado, y auer de prolongar todo su Ymperio contrastando los presidios, y guarniciones por el puestas, fue visto convenir traer los Capitanes consigo la fuerza de la gente suya.... (Cabello Valboa [1586] 1951, 3a Parte, Cap.16:325)

...Auqui [Yupangui], y Tilcayupangui [los tios] siguieron su camino por los llanos sin allar en todos ellos quien se les opusiesse solo se dice que venidos estos Capitanes con su exercito á la tierra y Provincia de los Jayancas fueron a traycion, y sobre siguro, asaltados de unos Yndios barbaros que vivian á las faldas de la sierra llamados Penachies, y mataron algunos de los de el Cuzco de lo qual los dos Capitanes Yngas se agraviaron mucho, y assi prendieron á el Cacique de Jayanca, sospechando auer sido hecha por orden suya aquella fealdad y torpeza, y preso fue lleuado á el Cuzco, ...[los] Capitanes Yngas ellos pasearon quietamente la tierra de los llanos, y llegaron á el valle de Chimo donde hallaron increible copia de riquezas de oro y plata y piedras de estima, no sabre decir si por amor y amistad, ó si por ventaja de armas se les entrego Chimo capac mas dicesse que de este viage lo sacaron consigo de Chimo, y lo llevaron á Caxamarca... (Cabello Valboa[1586] 1951, 3a Parte, Cap.18:331-332).

La relación de Cabello nos permite remarcar las relaciones especiales existentes entre los de Penachí y el señorío de Jayanca, que se expresaron por medio del intercambio de productos de la costa a cambio del agua de la Quebrada de Canchachalá. Cieza también remarcó que la presteza de los señores de la parte norte del territorio chimú en recibir a los incas fue una medida de su desconformidad con la soberanía de Chimor. Este anotó que fueron los señores de estos valles los que se sometieron sin batalla, permitiendo al estado inca colocar autoridades incas y construir instalaciones incas dentro de sus dominios (Cieza [1553] 1967, Cap.59:194-195). En otra parte, Cieza indica que el Chimor Capac se sometió voluntariamente al poderío inca y que se permitió la construcción de "grandes aposentos y casas de placer" incas en el Valle de Chimor (Cieza [1553] 1932, Cap.68:215).

Estas tradiciones constituyen la versión cuzqueña de los hechos. No sobrevivió ninguna relación costeña ni de la situación política que precedió a la conquista inca, ni del vencimiento de Chimor por los incas. Solo Calancha, cuyos informantes venían del Valle de Pacasmayo, anota que el último señor supremo chimú, a quien en las tradiciones serranas se denominaba "Chimor Capac" por su rango, levantó un ejército muy grande contra Topa Inca Yupangui (1638:550). Cieza nos cuenta de una batalla feroz en el Valle de Chimor, el Moche actual, en que casi fue vencida la hueste inca ([1553] 1967, Cap.59:195). Sin embargo, esta versión, aparentemente contradictoria, parece confundir dos acontecimientos. Cieza se queja de versiones contradictorias y de que sus informantes discreparon entre ellos, sobre si el Inca vencedor fue 
Topa Inca Yupanqui o su hijo Huayna Capac. Mas a propósito para un entendimiento del problema es el testimonio contenido en la genealogía de los señores de Chimor, donde se dice que después del sometimiento de Chimor al Tawantinsuyu, uno de los señores chimú se levantó contra el dominio inca, pero fue derrotado y muerto y se tomaron represalias por parte de los incas (Vargas Ugarte 1936:232). Zárate también recogió esta tradición ([1563] 1944, Cap.12:46).

Es de interés notar que, de cualquier manera que se hayan dado los acontecimientos de la conquista de Chimor por los incas, queda claro que fue más un proceso que un hecho único. Además, tanto la frontera cultural como la política se mantuvieron dentro de la zona de transición entre la costa y la sierra, la chaupiyunga, pero colocados los hitos para favorecer al máximo a los serranos (Netherly 1977, 1988, sfb).

\section{Tawantinsuyu y la Costa Sur: Un contraste}

La actitud inca hacia los estados costeños al sur ofrece luces sobre su política para con el Chimor. Se caracteriza por su flexibilidad y pragmatismo, pero también muestra una serie de paralelismos con los acontecimientos en el norte que permite un mejor entendimiento del modo de proceder inca. Los señoríos del sur eran más pequeños y su territorio y poderío más reducidos. Sin embargo, las principales estrategias incas frente a la costa se vislumbran más claramente en esta región más limitada. Los estados de la Costa Sur no fueron todos iguales ni tampoco utilizaban las mismas estrategias con respecto al estado inca. Pero igual que en el norte, la presencia inca representaba una intromisión y rompimiento de las antiguas relaciones a través de una frontera cultural y ecológica.

De haber tenido esta interacción un aspecto de reciprocidad económica o ideológica, sería difícil reconstruirlas sin la ayuda de la arqueología. Parece que antes de la llegada inca, los señoríos de mediana escala de la Costa Sur establecieron sus relaciones con los señoríos serranos por medio de guerrillas y escaramuzas. Castro y Ortega Morejón comentan sobre su belicosidad ([1558] 1974:93) y Cieza afirma que los de Chincha hicieron estragos entre los Sora y Lucana y hasta llegaron al Collao ([1553] 1932, Cap.74:229). La gente del señorío de la parte baja del moderno Valle de Cañete, que luego de la conquista inca fue llamado Guarco u "Horcón" en memoria de las represalias de los vencedores, también tenía fama de guerreros (Cabello Valboa [1586] 1951, Cap.18:338-339).

En el Valle de Ica, a pesar de las guerrillas que sostenían con los serranos a través de la frontera ecológica, la entrada de los incas fue aparentemente pacífica y sin oposición,

Y de aquí fue el Inca al valle de Ica, a donde halló resistencia más que en lo de la Nazca; mas, su prudencia bastó [a] hacer, sin guerra, de los enemigos amigos y se allanaron...

(Cieza [1553] 1967, Cap.60:199).

El testimonio arqueológico señala uno de los patrones que se puede asociar con una política inca determinada. La influencia inca estuvo limitada al centro preinca 
del valle. El uso de la cerámica de estilo inca, la cerámica con influencia inca o de cerámica autóctona con vasijas incas, se limitó a los centros administrativos reconocidos como incas o asociados con la élite autóctona de Ica (Menzel 1959).

En el Valle de Pisco, que se encuentra entre Chincha al norte e Ica al sur, se estableció una presencia inca de envergadura en dos sitios. El uno fue Lima La Vieja (Zangalla) cerca de Humay y el otro fue Tambo Colorado valle arriba. Ninguno de los dos estuvo asociado con un centro administrativo anterior (Menzel 1959). Sin embargo, Lima La Vieja demuestra una influencia inca mayor que cualquier sitio en el Valle de Ica y se ubicó sobre un camino principal entre la costa y la sierra al igual que Tambo Colorado (Menzel y Rowe 1966). Estos centros administrativos y los otros más al sur, se ubicaron todos sobre el principal camino inca de la costa. Estos caminos fueron en sí un componente importante de la administración inca (Menzel 1959; Hyslop 1984).

De los señoríos de la Costa Sur, el Reino de Chincha fue el objeto de mayor interés y codicia por parte de los incas. Chincha fue uno de los estados más fuertes de la Costa Sur antes de su conquista por los señoríos. Le correspondía un papel excepcional como nexo importante en la red de intercambio a larga distancia que se realizó por mar hacia el norte y por tierra hacia el sureste (Rostworowski 1970). Además, en el Valle de Chincha había un oráculo de gran prestigio llamado Chinchaycamay (Cieza [1553] 1932, Cap.74:229).

El primer intento de los incas por dominar al señorío de Chincha fue rechazado:

El Inca padre de Tupac Inca se dice que envió desde los Soras un capitán con gente de guerra, llamado Capac Inca, a que procurase atraer a los de Chincha al señorío suyo; mas, aunque fue y lo procuró, fue poca parte porque se pusieron en arma y de tal manera se querían defender quel orejón, lo mejor que pudo, se volvió; y estuvieron sin ver capitán del Inca ninguno hasta que Tupac Inca los sojuzgó,...(Cieza [1553] 1967, Cap.60:198 [énfasis de la autora]; ver Cieza [1553] 1932, Cap.74:229).

Tal como sucedió con Chimor, este éxito inicial en la defensa de su independencia no perduró. Parece, según testimonio de los informantes chinchanos y cuzqueños de Cieza, que a la llegada de Tupac Inca, los señores de Chincha le aceptaron como señor sin resistencia:

En Chincha estaban aguardando si el Inca iba a su valle, puestos más de treinta mill hombres a punto de guerra, y esperaban favores de los vecinos. Tupac Inca, como lo supo, les envió mensajeros con grandes presentes para los señores y para los capitanes y principales, diciendo a los embajadores que de su parte les hiciesen grandes ofrecimientos ....Los de Chincha oyeron lo que el Inca decía y recibieronle sus presentes y fueron para él algunos principales con lo que había en el valle y hablaron con él y trataron el amistad, de tal manera que se asentó la paz y los de Chincha dejaron las armas y recibieron a Tupac Inca,... (Cieza [1553] 1967, Cap.60:199).

Sin duda, ésta es una de las mejores descripciones que tenemos de una conquista inca por la vía diplomática. Sería de gran interés saber la naturaleza del trato que se 
hizo. Algo se vislumbra por los patrones arqueológicos y otros testimonios escritos. Hay que tener presente lo que ganaron los incas: no se trataba solamente de un señorío costeño rico y populoso, sino de los intermediarios indispensables en el intercambio de cobre y Spondylus, un intercambio que a los incas convenía controlar aún indirectamente; también tenía Chincha un oráculo de gran prestigio regional que igualmente les convenía mantener bajo su control.

¿Qué obtuvieron los señores de Chincha a cambio de su rendición pacífica y a qué costo? Más evidente es el hecho de que se mantuvieron en sus oficios y aparentemente continuaban efectuando el intercambio a larga distancia, aunque fuese bajo vigilancia inca. Conservaron su oráculo propio que seguramente fue un componente importante de su identidad étnica. Hay que tener presente que, por esta misma razón, la suerte de las huacas frecuentemente seguía las fortunas de sus adoradores entre los pueblos andinos. Finalmente, fueron premiados por su lealtad con tierras en el Valle de Guarco, a donde fue gente de Chincha en calidad de mitmaq o, por lo menos, compensados de esta manera con tierras entregadas a mitmaq en su propio valle (AGI Audiencia de Lima 1630 [1562] f2r; Cieza [1553] 1932, Cap.74:230).

El costo de la dominación inca incluía la presencia de funcionarios incas en el valle, la construcción de un templo al sol y la obligación de adorarlo, el establecimiento de un centro administrativo inca en plena capital chincha, la cesión de tierras para mitmaq foráneos y la obligación del señor principal de Chincha de ausentarse de su señorío y acompañar al inca en el Cuzco (Cieza [1553] 1932, Cap.74:230).

En contraste al caso de Ica, por ejemplo, la cerámica de los estilos alfareros incas, Inca Provinciano y hasta los forasteros sobresalen en la capital (Menzel 1959; Menzel y Rowe 1966), pero a diferencia de la opinión de Menzel y Rowe, cuyo estudio se basó en las colecciones de Uhle del cementerio inca, los actuales trabajos arqueológicos de Craig Morris en La Centenela y el Valle de Chincha sugieren que el estilo alfarero chincha perduraba en los áreas controladas por los señores chincha (Comunicación personal de C. Morris). Otro factor importante en la dominación de Chincha, fue la creación de una relación de subordinación al oráculo de Pachacamac en el Valle de Ichma o Lurín al norte. El estado inca tenía la política de favorecer este oráculo que fue a la vez una clave principal en la dominación de toda la costa (Santillán [1563] 1968, S28:111; Menzel y Rowe 1966; Netherly 1977, sfd).

Los costos no fueron todos visibles en el momento de la entrega de la soberanía por los señores chincha. Castro y Ortega Morejón relatan que todo el elenco de señores étnicos fue ejecutado por un uchucamayoq inca, como castigo por el supuesto delito de un principal, quien había tenido acceso carnal a una de las mujeres escogidas del Inca (Castro y Ortega Morejón [1558] 1974:99). De un solo golpe los incas lograron apagar cualquier posible desafección y ganar a la vez un control estrecho sobre los niveles inferiores del gobierno por medio de sus candidatos, quienes reemplazaron a los señores muertos. Hay que tener presente este hecho al evaluar el testimonio sobre el sometimiento pacífico de Chincha a los incas, ofrecido a Cieza por los señores de Chincha y la élite inca en el Cuzco. Cieza mismo anota que informantes 
"de otras provincias" dijeron que hubo una gran guerra ([1553] 1967, Cap.60:229). Esta es la relación que parece haber recogido Cabello Valboa, quien sugiere que los de Chincha participaron en la afamada defensa de Guarco:

...quiso [el Ynga] á sugetar los Yndios de ciertos valles allí cercanos que con gran menosprecio auian rehusado su amistada y obediencia. Estos eran Mara [Mala], Runaguana [Lunaguaná], y Chincha,...los del valle de Chincha se pusieron en determinada defensa, y lo mismo los Runaguanaes y Maras donde subcedieron cosas que requerian para contarse libro por si: la suma y remate fue que ellos fueron vencidos sugetos y castigados en una famosa fortaleza que fabrico Topa Ynga junto al mal [sic] donde fueron tantos los rebeldes, que en ella, y de sus murallas colgo que le quedo por nombre el Guarco (que quiere decir el colgadero). ([1586] 1951, Cap.18:338-339; [Interpolaciones entre corchetasde la autora]).

La campaña militar de los incas contra Guarco duró cuatro años. Este señorío ocupaba la parte baja del actual Valle de Cañete. Lo que no podemos saber es si entre los defensores de Guarco se encontraban contingentes de los valles vecinos, lo cual explicaría la existencia de dos versiones sobre la actitud de Chincha. En lo que todas las fuentes concuerdan es que al final, cuando se rindieron los defensores de Guarco, la represalia inca fue una masacre general de los señores y jefes militares vencidos (Cieza [1553] 1967, Cap.60:200-202). Aunque las fuentes no lo mencionan, con este acto los incas castigaron la tenacidad y bravura de los de Guarco y a la vez se dieron oportunidad de colocar adeptos suyos en el elenco de los señores. Pusieron en el valle un oficial inca y entregaron regulares extensiones de tierras a mitmaq procedentes de Chincha y del señorío de Coayllo en el Valle de Asia (AGI Audiencia de Lima 1630 [1562]:f2r; Rostworwoski 1978-80:165-166). El asentamiento de grupos procedentes de dos valles vecinos, que en el pasado habían mantenido relaciones a veces hostiles, más parece ser aquí un premio por servicios que una dispersión de la fuerza de sus señoríos de origen, dado que seguían sujetos a sus antiguos señores.

Esta larga digresión de las relaciones de los señoríos de la Costa Sur con los grupos serranos a través de su frontera común, ecológica y cultural, se justifica tanto por las semejanzas que presenta con la experiencia en el norte como por los contrastes. Es importante recordar que, además de su significado como vencimiento a manos de un estado más poderoso, para los señoríos de la costa representaba la conquista por sus opositores culturales al otro lado de una frontera que había fluctuado durante siglos y la pérdida del acceso consuetudinario a muchos recursos.

\section{La estrategia inca frente a la Costa Central}

Más luces sobre el control inca de los pequeños señoríos de la Costa Central aportan Rostworowski $(1967-68,1972,1977)$ y Murra $(1972,1975)$. El señorío de Collique del bajo valle del Río Chillón, al norte de la actual Lima, controlaba tierras en la parte baja del valle y también en Quivi, en la zona chaupiyunga media del valle, una zona particularmente apropiada para el cultivo de la coca. Lo significativo aquí, es la importancia que revestía esta zona como centro productor de este recurso esencial para el ritual andino, tanto para el señorío de Collique como para las etnias serranas ci- 
sandinas y el estado inca mismo (Netherly 1988). El alto valor dado por los incas a esta región, se manifiesta en la ejecución llevada a cabo por los incas de los señores étnicos de Quive y de Collique bajo el pretexto de una traición; la expropiación de chácaras productoras de coca en nombre de Huayna Capac y su madre y, por último, la transferencia del dominio de las chácaras de coca de la zona del señorío autóctono de Quive y el señorío costeño de Collique, quienes antes las habían compartido, al señorío serrano de los Yauyos, aliados de los incas. En este caso, los dos cocales pasaron a la directa dominación inca.

Las investigaciones arqueológicas realizadas por Dillehay en esta zona (1976, 1979), han descubierto la presencia de un centro administrativo inca de cierto tamaño en Huancayo Alto, sobre el camino principal entre la costa y el centro administrativo inca en Pun Pun (Bonbón), en la sierra de Junín. Este sitio está asociado con una zona de almacenamiento de tamaño regular y de gran antigüedad. Otro hallazgo todavía más significativo fue la ubicación de una presencia inca de envergadura en sitios claves de la sierra que dominaban los Valles del Chillón y del Rimac, en territorio de los Yauyos (Dillehay 1976, 1979 y comunicación personal).

Antes de pasar a la presentación de un modelo para la ocupación inca de la Costa Norte, quisiera llamar la atención una vez más sobre el hecho que la economía inca fue una economía "administrada" (Murra [1955] 1980), que involucraba la movilización de energía humana a gran escala y la concentración de artesanos y otras unidades de producción, sea en grandes centros administrativos tales como Huánuco Pampa (Morris 1972, 1974), sea en las zonas mismas de explotación de las materias primas necesarias para la producción (Murra 1978). Con excepción, tal vez, de Pachacamac y los centros en los valles de la Costa Sur, los centros administrativos incas más importantes se encontraban en la sierra. Las zonas costeñas adyacentes vinieron a depender en último caso del centro serrano más próximo. Es probable que la función de los centros secundarios tales como Huancayo Alto incluía controlar y facilitar el paso de los recursos humanos y materiales hacia estos centros serranos.

Este repaso de la política inca con los señoríos costeños permite ver con mayor claridad cual fue la política de ocupación inca con respecto al Reino Chimor. No es nada sorprendente encontrar que existen muchos elementos comunes entre las políticas puestas en práctica en la Costa Norte y las aplicadas en las Costas Central y Sur.

\section{La política inca en la Costa Norte}

Una vez sofocada la rebelión encabezada por el último Chimor Capac y logrado el dominio interno de los valles de la Costa Norte en el territorio chimú, los incas ponen en práctica una serie de estrategias con respecto a su antiguo rival que ofrecen semejanzas con la política inca frente a los señoríos de otros sectores de la costa del Pacífico. Estas estrategias de dominación fueron las siguientes:

1. La redefinición de las fronteras formalizadas entre Chimor y los señoríos de Huamachuco y Cajamarca para poner los valles de los cursos medios de los ríos de la 
Costa Norte bajo el control de los serranos. Durante siglos, estas zonas habían mantenido una frontera fluctuante de acuerdo al poder relativo de los señoríos serranos y costeños con una aparente hegemonía serrana durante el Horizonte Medio y una predominancia chimú en la época inmediatamente preinca. La nueva frontera por debajo de los $300 \mathrm{msnm}$ o menos, no involucró las tomas de las acequias madres que regaban los valles de la costa (Netherly 1984, 1988, sfa). No se conoce de ninguna instancia de asociación directa entre un centro administrativo inca y la toma de agua de un canal principal.

2. Una política de gobierno indirecto y la reducción de la prestigiosa élite del Reino Chimor, es decir el Chimor Capac, el señor de la segunda mitad y los señores principales quienes encabezaban las subdivisiones estructurales del señorío (Netherly 1984, 1990), a su antiguo corazón: la capital de Chan Chan y el Valle de Chimor o Moche.

3. La administración directa de las áreas periféricas al norte y al sur del Valle de Moche por los señores regionales, tal como lo describía Cieza de León ([1553] 1967, Cap.59:194-195).

4. La incorporación de la economía de Chimor dentro de la economía imperial inca con la diversión de recursos económicos costeños hacia la sierra, inclusive la explotación de nuevas zonas de recursos para el beneficio del estado inca. Incluida aquí está la apropiación de la mano de obra artesanal chimú para fines del estado inca que conlleva el traslado de muchos grupos de artesanos desde sus lugares de origen en el Chimor hasta localidades donde el estado inca podría aprovechar mejor su producción.

\section{El dominio serrano en la zona media de los valles}

Existen evidencias tanto históricas como arqueológicas de la disminución del señorío chimú en su frontera oriental. Documentos del siglo XVI indican que el distrito de Huacapongo, la zona media del Valle de Virú, pertenecía a la waranga de Huacapongo de Huamachuco (AGI Justicia 458 [1567] f.1790r-1792v; ANP AGUAS 3.3.10.68 [1562-1567]; Netherly 1977, 1988, sfa). Tanto Willey (1953) como Collier (1955) informaron sobre una ocupación inca de cierta envergadura en el sitio V-179, un conjunto de cercados adjuntos, en donde se recuperaron tiestos del estilo imperial, Cuzco Polícromado, los que son escasos en este valle aún en contextos Estero, el Período Inca local. El alto prestigio que gozaron los estilos alfareros chimús, aún bajo la dominación inca, sugiere que la existencia de tiestos de los estilos Inca Clásico o Inca Provincial indica la presencia de una unidad administrativa inca o la de un señor regional, quien mantenía estrechos lazos con el estado inca. Collier y Willey creyeron ambos que V-179 fue un sitio de un solo componente, construido y ocupado exclusivamente durante el Período Estero (Horizonte Tardío) (Collier 1955:97, 135; Willey 1953:322, 329-31). 
Collier también sugiere que existen afinidades con sitios incas de la sierra (1955:97). Es evidente que, si se pensaba dividir al Valle de Virú, antes completamente bajo el dominio chimú, habría necesidad de un nuevo centro administrativo en la parte media del valle al otro lado de la nueva frontera.

Valle abajo se encuentran evidencias de cerámica Inca o Estero en V-171, en la parte oriental del valle bajo, construido durante el Período Tomoval, pero intensamente utilizado durante el Período Estero, tal vez en asociación con el camino inca (Willey 1953:323, 324-29; Collier 1955:95). Sin embargo, la continuidad administrativa entre los regímenes chimú e inca en el valle bajo se aprecia mejor en el sitio V-124 por sus semejanzas arquitectónicas con las ciudadelas de Chan Chan, pero donde Collier notó que el 3\% de los tiestos recuperados del relleno sobre el cuarto en forma de U, fueron de tipo Inca (1955:95). El sitio V-124 se encuentra cerca del litoral. En otra estructura, también aparentemente con funciones administrativas, la V-123, se recuperó cerámica Estero indicativa de una presencia inca. En estos dos casos se puede hipotetizar la presencia de señores regionales duales, siendo el que ocupaba V-124 de mayor jerarquía que el señor de V-123 (Netherly 1984, 1990).

También se puede demostrar por medio de la documentación española del siglo XVI que en el Valle de Chimor, la zona media del valle alrededor de Poroto y el valle lateral del Río Sinsicap, afluente del Río Moche, también cayeron bajo el señorío de Huamachuco (AGI Justicia 458 [1567]; ANP Aguas 3.3.18.68 [1562-1567]; Netherly 1976, 1977, 1988).

Otra evidencia, esta vez desde el punto de vista serrano, de la apertura de la zona media del valle al dominio de los señoríos serranos, proviene del Valle de Jequetepeque. Se trata del testamento hecho en 1565 por don Melchor Carhua Rayco, quien fue a la vez señor principal de Cajamarca y señor de Guzmango (Cuismancu) o Contumazá en la sierra entre los Valles de Chicama y Jequetepeque. Como tal, disponía de tierras yungas en Chilete en el Valle de Jequetepeque y también de chácaras en Cascas en el Valle de Chicama (ART Juan de Mata 1565; Netherly 1977, sfb).

Las referencias escritas sobre la presencia inca en la zona media del valle del Río Zaña y su afluente el Río Nanchoc son escuetas. Estas se encuentran en las relaciones hechas por los primeros conquistadores sobre su viaje por el camino inca desde la costa hasta Cajamarca. Dejando al tambo de Zaña en el valle bajo del mismo nombre, prosiguieron el viaje valle arriba por un camino que se dirigía hacia la sierra aparentemente por la Quebrada Nanchoc y se alojaron en una instalación inca antes de ascender el escarpado abrupto de Carahuise por el camino inca (Mena [1534] 1967; Jerez [1534] 1862). La instalación inca existe todavía al lado este del actual pueblo de Nanchoc. Cuando se visitó primero en 1974 estaba en mejores condiciones que las actuales. Se trata de una gran cancha cerrada, dentro de la cual habían otras cercadas con estructuras rectangulares. Toda ella estuvo rodeado por una serie de anchas terrazas. El efecto general es de un centro administrativo inca parecido a Huancayo Alto pero más grande. 
De mayor interés para el entendimiento de la política inca es que alrededor del centro de Nanchoc hay una serie de instalaciones incas adicionales ubicadas sobre los cerros circundantes. Estas incluyen complejos de terrazas, zonas de procesamiento y almacenamiento y otras de control estratégico. Sobre uno de los cerros existe un poblado inca de regular tamaño (Dillehay y Netherly 1983). A ésto se pueden sumar las instalaciones incas registradas por Lechtman (1976) sobre el Cerro Landosa, en la boca misma de la Quebrada Nanchoc entre los pueblos modernos de Nueva Arica y Oyotún. Se trata no solo de un lugar de producción metalúrgica sino también de una serie compleja de terrazas de producción, almacenamiento y vigilancia, tanto hacia el área de Nueva Arica como hacia Oyotún, ambas en el Valle del Zaña. Claro está, que también facilitaba el control del camino a Cajamarca, que en este punto deja el Valle de Zaña para ascender la Quebrada Nanchoc.

\section{Gobierno indirecto y la reducción del Valle de Chimor}

El prestigio enorme de la cultura chimú y de su capital Chan Chan, determinó el matiz del gobierno inca en el Valle de Moche, el corazón del reino vencido. Las investigaciones recientes en Chan Chan no descubrieron ninguna concentración de cerámica inca, tal como fue el caso, por ejemplo, en La Centinela o Lima la Vieja (Comunicación personal de Carol Mackey). Más bien, las investigaciones realizadas revelan la continuación de un gobierno chimú, pero a una escala muy reducida (Netherly 1990; Conrad 1982). De hecho, la cerámica inca es tan escasa que fue muy difícil identificar en forma segura la cerámica asociada por la fuerte continuidad de los elementos estilísticos chimús. El estilo compuesto Chimu-Inca, los aríbalos de cerámica negra más otras vasijas características, aparecen con mayor frecuencia fuera del Valle de Chimor propiamente dicho, indicando la preocupación inca con respecto a la cerámica chimú, valorizada por su prestigio y a los alfareros que la producían, apreciados por su gran habilidad y la calidad de su obra (Espinoza Soriano 1969-70).

Existen tres lugares en el Valle de Moche, donde se recuperó cerámica de estilo Inca Provincial, indicando una asociación con el régimen inca. Uhle encontró unas vasijas de estilo Inca Provincial en sus excavaciones en el gran complejo en Moche, entre las huacas conocidas con los nombres de Sol y Luna (Menzel 1977). La fábrica de estos monumentos que datan del período Moche fue descrita no hace mucho (Hastings y Moseley 1975) y su asociación con el camino inca fue notada por el propio Uhle (Menzel 1977). Otro sitio pequeño también asociado con el camino inca fue ubicado en la banda norte del Río Moche (comunicación personal de Michael Moseley).

Para explicar mejor la presencia de los aríbalos de estilo Inca Provincial encontrados por Uhle en la zona de las huacas llamadas Sol y Luna, que en otras partes se asocia con la cerámica estatal en los centros administrativos, es preciso considerar los patrones de la dominación inca en la Costa Sur. Fernando de Santillán, un funcionario colonial del siglo XVI, anotó en su relación que para entender al sistema inca de gobierno había que entender el sistema religioso ([1563] 1968, 25:110). Dijo que el orá- 
culo en Pachacamac tenía cuatro "hijos" o subsidiarios: en Mala, en Chincha, en Andahuaylas cerca del Cuzco y uno que acompañaba al Inca, Topa Inca Yupanqui, en sus viajes (1968, S28:111). Otros centros religiosos fueron llamados las "esposas" de Pachacamac (Dávila Briceño [1586] 1965; Rostworowski 1972, 1977). Pero es el cronista indígena Juan Santa Cruz Pachacuti quien proporciona la clave final. Escribe que los sacerdotes de Pachacamac habían pedido a Huayna Capac, por medio del oráculo, el establecimiento de un subsidiario o churin en el pueblo de Chimor, a lo cual accedió el Inca ([1613] 1968:309). La relación entre el estado inca y Pachacamac fue tan estrecha que allí se construyó un templo al Sol, al lado de la huaca grande dedicada a Pachacamac y su oráculo.

No especifica Pachacuti dónde se ubicó el templo dedicado a Pachacamac en Chimor. La codicia de los españoles por los tesoros enterrados en los centros ceremoniales de la Costa Norte proporciona la respuesta. Durante la década de 1560 había una fiebre de "minar" huacas y una de las más ricas, fue conocida como "la huaca grande del río" o "el templo de Pachacamac" (ART Juan de Mata 1565). La única huaca en el Valle de Chimor que encaja con esta descripción es la estructura que se conoce como la Huaca del Sol.

La importancia estratégica de este complejo reside en parte en la posición dominante que ocupa y la vista de toda la parte baja del valle que se tiene desde su cima, un hecho que observó hace años A. Bandelier (1893 manuscrito). Nada sucedía en la parte baja del valle ni en las cercanías de Chan Chan sin ser observado por los sacerdotes de Pachacamac, aliados del Inca. Menzel (1977) y también Beck (1979) remarcaron la relación entre esta huaca y los caminos.

La otra zona del Valle de Chimor que muestra evidencias de una ocupación inca se encuentra cerca del mar.

Excavadores que trabajaban con el arqueólogo Francisco Irriarte, recuperaron una serie de finas vasijas negras con elementos estilísticos inca en tumbas ubicadas cerca a la iglesia de Huanchaco y con vista al mar. Estas vasijas ahora se encuentran en el museo del sitio de la Huaca Dragón en Trujillo. Como el interés inca en los recursos del mar y del litoral fue tan intenso, poco puede sorprender la ubicación de estas tumbas. Larco, por ejemplo, nos informa sobre un cementerio inca en la Hacienda Salamanca, cerca del mar en el Valle de Chicama (1939:41). También hay que tener presente al que debe haber sido un centro de influencia inca en la parcialidad o señorío subordinado de Guamán, inmediatamente al sur de Chan Chan, donde la existencia de vasijas Chimu-Inca de Huanchaco parece provenir de entierros de autoridades incas, puesto que semejantes vasijas no se encuentran en las tumbas de la élite chimú de la época (Netherly 1990).

Tal como ocurría en otros valles de la Costa Norte, se enajenaron tierras a nombre del Inca (ART Juan de Mata 1565; Consejo Provincial de Trujillo [1561] 1969; Netherly 1977, 1988, sfb). Además, las élites locales fueron obligadas a mantener a los funcionarios incas en residencia, abastecer los tambos del camino inca y propor- 
cionar grandes cantidades de mano de obra capacitada y no capacitada para el servicio del estado inca. La mano del Inca fue dura sobre el Reino Chimor, a pesar del simulacro de autonomía.

\section{Gobierno inca directo fuera del Valle Chimor}

Luego de la rebelión chimú contra la dominación inca, es evidente que el gobierno inca impuso una serie de medidas drásticas, que alteraron lo que podemos suponer fue la política anterior a la época de Topa Inca Yupanqui. Podemos hipotetizar que después de la primera conquista de Chimor por el imperio inca, se impuso una política de gobierno indirecto, es decir, que poco se desmanteló el aparato del estado chimú y mientras que se cumplía con las exacciones económicas del estado inca, los señores tradicionales retenían gran parte de su poder. Es probable que se comenzara la construcción de los centros administrativos en la parte media o alta de los valles costeños, pero la evidencia de algunos cronistas sugiere que la imposición inca de gobernadores permanentes no data de este primer período de la dominación inca.

Los acontecimientos de la rebelión, cuya noticia nos llega de una fuente de origen costeña y no cuzqueña, se desconocen (Vargas Ugarte 1936). Se puede suponer que antes de la sublevación todavía existían ejércitos chimús o más probablemente, los soldados costeños fueron dispersados a sus señoríos de origen, desde donde el último Chimor Capac les hizo llamar. Hay que suponer también que el máximo señor chimú y sus asociados en el gobierno de Chimor (Netherly 1977, 1990, sfb), todavía tuvieron acceso a una base económica suficientemente grande como para sostener semejante esfuerzo.

La política inca fue tajante una vez que recuperaron el poder. El Chimor Capac fue muerto y su linaje desprovisto del dominio (Netherly 1990). Otro linaje de aparente origen costeño y lealtad firme hacia el Inca fue elevado al máximo señorío chimú. Aunque los señores de Chimor quedaban en el valle del mismo nombre, como hemos visto, la estructura del estado chimú fue desmantelada de tal modo que las principales autoridades autóctonas en cada uno de los valles norteños, fueron los señores regionales y cada valle fue dividido entre varios señoríos. Aún más subdivisiones se lograron con la política sistemática de dividir los grandes señoríos entre dos hermanos a la muerte del antiguo señor (Netherly 1977, 1990, sfb; Rostowrowski 1961). Así, los incas lograron subdividir y debilitar los señoríos del antiguo Reino Chimor en una forma que aprovechaba las líneas de fractura de las estructuras siguiendo la organización sociopolítica andina y eliminando las unidades grandes, focos de posible rebelión, sin oposición abierta.

Es seguro también, que la política de enviar una gran parte de la población como mitmaq, tanto los agricultores y potenciales soldados como los artesanos, cuya habilidad fue grandemente admirada por todo el imperio, servía para debilitar aún más sus señoríos de origen. Se debe notar que, al parecer, no prosiguieron esta política con los grupos de pescadores, tal vez por la importancia que revestían los productos del mar. 
El trato inca con las áreas al norte y al sur del Valle de Chimor parece estar de acuerdo con el modelo propuesto para la periferia del estado chimú. Al norte de Chimor se encuentran dos sitios en la parte sur del Valle de Chicama de donde se ha recuperado cerámica inca. Es significativo que ambos estén asociados con los caminos incas. Keatinge recuperó una cerámica Inca Provincial burda en Médanos de San José, un sitio de habitación y chácaras hundidas sobre el camino del litoral, al sur de la zona de cultivo en el Valle de Chicama $(1972,1973)$. Las excavaciones de Conrad en Chiquitoy Viejo, un complejo de élite con funciones residenciales y administrativas, que controlaba el camino que pasa al este del Cerro Campana, arrojaron tiestos provenientes de una sola vasija inca, un pequeño aríbalo de caolín blanco de decorado fino en el estilo Cuzco Policromado (1976). Esta vasija tiene que haber sido un regalo. Esto, más la presencia de una plataforma de entierro con una sola tumba, indica, a pesar del argumento de Conrad que Chiquitoy Viejo fue la sede de un "gobernador" inca, que se trataba más bien de la sede de un señor chimú, leal al Inca y con responsabilidades especiales con respecto al camino entre el Valle de Chicama y Chimor.

Además, se comienza a encontrar evidencias sobre centros de control y administración inca en la parte baja de algunos valles de la Costa Norte, que no fueron tambos u otras instalaciones relacionadas con los caminos principales de la costa. Uno es el Cerro Jotoro, una pequeña colina aislada que se levanta sobre el bajo valle del Río de la Leche, en el antiguo territorio Jayanca. Jayanco fue un señorío con una relación especialmente estrecha con el estado inca. El antiguo señor había sido eliminado por el Inca y reemplazado por su hijo, quien había pasado algún tiempo en el Cuzco (Cabello [1586] 1951, 3a Parte, Cap.18:331; Netherly 1977). Jotoro, que se parece al Cerro Landosa en el Valle de Zaña, tiene sus laderas transformadas en grandes terrazas para el procesamiento y almacenamiento de productos. En la cima existen una serie de estructuras con fines de control y en la base una serie de cuadros de paredes muy bajas, que pueden haber sido utilizados para fines de contabilidad.

Todavía resta por hacer los reconocimientos arqueológicos necesarios para determinar si existen otros centros semejantes en los valles al sur de Chimor y si existen otros más al norte en Motupe o Piura. Los cronistas de la conquista española: Mena ([1534] 1967), Jerez ([1534] 1862), Sancho ([1534] 1962) y Trujillo ([1534] 1970), nombraron los centros incas que vieron en su camino entre Tumbes y Cajamarca. Parece que habían tambos grandes y, tal vez, centros administrativos medianos en Motupe (Motux), Cinto, Saltur y Zaña.

Lo que parece novedoso es el descubrimiento e identificación de centros incas, tales como Nanchoc, ubicado en la Quebrada Nanchoc, en un punto estratégico de donde fue posible dominar las rutas de comunicación al Valle de Chamán al sur, al Valle de Zaña al norte y, al este, la importante ruta a la sierra. Hay otros centros sobre las rutas laterales. Sarrán, arriba de Pabur en el Valle de Piura sobre el cruce con el camino a Caxas, es con toda probabilidad un sitio inca. Tumbes, en el valle del mismo nombre, también tenía una instalación inca, cuya importancia fue más allá de su ubicación al final de un importante camino a la sierra norteña de Loja y la zona Cañar. Proporcionaba al estado inca acceso al mar en una zona de señoríos débiles y también 
un acceso al comercio de Spondylus, entre otras cosas. En su organización y arquitectura, el centro inca de Tumbes, conocido hoy como Tumbes Viejo, fue similar a Huancayo Alto (Comunicación personal de Georg Petersen; Dillehay 1979).

\section{CONCLUSIONES}

En resumen, podemos ver que la política de los señores incas frente al Reino Chimor, como su política frente a los señoríos más pequeños de las Costas Central y Sur, se basaba, en primer lugar, en favorecer a las vecinas provincias serranas a expensas de los reinos costeños. Los centros administrativos incas de mayor tamaño se ubicaron en la sierra y los señoríos costeños se subordinaron a un centro serrano próximo. En el caso de Chimor, en una primera instancia este centro fue Cajamarca.

Los centros incas de menor envergadura se establecieron en la costa, en la zona media de los valles o más bien, en el ámbito costeño de los caminos laterales a la sierra. El centro inca en Nanchoc, ubicado sobre los caminos que penetraban la sierra desde los Valles de Zaña y Chamán, constituye un ejemplo de esta política.

La presencia de centros de administración inca dentro de los valles costeños propiamente dichos es más rara y, al parecer, indica una política específicamente hostil o tal vez muy interesada. Tal es el caso de Chincha, donde un complejo administrativo inca fue construido en medio del antiguo centro administrativo autóctono (Comunicación personal de C. Morris). Tal vez, el complejo inca en Jotoro sobre la banda norte del Río de la Leche, dentro del territorio de Jayanca, sea otro de estos centros. El complejo inca en Tumbes Viejo, que llegó a incluir un templo dedicado al sol, puede ser ejemplo de la creación de un centro inca en una zona de interés económico. Por toda la Costa Norte, el sistema vial funcionaba como una red en la cual los tambos y los centros administrativos proporcionaban una base de operaciones para los conquistadores serranos.

Los centros costeños de gran prestigio, tales como Pachacamac en la Costa Central, Chinchaycamay en Chincha o la capital política y religiosa chimú en el Valle de Chimor, no fueron destruidos. Más bien fueron incorporados dentro del sistema estatal inca. Los sacerdotes de Pachacamac podrían haber conseguido mayores beneficios de un subsidiario norteño, que los señores-títeres de Chimor, quienes gobernaban sin poder en un mínimo remanente de su antiguo reino.

Sin embargo, a pesar del esfuerzo inca por incorporar a Chimor dentro de su imperio, las fronteras culturales y políticas entre la costa y la sierra permanecieron, perdurando cinco siglos y siendo vigentes hasta hoy. 


\section{BIBLIOGRAFIA}

AGI Archivo General de Indias, Sevilla.

Audiencia de Lima 1630 [1562]. Términos de la Villa de Cañete. En Rostworowski 1978-1980.

Justicia 458 [1565-1567]. Residencia de Gregorio González de Cuenca oidor de la Audiencia de los Reyes por Pedro Sánchez de Paredes.

ANP Archivo de la Nación (Perú), Sección Histórica.

Aguas 3.3.18.68 [1817]. Autos promovidos por D. Francisco Javier Noriega Cespedes Tito, Administrador de la hacienda Collambay... Corren insertos en este cuaderno documentos probatorios, fechados en $1565 \ldots$

ART Archivo de la Nación (Perú), Archivo Regional de Trujillo.

Juan de Mata 1565. Registros notariales.

Bandalier, Adolph

[1895] Journal of 1893. Manuscrito archivado en el Departamento de Antropología, American Museum of Natural History. New York, Estados Unidos.

Beck, Coleen M.

1979 Ancient roads on the North Coast of Peru. Tesis doctoral inédita. University of California, Berkeley. University Microfilms. Ann Arbor, Michigan, Estados Unidos.

Brüning, Heinrich

1923 Reglamentación de las aguas del Taimi. D.Mendoza, Chiclayo, Perú.

Cabello Valboa, Miguel

[1586] Miscelánea antártica. Universidad Nacional Mayor de San Marcos. Lima. 1951

Calancha, Antonio de la

1638 Crónica moralizadora del orden de San Agustín en el Perú... Pedro de la Cavallería. Barcelona, España.

Castro, Cristóbal de y Diego de Ortega Morejón

[1558] Relación y declaración del modo que este valle de Chincha y sus

1974 Chincha y sus comarcanos se governavan... En Juan Carlos Crespo, La relación de Chincha (1558). Historia y Cultura 8:91-104

Cieza de León, Pedro

[1553] La crónica del Perú. Espasa Calpe. Madrid.

1932

[1553]El señorío de los incas. Ministerio de Educación Pública. Lima. 1967

Collier, Donald

1955 Cultural chronology and change as reflected in the ceramics of the Viru Valley, Peru. Fieldiana: Anthropology. 43. Field Museum of Natural History, Chicago, Estados Unidos. 


\section{Conrad, Geoffrey}

1982 The burial platforms of Chan Chan: Some social and political implications. En Andean Desert City. Compilado por Michael E.Moseley y Kent C.Day. University of New Mexico Press, Albuquerque, N.M. Estados Unidos.

Consejo Provincial de Trujillo

[1549-60] Actas del Cabildo de Trujillo 1549-1560. Tomo I. Lima. 1969

Dávila Briceño, Diego

[1586] Descripción y relación de la provincia de los Yauyos.... En Relaciones 1965 Geográficas de Indias, T.III. Biblioteca de Autores Españoles. 183. Editorial Atlas. Madrid.

Dillehay, Tom D.

1976 Competition and cooperation in a prehispanic multi-ethnic System in the Central Andes. Tesis doctoral inédita, Department of Anthropology, University of Texas, Austin. University Microfilms. Ann Arbor, Michigan. Estados Unidos.

1979 Prehispanic resource sharing in the Central Andes. Science 204(4388).

Dillehay, Tom D. y Patricia J. Netherly

1983 Exploring the Upper Zaña Valley of Peru: A unique tropical forest setting offers new insights into the Andean past. Archaeology. 37(6):23-30.

Espinoza Soriano, Waldemar

1969-70 Los mitmas yungas de Collique en Cajamarca, Siglos XV, XVI y XVII. Revista del Museo Nacional. 36. Lima.

Hastings, C. Mansfield y Michael E. Moseley

1975 The adobes of Huaca del Sol and Huaca de la Luna. American Antiquity 40(2):726-732.

Hyslop, John

1984 The Inka Road System. Academic Press. Orlando, Florida. Estados Unidos. Jerez, Francisco de

1534 Conquista del Perú: Verdadera relación de la conquista del Perú. En

[1862] Historiadores primitivos de Indias. Compilado por E. de Vedia. Tomo 2. Biblioteca de Autores Españoles. 26. Madrid.

Kroeber, Alfred L.

1925 The Uhle Collection from Moche. University of California Publications in American Archaeology and Ethnology 21(5):191-234. Berkeley, California, Estados Unidos. 
Larco Hoyle, Rafael

1938-39 Los mochicas. Tomo 2. Lima.

Lechtman, Heather

1976 A Metallurgical Site Survey in the Peruvian Andes. Journal of Field Archaeology 3(1):1-42.

Mena, Cristóbal de

1967 La conquista de la Nueva Castilla. En Las relaciones primitivas de la

[1534] conquista del Perú. Compilado por Raúl Porras Barrenechea, Universidad Nacional Mayor de San Marcos. Lima.

Menzel, Dorothy

1959 The Inca Occupation of the South Coast of Peru. Southwestern Journal of Anthropology 15:125-142.

1977 The Archaeology of Ancient Peru and the Work of Max Uhle. Lowie Museum of Anthropology, University of California Press. Berkeley, CA, Estados Unidos.

Menzel, Dorothy y John H.Rowe

1966 The Role of Chincha in Late pre-Spanish Peru. Ñawpa Pacha 4:63-76.

Morris, Craig

1972 State Settlements in Tawantinsuyu. En Contemporary Archaeology: A Guide to Theory and Contributions. Compilado por Mark Leone. Southern Illinois University Press. Carbondale, IL. Estados Unidos.

1974 Reconstructing Patterns of Non-agricultural Production in the Inka Economy. En Reconstructing Complex Societies. Compilado por Charlotte B. Moore. American School of Oriental Research. Cambridge, MA, Estados Unidos.

Murra, John V.

1972 El control vertical de un máximo de pisos ecológicos en la economía de las sociedades andinas. En Visita a la provincia de Léon de Huánuco (1562), Iñigo Ortiz de Zuñiga. Tomo 2. Universidad Nacional Mayor Hermilio Valdizán, Huánuco, Perú.

1975 Formaciones económicas y políticas en el pasado andino. Instituto de Estudios Peruanos. Lima.

1978 Los olleros del Inka: Hacia una historia y arqueología del Collasuyu. En Historia: Promesa y Problema. Homenaje a Jorge Basadre. Compilado por F. Miro Quesada et al. Pontificia Universidad Católica del Perú. Lima.

1980 The Economic Organization of the Inka State. JAI Press. Greenwich, CT.24. 
Netherly, Patricia J.

1976 Inka CocaLands on the North Coast of Peru. Ponencia leída en la 42a Reunión de la Society for American Archaeology. New Orleans. Abril, 1976.

1977 Local Level Lords on the North Coast of Peru. Tesis doctoral inédita. Department of Anthropology, Cornell University. University Microfilms. Ann Arbor MI, Estados Unidos.

1984 The Management of Late Andean Irrigation Systems on the North Coast of Peru. American Antiquity. 49(2):227-254.

1988 From Event to Process: The Recovery of Late Andean Organizational Structure by Means of Spanish Colonial Written Records. En An Overview of Peruvian Prehistory. Compilado por Richard Keatinge. Cambridge University Press, New York, Estados Unidos.

1990 Out of Many,One: The Organization of Rule in the North Coast Politics. En The Northern Dynasties: Kingship and Statecraft in Chimor. Compilado por Michael E. Moseley y Alana Cordy-Collins. Dumbarton Oaks. Washington, DC.

sfa El manejo de los sistemas de riego tardíos en la Costa Norte. En El manejo del agua en el antiguo Perú. Compilado por Patricia J. Netherly. Por aparecer.

sfb Lords and Ancestors. Manuscrito en la posesión de la autora.

Netherly, Patricia J. y Tom D. Dillehay

1983 Dualism and Ceremonial Architecture in the Zaña Valley. Ponencia leída en la 2a Reunión Anual de la Northeastern Association for Andean Archaeology and Ethnohistory. New York, Estados Unidos, Noviembre, de 1983

Pachacuti Yamqui Salcamayhua, Juan de Santa Cruz

[1613] Relación de antigüedades deste reyno del Perú. En Crónicas peruanas de

1968 interés indígena. Biblioteca de Autores Españoles 209. Compilado por Francisco Esteve Barba. Editorial Atlas, Madrid.

Rostworowski de Diez Canseco, María

1961 Curacas y sucesiones. Lima.

1967-68 Etnohistoria de un valle costeño durante el Tawantinsuyu. Revista del Museo Nacional. 35. Lima.

1970 Mercaderes del valle de Chincha en la época prehispánica. Revista Española de Antropología Americana. 5. Madrid.

1972 Las etnias del valle del Chillón. Revista del Museo Nacional. 38. Lima.

1973 Breve ensayo sobre el señorío de Ichma o Ychima. Arqueología PUC: 13. Instituto Riva Agüero, Pontificia Universidad Católica del Perú, Lima.

1977 Etnia y sociedad. Instituto de Estudios Peruanos, Lima.

1978 Guarco y Lunaguaná: Dos señoríos prehispánicos de 
1980 la costa sur central del Perú. Revista del Museo Nacional. 46. Lima.

Rowe, John H.

1948 The Kingdom of Chimor. Acta American 6. México.

Rubiños y Andrade, Justo Modesto de

[1782] Successión chronológica o serie historial de los curas de Mórrope y

1936 Pacora en la provincia de Lambayeque del obispado de Truxillo del Perú. Revista Histórica 10. Lima.

Sancho, Pedro

[1532] Relación de la conquista del Perú. Compilado por Joaquín García Icazbal-

1962 ceta. Editorial José Porrua Turanzas, Madrid.

Santillán, Hernando de

[1563] Relación del origen, descendencia, política y gobierno de los Incas. En

1968 Crónicas peruanas de interés indígena. Biblioteca de Autores Españoles. 209. Compilado por Francisco Esteve Barba. Editorial Atlas, Madrid.

Topic, Theresa L. y John R.Topic

1981 Prehistoric Fortification Systems of Northern Peru: Preliminary Report on the Final Season, January-December 1980. Mimeógrafo. Departamento de Antropología, Trent University. Peterborough, ON, Canadá.

Trujillo, Diego de

[1534] Una relación inédita de la conquista, La crónica de Diego de Trujillo.

1970 Instituto Raúl Porras Barrenechea, Universidad Nacional Mayor de San Marcos. Lima.

Willey, Gordon R.

1953 Changing Settlement Patterns in the Viru Valley, Peru. Bureau of American Ethnology, Bulletin 155. Smithsonian Institution, Washington, DC. 


\title{
MAS ALLA DE LAS FRONTERAS DE CHINCHA
}

\author{
Craig Morris
}

\section{INTRODUCCION}

El mayor interés en las fronteras se ha enfocado sobre las condiciones especiales de los contactos sociales y económicos y en las interrelaciones que los caracterizan. Como Latimore (1940) y otros observaron, frecuentemente las fronteras presentan las condiciones para la innovación y el cambio. Las fronteras móviles pueden proveer vigor y crecimiento a largo plazo para los señoríos en expansión. Además de ser el escenario para los contactos entre diversos grupos, muchas veces también las fronteras alientan ambigüedades, las cuales, a su vez, proveen estímulos para soluciones nuevas, comportamientos modificados y cambios en la estructura socio-política.

Por lo general, las fronteras se conciben como líneas que separan entidades políticas y/o culturales distintas. Estas líneas se pueden diferenciar mucho en su permeabilidad, pero normalmente están consideradas como líneas continuas que forman básicamente límites geográficos. En contraste con estas fronteras geográficas, hay otras situaciones en las cuales se encuentran muchas de las características sociales, económicas y culturales fronterizas, aunque no exista una línea continua que separe dos entidades distintas. Los dos ejemplos principales de situaciones de frontera, llevadas más allá de las líneas usuales de las fronteras geográficas, son los puertos de intercambio (Revere 1957) y las colonias. En ambos ejemplos, la frontera puede adquirir una cualidad esparcida e insular; ambos han sido reconocidos por el importante papel que juegan en las transformaciones políticas y económicas. Ambos se distinguen principalmente por el grado y la manera en que la interacción social y económica es controlada por alguna sede de poder relativamente distante.

En el caso de los incas, ha sido posible trazar los límites geográficos del Tawuantinsuyo en casi todas las zonas, por lo menos en términos de la máxima extensión de los puntos donde las fuerzas del Cuzco pudieron construir caminos e instalaciones (Hyslop 1984). Sin embargo, el significado, la variación y la estabilidad de estas "fronteras" son temas de investigación en los cuales la mayor parte del trabajo todavía queda por hacer. Carecemos de una verdadera historia de la expansión inca que nos proporcione los eventos y las motivaciones para entenderla. Sin embargo, la evidencia para la forma de colonización realizada por los incas y otros pueblos andinos es bien aceptada (Murra 1972) y situaciones semejantes en algunos aspectos a las de los puertos de intercambio se pueden también haber presentado. Ciertamente, tanto las fuentes escritas como el registro arqueológico, proporcionan un mosaico cultural de numerosas y probablemente cambiantes dimensiones internas.

Algunos de los principios de la organización socio-política y económica en ciertas partes de los Andes no se predispusieron hacia una expansión uniforme a lo largo 
de fronteras continuas. En casi toda la región los recursos están dispersos en ricas zonas y fajas, muchas veces separados por áreas prácticamente inhabitadas. Los sistemas de complementaridad ecológica que se presentaron en muchas zonas de los Andes centrales, enfatizaron el control directo de los recursos dispersos. Esto resultó en unidades políticas que eran con frecuencia discontinuas (Murra 1972). Los patrones de expansión debido a la colonización a veces conducían a un entrelazamiento: al compartimiento de ciertas áreas de recursos por unidades políticas distintas y a estratificaciones complejas de organización y autoridad.

Mientras que la expansión inca desde el Cuzco combinaba muchos elementos y estrategias, los principios de una política discontinuada formaban una parte esencial de ella (Morris 1985). Se enfatizaban más las expansiones rápidas que una difusión uniforme. Se crearon islas de poder inca que se ocupaban de las áreas que las rodeaban en varias maneras. El resultado fue una política heterogénea que probablemente puede ser concebida mejor como una serie de partes interrelacionadas que como una sola extensión grande sobre un mapa. Vistas de esta manera, las fronteras incas no eran solamente los límites más exteriores de la avanzada inca en el norte, el sur y el este, también eran las interrelaciones y fricciones continuas entre numerosos componentes internos.

Dada la heterogeneidad demostrada del Tawantinsuyu y la falta de una historia de su formación, nuestra mejor táctica es intentar reconstruir los fragmentarios registros escritos y arqueológicos para zonas específicas. El trabajo que el autor y otros colegas acabamos de emprender en Chincha se relaciona más directamente con la cuestión de las fronteras que en un principio pudieran ser aparentes para un punto tan cerca del centro norte-sur del área sobre la cual el Cuzco extendió sus caminos.

El estudio de María Rostworowski de lo que es todavía un registro escrito limitado sobre el reino de Chincha, sugiere que puede haberse derivado principalmente del patrón serrano de colonias vinculadas por la distribución y el intercambio recíproco. Parece haber tenido un grupo de "mercaderes" especializados y haber dirigido un comercio marítimo a larga distancia, hacia el norte al Ecuador y hacia el sur al Collao, desde su posición en la costa sur-central del Perú (Rostworowski 1970). Otra evidencia fragmentaria, como lo es la presencia del señor de Chincha acompañando en una litera a Atahualpa en Cajamarca, señala un estatus social privilegiado de alguna manera y poco común para Chincha.

En este artículo se trata con dos grupos de cuestiones. Uno se refiere a la relación entre Chincha y el extremo norte, la frontera como se suele concebir y un poco más allá. El otro tiene que ver con la relación interna entre Chincha y el Cuzco.

I. El conocimiento de la implicación de Chincha en el extremo norte del Tawantinsuyu proviene hasta ahora de una sola fuente, el anónimo Aviso de "el modo que havia en el govierno de los Inkas..." publicado y analizado por María Rostworowski en 1970. Este documento no tiene una fecha segura, pero Rostworowski cree que fue escrito entre 1570 y 1575 . Es inequívoco al afirmar una relación comercial con el 
norte: Avia en este gran valle de Chincha, seis mil mercaderes... y con sus compras y ventas iban desde Chincha al Cuzco, por todo el collao, y otros iban a Quito y a Puerto Viejo.... También hace énfasis en la relación comercial con el norte al afirmar que los comerciantes de Chincha eran únicos en el sentido que "trataban con moneda, porque entre ellos compraban y vendían con cobre lo que avian de comer y vestir" (Rostworowski 1970:138).

El cuadro de un comercio especializado se completa con la descripción del valle y la manera en que estaba dividido en poblaciones especializadas: 12,000 agricultores, 10,000 pescadores, y 6,000 "mercaderes". Los "mercaderes", considerando que no están claramente definidos, se clasifican entre los otros como una especialidad económica, reflejando mucho mejor las costumbres y la organización de las zonas del norte que las de las regiones serranas del sur, con las cuales estaban probablemente también unidos por el comercio y a través de un fácil acceso terrestre.

La sugerencia de una relación comercial con el norte está apoyada indirectamente por otras fuentes que se refieren a las riquezas y la importancia del señor de Chincha y al gran número de balsas que tenía en el mar (Cieza 1962, Pizarro 1948). La existencia de algún tipo de intercambio marítimo también está implicada en la famosa balsa cargada de hombres y bienes capturada por Bartolomé Ruíz (cf Rostworowski 1970:116-117). Desde luego, no hay necesariamente una conexión entre esa balsa en particular y Chincha.

En principio, el uso de la arqueología para evaluar las revelaciones del Aviso es relativamente sencillo. Necesitamos buscar aquellos bienes que se pudieron haber trasladado en tal relación de intercambio y definir los contextos en que ocurrieron en términos de una amplia gama de criterios sociales, ecológicos y económicos.

Dada la extensión geográfica involucrada y la complejidad de los problemas contextuales, tal estudio arqueológico es, desde luego, muy difícil de realizar en la práctica. Estamos intentando fomentar una serie de esfuerzos coordinados que buscarán en diversos sitios pruebas tanto arqueológicas como escritas. Es tan importante buscar la evidencia en el Ecuador y en el norte como en Chincha mismo.

En este momento no podemos avanzar mucho más allá de la serie de hipótesis formuladas por Rostworowski en su análisis de Aviso. Siguiendo en parte a Olaf Holm (1966/67), quien sugiere que mullu o Spondylus, un artículo principal de intercambio en el norte, era el componente crítico de la conexión septentrional de Chincha. También sugiere que la importancia del acceso al Spondylus era uno de los principales motivos por los cuales los incas permitieron que Chincha mantuviera su prestigio y función casi sin interrupción. El cobre se considera como la contraparte del sur. El argumento sobre la importancia del Spondylus es convincente, en lo que se refiere a su importancia en la religión andina, desde hace mucho tiempo atrás. El cobre pudo, ciertamente, haber sido movilizado para el comercio, como también pudo haberlo sido la plata. Objetos de plata fueron encontrados en abundancia por Uhle en sus excavaciones en las tumbas de Chincha (Menzel y Rowe 1966, Uhle 1924) y las minas 
cercanas de Castrovirreyna fueron aparentemente ricas en plata. Sin embargo, se podría dudar del transporte de metales a través de distancias como éstas cuando había fuentes disponibles más al norte.

Los actuales reconocimientos arqueológicos de Luis Lumbreras y otros en Chincha, ampliando un reconocimiento hecho por Dwight Wallace (1971) en los años 50, han documentado la riqueza y la importancia de Chincha, por lo menos, desde el Horizonte Temprano. Sin embargo, ni los reconocimientos ni las pequeñas excavaciones de prueba en tres sitios, ni aún los estudios del material de Uhle reportados por Rowe y Menzel, muestran una evidencia concluyente de estrechos lazos con la región ecuatoriana. Un pequeño número de artefactos de concha Spondylus han sido encontrados, pero no en cantidades que se puedan considerar excepcionales, tomando en cuenta la importancia del material a lo largo de los Andes centrales. Hay que tener presente dos puntos: (1) La muestra es todavía demasiado pequeña y desigual para ser indicativa. (2) Si los contactos fueron limitados al comercio e involucraron materias primas principalmente, éstas no serían fácilmente detectadas en las distribuciones de artefactos en general, provenientes sobretodo de las recolecciones superficiales. Sería necesario localizar los talleres donde la materia prima se convertía en artefactos, o los depósitos de materias importadas; no es muy probable que se encontrará ninguno de éstos en un trabajo preliminar. También es esencial indagar en el Ecuador, el otro extremo de este intercambio.

II. Ahora bien, examinando el interior y el sur, la relación entre Chincha y el Cuzco y la parte sur del Tawantinsuyu fue, según el Aviso, creada también por medio del comercio. Existe ya más evidencia arqueológica a considerar de la que había en el caso de la relación con el norte. La evidencia deja ver claramente el papel importante de Chincha dentro del esquema global inca y demuestra que la relación fue más allá de unos débiles lazos comerciales.

El reconocimiento de la construcción inca en La Centinela, el principal sitio de Chincha, data desde Uhle por lo menos. Menzel y Rowe también definieron un componente principal inca en las tumbas excavadas por Uhle y una influencia inca sobre los estilos cerámicos locales.

Nuestros propios levantamientos y excavaciones en La Centinela definieron las áreas de construcción inca y las modificaciones. La utilización de adobes en lugar de la anterior construcción chincha de tapia da importancia a los esfuerzos incas en La Centinela. De los centros pre-existentes en la costa, probablemente solo Pachacamac fue escenario de una mayor actividad de construcción inca. Nuestro entendimiento de la arquitectura inca no es lo suficientemente avanzado para determinar la naturaleza de la mayor parte de la construcción sin excavación. Pero las semejanzas con otros sitios mejor conocidos, tal como Huánuco Pampa, son suficientes para sugerir que un complejo inca administrativo y ceremonial fue añadido al temprano centro chincha con sus grandes montículos de tapia. Una extensa plaza pública y plazas secundarias más pequeñas están presentes, como también un complejo de pequeños edificios finamente construidos y de acceso restringido. Detrás de los edificios hay una 
plataforma espaciosa que mira hacia el mar. Una vez más, este complejo es similar a uno de Huánuco Pampa. La plataforma allí mira hacia un estanque artificial. Una importante diferencia entre la construcción inca en La Centinela y los sitios como Huánuco Pampa es que, según parece, no hubo necesidad de construir grandes cantidades de viviendas comunes, ya que la población que usaba los servicios públicos de las instalaciones incas vivía en las cercanías.

Los resultados preliminares de excavaciones pequeñas en una parte de la instalación inca en La Centinela sugieren otra semejanza más con Huánuco Pampa: la producción de tela. El conjunto de grandes jarras que se considera sugiere la producción de chicha y una unidad de producción de las mujeres aklla, no parece estar presente aquí, pero hay una variedad de tela, cuerda y otros materiales relacionados con textiles en sus diversas etapas de producción.

Si una excavación posterior de una muestra mayor confirma el contexto de estos hallazgos, entonces tendremos más evidencia de la importancia de la fabricación de tejidos en una situación administrativa inca (Morris 1974). Cualquiera que haya sido la relación comercial entre Chincha y la frontera del norte, es probable que los incas hayan usado tácticas serranas tradicionales para reforzar su relación con Chincha; obsequios de tela fueron producidos y distribuidos por los incas en una instalación del estado, en este caso en el corazón del centro principal de Chincha. También se puede suponer la posibilidad de que la tela, o la lana de alpaca y algunas otras materias primas, pudieron haber sido introducidas en una red de intercambio entre Chincha y el norte. La tela se destaca prominentemente en la carga de la balsa capturada por Bartolomé Ruíz (cf Rostworowski 1970:116-117).

Como sugerí al principio, creo que los lazos entre las partes fueron más importantes que los límites generales para llegar a una concepción satisfactoria del Tawantinsuyu. El camino que comunicaba Chincha con el Cuzco y el corazón del Tawantinsuyu es particularmente impresionante e implica una importancia especial para la región que atraviesa. Hyslop documentó recientemente una parte del camino (1984). Pasa por el Valle de Pisco, encontrándose con el principal camino serrano en Vilcas Waman. A lo largo del camino hay una serie de centros incas de excepcional interés en términos de arquitectura y planificación, incluyendo Lima La Vieja, la cual tuvo también ocupaciones pre-incas, Tambo Colorado, Huaytara e Inkawasi (que no se debe confundir con el famoso sitio en el Valle de Cañete). Todos estos sitios parecen haber tenido una importante arquitectura administrativa y ceremonial inca. Sin embargo, ninguno de ellos ha sido investigado a fondo.

El propósito de tal esmero y elaboración arquitectónica no es claro. El caso de Inkawasi es especialmente curioso, puesto que carece casi totalmente de arquitectura residencial común, más bien parece aislado de otros centros habitacionales. ¿Fue esta serie de extraordinarios centros incas construida específicamente para vincular el Cuzco y la sierra con Chincha y la costa? ¿O existieron otras razones para su construcción? Probablemente no es una coincidencia que la mayoría de las instalaciones se hallen muy cerca de una línea proyectada hacia el oeste desde el Cuzco al océano. 
Esto no quiere decir que la razón para su ubicación era principalmente astronómica o ritual, sino que tales preocupaciones acerca de la planificación inca ahora parecen ser tan suficientemente claras, que deben ser consideradas junto con (o aún como parte de) las preocupaciones más materiales acerca del acceso a los artículos críticos.

En cuanto a las preguntas frecuentemente formuladas acerca de la defensa y la expansión político-militar a lo largo de las fronteras exteriores, Chincha nos dice poco. Sin embargo, por lo que se refiere a la variedad de tácticas y relaciones a lo largo de las fronteras internas, la información, sí es segura y proporciona bastante claridad sobre las estrategias incas tanto de crecimiento como de control.

En resumen, la información actual sugiere que a Chincha le fue otorgado respeto e importancia especiales por los gobernadores del Cuzco. Aunque los métodos de control consistían en la donación de obsequios y la concesión de prestigio tradicionales, ni la evidencia arqueológica ni la escrita indican coerción. Sin embargo, ambas clases de evidencia demuestran que la relación no era puramente, o inclusive principalmente, comercial. En relación a Huánuco y otras regiones del Tawantinsuyu, con las cuales estoy familiarizado, los restos materiales indican una intimidad poco común entre los dos grupos. Aunque está bien definido como una unidad distinta y básicamente ajena, el recinto inca en La Centinela se sitúa cómodamente entre los montículos de Chincha. Un pequeño montículo piramidal nuevo que forma parte del complejo, casi parece ser un tributo de los arquitectos incas a las tradiciones de Chincha. Las cerámicas que imitaban la del Cuzco no son solamente numerosas comparadas con otras zonas costeras, sino que algunos de los estilos son formados por la combinación cuidadosa y aparentemente intencionada de motivos incas y de Chincha. La refinada arquitectura a lo largo del camino que conduce a la sierra también es significativa aquí, y, tal vez, simbólica de los importantes recursos que este enlace con el mar proporcionaba.

La evidencia material altamente formalizada para contactos directos con el Cuzco, ofrece un contraste agudo con las relaciones que Chincha mantuvo supuestamente con el extremo norte, aparentemente más allá de lo que era todavía la frontera político-militar inca (Hyslop, este tomo). Cualquiera que hayan sido los vínculos comerciales, la relación política con el Cuzco era firme.

Concluyo con una especulación. Asumiendo que nuestras últimas temporadas de trabajo confirman el comercio con el norte y asumiendo que se hubiera permitido al Tawantinsuyu seguir su propio caminos de desarrollo, ¿se hubiera perpetuado la indirecta avenida marítima por la cual se obtenían los productos de las cálidas aguas del norte $¿ \mathrm{O}$ acaso la creciente presencia inca en la Sierra Septentrional hubiera tentado al inca a optar por un control más directo de aquellos recursos que parecen haber sido la principal tradición de la sierra meridional?

El cosechar mullu es una especialidad costera y una que pudo haber sido manipulada por medio de movimiento de poblaciones, una táctica predilecta de los incas para controlar directamente la producción de los artesanos. Sin embargo, dadas las indicaciones de una complacencia por la adopción de instituciones nuevas, sobretodo 
estando lejos del Cuzco, mi conjetura sería que Rostworowski (1970) está en lo cierto al sugerir que un sistema eficiente de acceso y control de los recursos esenciales por parte de los incas existía de hecho; es más, las modificaciones drásticas de un sistema que funcionaba bien aún no eran evidentes. De alguna manera, el papel de Chincha, como colonia tanto como puerto de intercambio, funcionando como intermediario entre los incas y más allá de su frontera, era probablemente lucrativo y seguro. En esta coyuntura muy temprana de nuestras investigaciones, Chincha aparece como una especie de puerto de intercambio modificado, gozando de una independencia restringida por el estatus directo, casi colonial, que tuvo con los incas. Esperamos ansiosamente una mejor evidencia arqueológica acerca de los aspectos marítimos de las fronteras de Chincha. 


\section{BIBLIOGRAFIA}

Cieza de León, Pedro

1962 La crónica del Perú. Primera Parte. Ediciones Espasa - Calpe. Buenos [1533] Aires.

Holm, Olaf

1966/67 Money Axes from Ecuador. Folk, T.8-9. Copenhagen.

Hyslop, John

1984 The Inka Road System. Academic Press. New York, Estados Unidos.

Latimore, Owen

1940 Inner Asian Frontiers of China Research Series. American Geographical Society. No.21. Washington D.C.

Menzel, Dorothy and John H. Rowe

1966 The Role of Chincha in Late pre-Spanish Perú. Nawpa Pacha 4:64-76. Berkeley, CA, Estados Unidos.

Morris, Craig

1985 From Principles of Ecological Complementarity to the Organization and Administration of Tawantinsuyu. In Andean Ecology and Civilization. Compilado por Shozo Masuda, Izumi Shimada y Craig Morris, pp.477490. University of Tokyo Press. Tokyo.

Pizarro, Pedro

1948 Relaciones del descubrimiento del reyno del Perú. Publicaciones de la

[1571]Escuela de Estudios Hispano-Americanos de Sevilla, Serie 7A, No.4. Sevilla, España.

Rostworowski de Diez Canseco, María

1970 Mercaderes del Valle de Chincha en la Epoca Prehispánica: Un Documento y unos Comentarios. Revista Española de Antropología Americana 5:135-177. Madrid.

Samanos, Juan de

1842 Relación de los primeros descubrimientos de Francisco Pizarro y Diego del

[1526] Almagro, sacada del codice Numero CXX de la Biblioteca Imperial de Viena. En Colección de documentos inéditos para la historia de España. T.V. Madrid.

Uhle, Max

1924 Explorations at Chincha. University of California Publications in American Archaeology and Ethnology 21(2):55-94.

Wallace, Dwight T.

1971 Sitios arqueológicos del Perú - Valles de Chincha y Pisco. Arquelógicas 13. Museo Nacional de Antropología y Arqueología, Lima. 


\title{
PATRONES DE ASENTAMIENTO INCAICOS EN EL NORTE GRANDE DE CHILE
}

\author{
Hans Niemeyer F. \\ Virgilio Schiappacasse F.
}

\section{INTRODUCCION}

La convocatoria al simposio "Las Fronteras del Imperio Incaico", desarrollada en el $45^{\circ}$ Congreso de Americanistas, no aclaraba si era necesario referirse en las ponencias, únicamente al área periférica de contacto comprometida por la expansión final del imperio en el momento de su colapso, o a las áreas mayores alejadas del núcleo central, desde el cual se ejercía el poder y que fueron siempre consideradas marginales o "de borde". En este último sentido propusimos como tema "El Inca en el Norte Grande de Chile", empresa que resultó demasiado ambiciosa para desarrollarse en tan breve espacio. En vista de esta circunstancia, decidimos tipificar la ocupación inca del Norte Arido a través de los rasgos más característicos de la misma en la cuenca transversal del extremo norte, la de Camarones y la cuenca en el sur de esa gran área, del Salar de Atacama.

El llamado Norte Grande o Norte Arido comprende las actuales Regiones de Tarapacá y Antofagasta, cuya característica más sobresaliente es su extrema aridez. Esta extensa zona colinda por el este, desde el Valle del Lluta en el norte y la cuenca alta del Loa por el sur, con el altiplano boliviano, fuente nuclear de alta cultura. Le sigue al sur el Salar de Atacama con pequeñas poblaciones en su margen oriental que mantenían en la prehistoria lazos estrechos con las poblaciones de la Puna Salada, en áreas hoy situadas en territorio argentino. Del sur de Peine, el más austral y el último de los oasis del Salar de Atacama, hasta el Valle de Copiapó se extendía el Despoblado de Atacama por $500 \mathrm{~km}$, prácticamente sin recursos de agua y sin habitantes permanentes. Solo a partir de Copiapó, hacia el sur, los ríos son de regímenes de escurrimiento permanente con caudales de cierta consideración y ofrecen condiciones de suelo, clima y recursos hidrológicos de buena calidad para desarrollar una agricultura más intensiva. Además, el Norte Semiárido tenía el atractivo económico de sus veneros mineralizados, especialmente de cobre, plata y oro. A no más de $190 \mathrm{~km}$ al norte de Copiapó, existía una explotación de turquesas y posiblemente otra análoga cerca de Ovalle, en la cuenca del Río Limarí.

En contraposición, los ríos de los valles del extremo norte tienen sus cabeceras en la precordillera y atraviesan la pampa desértica en cajones estrechos y profundos para vaciarse en el mar con caudales intermitentes. La calidad del agua se deteriora en su trayecto por contaminación de sales. El Lluta, el primero de esos ríos, si bien alcanza al mar con un exiguo caudal, sus aguas llegan altamente contaminadas por lo que los terrenos bajos han sido inutilizados por los álcalis. De allí que el atractivo mayor para los incas al dominar estos valles no fuera precisamente la riqueza agropecua- 
ria, sino que más bien los productos costeros de alta apetencia en el interior: el pescado (y moluscos), seco o bien salpreso, y el guano de los roquedales depositado por las aves marinas como los cormoranes (Phalocrocorax sp.), el pelícano o guajache (Pelecanus occidentalis), el piquero (Sula variegata), entre otras. Cabe recordar que el guano era el fertilizante más rico del Norte Grande antes del descubrimiento del salitre en tiempos recientes

Una hipótesis en boga (Llagostera 1976) es que los incas ejercieron el poder político en esos valles desde las capitales de los reinos del altiplano sometidos a su dominio, los que habrían tenido colonias en ellos. A estas colonias se les imponían estructuras arquitectónicas incaicas. Los valles habrían servido de corredores para ejercer este dominio.

Otra hipótesis es que los establecimientos incaicos estuvieron localizados principalmente en las proximidades de dos rutas longitudinales que convergían hacia el alto Loa, $400 \mathrm{~km}$ al sur del Lluta. Los valles, entonces, habrían desempeñado un papel de apoyo logístico a los caminos que conducían al sur.

Una de estas rutas pasaba por Mollepampa en el Lluta; por Alto Ramírez en Azapa; por Chaca en la Quebrada de Codpa; por el sitio incaico de la Hacienda Camarones (o bien por Conanoxa), en el Valle de Camarones; por Suca, en su afluente la Quebrada de Chiza, para dirigirse a Calatambo en la Quebrada Camiña y a la desembocadura de la Quebrada de Tarapacá y desde allí, hacia el sur por el borde oriental de la Pampa del Tamarugal; tocaba Tambillo en el sistema Juan de Morales; Pica, enclave obligado en el borde de la Pampa; Puquio Núñez; Cahuiza y Tiquima, remontaba la Quebrada Guatacondo hasta Copaquire y el alto Loa; empalmaba con el camino que venía por la precordillera y cuencas altas intermontanas. Probablemente, este camino venía desde Tacna hasta las proximidades de Putre y Socoroma y continuaba hacia el sur por la media falda de la vertiente occidental de la precordillera andina. Luego, nuestra ruta unía Zapahuira con establecimientos incaicos cercanos a Belén como Incahullo, Tignamar, Episcacha y Pachama, el Tambo San Antonio de Taruguire, Mulluni, Isluya, Cancosa, Collacagua en el Salar del Huasco, El Tojo, Vertiente del Huasco (en el saladar del mismo nombre), la Aguada de Coposa, al oeste del Pabellón del Inca; para continuar a Pampa de Ujina y la aguada en el saladar de este nombre, hasta Ollagüe. De este punto se desprendía un ramal que se juntaba en Miño con el proveniente de la Pampa del Tamarugal. De Miño, seguía el camino descendiendo la rama norte-sur del curso superior del Loa hasta los oasis de Lasana y Chiu Chiu. Seguramente se bifurcaba el camino en un ramal a Calama y otro, el principal, a Turi, Caspana, curso del Río Chuschul hasta San Bartolo, Catarpe y Quitor. Al sur de San Pedro, el camino inca se sigue con facilidad por la orilla oriental del Salar de Atacama hasta Peine y Tilomonte, pasando por Tambillos, Aguada de Carvajal y Socaire. De Ollagüe a Turi hay otras alternativas que no vienen al caso detallar.

El Salar de Atacama, es sabido, fue tomado por fuerza militar y la mayor razón de su dominio emanaba aparentemente de su condición de pasaje obligado hacia el sur, 
hacia Copiapó y demás valles del Norte Semiárido y, sobretodo, a los de Aconcagua y Mapocho-Maipo que habrían sido metas de la expansión incaica.

\section{LA EVIDENCIA ARQUEOLOGICA INCA EN CAMARONES}

El Valle de Camarones es el cuarto valle transversal al sur de la actual frontera política chileno-peruana y se desarrolla desde la cordillera al mar, a unos $100 \mathrm{~km}$ al sur de la línea de la Concordia. Su hoya comprende una extensión de 4,760 km², de la cual el $46 \%$ corresponde a la Quebrada de Chiza, un afluente principal aunque la mayor parte del tiempo inactivo (Niemeyer y Cereceda 1984).

El principal afluente formativo del Camarones es el Río Ajatama que sitúa sus cabeceras en la falda occidental del Volcán Chuquiananta, antepuesto a la gran depresión del Salar de Surire. Las aguas del Camarones, con un gasto promedio de $0.46 \mathrm{~m}^{3} / \mathrm{s}$, se contaminan con sales, a medida que avanzan hacia el mar, a donde no siempre llegan.

El Río Camarones riega unas 500 hectáreas de terreno cultivable distribuidas en tres grandes ensanchamientos principales, separados por otras tantas angosturas. Ellos son los distritos de Guancarane, las antes Hacienda Camarones y Hacienda de Cuya, aparte de otras secciones menores, vecinas al poblado actual de Esquiña, de su curso superior.

En el Valle de Camarones, desde sus cabeceras al mar, se pueden diferenciar varios tipos de asentamientos incaicos. Así, se encuentran algunos que, por su arquitectura y por su moblaje, son de indudable tipología inca o contemporánea inca. A tal patrón pertenece el Tambo Taruguire 3 y el asentamiento de Saguara 2, que describiremos a continuación, probablemente también el Pachica prehistórico. El segundo tipo es aquél en que algunas estructuras arquitectónicas incaicas se sobreponen a asentamientos preexistentes. La influencia inca queda manifiesta por tales estructuras de piedra y por algunos objetos, como la cerámica, de tipo diagnóstico. La tercera alternativa es aquella en que la arquitectura es totalmente preexistente o de índole local y que, junto a la cerámica del desarrollo local de Arica u otro, aparece cerámica Saxamar adscribible a la época inca. Tal es el caso de los poblados de Sabaipugro y Quiguatama 2, ambos en los aledaños del actual pueblo de Esquiña. También a esta categoría, aunque bastante más tardío, pertenecería el poblado de Guancarane 2.

Un ordenamiento, de la cordillera al mar, de los sitios incaicos de la Quebrada de Camarones se puede seguir en el mapa de la Figura 1.

Chilcaya 5. En la cuenca del Salar de Surire, en su ribera nororiental, encontramos en 1971 una pequeña aldea a orillas de un bofedal que denominamos Chilcaya 5 (Figura 2). Compuesta de diez recintos circulares de cimientos pircados, arrojó en la superficie fragmentos de cerámica Negro sobre Rojo, la cual habría sido, sin duda, contemporánea inca. 


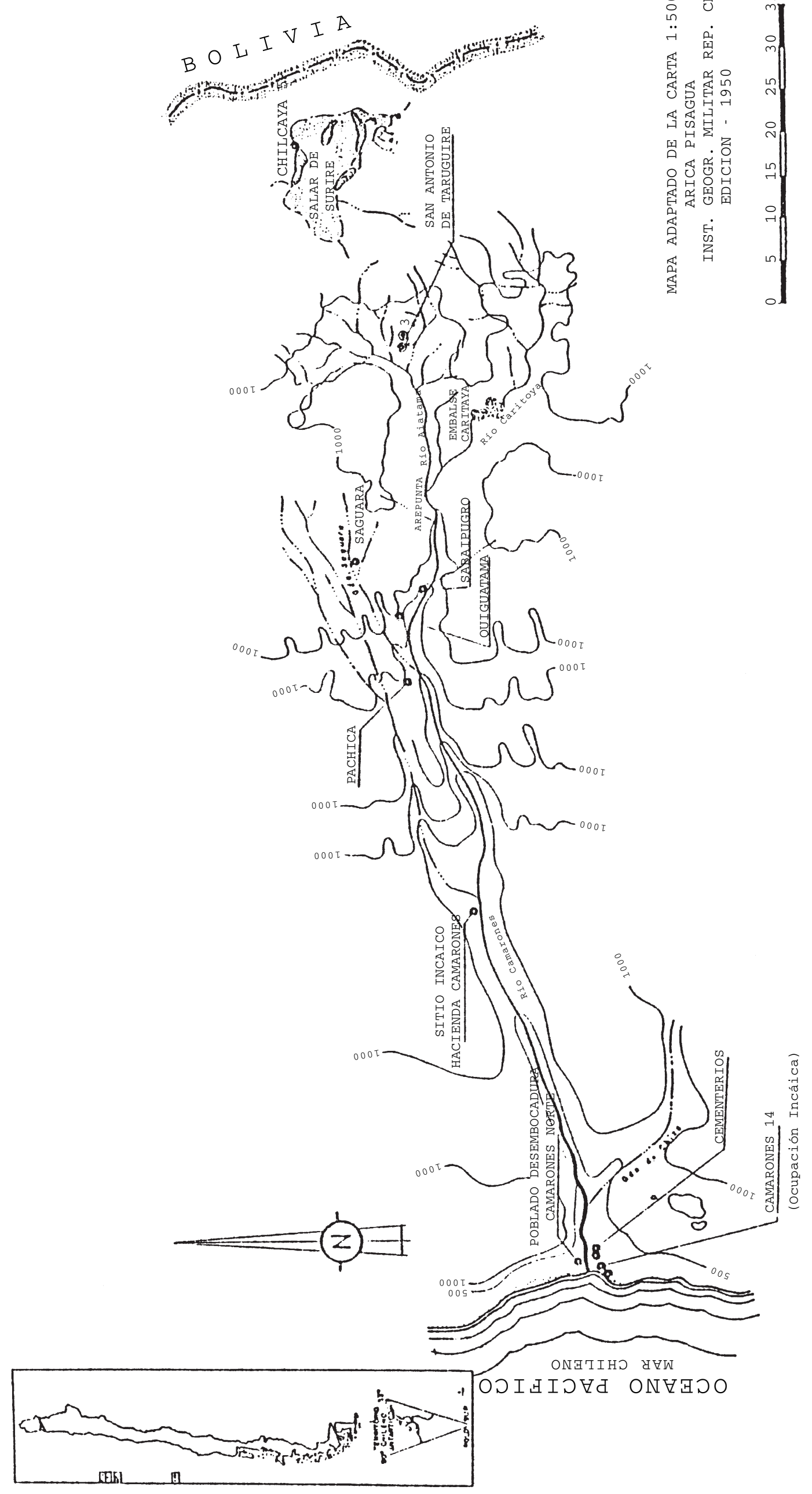




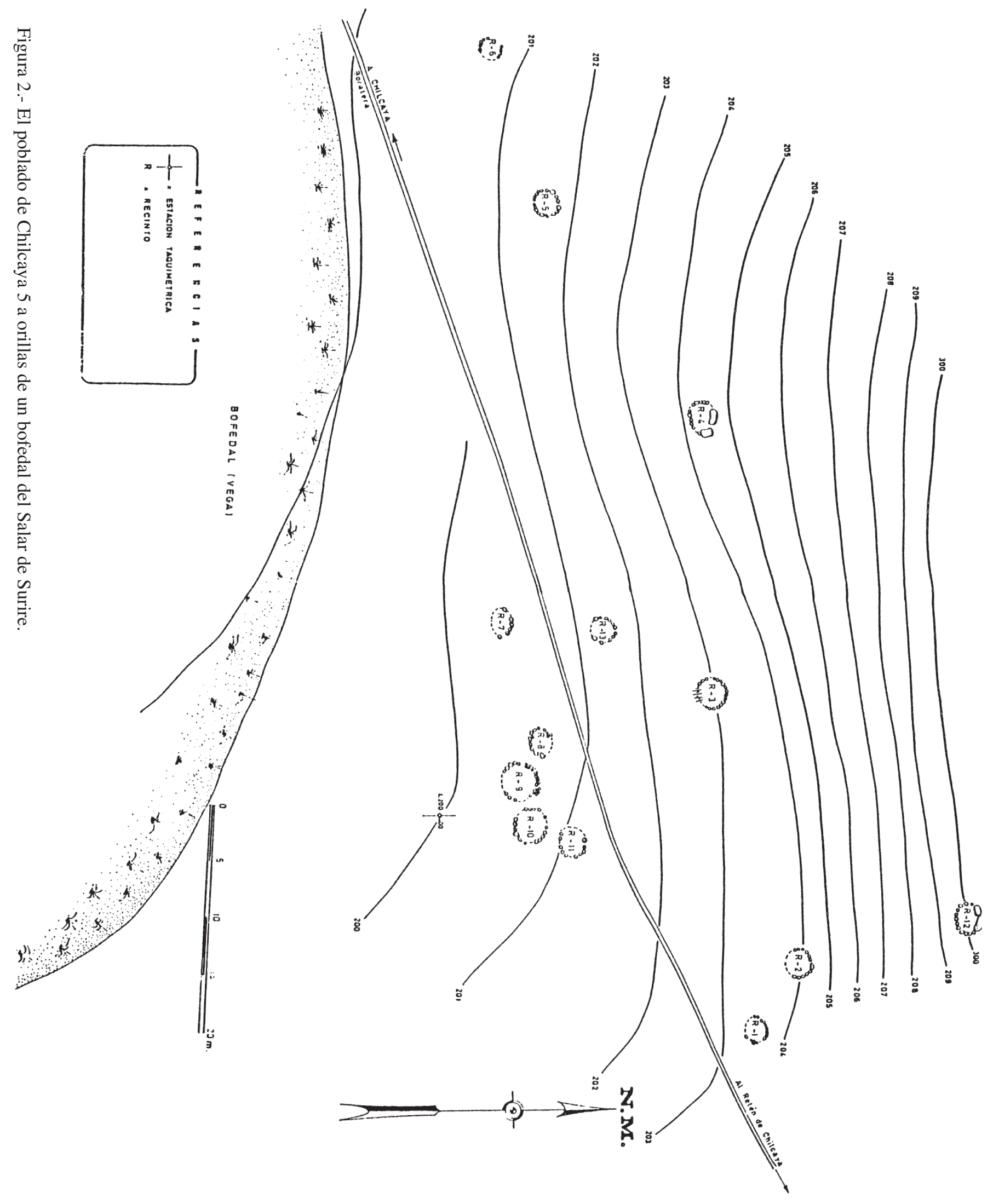




\section{San Antonio de Turuguire 3}

Traspuesto el portezuelo de la divisoria de aguas de la cuenca de Surire con las nacientes de la Quebrada de Codpa, se baja por Itiza al río Umirpa y de allí a las nacientes del Río Ajatama. En esta zona se halla el tambo incaico de San Antonio de Taruguire 3 (Figura 3), aparte de otras estructuras vecinas no bien diagnosticadas. Este tambo consiste en una estructura de piedra relativamente pequeña con una longitud total de $32 \mathrm{~m}$ y una anchura de $15 \mathrm{~m}$, sin contar un muro lateral que se desprende hacia el oriente de la estructura a manera de apéndice. Está situado a 3,620 msnm, sobre un antiguo camino que corre a media falda en la Cordillera Central. De Taruquire se va a Parcoalla, pueblo situado en la falda del Volcán Chuquiananta, y finalmente se puede pasar desde aquí a la cuenca cerrada del Salar de Surire y también seguir a Isluya y Cariquima.

Desde un patio rectangular de esta estructura arquitectónica, se tiene acceso a tres habitaciones situadas en paralelo en el costado poniente. En el extremo norte hay otras áreas complementarias cerradas. Probablemente, desde este sitio se viajaba a Aico, también en un subafluente del Río Camarones.

\section{Saguara 1 y 2}

En un clima mucho más benigno, a no más de 3,000 msnm, con sol radiante permanente y aire más bien cálido en el día y templado por la noche, se encuentran los poblados prehistóricos de Saguara 1 y Saguara 2, sobre la quebrada del mismo nombre, tributario por el norte del Río Camarones. Es la misma modesta arteria fluvial que pasa más adelante cerca de Pachica. Los recursos de agua, escasos aunque de excelente calidad, se acumulan durante la noche en un estanque para ser distribuidos por turnos en el riego de unas pocas eras de cultivo en el día. A juzgar por la seras de cultivo mucho más extensas de antaño, el agua de esta quebrada era antiguamente más abundante (Figura 4). Saguara 1, situado en el piedemonte del flanco sur de la Quebrada de Saguara, corresponde a un poblado incaico obliterado por construcción aymara más moderna que usó los cimientos rectangulares antiguos e incluso las piedras de las viejas estructuras para construir el actual poblado, compuesto de ocho unidades habitacionales.

En el lado opuesto de la quebrada, sobre una explanada de forma triangular delimitada por dos quebradas, por la principal y otra secundaria, se alza el poblado Saguara 2 que podría ser interpretado como un sitio de triple función (Figura 5). Consta, en lo principal, de recintos aislados o individuales de forma predominantemente rectangular, aunque también hay dos recintos amplios de planta circular. El número de recintos asciende a 17, bien configurados con muros de albañilería ordenadamente dispuestos en dos hileras y varias hiladas. De ellos, solo dos guardan una relación de contigüedad entre sí. Al lado de estos recintos principales de buena arquitectura, distribuidos sobre la explanada en forma marginal, hay unos 13 recintos de muros bajos, circulares o elípticos o más bien algo alargados, con cimientos simples de una hilera y de una hilada. 


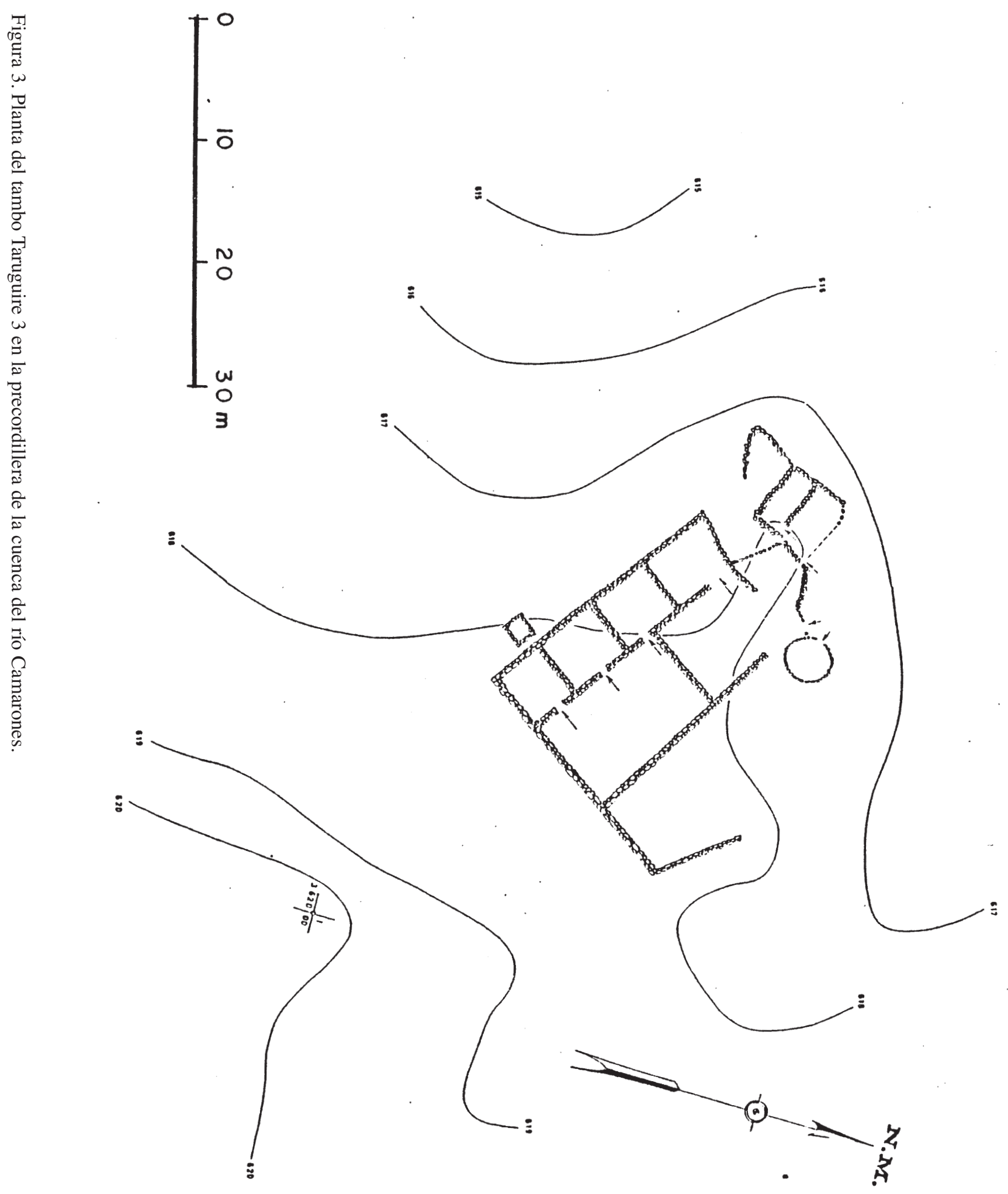




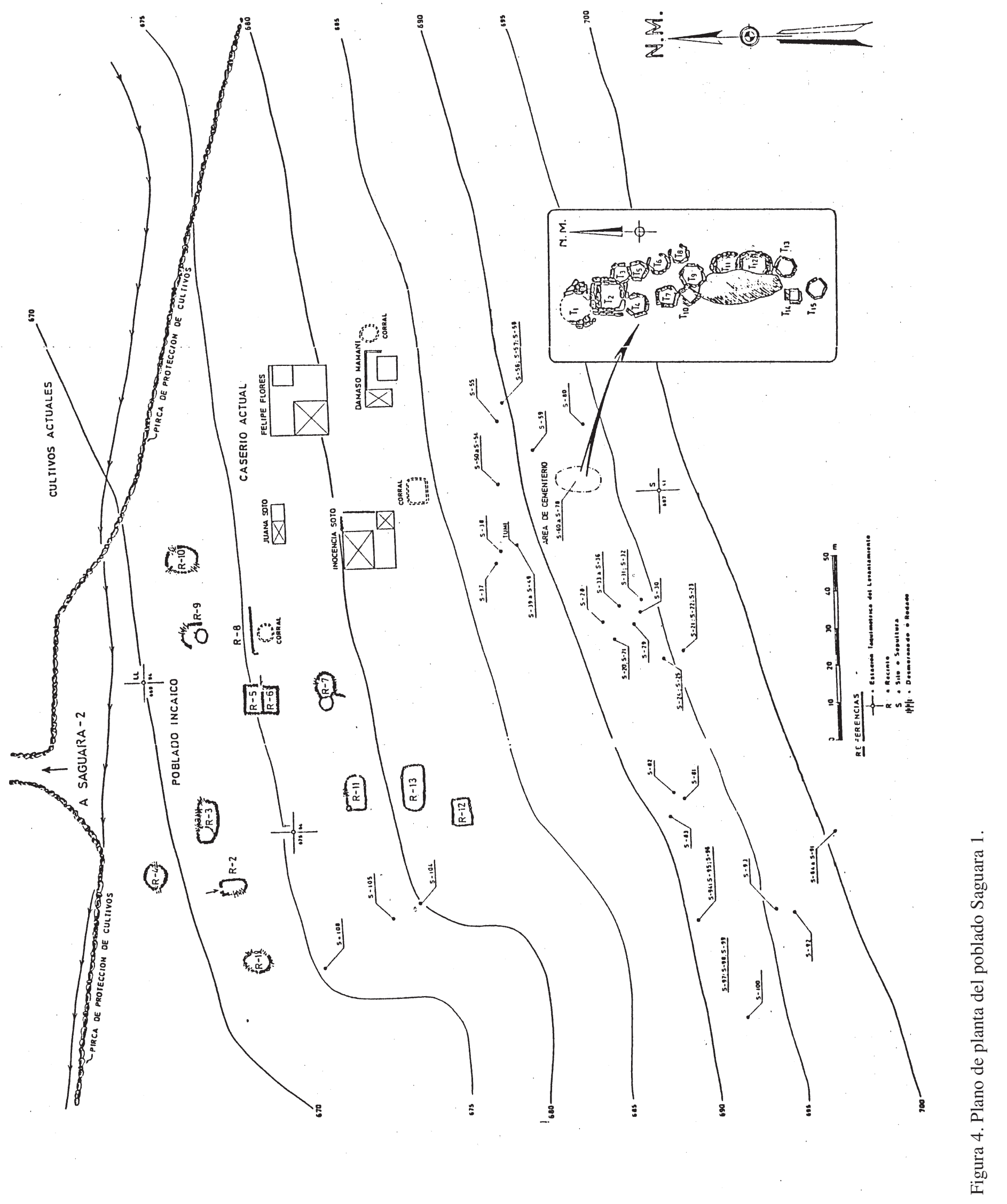




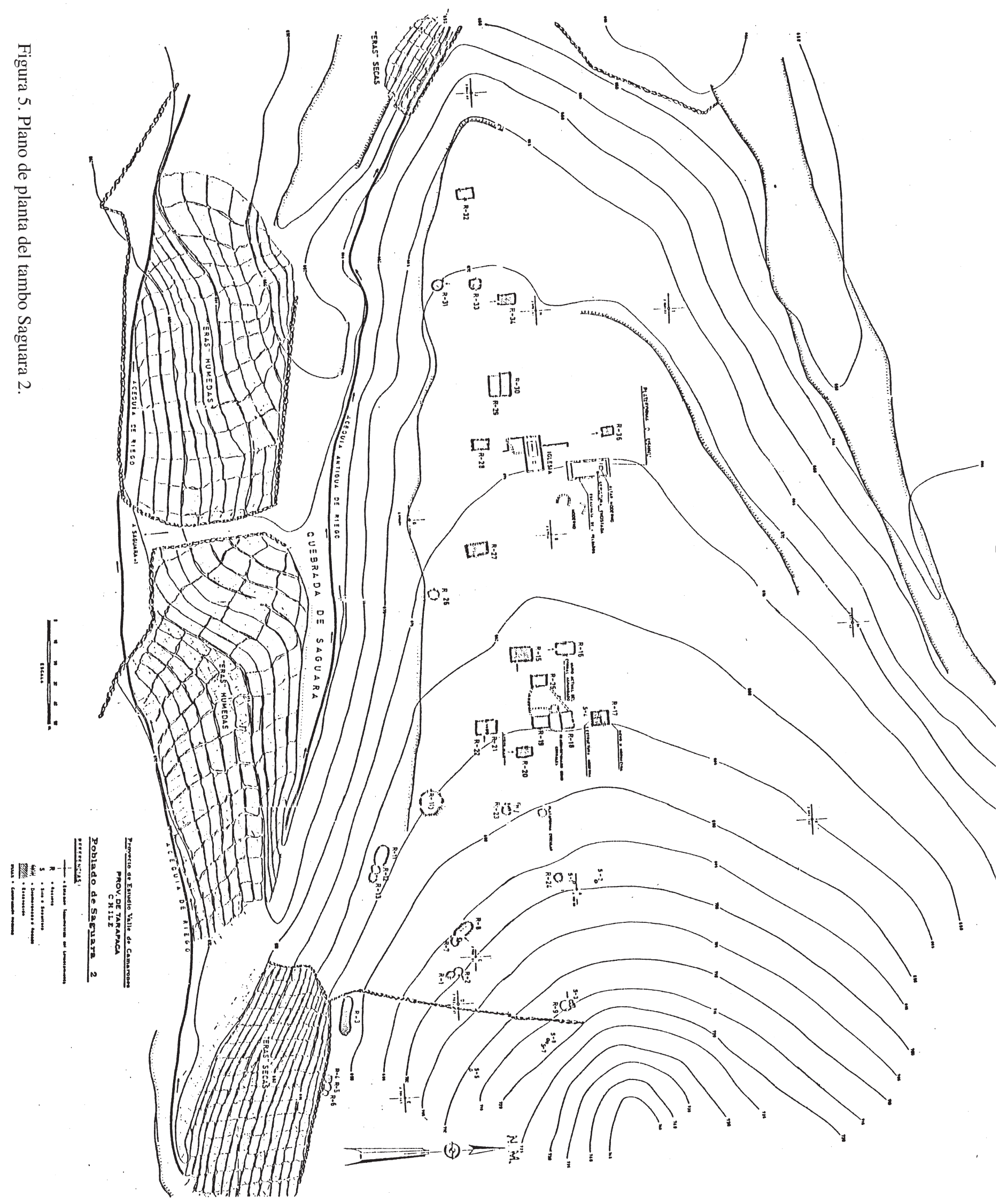


Las dimensiones de los recintos rectangulares son similares entre sí, con una superficie interior representativa de $45 \mathrm{~m}^{2}$ por recinto. Los diámetros interiores de los recintos circulares son de aproximadamente $4.50 \mathrm{~m}$. Todos tienen accesos bien configurados que por lo general tienen una piedra atravesada que constituye el umbral. En algunos casos la puerta está precedida y protegida por un muro curvo en forma de una coma, constituyendo un rasgo arquitectónico muy característico. En alguno de los recintos se detectan nichos u hornacinas interiores.

Sin duda, la construcción prehistórica de mayor relieve en Saguara está constituida por una plataforma elevada $2 \mathrm{~m}$ por sobre la superficie general del suelo, en forma de una pirámide truncada de base rectangular, de $23.50 \mathrm{~m}$ de largo por $11.20 \mathrm{~m}$ de ancho, la cual conserva dos sectores de escalinatas en sus costados. Se trata de un ush$n u$, el cual tendría como función la reafirmación de la autoridad inca y desde él se habrían impartido las normas administrativas. También tendría una función ritual en relación con la adoración del sol, la luna y probablemente las montañas. La Iglesia Católica levantó muy cerca de ella una capilla y todos los años se hace una fiesta religiosa a la cual acude la gente de todos los pueblos de los alrededores.

En Saguara 2, la cerámica decorada en tres colores es muy frecuente, tanto en la superficie como en algunos recintos excavados. La mayoría de los fragmentos corresponde a platitos con decoración tricolor; algunos llevan la figura de un ave u otro motivo. Hay una buena cantidad de fragmentos con motivos netamente cuzqueños y piezas metálicas de tipo incaico (Figuras 6,7).

Obras comunitarias comunes a las dos Saguaras prehistóricas, son los canales de regadío, la cocha en que se almacena el agua de noche de la vertiente y las eras de cultivo que totalizan unas ocho hectáreas, de las cuales la mitad son húmedas y continúan en producción en la actualidad.

Dentro de las obras comunitarias, cabe destacar sectores de silos aéreos bastante alejados de los recintos habitacionales; dos agrupaciones para Saguara 1 (de 22 depósitos para la mayor) y una para Saguara 2 (compuesta de siete depósitos).

Sobre el piedemonte donde está asentado Saguara 1, se han identificado dos áreas de cementerios. Una consiste en una agrupación aglutinada de fosas subterráneas circulares o poligonales en planta, techadas con lajas que forman una falsa bóveda, de 0.5 a $1.0 \mathrm{~m}$ de diámetro. La otra se compone de sepulturas adosadas a bloques dispersos de un rodado.

\section{Pachica}

En el curso inferior de la Quebrada de Saguara, en un tablazo del talud norte del Valle de Camarones, se levanta el actual pueblo de Pachica, hoy prácticamente abandonado. Este obtiene sus recursos hidrológicos de un par de vertientes de buena calidad. Al lado del pueblo actual existió un poblado de tiempos coloniales que fue des- 

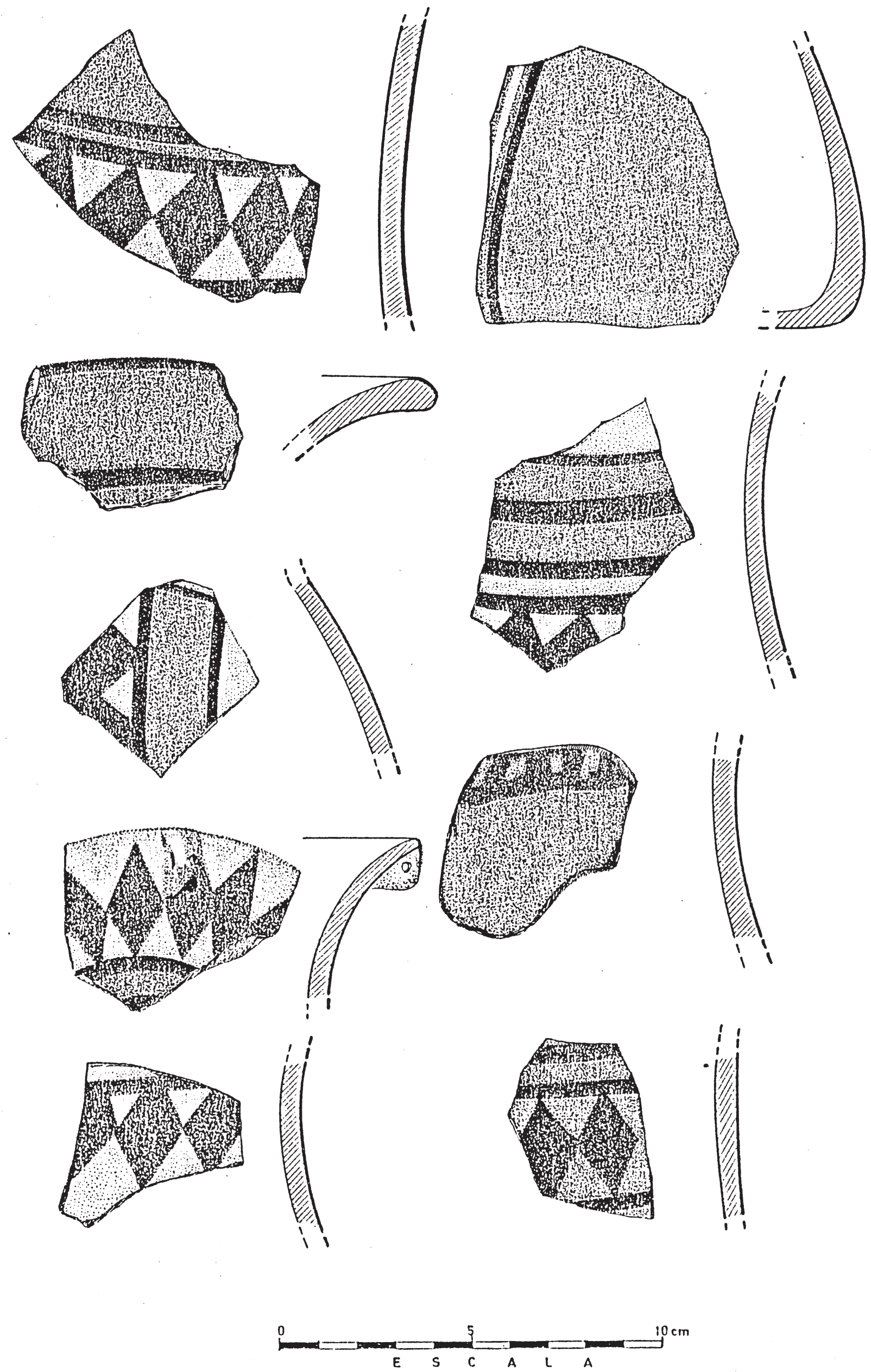

Figura 6. Cerámica procedente de Saguara 2. 

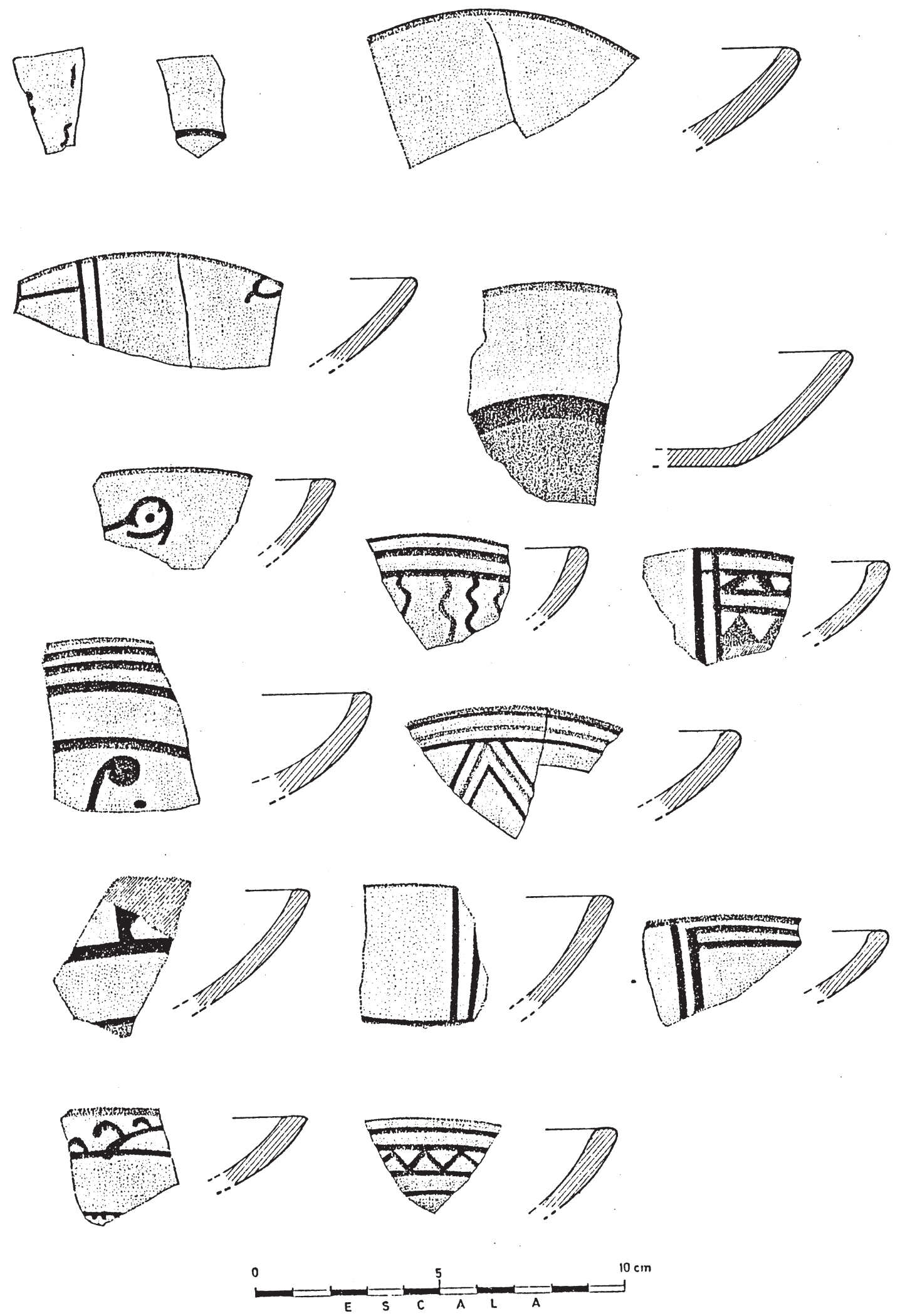

Figura 7. Cerámica procedente de Saguara 2. 
truido por un terremoto, a raíz del cual fue deshabitado y trasladada su población, conservándose sólo la iglesia del pueblo antiguo.

El pueblo colonial de Pachica estaba construido en buena parte sobre cimientos y basura incaicas, según se ha podido comprobar en excavaciones realizadas en 1981. La cerámica detectada, corresponde muy estrechamente con la observada en Saguara, con tipos análogos de pasta, forma y decoración, correspondiente a tiempos incaicos.

Sitios muy representativos de poblados tardíos de la Quebrada de Camarones son Sabaipugro y Quiguatama y, algo más al occidente, Chibaljaya 1 y Chibaljaya 2.

\section{Sabaipugro (Figura 8)}

Está situado en la ladera norte de un espolón rocoso de $50 \mathrm{~m}$ de altura sobre la caja del Río Camarones y a $3.5 \mathrm{~km}$ aguas arriba de Esquiña. Comprende una superficie de 15,200 $\mathrm{m}^{2}$ y está formado por 135 recintos aglutinados, de los cuales 125 son de planta circular o elíptica y solo 16 rectangulares. La superficie promedio de los recintos es $3.25 \mathrm{~m}^{2}$. En el interior de los recintos son especialmente abundantes las piedras molinos y morteros. Predominan en Sabaipugro los estilos cerámicos incaicos Negro sobre Rojo y, en menor proporción, la cerámica de desarrollo local de Arica (Niemeyer, Schiappacasse y Solimano 1971).

\section{Quiguatama 2 (Figura 9)}

Corresponde a un poblado situado sobre una ladera suave entre Pachica y Esquiña, a unos $4 \mathrm{~km}$ al poniente de este último. Posee una superficie de 10,200 $\mathrm{m}^{2}$ y 34 recintos de plantas, en su mayoría circulares o elípticas, de disposición aislada. Vecina al poblado, se encuentra el área de depósitos con 22 silos formados por oquedades naturales en bloque cuya abertura se ha sellado con una pared de piedras unidas por argamasa. Próximo al poblado, existe un cementerio de 36 sepulturas subterráneas revestidas que llevan techo de falsa bóveda. El complejo habitacional se complementa con un campo de eras de cultivo regadas con buena agua de vertiente. Predomina en Quiguatama 2 la cerámica Negro sobre Rojo, imputable en alguna medida al período incaico, pero también hay en pequeña proporción fragmentos de la Cultura Arica. En los poblados Chibaljaya 1 y Chibaljaya 2, bastante cercanos uno del otro, prima el estilo cerámico Negro sobre Rojo, siendo el de estilo incaico muy escaso.

Dos de estos poblados, Sabaipugro y Chibaljaya 2 poseen elementos defensivos, amén de su posición altamente estratégica, sobretodo el último nombrado.

\section{Guancarane 2}

En el ensanchamiento correspondiente al sector Guancarane las manifestaciones imputables a los incas, siempre de muy escasa presencia, se encuentran en el pobla- 

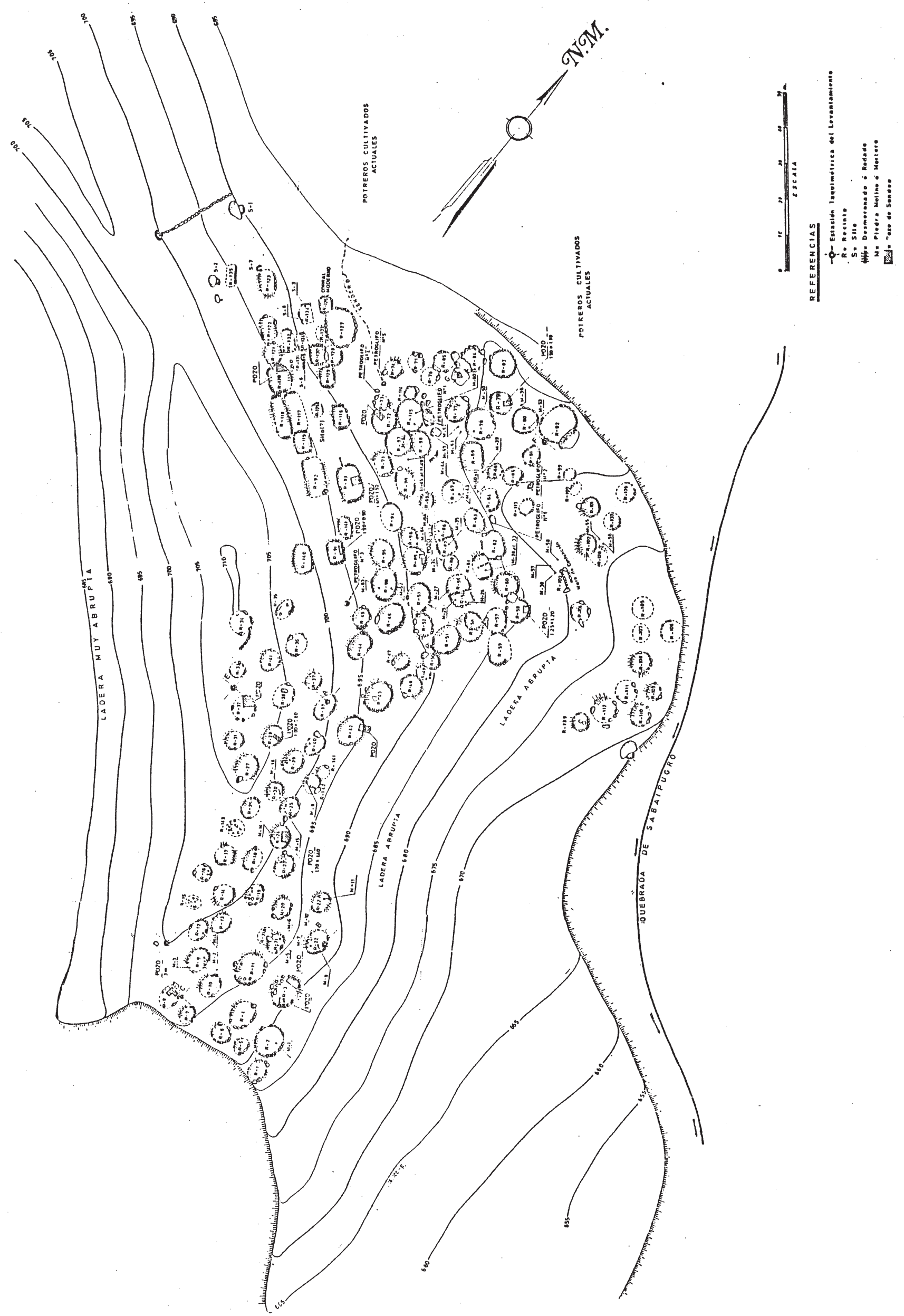

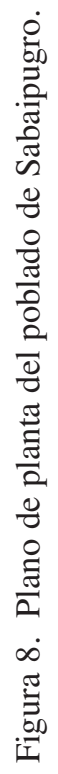




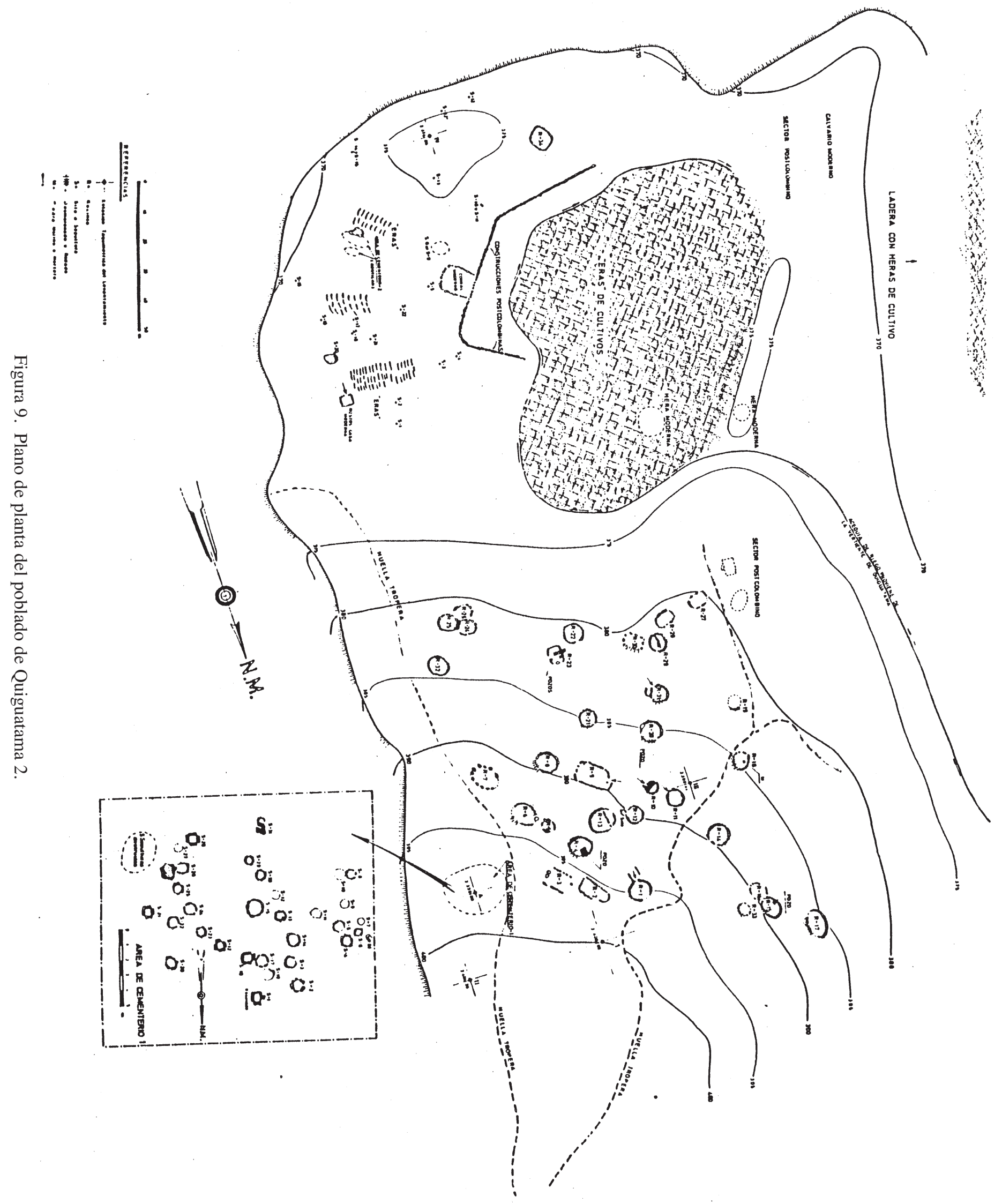


do Guancarane 2 y en otros dos recintos situados algo más al occidente del primero (Figura 10).

Guancarane 2 es un caserío de patrón disperso, situado a 1,120 m en el piedemonte del lado norte del valle y ocupa una longitud de $40 \mathrm{~m}$ por una anchura máxima de $100 \mathrm{~m}$. Se compone de un total de 46 recintos de variadas formas en su planta, aislados unos de otros con excepción de dos o tres aglutinados. Están delimitados por pircas de dos hileras de piedras y de una hilada, de $0.70 \mathrm{~m}$ a $0.80 \mathrm{~m}$ de espesor. El tamaño promedio de estos recintos alcanza los $20 \mathrm{~m}^{2}$. Independiente de los recintos y también aislados entre sí, se encuentran hasta 10 silos subterráneos, por lo general revestidos de piedras. La cerámica decorada es escasa y un 30\% de los fragmentos corresponde al desarrollo local de Arica y el 70\% a Negro sobre Rojo. Parte de sus estructuras fueron reutilizadas en tiempos modernos (véase Niemeyer y Schiappacasse 1981).

\section{Hacienda Camarones}

El próximo ensanchamiento del valle se identifica con la antes Hacienda Camarones. En su cabecera, traspuesta la angostura de Taltape, se encuentra el sector de este nombre, en cuyo piedemonte del flanco norte se encuentran más de 25 sitios arqueológicos constituidos por poblados en ruinas y cementerios saqueados. Este espacio, de unos $4 \mathrm{kms}$ de longitud, si bien está explorado y levantados los mapas, aún no se ha hecho el estudio exhaustivo de sus materiales, ni practicado excavaciones definitivas.

En la parte media del Valle de Camarones, a unos $60 \mathrm{~km}$ de la desembocadura, se encuentra este asentamiento incaico, poco típico desde el punto de vista arquitectónico. Se le ha denominado Sitio Incaico Hacienda Camarones y está situado en un tablazo de $80 \mathrm{~m}$ sobre el fondo del valle frente a la casa patronal de la antes Hacienda Camarones (Figura 11). Se compone de cinco unidades de recintos circulares más o menos aglutinados sobre sendas colinas, los cuales pueden llevar muros delimitados de piedra o ser simples depresiones sin muro materializado. Al excavarlas, en el piso de estas habitaciones, suele encontrarse una estera de totora.

Las instalaciones arquitectónicas incas consisten primero en un gran espacio rectangular delimitado por pircas de doble hilera y dos o tres hiladas, con dimensiones de $35 \mathrm{~m}$ por $25 \mathrm{~m}$ más un apéndice semicircular en su cabecera. En el interior de esta estructura había dos silos subterráneos. Las excavaciones de prueba demostraron que esta estructura fue construida sobre depósitos de basura preexistentes provenientes de los recintos circulares. Otra construcción rectangular muy sólida, de piedras de gran tamaño en la base cuyos cimientos se conservan bien, parece haber correspondido a un templete. Está situada al borde del tablazo frente a los restos de una apacheta. La tercera construcción de piedra está situada más al interior en una pequeña hondonada. Tiene una planta rectangular de $18 \mathrm{~m}$ por $12 \mathrm{~m}$ y su función pudo ser de corral para las llamas en relación con el tráfico caravanero. La instalación se complementa con un área funeraria (Figura 12,13). Se trata de un tipo de cementerio provinciano y las piezas característicamente incaicas son menos frecuentes, presentando una correspondencia que es propia de la cultura local preexistente (Niemeyer 1959b, 1963). Se excava- 


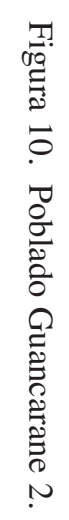

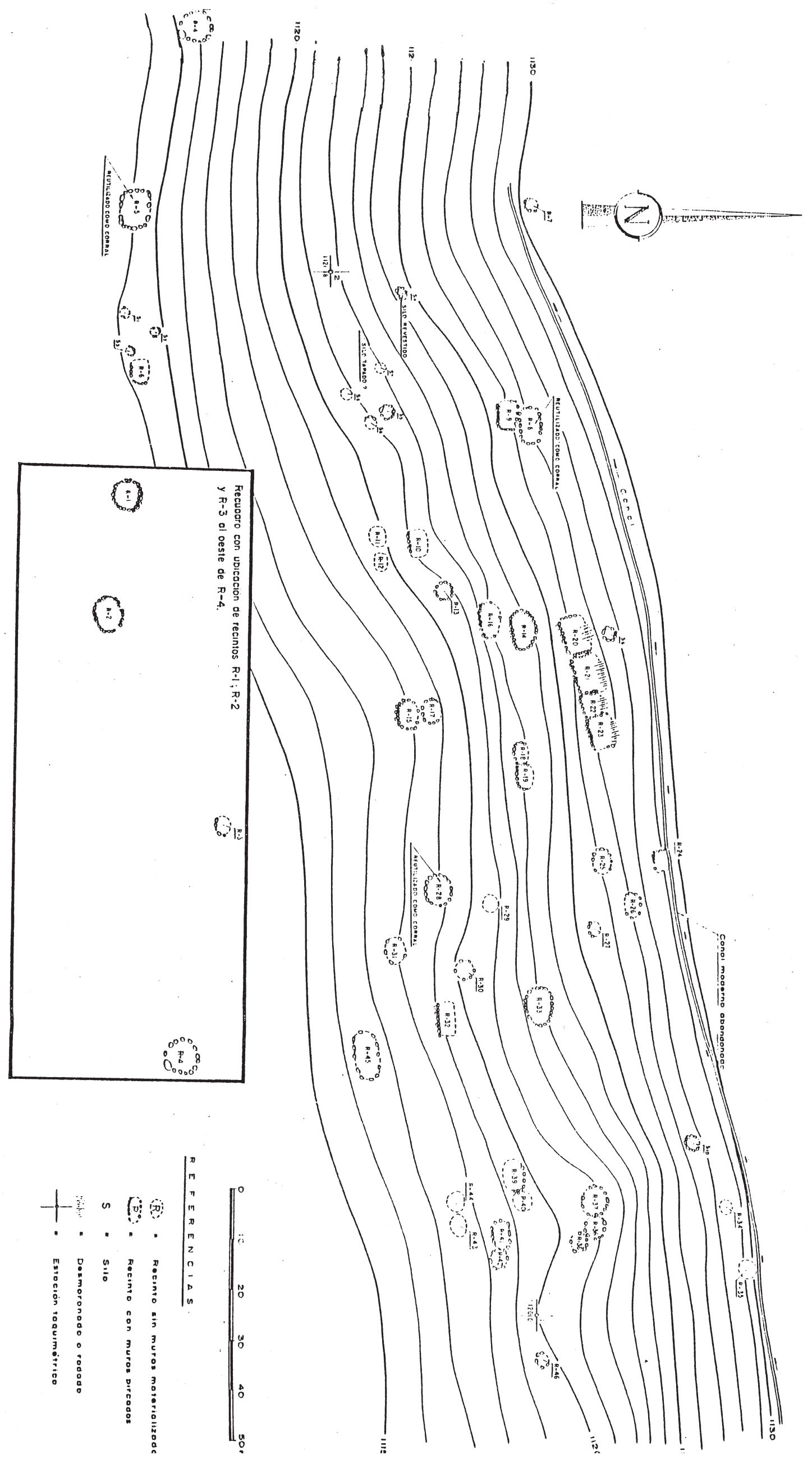




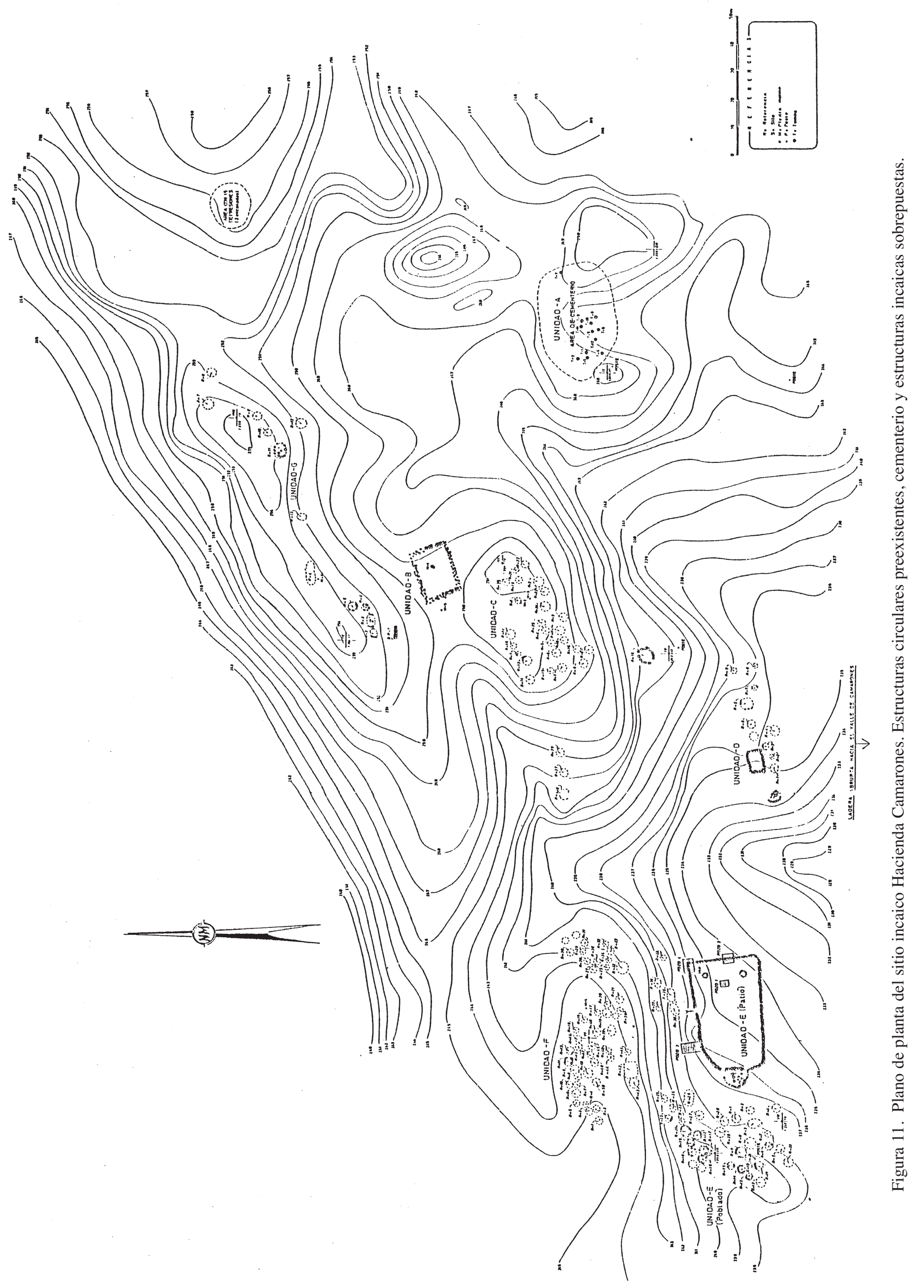


ron doce sepulturas cilíndricas, que se identificaron en la superficie por círculos de piedras plantadas. La tónica de este cementerio es la cantidad grande de mazorcas de maíz; herramientas de la industria textil que acompañaban a los esqueletos femeninos; uso de la calabaza como recipiente; cajitas y keros de madera; peines dobles de madera; paquetes de totora y de paja; uso de ojotas de cuero; flautas de pan hechas de cañas; cerámica corriente y un pequeño aríbalo provisto de un arnés de cuero crudo. Los tejidos de vestimentas de varios colores y restos vegetales fueron irrecuperables por encontrarse enteramente apolillados. También se encontraron ovillos de lana, bolsitas con tierra de color, abundantes restos vegetales de totora, espinas de cactos, maíz, calabazas partidas sagitalmente usadas como contenedores. La posición de los cadávares era la genuflexa sentada, apoyada en la pared o genuflexa en decúbito lateral.

La extensión del cementerio se puede inscribir en un rectángulo de $30 \mathrm{~m}$ por $10 \mathrm{~m}$ que queda inserto dentro del conjunto de las cinco pequeñas unidades de habitaciones circulares.

Según el informe de Mary Frances Ericksen (Niemeyer 1963), los cadáveres de adultos jóvenes son de edades entre 20 y 30 años y tres corresponden al sexo masculino, cinco al femenino, además de tres niños. Un adulto masculino es el único que alcanzó la edad mediana. Todos presentan escasa patología, aunque con evidencia de deficiencias dietéticas. La estatura era baja, con una medida de $154 \mathrm{~cm}$ y de talle delicado. Todos los cráneos tienen deformaciones de tipo tabular erecta, simétrica y de grado moderado.

Un cementerio parecido al de la Hacienda Camarones fue excavado en el Valle de Codpa por el grupo de arqueólogos de Arica encabezados por P. Dauelsberg, mas no han sido publicados los resultados por lo que no se conocen sus detalles.

Sin duda, este poblado está situado en la parte alta sobre el valle por razones de mejor ventilación que permitía evitar a los zancudos Anopheles, propagadores de la malaria. Sus habitantes se dedicaban, sobretodo a la agricultura del maíz, ají y zapa1lo, además de tener una industria textil bien desarrollada, a juzgar por la abundancia de herramientas para tejer que se exhumaron de las sepulturas.

La recolección de la cerámica en la superficie y en las excavaciones practicadas en algunos de los recintos circulares, arrojó abundantes fragmentos de tipo Negro sobre Rojo (Saxamar) pertenecientes especialmente a escudillas planas.

Un estudio preliminar de los materiales provenientes de este asentamiento permite concluir que la cerámica, tanto la corriente como la decorada, se distribuye en forma semejante en todas las unidades, de modo que parece ser que cada unidad funcionaba con todas las actividades de la vida diaria integradas en ella.

Otros materiales de relevancia en este asentamiento incaico son los de origen metalúrgico, como moldes y escorias, repartidos en unidades diferentes. También hay muchos restos de tejidos, cordelería de fibra animal y vegetal, plumas, etc. Restos de 

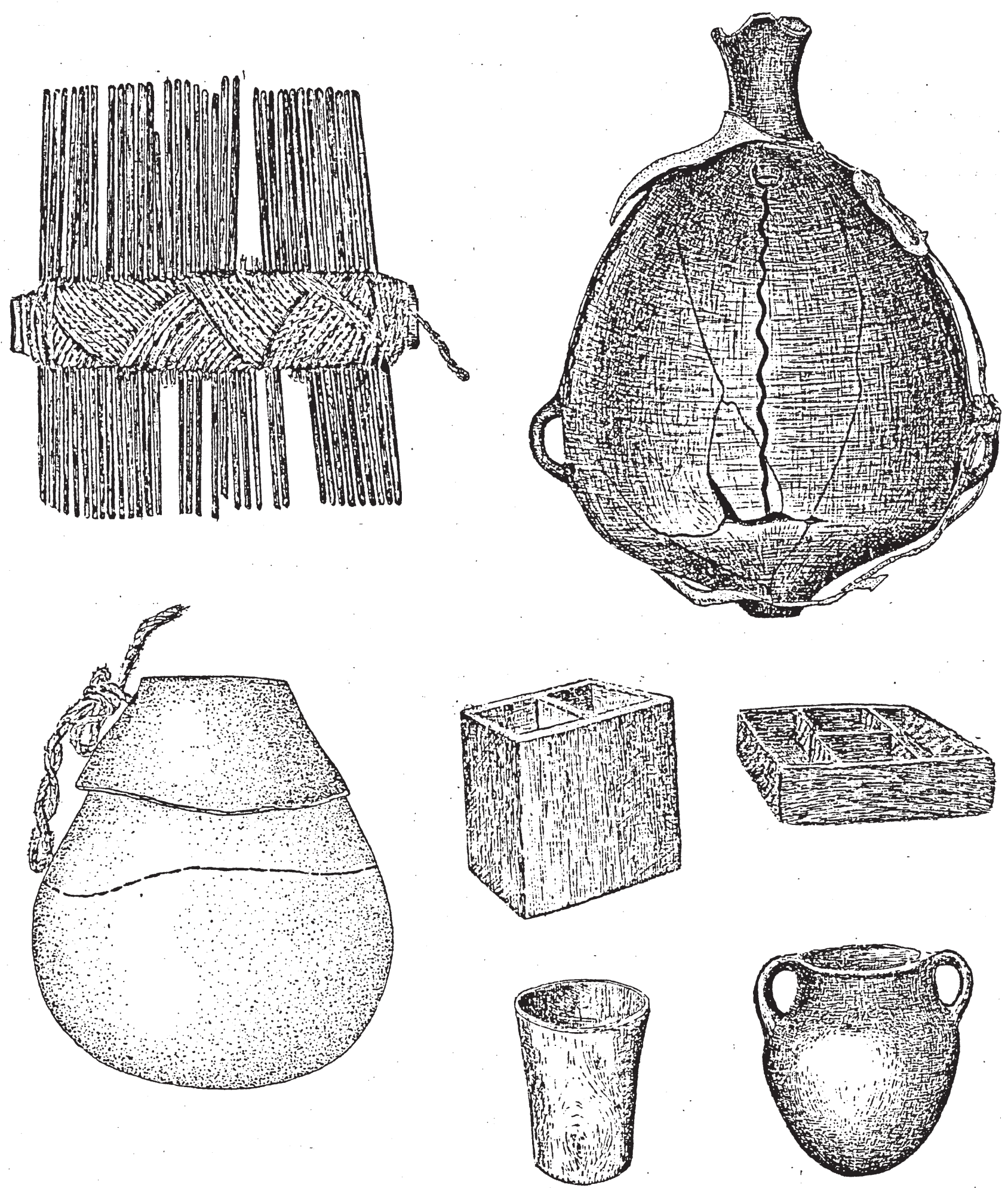

Figura 12. Objetos diversos exhumados en el cementerio del Sitio Incaico Hacienda Camarones. 

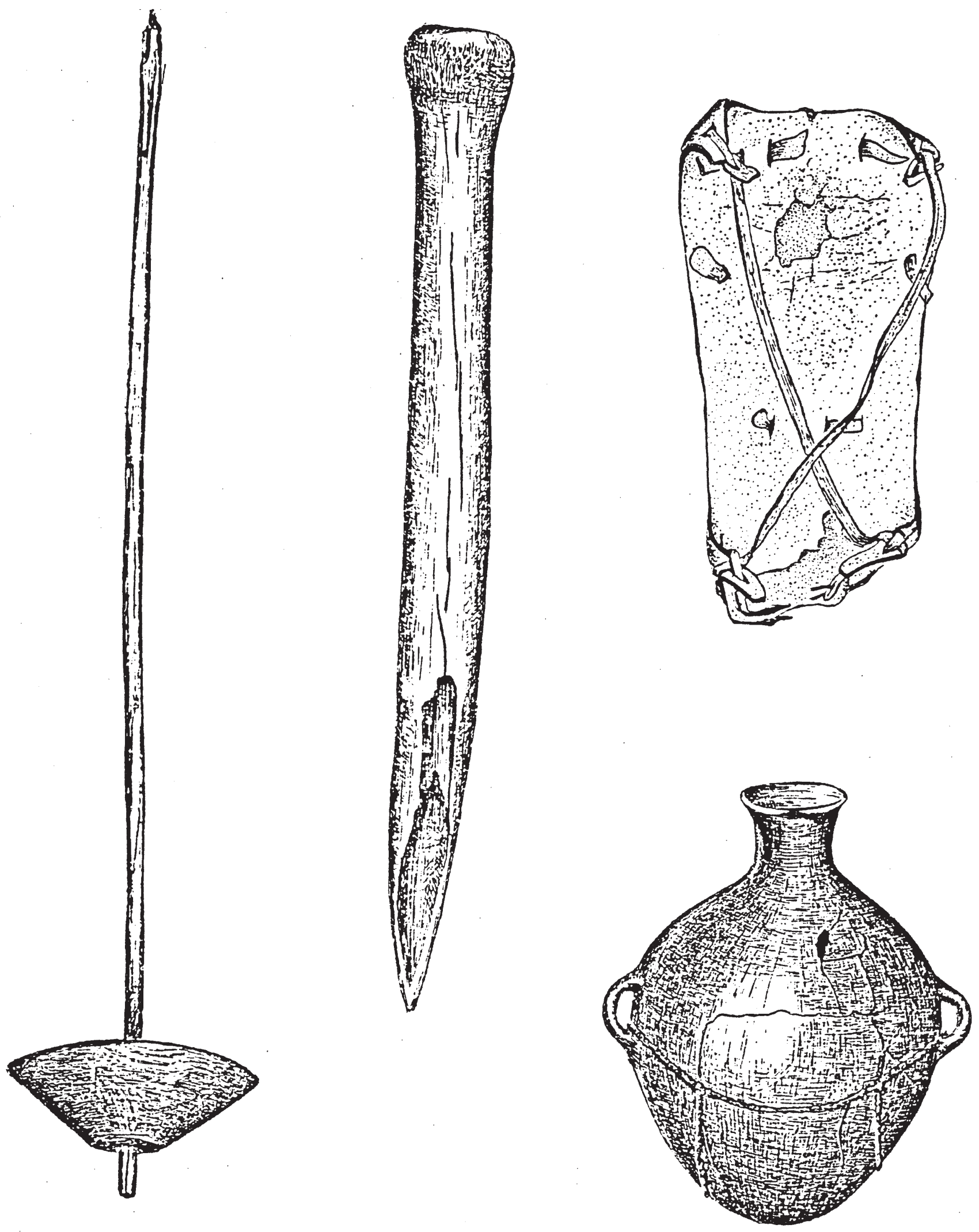

Figura 13. Objetos diversos exhumados en el cementerio del sitio incaico Hacienda Camarones. 
alimentos: maíz, moluscos, calabazas, porotos, vainas de Prosopis sp, tubérculos, caparazones de camarones, entre otros.

\section{Camarones 14}

Finalmente en la costa, en la desembocadura de la Quebrada de Camarones, sobre un sector de la terraza del flanco sur en el sitio Camarones 14, se detectó ocupación incaica, además de un gran cementerio cercano a este sitio conocido con la sigla CA9 que ha sido adscrito a esta fase cultural, aunque las manifestaciones diagnósticas incas son escasas .

Poblado Desembocadura Camarones Norte. Un poblado de difícil adscripción cultural es el llamado por nosotros "Poblado Desembocadura Camarones Norte" que, a pesar de su estructuración de plantas rectangulares, prácticamente no presenta un residuo cultural diagnóstico (Figura 14). Se sitúa, sin embargo, sobre una ocupación precerámica tardía.

Este poblado se encuentra en el faldeo del flanco norte del Valle de Camarones, próximo a su desembocadura en el Pacífico. Se asienta sobre el cono de deyección de una antigua quebrada de erosión, actualmente colgada respecto del valle con una pendiente de $26 \%$. Posee dimensiones extremas de $230 \mathrm{~m}$ de longitud, desde el vértice del cono donde se encuentran los recintos a mayor altura hasta la orilla del acantilado donde éste queda colgado y una anchura máxima en su sector central de $80 \mathrm{~m}$. Su altitud va de 60 a $115 \mathrm{msnm}$.

El poblado se compone de una serie de recintos rectangulares, orientados, como es de suponer, con el eje mayor según una curva de nivel, adaptándose así a la topografía en ladera, así como de recintos circulares de pequeño diámetro. Unos y otros tienen delimitaciones de piedras plantadas provenientes del mismo cerro.

Los recintos rectangulares se presentan más o menos ordenados escalonadamente según líneas de máxima pendiente y, en ciertas agrupaciones, mantienen relación de contigüedad unos con otros. Estos ocupan el sector central del poblado, entre las cotas de 95 y 70 m, aunque excepcionalmente hay recintos alejados del núcleo central. En general, tienen dimensiones más o menos amplias que varían dentro de una escala que va de $2 \mathrm{~m}$ de longitud por $1.60 \mathrm{~m}$ de anchura para los menores y de $8 \mathrm{~m}$ de longitud por $4.40 \mathrm{~m}$ de anchura para los mayores. La superficie interior total alcanza $865 \mathrm{~m}^{2}$.

Las delimitaciones consisten en muros bajos en técnica de pirca seca de cantos agudos, por lo general dispuestos en dos hileras y en un número variable de hiladas, que va de una a cinco. Muchos de los muros a monte se encuentran destruidos, al parecer por agentes naturales. Algunas veces los muros incorporan peñascos naturales de mayores dimensiones dejados in situ originalmente. Tienen vanos de acceso enmarcados por piedras prismáticas. 


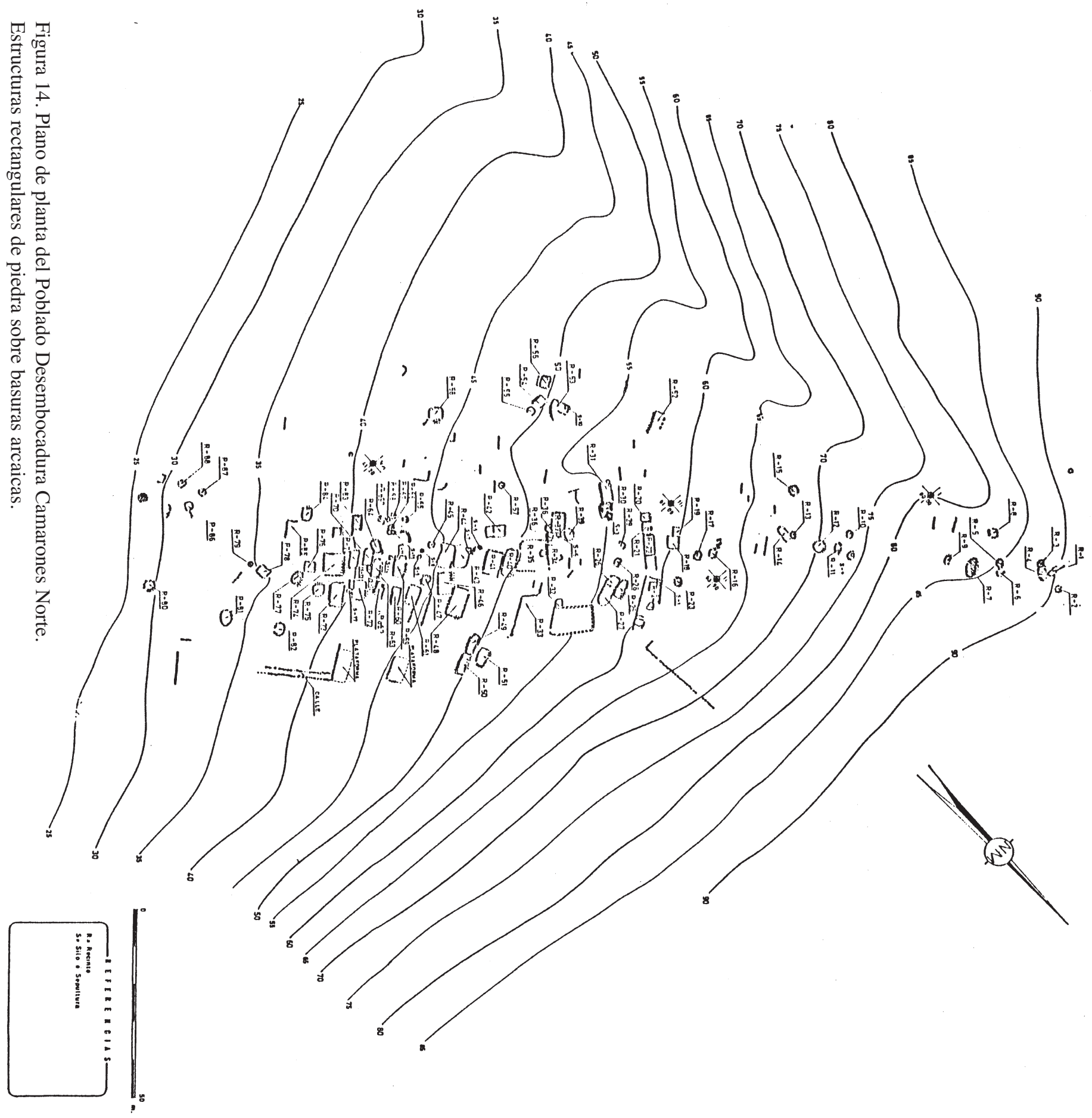


Algunos recintos poseen silos o depósitos de planta circular revestidos de piedras, situados interiormente en un rincón o bien exteriormente adosados a un muro. Un rasgo característico de algunos silos excavados parece ser la presencia en el fondo de un piso duro y compactado con ceniza.

Estructuras análogas aisladas, en terreno sin otra construcción entre recintos, han sido interpretadas también como depósitos. No se descarta la posibilidad de que sean sepulturas saqueadas, aunque no hay comprobación de ello.

En el interior de los recintos se han encontrado pequeños fogones, además de basura. También, en el piso suelen haber hoyos rellenos con basura. En el R-49 se construyó una especie de hogar circular delimitado con dos hileras de piedras.

Otras estructuras consideradas coetáneas con los recintos rectangulares y ejecutadas con técnica análoga se encuentran en este poblado: a) Muros transversales rectos, por lo general de una hilera y una hilada de piedras, con longitudes variables de $1.80 \mathrm{~m}$ a 3 ó $3.5 \mathrm{~m}$ situados en el talweg de pequeñas cárcavas locales. A veces estos muros, que se orientan según una curva de nivel, toman forma semicircular o en medialuna. Se interpretan como muros de control de la erosión; b) Plataformas que consisten en un terraplén bajo y horizontal, con muro de sostenimiento al valle, con longitud entre $6.5 \mathrm{~m}$ a $8 \mathrm{~m}$. Cuando menos dos de ellas son fácilmente discernibles, encontrándose la una en la cabecera de dos lineamientos paralelos de piedras, dispuestos a modo de una calle; c) Muros en L, compuestos de dos alineaciones en ángulo recto de piedras de una hilera.

Mientras la recolección de superficie fue prácticamente negativa en cuanto a materia cerámica, las excavaciones de algunos de los recintos practicadas en 1973 y 1980, revelaron una muy débil ocupación del sitio, siendo los restos de alimentos los más frecuentes: conchas de moluscos, raquis y cañas de maíz, semilla de Prosopis sp, guano de camélidos, caparazones de camarón, entre otros.

Creemos que este poblado es inca, en virtud de que algunas estructuras en los accesos a los recintos son semejantes a las de Saguara 2, consistentes en una pirca de dos hileras dispuestas en forma de una coma. También debido al hallazgo de un tejido de lana, posiblemente de filiación inca, en la excavación de un recinto. Esta es una hipótesis que hay que aclarar.

Aunque los sitios Chilcaya 5, Taruguire 3, Saguara, Pachica y Hacienda Camarones están entre sí a más o menos una jornada de camino a pie, entre la última instalación y la costa hay una distancia grande. Nos asiste, por consiguiente, la sospecha de que sobre las terrazas de Conanoxa o en la antes Hacienda de Cuya, que siguen aguas abajo de la angostura Conanoxa y que se encuentran poco exploradas, debió existir un tambo o una estructura inca, probablemente hoy destruida u obliterada. Asimismo, en la cadena de sitios incas de la sierra, carecen de exploración las localidades de Sucuna y Aico que pueden deparar más de una sorpresa. 


\section{REFLEXIONES SOBRE LA OCUPACION INCAICA DEL VALLE DE CAMARONES}

El Incanato centró su escaso interés en el Valle de Camarones en algunos aspectos económicos que se han insinuado en la exposición precedente. En primer lugar, un aspecto de control pecuario en los bofedales de la cuenca del altiplano del Salar de Surire y una explotación agraria en el valle, limitada por la relativamente escasa disponibilidad de tierra y mala calidad del agua. Es sabido que ésta sufre deterioro cuando se le reune al Río Ajatama el Río Caritaya cuyas aguas son más salobres. Pero el mayor deterioro lo sufre el agua a partir de la angostura de Taltape, exactamente donde el valle se ensancha y ofrece la mayor superficie cultivable. Además, acrecentó en el curso medio la industria textil y seguramente, aunque no lo hemos comprobado, explotó en pequeña escala alguna mina del curso medio superior (Zona de Esquiña). La costa, por su parte, le proveía de moluscos y pescado seco. También un producto de máximo atractivo habría sido el guano generado por las aves marinas, para fertilizar tierras en el valle mismo y en la sierra. Con alguna dificultad lo obtendría de los roquedales que cierran por el sur la rada de Camarones.

En un aspecto distinto al económico, no debe olvidarse que en la parte media del valle de Camarones, en un lugar de clima benigno con permanente sol y a una altura grata de 3,000 msnm, se construyó una instalación de patrón incaico muy depurado que incluye un ushnu, el único hasta ahora conocido en la Región de Tarapacá. Además de funcionar como tambo en el camino de los Andes a la costa por el Valle de Camarones, habría tenido una connotación de pueblo santuario y, quizás, de sitio de recogimiento y descanso.

\section{LOS INCAS EN LA CUENCA DEL SALAR DE ATACAMA}

La cuenca del Salar de Atacama se desarrolla al centro oriental de la Región de Antofagasta y es una de las depresiones intermontanas más grandes del norte de Chile con una extensión de $15,620 \mathrm{~km}^{2}$, una máxima longitud norte-sur de $210 \mathrm{~km}$ y una anchura máxima de $110 \mathrm{~km}$. Esta cuenca queda encerrada por una cadena andina de altos volcanes pleistocénicos por el este y por la Cordillera de Domeyko por el occidente. El fondo de la cuenca está ocupado por el saladar propiamente dicho, el cual, con una superficie húmeda de unos $1,500 \mathrm{~km}^{2}$, una elevación media de 2,400 m, constituye la base de equilibrio de una profusa red de irrigación. A su cabecera norte llegan los Ríos San Pedro de Atacama y Vilama. El primero es el principal aporte del saladar y el que sustenta la mayor área regada en los ayllos aledaños al pueblo. Ambas corrientes presentan aguas con un alto grado de contaminación por sales (Niemeyer y Cereceda 1983).

Otros afluentes se generan en vertientes al pie de los volcanes de la puna y descienden por el flanco oriental del saladar, constituido por un plano inclinado de fuerte pendiente. Estos recursos hidrológicos fertilizan pequeños oasis situados en el piedemonte oriental del saladar, tales como Toconao, Socaire y Peine, aparte de otros 

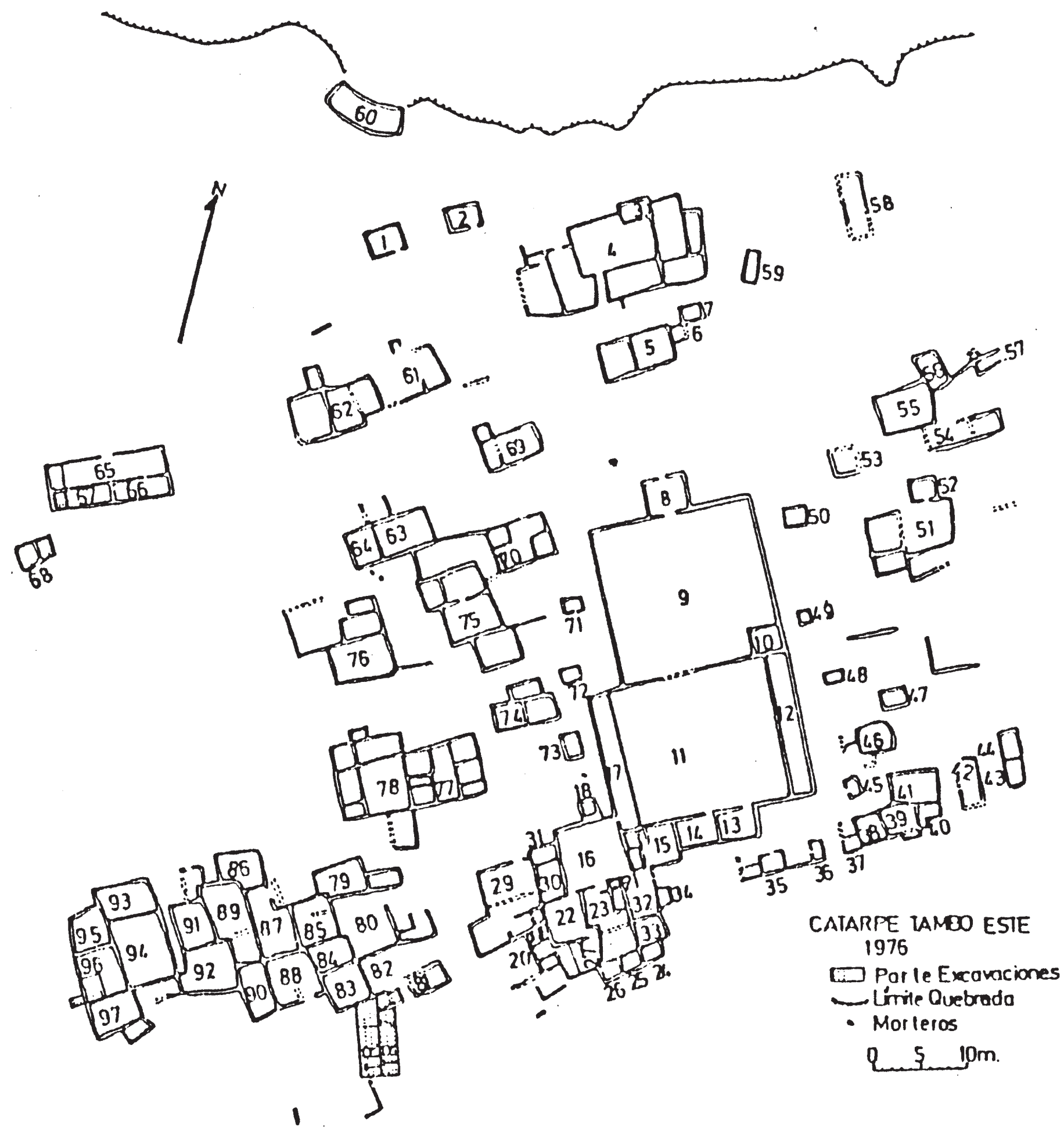

Figura 15. Planta del Tambo Este de Catarpe, en la cuenca del Salar de Atacama (Tomado de T. Lynch, 1977). 
más pequeños. El algarrobo y el chañar son los dos árboles que prosperan en estos oasis y son de gran utilidad para los naturales de la zona.

Según G. de Bibar, "el valle de Atacama era ancho y fértil. El riego se hacía mediante acequias que eran muy numerosas. El alimento principal de sus habitantes era el maíz, las papas, los porotos, la quínoa, la algarroba y el fruto del chañar". Poco es el cambio habido desde la visita de Vivar hasta nuestros días. Habría que agregar algunos árboles frutales resistentes a la salobridad de las aguas y el hecho de que el riego hoy se ejerce mediante canales revestidos.

\section{Catarpe}

Para dominar esta cuenca los incas tuvieron que tomarse la fortaleza de Quitor, donde, a su vez, se hicieron fuertes en unión con los habitantes locales para combatir a los conquistadores españoles. Es sabido que este pucara fue tomado por asalto a caballo por Don Francisco de Aguirre. Pero sin duda, la principal instalación inca se encontraba en Catarpe, poblado situado sobre una terraza del flanco oriental o izquierdo del Río Atacamas (hoy Río Grande o San Pedro), a unos $10 \mathrm{~km}$ al norte del pueblo actual de San Pedro de Atacama. Por aquí pasaba el camino inca que venía del norte, desde Turi, y continuaba hacia el sur por el pie de la ribera oriental del Salar de Atacama.

A Catarpe se le ha dado el carácter de tambo (Lynch 1977), pero a juicio nuestro, por su magnitud y complejidad, escapa al concepto de un simple tambo como se conoce en territorio chileno y más bien es una pequeña ciudad o aldea (Figuras 15, 16). Se compone de dos partes separadas por una quebrada de erosión que corre más o menos de norte a sur. Se ha diferenciado entre "Tambo Oeste" y "Tambo Este". Un levantamiento parcial de la aldea fue realizado por el arquitecto Carlos Montt para G. Mostny (1948). Años más tarde, Gustavo le Paige practicó excavaciones del cementerio de Catarpe y solo en época más reciente, Thomas Lynch, de la Universidad Texas A\&M, EU, hizo con algunos alumnos un nuevo levantamiento con cinta métrica y algunas excavaciones de poca envergadura en Catarpe "Tambo Este" (Lynch 1977).

Ambos "tambos" son similares en muchos aspectos. Prima absolutamente en ellos la planta rectangular de recintos contiguos que comprenden plazas, habitaciones, patios y bodegas o colcas. En Catarpe Oeste se encuentran alrededor de 120 de estos recintos, agrupados en dos mitades separadas por una quebrada de erosión. En Catarpe Este se hallan dos espacios mayores con características de plazas de planta cuadrada, de 18 a 20 m por lado y alrededor de ellas se dispone una decena de agrupaciones de recintos cuadrangulares contiguos, siendo la mayor de ellas la que ocupa el extremo suroeste del "tambo".

Los muros de estas estructuras son de adobe combinado con grava y bolones de río; es decir, para sus construcciones los incas sacaron partido estricto de los materiales que les ofrecía la localidad, y así, los muros de Catarpe contrastan con el patrón más generalizado de la albañilería típica inca de piedra angular. 


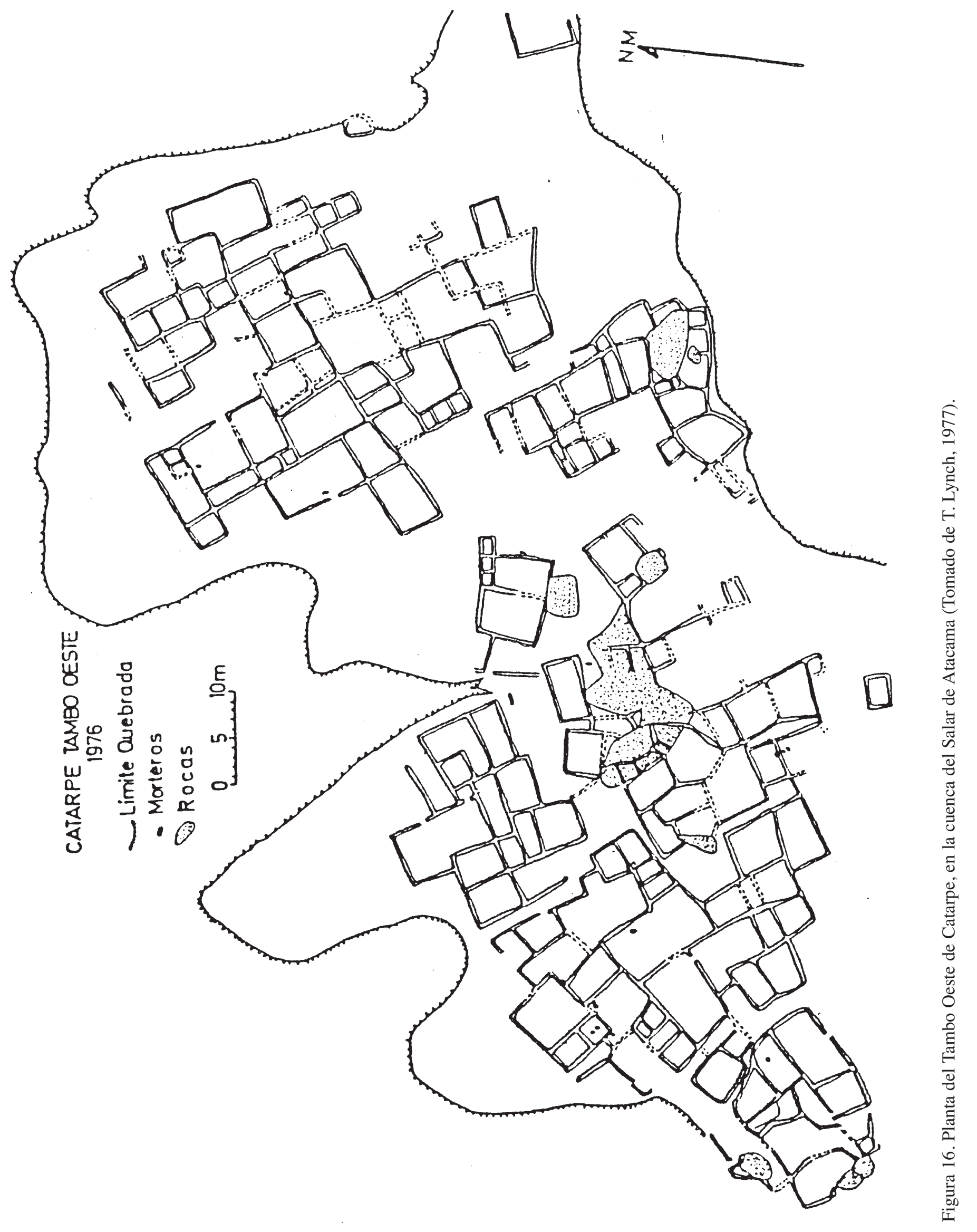


Catarpe resulta ser uno de los centros administrativos incas más importantes del actual territorio chileno, por su extensión y número de recintos, desde el cual se ejerció control político sobre los pucaras locales, sobretodo, el pucara de Quitor que era sin duda el más fortificado y de mejor situación estratégica del área atacameña. Seguramente Catarpe jugó un papel asaz importante en la habilitación de personas en tránsito y de caravanas de llamas. Aquí seguramente, se colectaba la mercadería procedente de la cuenca y después de más al sur, cuando estuvo en uso el camino inca por el Despoblado de Atacama. De acuerdo con ésto, Catarpe habría sido un centro de carguío y reexpedición de tributos hacia el centro del imperio o hacia centros del altiplán bajo dominio inca, tributos tales como metales, piedras semipreciosas (turquesas) y madera, como el algarrobo que tanto abundaba y abunda en el saladar. En fin, desde Catarpe se organizó y planificó la gran aventura para conquistar el Valle de Copiapó y los que le seguían al sur, franqueando el Despoblado de Atacama, aunque según últimas ideas la conquista original no se hizo por esa vía (comunicación personal de John Hyslop).

Al parecer, los incas no modificaron las tradiciones locales en cuanto a artesanías. Los productos artesanales de cánones cuzqueños son mínimos en la cuenca del Salar de Atacama. La cerámica reproduce formas clásicas como el aríbalo, jarritas con una asa oblicua y escudillas ornitomorfas. Les interesaría, sobretodo, la extracción de metales y elaboración ornamentales de turquesas. En relación con este último preciado bien, Hans Ruppert (1984) ha hecho un estudio muy exhaustivo sobre 1,500 muestras de turquesas del mundo prehispánico con el objeto de descubrir su procedencia. Ruppert llega a la conclusión que gran cantidad de las turquesas de Tiahuanaco y del noroeste argentino pueden derivarse de minas del norte de Chile y que el oasis de San Pedro de Atacama fue un centro de manufactura de ornamentos de turquesa por un lapso de 1,550 años. Una buena parte del mineral provenía de las minas de El Salvador, en la actual Región de Atacama. En tiempos del dominio incaico, habría llegado a Catarpe a través del camino del Despoblado de Atacama para su redistribución e intercambio.

También desde Catarpe habrían salido los constructores de la mayoría de las estructuras ligadas al culto de las montañas. Cabe recordar que una buena parte de las cumbres volcánicas que circundan el Salar de Atacoma contenían ruinas arquitectónicas y objetos muebles de tipología incaica. El mejor ejemplo lo brinda el Volcán Licancabur, pero hay muchos más en la puna que las tienen, entre otros el Chiliques, el Pili, el Pular, el Llullaillaco, el Quimal, este último al occidente del Salar de Atacoma.

Se han excavado cementerios del Período Inca en las proximidades de Catarpe. Las tumbas contenían cerámica de patrón inca, pero manufacturada por los artesanos atacameños que convivían con los funcionarios incaicos y servidores del altiplán. También impusieron sobre la lengua kunza, propia de los habitantes de la región, la lengua oficial del imperio, el quechua.

Futuras excavaciones de mayor intensidad en Catarpe podrían reflejar quizás, en alguno de los recintos o en varios, algún taller parecido al que encontró Pedro Krapovickas en la Quebrada Humahuaca, en Tilcara, en 1964 y que ha reinterpretado recientemente (1981-82). Nos referimos a un auténtico taller lapidario donde los artesanos 
locales trabajaban objetos de adorno y de prestigio en materiales preciosos y semipreciosos con modelos impuestos por los incas. Catarpe sería el lugar más apropiado del Norte Grande para encontrarlo.

\section{Tambo de Peine}

Inadvertido para los investigadores de las ruinas que circundan el saladar había pasado el Tambo de Peine, hasta que la expedición conjunta del Instituto de Investigaciones Andinas y de la Universidad de Antofagasta en 1980, en la cual tuvimos la suerte de participar, lo descubrió para la investigación científica (Niemeyer y Rivera 1983).

En efecto, al noroccidente del actual pueblo de Peine, sobre una colina de aluvión situada a unos $50 \mathrm{~m}$ de valle de un poblado colonial abandonado, se encuentra la ruina del Tambo de Peine, a la vera del Camino del Inca. Este camino se muestra al sur de Peine tal cual era, una faja de $3 \mathrm{~m}$ o algo más de ancho, despejado de piedras y felizmente no contaminado ni obliterado por la huella tropera o de vehículos que corren más al occidente. Su altitud es de 2,380 msnm. El tambo se compone fundamentalmente de tres unidades de construciones relacionadas entre sí y alineadas según un eje este-oeste, con una longitud total de $62 \mathrm{~m}$ y una anchura media de 25 $\mathrm{m}$. Todas son de plantas rectangulares configurando tres grandes espacios que llevan alguna división interna. En el interior de la Unidad $\mathrm{C}$ se alza un recinto rectangular de paredes altas bastante bien conservado, de $8 \mathrm{~m}$ de largo por $4.5 \mathrm{~m}$ de ancho, con una albañilería bien trabajada y calzada de sillares de piedras de laja, dispuestas a soga en dos hileras. La sillería lleva una argamasa compuesta de barro, ripio fino y anhidrita. En 1980 se recolectaron alrededor de 100 fragmentos cerámicos de la superficie de este sitio, la mayoría de los cuales se definió como de tipo inca; además, trozos de turquesa y de ónix (Figura 17).

Al sur de Peine, sobre el camino inca que va por el Despoblado de Atacama, siguiendo las aguadas entre la Cordillera de Domeyko al oeste y la cadena de volcanes de la cordillera andina al este, se encuentran varias estructuras mayores.

\section{Meteorito}

En medio de una desolada pampa alta, en la actualidad sin recurso de agua ni de leña, se alza en la cota 3,220 msnm el Tambo del Meteorito, a $43 \mathrm{~km}$ al sur de Peine. También fue descubierto en 1980. Como la de Peine, esta ruina consta de tres unidades vecinas, aunque no contiguas, dispuestas en línea, que comprenden una longitud de $60 \mathrm{~m} \mathrm{La}$ Unidad A, la más al norte, consta de tres cuartos análogos y contiguos de planta rectangular con dimensiones de 3 a $3.5 \mathrm{~m}$ de largo por $2 \mathrm{~m}$ de ancho, con vanos de acceso hacia el camino inca que pasa a su vera. La Unidad B, en el centro, consiste en un espacio rectangular de $12 \mathrm{~m}$ por $7 \mathrm{~m}$. La Unidad C es la más compleja. En el interior de un espacio rectangular con muros en su perímetro, se levantan dos recintos de planta rectangular que conservan muy bien sus muros. Uno de ellos está en situación central e independiente, el otro, ligado al perímetro, conserva un dintel mo- 


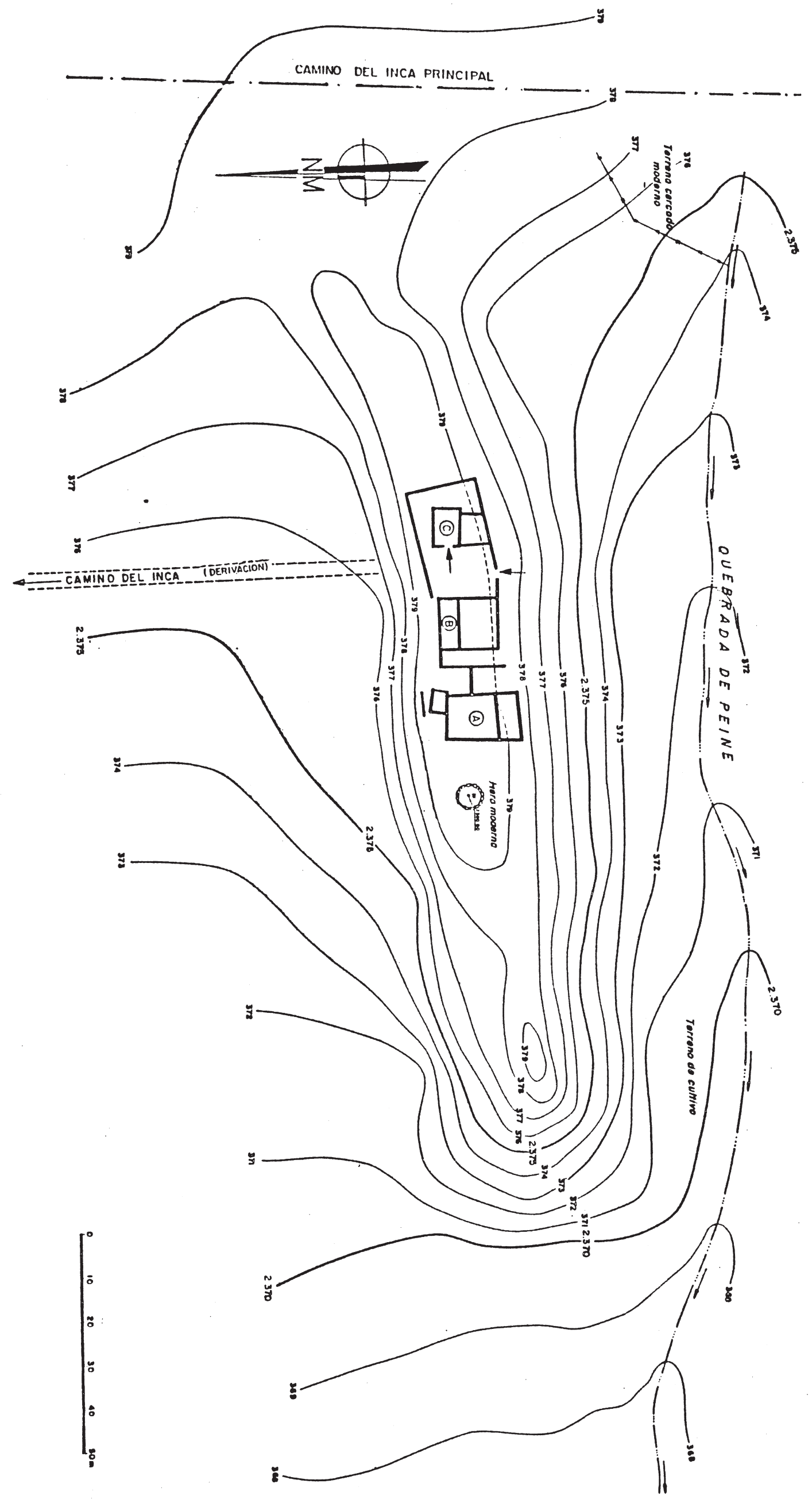




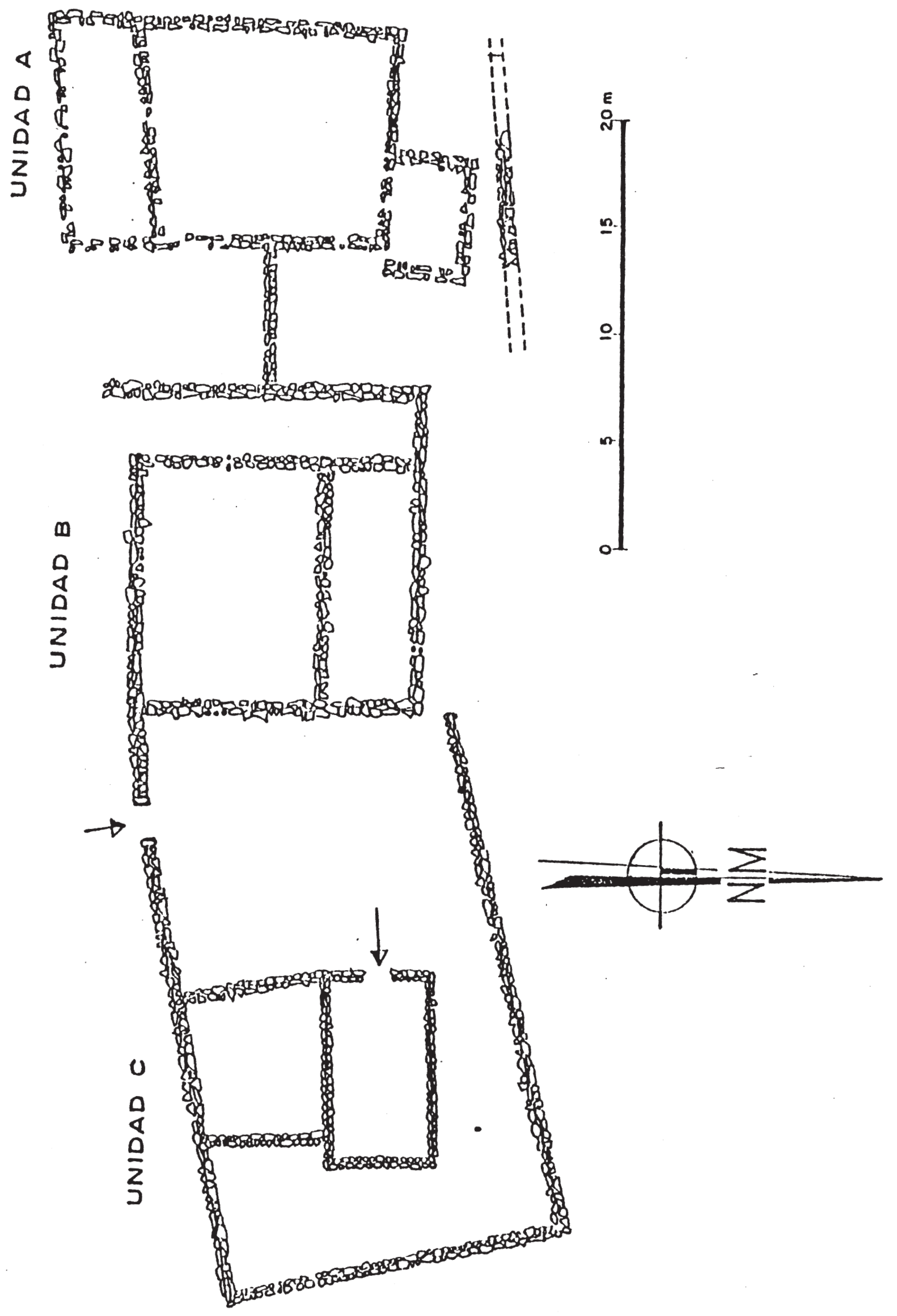


nolítico en su puerta de acceso. Estos vanos son ligeramente trapeciales. Los muros de ambos recintos presentan una albañilería bien acabada y bien trabada, que ha contribuido a la conservación de las estructuras (Figura 18).

\section{Aguada de Puquios}

Una tercera estructura mayor del camino inca al sur de Peine es el Tambo de Aguada de Puquíos. Este es un punto obligado de habilitación, puesto que es el primer lugar con agua potable al sur de Peine. Aquí los incas construyeron un pequeño tambo muy peculiar, repitiendo una planta arquitectónica sencilla, ya usada a orillas del camino, pero que aquí se conserva bastante bien. Se encuentra en el costado este de la Quebrada de Puquíos de la Sierra de Almeida a 3,730 msnm, próxima y aguas abajo de la aguada que da fama al lugar.

La distancia a Peine es de $85 \mathrm{~km}$. Su estructura consta de un volumen de planta rectangular de dimensiones de 2.5 por $2.1 \mathrm{~m}$ que engrana en otra mayor, traslapándose (Figuras 19,20). El recinto menor tiene una puerta de comunicación con el mayor, con un vano de $0.5 \mathrm{~m}$ y umbral monolítico. Este, a su vez, presenta una puerta al espacio exterior, provista de un umbral seguido de una escalinata de tres peldaños. Las dimensiones interiores del recinto principal son de 3.6 por $2.5 \mathrm{~m}$. A este espacio habría que agregar el cuadrado del sector de imbricación de ambos recintos de $1.3 \mathrm{~m}^{2}$. En el recinto principal, en su centro, se encuentra un fogón rectangular delimitado por un brocal de piedra ordenada. Los muros de esta construcción son de piedra en seco, de 0.3 a $0.4 \mathrm{~m}$ de espesor, dispuesta en doble hilera.

Una estructura semejante en planta, aunque menos conservada, se encuentra también a orillas del camino inca a $35 \mathrm{~km}$ al sur de Peine y se ha denominado Tambillo El Cráter en la literatura pertinente (Niemeyer y Rivera 1983).

Al sur de Aguada de Puquios, ya fuera de la hoya hidrográfica del Salar de Atacama, se han identificado otros tambos de estructuras más atípicas, como el de Barrancas Blancas, el de Río Frío, el de Altos de Quebrada Vaquillas, dentro de la Región de Antofagasta (ver Niemeyer y Rivera 1983).

\section{Licacambor}

Hay otros dos tambos que son conocidos en la cuenca del Salar de Atacama, pero desligados del camino inca principal. Uno es el Licancabur o Pueblo de Arriba, situado a 4,600 msnm, en el portezuelo entre el Volcán Licancabur y su vecino al oriente el Juriques y distante $2 \mathrm{~km}$ de la Laguna Verde. Es el principal centro religioso inca en la zona. Ha sido estudiado por varios exploradores, entre ellos Le Paige (19581978), G.Serracino y John Reinhard (1983). La estructura se compone de un gran patio rectangular pircado, de 10 o más metros de largo, rodeado de estructuras circulares y rectangulares menores, contiguas externamente al patio o independientes. Estaría destinado a albergar a la gente que acudía en peregrinaje. La cerámica es abundan- 


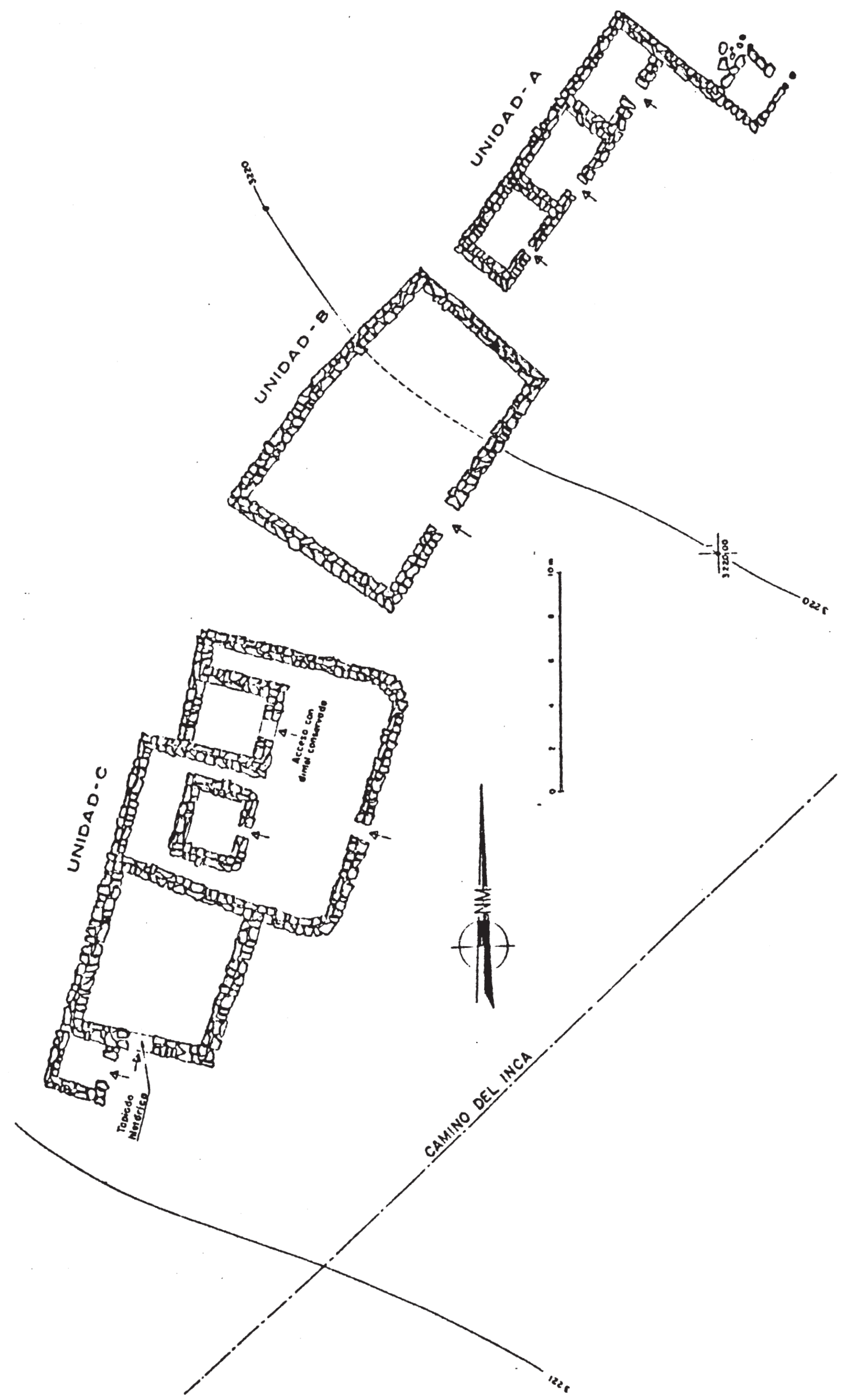



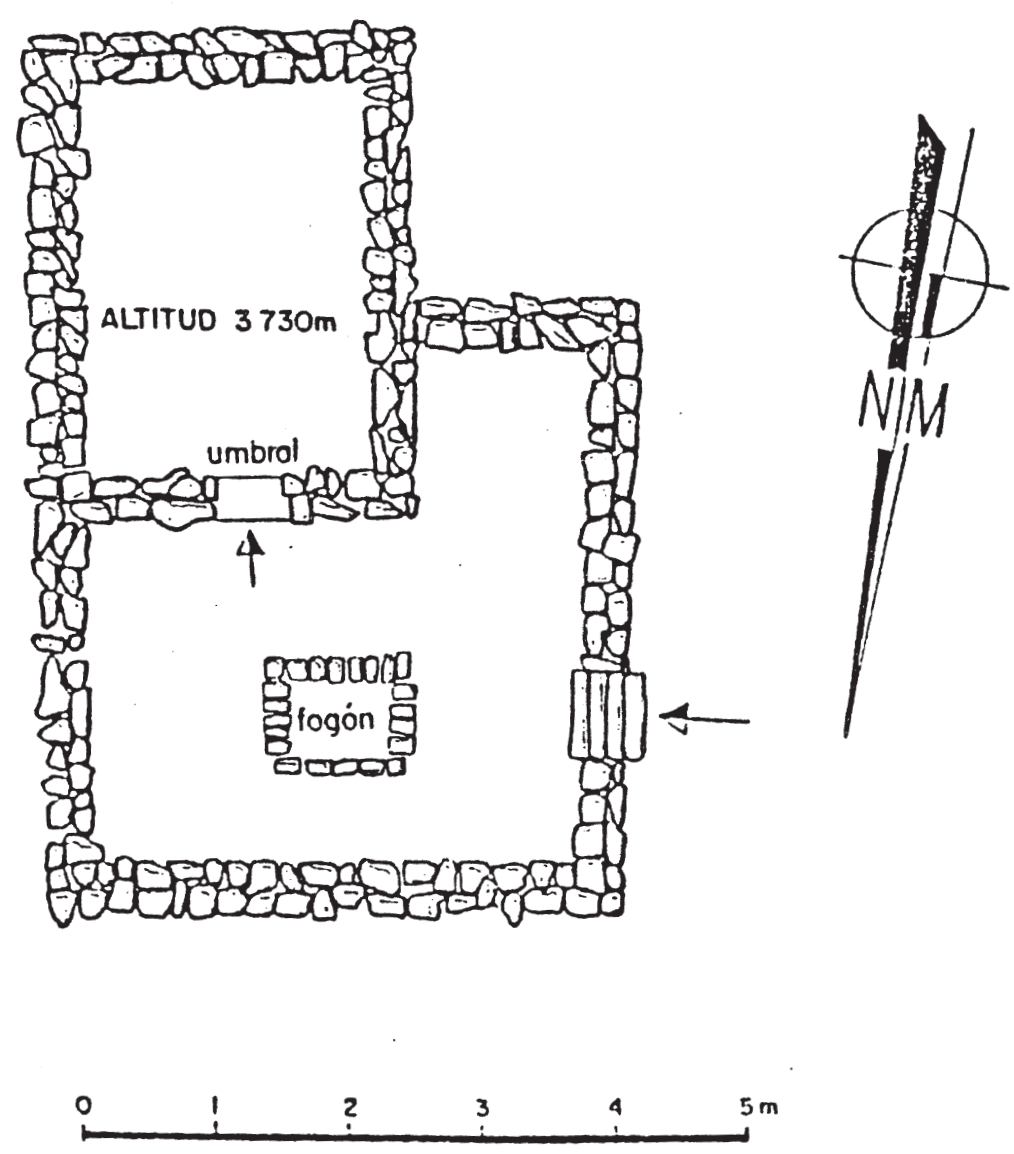

Figura 20.- Tambo Aguada de Puquios, en el despoblado de Atacama, a $85 \mathrm{Km}$ al sur de Peine. Planta. (Tomado de H. Niemeyer y M. Rivera 1983).

te, ya que es necesario llevar agua porque no la hay de calidad aceptable en las cercanías. La cerámica está bien cocida y es homogénea en su pasta, decorada con llamitas o pajaritos; incluye fragmentos de aríbalos y de escudillas planas con asa zoomorfa, o sea, fácilmente identificables como incas.

El camino que conduce desde el tambo a la cumbre del Licancabur está jalonado por otras ruinas, a 4,900 y a 5,800 msnm. En el cráter mismo, a 5,921 msnm, hay tres recintos pircados, uno central semicircular y uno cuadrado de cada lado.

\section{Salin}

El otro tambo es el de Salin, en la falda del Volcán Salin, situado entre dos volcanes mayores, el Pular por el norte y el Socompa por el sur. Sabemos de él por referencia del guía Estanislao Ramos, quien nos condujo en 1980 y 1981 por el camino inca al sur de Peine. Estaría localizado a unos 4,000 $\mathrm{msnm}$ en un paso de la cordillera que seguiría un camino al que se refiere Le Paige (1958). 


\section{REFLEXIONES SOBRE LA OCUPACION INCAICA DE LA CUENCA DEL SALAR DE ATACAMA}

Le Paige (1957-8) expresa varias afirmaciones muy positivas con respecto al dominio incaico en la cuenca de Atacama. Durante su larga permanencia en la zona, pudo captar que entre la gente existe un respeto y admiración legendarios por los incas.

En realidad el inca fue un realizador inteligente y práctico; al llegar estableció sus centros de influencia: Catarpe centro administrativo y militar; Licancabur, centro religioso....

A pesar de haber sido un conquistador como el español, el Inca ha dejado tras de él una huella profunda, una leyenda dorada, un recuerdo encantador, la idea de un liberador, en contraste con su sucesor el español. Esto es el resultado de dos cosas: $1^{\circ}$ una política de conquista totalmente diferente de la española; $2^{\circ}$ haber sido el organizador de la resistencia atacameña al llegar los españoles....

El Inca trató de conquistar a los atacameños en dos ocasiones. La primera fue derrotado y cuando en la segunda expedición logró su objetivo, se dedicó a organizar el país y a la llegada de los españoles se puso a la cabeza de los atacameños para defender su nuevo patrimonio....

Desde 1475 hasta 1540, tiempo muy corto para implantar una nueva cultura, el Inca logra un éxito tan grande que deja la impresión de una edad de oro. La individualidad del atacameño fue reemplazada por la maravillosa centralización inca tan conocida. Esto se manifestó en Atacama, no por una nueva red de caminos ya que éstos existían, sino por un perfeccionamiento y una orientación centralista. En esa época se levantaron los tambos y tambillos o posadas del correo. (Le Paige 1957-8).

Creemos que la interpretación dada por Le Paige a la ocupación incaica de la cuenca es acertada y ese dominio no tuvo influencia trascendente entre los pueblos atacameños a orillas del saladar. Aparentemente, intensificó costumbres y creencias preexistentes, sobretodo en lo que se refiere al culto a las montañas, fomentando nuevos centros religiosos de altura como una manera de dar unidad al imperio. 


\section{BIBLIOGRAFÍA}

Bibar, Geronimo de

[1558] Crónica y relación copiosa y verdadera de los Reinos de Chile. MDVIII. Fondo Histórico y Bibliográfico José T. Medina. Santiago.

Cuneo-Vidal, Rómulo

1914 El Collosuyo de los incas. Revista Chilena de Historia y Geografía. (13):179-192.

Garcilazo De La Vega

1967 Comentarios reales de los incas. Colección de autores peruanos. Editorial Universo. Lima.

Hidalgo, Jorge

1978 Revista a los Altos de Arica en 1950 por don Joaquín de Cárdenas. Universidad del Norte, Arica. Chile.

Julien, Catherine S.

1978 Inca Administration in the Titicaca Basin as Reflected at the Provincial Capital of Hatun Colla. Tesis doctoral. University of California, Berkeley. University Microfilms International, Ann Arbor, Michigan. Estados Unidos.

Keller, Carlos

1946 El Departamento de Arica. Ed. Zig Zag. Santiago.

Krapovickas, Pedro

1981-82 Hallazgos incaicos en Tilcara y Yacoraite (una reinterpretación). Relaciones de la Sociedad Argentina de Antropología. 14(2):67-80. Buenos Aires.

Le Paige, Gustavo

1958 Antiguas culturas atacameñas en la cordillera chilena. Anales de la Universidad Católica de Valparaíso. 4-5:150-144.

1978 Vestigios arqueológicos incaicos en las cumbres de la zona atacameña. Estudios Atacameños (6):36-52. Universidad del Norte, Museo de Arqueología, San Pedro de Atacama, Chile.

Lynch, Thomas

1977 Tambo incaico Catarpe-Este (Informe de avance). Estudios Atacameños 5:142-147. Universidad del Norte, Museo de Arqueología. San Pedro de Atacama, Chile.

Llagostera M., Agustín

1976 Hipótesis sobre la expansión incaica en la vertiente occidental de los Andes Meridionales. Homenaje al Dr. Gustavo Le Paige. pp. 203-218. Universidad del Norte. Chile. 
Mostny, Grete

1948 Ciudades atacameñas. Boletín del Museo Nacional de Historia Natural. 24:125-211. Santiago.

Niemeyer F., Hans

1962 Tambo incaico en el valle de Collacagus (Provincia de Tarapacá). Revista Universitaria. 25:127-149. Santiago.

1963 Excavación de un cementerio incaico en la Hacienda Camarones (Provincia de Tarapacá). Revista Universitaria. 26:207-233.

1971 Padrones de poblamiento en la Quebrada de Camarones (Provincia de Tarapacá). Estudio preliminar que comprende el Sector Medio y Superior del valle. Acta del VI Congreso de Arqueología Chilena (1971). Universidad de Chile. Santiago.

Niemeyer, H. y V. Schiappacasse

1981 Aportes al conocimiento del Período Tardío del Extremo Norte de Chile: Análisis del Sector Hunancarane del valle de Camarones. Chungará 7. Universidad del Norte, Departamento de Antropología, Arica, Chile.

Niemeyer F., Hans y Mario Rivera D.

1983 El camino del inca en el Despoblado de Atacama. Prehistoria de Chile 9. Departamento de Sociología y Antropología de la Universidad de Chile, Santiago.

Niemeyer F., Hans y Pilar Cereceda

1984 Hidrografía, Geografía de Chile. Tomo VIII . Instituto Geográfico Militar. Santiago.

Reinhard, Johan

1983 Las montañas sagradas: Un estudio etnoarqueológico de ruinas en las altas cumbres andinas. Cuadernos de Historia 3:27-62. Santiago.

Rex González, Alberto

1967 Patrones de asentamiento incaico en una provincia marginal del Imperio. Relaciones de la Sociedad Argentina de Antropología 19(1):63-83. Buenos Aires.

Rowe, John H.

1944 An Introduction to the Archaeology of Cuzco. 27(2). Papers of the Peabody Museum of American Archaeology and Ethnology. Harvard University. Cambridge, MA, EU.

Ruppert, Hans

1984 Zür Verbreitung und Herkunft von Türkis und Sodalith in prakolumbischen Kulturen der Kordilleren. Baessler-Archiv NF. 30:69-124. Alemania Federal. Traducción de Hans Bergholz. 
Ryden, Stig

1947 Archaeological Researches in the Highland of Bolivia. Goeteborg, Suecia.

Tschopik, Marion H.

1946 Some Notes on the Archaeology of the Department of Puno. Papers of the Peabody Museum of American Archaeology and Ethnology. 27.3. Harvard University, Cambridge, Massachússets, Estados Unidos.

Vásquez de Espinosa, Antonio

1948 Compendio y descripción de las Indias Occidentales. Smithsonian Miscellaneous Collections. Tomo 108. Washington, DC 


\title{
RED VIAL INCAICA EN LOS TERMINOS MERIDIONALES DEL IMPERIO: TRAMO VALLE DEL LIMARI-VALLE DEL MAIPO
}

\author{
Rubén Stenberg \\ Nazareno Carvajal
}

\section{INTRODUCCION}

A poco más de un año de haber reiniciado nuestras exploraciones en el Camino del Inca en la zona del Norte Chico Chileno, elaboramos este informe en el cual profundizamos sobre los antecedentes que nos condujeron a realizar estas investigaciones y sobre los significativos resultados que han emergido de ellas.

La extensión alcanzada por el imperio inca entre los siglos XIV y XVI de nuestra era, desde la frontera sur de Colombia al centro de Chile, comprendiendo los actuales países de Perú, Ecuador y partes de Argentina, Bolivia y Chile fue posible gracias a la construcción del largo camino imperial; por sus vías principales, sus arterias y ramales, circuló la energía necesaria para la consolidación del estado, constituyéndose en la columna vertebral del imperio.

El éxito alcanzado por los incas en gran medida radicó en su capacidad para resolver los problemas que a la sazón agobiaban a los reinos andinos: la necesidad de proveerse de recursos sustitutivos y complementarios en pisos ecológicos ajenos al propio y la existencia de una situación de conflicto entre las etnias, posiblemente provocada por lo primero; tal situación, mantenía a gran parte de la población habitando reductos fortificados de cumbre y en estado de guerra permanente. Los incas resolvieron estos problemas organizando, al amparo de un poderoso ejército, un sistema de traslado de bienes y servicios de un piso ecológico a otro, trayendo paz y bienestar al área. A cambio de estos servicios, solicitaron una retribución en energía humana (mita) para labores de cultivo y pastoreo en terrenos estatales destinados al mantenimiento de la élite gobernante, funcionarios, templo y camino real.

A lo largo de los principales territorios incorporados, en sentido longitudinal, los incas construyeron dos vías o arterias principales que se hallaban unidas transversalmente por numerosos ramales, algunos de los cuales conducían hacia santuarios de altura y que en conjunto llegaron a tener una red vial de más de 20.000 kilómetros construídos, debidamente protegidos y señalizados; estos caminos estaban dotados de posadas, albergues, puentes, escalinatas, señales indicadoras y un eficiente sistema de postas con chasquis mensajeros, todo lo cual contribuía a hacer más expedito su tráfico y facilitaba las comunicaciones del estado. A través de la ruta principal el tránsito estaba reservado exclusivamente para el ejército, funcionarios y bienes del imperio. 
La irrupción de los conquistadores españoles en el Perú a comienzos del siglo XVI y su establecimiento en el Cuzco provocó el rápido desmoronamiento del imperio incaico. Previo a la llegada de éstos, se había originado una disputa por la sucesión del poder entre los hermanos Huáscar y Atahualpa, hecho que fue aprovechado con habilidad por los españoles quienes profundizaron el conflicto civil existente entre los hermanos, concluyendo con la muerte de Huáscar y el presidio de Atahualpa. Los ejércitos del Inca y los funcionarios del estado convergieron en el Cuzco y reconocieron a los nuevos gobernantes, poniendo fin a la breve pero intensa historia de expansión y conquista del reino Quechua de los Hijos del Sol.

El territorio de los incas se hallaba dividido en cuatro partes, definidas por los puntos cardinales, que se comunicaban con la capital por medio de los caminos que cada uno había construído. Hacia el Killasuyo o los territorios del sur iban dos arterias principales: uno de estos caminos recorría el altiplano Boliviano y la puna Argentina internándose por los valles orientales del macizo andino que corren en sentido longitudinal, en paralelo a la cordillera, llegando hasta la altura de la actual ciudad de Uspallata, y el otro, salía del Cuzco hasta el altiplano chileno recorriendo los desiertos y salares nortinos y llegaba hacia el llano central, después de sortear numerosas dificultades provocada por la accidentada geografía de los valles transversales, comprendidos en la zona del "Norte Chico" del país.

Hasta la fecha, el trazado del Camino del Inca en territorio chileno solo había sido establecido con precisión a través del altiplano y desierto del norte hasta el valle del Río Copiapó $\left(27^{\circ} 20^{\prime} \mathrm{S}-71^{\circ} 24^{\prime} \mathrm{W}\right)$. A partir de éste no había certeza sobre su continuación hacia el extremo meridional, existiendo una serie de antecedentes, hipótesis e investigaciones parciales que sugerían tres posibilidades: 1) su desvío hacia el lado Argentino, 2) la existencia de un solo camino costero ó 3) su bifurcación en dos vías paralelas una de las cuales iba por la montaña y la otra próxima al mar.

El objetivo de nuestra investigación y expediciones tuvo como fin determinar el trazado del Camino del Inca en una parte significativa de esta área tomando como punto de partida el Pucará de Chena, fortificación de altura más austral establecida por el imperio inca a orillas del Río Maipo. A partir de éste, reconocimos minuciosamente todas las rutas posibles entre el valle del Maipo y el Río Limarí, con énfasis en la zona comprendida entre Río Choapa y el Río Limarí, obteniendo resultados y conclusiones que contribuyen de manera importante al conocimiento de la historia prehispánica y de los pueblos aborígenes de Chile.

\section{ANTECEDENTES}

A continuación se proporcionan los principales antecedentes tenidos en cuenta sobre las rutas de penetración incaicas al centro de Chile, las que fueron extraídas a partir de la bibliografía disponible y de nuestra propia experiencia. Estas ideas las hemos organizado en orden cronológico y con relación a ciertas posturas sostenidas sobre el camino y su trayectoria. 


\section{Doble ruta al sur de Copiapó}

El primer cronista español del Reino de Chile fue Gerónimo de Bibar quien, al referirse al avance de la expedición conquistadora española de Pedro de Valdivia (1540) en su camino desde el valle de Copiapó hacia el valle del Río Huasco más al sur, señaló que el General mandó que "el maese de campo fuese por un camino que es por las cabezadas de los valles y el otro caudillo por lo llano por la costa de la mar" (Bibar 1966:28).

Recientemente Ampuero (1935) sugirió la existencia de dos caminos paralelos entre Conderiaco $\left(29^{\circ} 48^{\prime} \mathrm{S}-70^{\circ} 50^{\prime} \mathrm{W}\right)$ y el Río Hurtado $\left(30^{\circ} 25^{\prime} \mathrm{S}-71^{\circ} 00^{\prime} \mathrm{W}\right)$.

Más al sur, desde el valle del Choapa hasta el Río Maipo, en el extremo meridional del Kollasuyo, esta situación de caminos paralelos vuelve a encontrarse. En expediciones anteriores realizadas por nosotros, hemos descubierto un importante tramo del Camino del Inca, en sectores de precordillera andina a unos 2,000 msnm y la presencia de dos tambos en Conchuca y Alicahue (Stehberg, Carvajal y Seguel 1985). Recientemente, Rivera y Hyslop (1984) han descubierto un importante tramo del camino entre el valle de Aconcagua y Santiago en lo que representaría la continuación de este camino hasta el Río Mapocho.

En paralelo y por el interior de los valles de la Cordillera de la Costa chilena, a unos $30 \mathrm{~km}$ del mar, conocíamos una ruta que corre desde el valle del Choapa pasando por el pueblito de Caimanes, La Ligua, Chilicauquén hasta Quillota y nos motivaba la necesidad de obtener mayores antecedentes sobre el probable paso por ésta de Diego Calvo de Barrientos en 1534 y luego el de la expedición de Diego de Almagro en 1536.

Los nombres de los pueblos y localidades y la tradición oral recordaba la presencia de los incas, pero nos llamaba la atención la ausencia de vestigios arqueológicos. Pensabamos que el Camino del Inca Costero posiblemente había utilizado una ruta nativa local de antigua data, introduciendo en ella solo mínimas modificaciones y ésta era una hipótesis importante que queríamos confirmar. Por su parte, Manuel Magallanes (1912:15) sin aportar ningún tipo de prueba, señalaba que "El Camino del Inca de la costa llegaba al pueblo de Coquimbo y de aquí a Tongoy, Quilimarí, La Ligua, Quillota, La Dormida y en Colina, se unía al camino que venía de Chacabuco". En cambio, el Camino del Inca o del Choapa venía de "Paitanas a Combarbalá, Illapel, Putaendo Quilpué (de Aconcagua), Curimón y de aquí, por Chacabuco a Colina". (Magallanes 1912:33). En otra parte de su obra el autor agregaba que habría otro camino que podría llamarse Andino "que va siempre por los altos valles de la cordillera siguiendo quebradas longitudinales y a un altura no inferior a 2,000 m.s.n.m. sobre el nivel del mar... Este camino viene de Huasco Alto, pasa al interior de la ciudad de Vicuña y sigue al Hurtado y antiguos pueblos de Caren hasta Choapa Alto, para ir por Alicahue al valle de Aconcagua" (Magallanes 1912:22).

Y finalmente, lo que decía el historiador Carlos Keller (1959) sobre el Camino del Inca en la costa: que salía éste hacia el sur de Quillota, curso inferior del valle 
Aconcagua, por el Portezuelo de San Pedro y Limache, Marga Marga, Talagante y de la Angostura de Paine a la frontera de los Mapuches.

\section{Penetración vía trasandina}

La hipótesis de que la conquista de Chile Central se realizó a través de la Cordillera de Los Andes por los pasos cordilleranos de Valle Hermoso (32 $22^{\prime} \mathrm{LS} 70^{\circ}$ $\left.15^{\prime} \mathrm{LW}\right)$ y Uspallata-Caracoles $\left(32^{\circ} 50^{\prime} \mathrm{LS} 70^{\circ} 06^{\prime} \mathrm{LW}\right)$ es de antigua data. Miguel de Olavarría, historiador del siglo XVII (cit. por Medina 1882:328), al referirse a la conquista de Chile señaló que los incas "hicieron su entrada por la gobernación de Tucumán i acometieron a pasar la cordillera nevada por el mismo camino que usan los españoles desde Mendoza i San Juan a la ciudad de Santiago, según hoi se vé i yo lo he visto por las ruinas", agregando que la razón de tan grande rodeo fue el evitar cruzar el despoblado de Atacama el enorme ejército que llevaban. El erudito historiador José Toribio Medina (1882:328) recogiendo la opinión de los cronistas Diego de Rosales, Pérez García y el mismo Miguel de Olavarría concluye: "según todas las probabilidades, los incas llegaron a Chile por dos caminos, el del despoblado i el de la cordillera, que atravesaron para salir directamente al valle de Aconcagua".

La influyente opinión de Medina retrasó la búsqueda del camino incaico en el Norte Chico por casi un siglo, pero finalmente se acumuló suficiente evidencia como para descartar que esta vía, sugerida por él, fuera la única utilizada. El abandono final de esta hipótesis fue decidido por los participantes de la Mesa Redonda "Hipótesis sobre las causas de la presencia incaica en los Andes Meridionales" celebrada en el VII Congreso Nacional de Arqueología Argentina (San Luis, Noviembre 1982), concluyéndose que si bien dicha ruta fue utilizada intensamente en la época, quedaba cerrada cada invierno por las condiciones climáticas. Asimismo, la presencia de restos arqueológicos Diaguitas del Norte Chico Chileno entre el material inca-local de Aconcagua y Maipo claramente sugiere la existencia de uno o más caminos alternativos por el lado chileno.

No obstante, considerando la opinión de J. T. Medina (1882) sobre los pasos cordilleranos la necesidad de contacto trasandino y la práctica ritual incaica que los llevaba a construir caminos hacia sus santuarios de altura, pensabamos que se justificaba la existencia de otros pasos de cordillera. Actualmente esta opinión es sustentada por H. Schobinger (45 Congreso Internacional de Americanistas, Julio 1985, Bogotá, Colombia).

\section{Un camino andino}

La posibilidad de que los incas hubieran utilizado una sola vía de penetración hacia el centro del país, desde Copiapó hasta Santiago o Talca por el sur, está sugerida en los mapas de la mayoría de los investigadores contemporáneos que se han preocupado de la vialidad imperial en Chile (von Hagen 1958; Strube 1963 y Raffino 1981). 


\section{Nuestra hipótesis de trabajo}

Sobre la base de los antecedentes históricos y contemporáneos disponibles nosotros postulamos inicialmente la existencia al sur de Copiapó de dos caminos del inca que corrieron paralelos y en sentido longitudinal por la vertiente occidental de los Andes Meridionales hasta el Río Maipo por el sur. El primero de ellos, que designamos "Camino Inca Andino", se iniciaba en Copiapó y continuaba por las nacientes andinas de los Ríos Huasco, Elqui, Limarí, Choapa, Alicahue y cursos medios de los valles de Aconcagua y Maipo-Mapocho. Los argumentos más fuertes en favor de esta hipótesis lo proporcionaron por una parte, la temprana referencia de Bibar (1966) a un camino indígena por las cabezadas de los valles de Copiapó y Huasco, que utilizó parte de la expedición de Pedro de Valdivia en 1540. Y por otra parte, nuestros propios hallazgos del camino incaico en las cordilleras de Alicahue y el Sobrante en el año 1983 y las descripciones de su continuación entre Curimón y Mapocho por Rivera y Hyslop (1984).

El segundo camino que denominamos "Camino Inca Costero", sosteníamos que tenía idéntico origen en Copiapó y bajaba lentamente hacia el litoral pasando por Vallenar, en el Río Huasco, hasta llegar a Altovasol y Coquimbo en el curso inferior del Río Elqui. Proseguía por el interior de la Cordillera de la Costa pasando por Limarí, Cuzcuz (Illapel), La Ligua, Quillota y Talagante. Vendría en apoyo de esta hipótesis la referencia de Bibar (1966) en el sentido de que la otra parte de la expedición de Pedro de Valdivia se había dirigido hacia el sur de Copiapó por un camino indígena costero y asimismo las referencias históricas del paso de los primeros españoles por las localidades costeras antes señaladas.

La utilización que ellos habían hecho de los caminos incaicos sugería la existencia de esta ruta costera pese a que se carecía de evidencias arqueológicas sobre el particular.

Los trabajos de verificación de hipótesis se concretaron en esta etapa al territorio comprendido entre los valles de Limarí por el norte y Maipo por el sur, dejando el tramo comprendido entre el primero y el valle de Copiapó para futuros estudios. Los trabajos de búsqueda de antecedentes empíricos y confirmación de hipótesis se elaboraron a base de una metodología específica que se detalla a continuación.

\section{MATERIALES Y METODOS}

La metodología contempló fundamentalmente tres sistemas de información que se sucedieron y alternaron consecutivamente y que permitieron ir avanzando progresivamente en el reconocimiento del Camino del Inca. Las predicciones de los dos primeros fueron puestas a prueba mediante la contrastación empírica en el terreno.

Información oral. A través de las entrevistas a informantes claves, profesores de historia, anticuarios, viejos campesinos y/o arrieros en cada localidad, se recogió información en torno a la existencia de antiguos senderos y/o topónimos quechuas (por 
ejemplo Tambillos). En algunos lugares la tradición oral conservaba el recuerdo del paso de los incas o la existencia de restos de su camino por determinado sector.

Interpretación de imagen de satélite y cartas geográficas. La data anterior fue analizada a la luz de la información proporcionada por la imagen de satélite Landsat, la cual por su visión sinóptica (180x180 km cada 18 días) y su gran periocidad ofreció una gran ayuda para prospectar la presencia de la vegetación y agua en las rutas probables establecidas en la etapa 1. Estos elementos, especialmente la existencia de pequeños cuerpos de agua, lagunas y vegas se encuentran presentes en la mayor parte de la ruta incaica y en la imagen Landsat presentan niveles de emisión de energía muy particulares que facilitan su identificación y localización en una carta topográfica de detalle.

Esto, unido a los antecedentes cartográficos existentes permitió predecir la ruta más probable seguida por los incas e incluso sugerir la posible localización de los respectivos tambos.

La forma de operar de esta etapa fue la siguiente: los datos entregados por los informantes se identificaron y localizaron en las cartas topográficas de manera tal que se pudo obtener su distribución espacial. En seguida se superpuso esta situación con la imagen del satélite y se analizó su correlación con la existencia de portezuelos, agua y vegetación. Ello, unido a los conocimientos tradicionales de las trayectorias seguidas por los caminos incaicos conformaron un panorama de posibilidades que incluyeron la localización tentativa de tambos; con esta información se retornó a la carta topográfica proponiendo una ruta que se analizó en el terreno mismo.

\section{Reconocimientos y prospección}

Se procedió a reconocer en terreno la ruta elegida, localizando con precisión su trazado en la carta geográfica 1:50,000 del Instituto Geográfico Militar y recogiendo evidencias que pudieron confirmar su adscripción incaica.

Cabe destacar que en estas expediciones fue imprescindible hacerse acompañar de un informante clave, dado que era muy fácil confundir la información que portábamos con la localización exacta de la evidencia buscada. Esta etapa fue la que permitió confirmar la existencia de tres tambos y una significativa cantidad en kilómetros de senderos con indiscutibles rasgos de adscripción incaica.

\section{LAS EXPEDICIONES REALIZADAS}

\section{Expedición $\mathbf{N}^{0} 1$}

Tuvo por objetivo reconocer las rutas incaicas costera y andina entre los Ríos Aconcagua por el sur y Choapa por el norte. Se prospectó con detención Quillota, Cuesta Vieja de Chilicauquén, Nogales, La Ligua, Río Longotoma y Caimanes. 


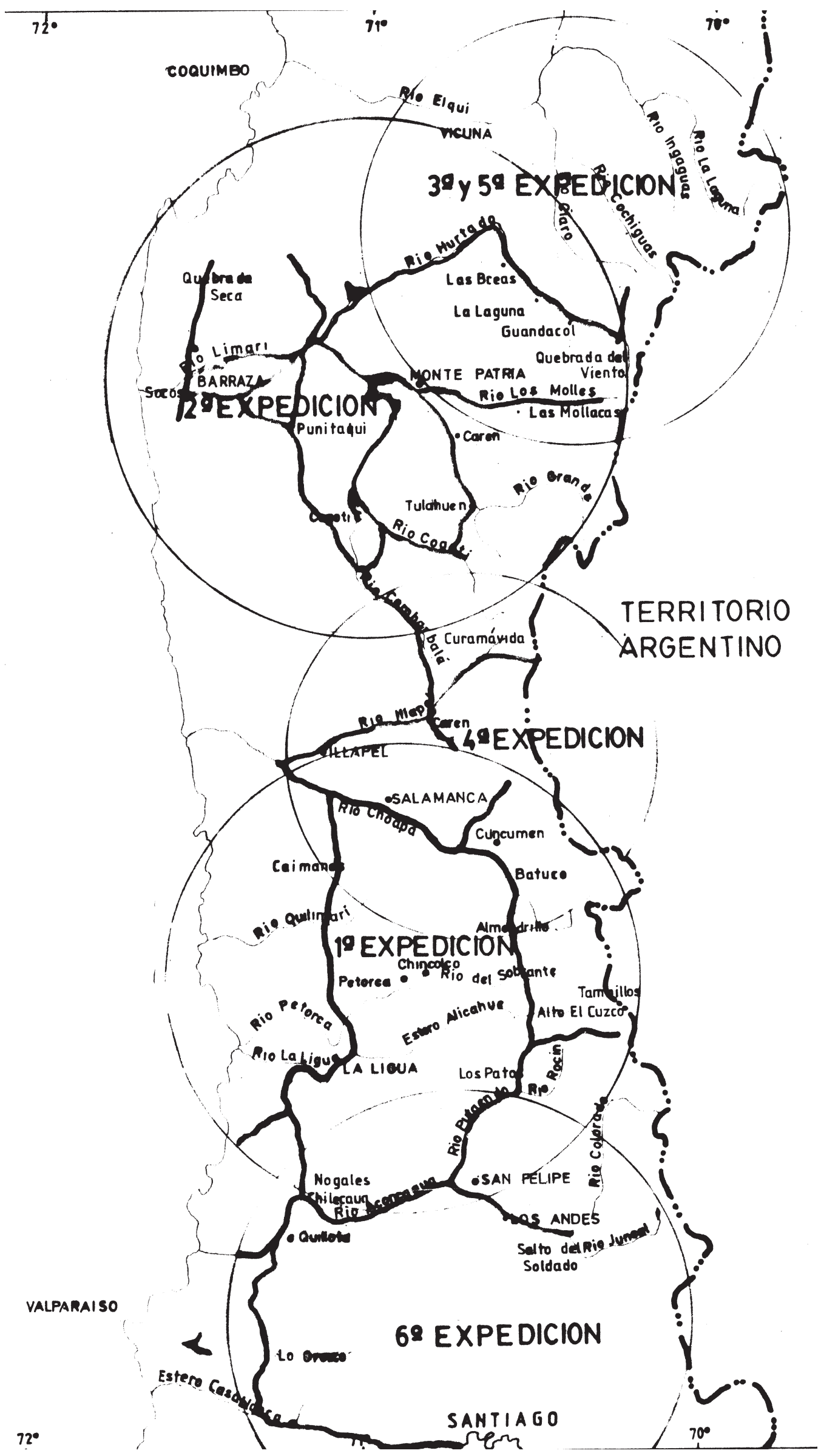

Figura 1. Mapa de las expediciones realizadas. 
La prospección del sector andino tuvo por objetivo específico continuar los descubrimientos del Camino del Inca Andino al norte del Portezuelo Las Mesas, último punto que se llegó a reconocer en etapas previas de trabajo. Se prospectó el estero El Chacay y el estero del Valle, en el curso superior del Río Choapa desde potrero El Chacay, pasando por Cuncumén, Batuco, Almendrillo, Laguna Conchuca hasta Portezuelo Las Mesas.

\section{Expedición $\mathbf{N}^{0} 2$}

Tuvo por fin obtener información de la continuación de las rutas incaicas costera y andina entre el Río Choapa y el Río Limarí. Para ello se realizaron dos recorridos. El primero, consistió de un circuito costa-cordillera e incluyó las localidades de Socos, Zorrillas, Barraza, Ovalle, Ramada de Punitaqui, Combarbalá, Rincón de Las Chilcas, Cogotí, Tulahuén.

El segundo recorrido contemplo el reconocimiento del curso superior del Río Chalinga, afluente norte del Río Illapel. Se visitaron los sectores de Las Tolas y La Palmilla.

\section{Expedición $\mathbf{N}^{\circ} 3$}

Tuvo por objetivos estudiar la existencia del Camino Inca Andino por las cordilleras de Río Los Molles y Hurtado en el curso superior del Río Limarí.

\section{Expedición $\mathbf{N}^{\circ} 4$}

Su finalidad fue el reconocimiento del Camino Inca Andino en las cordilleras de Chalinga e Illapel, afluente norte del Río Choapa. La expedición cubrió los siguientes tres sectores. El primero, la falda occidental de la Cordillera de Fredes, al pie del cerro Curamávida entre Calabozo y nacientes de Valle Hermoso. El segundo consistió en una nueva visita a la precordillera de Valle Hermoso, Combarbalá y Cogotí. El tercero, consistió en una visita a caballo a la cordillera de Chalinga.

\section{Expedición $\mathbf{N}^{\circ} 5$ y 6}

Se materializaron a través de 3 salidas diferentes y tuvieron por objetivo reconocer sectores anteriormente no estudiados y resolver problemas pendientes de las expediciones anteriores.

En la primera se regresó al curso superior del Río Hurtado a fin de completar los estudios realizados en dicho ramal incaico trasandino y visitar algunas ruinas. La segunda salida cubrió $80 \mathrm{~km}$ de la cordillera de Los Patos, en el curso superior del Río Putaendo. Se orientó a confirmar la existencia del ramal incaico trasandino de La Ligua, Alto El Cuzco, Quebrada Tambillos y Valle Hermoso. La tercera salida con- 
sistió en un circuito costa-cordillera en el valle Maipo y Aconcagua. Tuvo por objetivo estudiar la ruta incaica costera sugerida por Carlos Keller (1959) entre Talagante por el sur y Quillota por el norte. Además, verificar la existencia de un tambo en el sector cordillerano de Salto El Soldado.

\section{RED VIAL INCAICA}

Se iniciaba en las inmediaciones de Angostura de Paine por el sur $\left(33^{\circ} 51^{\prime} \mathrm{S}-70^{\circ}\right.$ 46'W) y se extendía por los llanos del curso medio del Río Maipo y Río Mapocho. Sus vestigios arqueológicos han desaparecido como consecuencia del proceso de expansión urbana y agrícola de la metrópoli de Santiago. Empero, algunos antecedentes etnohistóricos han señalado puntos por los que atravesó este camino; uno de ellos, corresponde al puente para cruzar el Río Maipo que los incas construyeron en el sector de Los Morros (Bibar 1966). Esta localidad está situada a pocos kilómetros al oriente de la fortaleza de Chena, el vestigio arquitectónico más austral del Imperio en el Kollasuyo. En Pirque, localidad situada poco más al sur donde estuvo el puente, se ha mencionado la existencia de un tambo (Cabeza y Tudela 1985); hasta el momento no se ha establecido su adscripción al imperio. Desde el centro de Santiago hacia el norte se ha determinado que el Camino del Inca siguió igual trazado que la actual Avenida Independencia, luego cruzaba el Portezuelo Huechuraba, Colina La Vieja y la Cuesta de Chacabuco hasta alcanzar el curso medio del Río Aconcagua (Rivera y Hyslop 1984), donde se unía al ramal incaico trasandino de Caracoles-Uspallata. A partir de dicho punto se carece de antecedentes por espacio de $50 \mathrm{~km}$ del camino hasta Alicahue Adentro. En este sector, el camino cruza el Portezuelo Panteón de los Indios a 2,500 msnm y sigue una trayectoria levemente curva hacia el poniente por el acarreo de falda del cerro Lingue perdiendo altura en forma pronunciada hasta llegar a Cambillos, en la segunda terraza del estero Alicahue, donde emplazaron un tambo.

Desde el tambo Alicahue hacia el norte el camino se desarrolla sobre la falda oriente del cerro Maiten, ganando altura hacia Paso El Inca a 2,400 msnm y, desde allí, el camino desciende rápidamente para cruzar el estero El Sobrante y prosigue por una zona de quebradas y vegas hasta Portezuelo Las Mesas (Stehberg y Carvajal 1985). Desde Alicahue Adentro hacia el norte el trazado del camino incaico aprovechó la falla geológica de Polcura que se caracteriza por poseer una dirección norte sur bien definida. A partir del Portezuelo Las Mesas, sector de unos 2,500 msnm, esta falla adopta la forma de un cajón cordillerano, dando nacimiento al estero del Valle, afluente sur del Río Choapa. Los reconocimientos de terreno mostraron que el camino incaico bajaba por la ladera oriental del cerro Las Mesas, desarrollándose en su mayor parte por lomajes suaves hasta llegar a las nacientes del estero del Valle, donde bordeaba una hermosa vega tras la cual llegaba a la laguna Conchuca, lugar donde los incas edificaron una posada (tambo). 


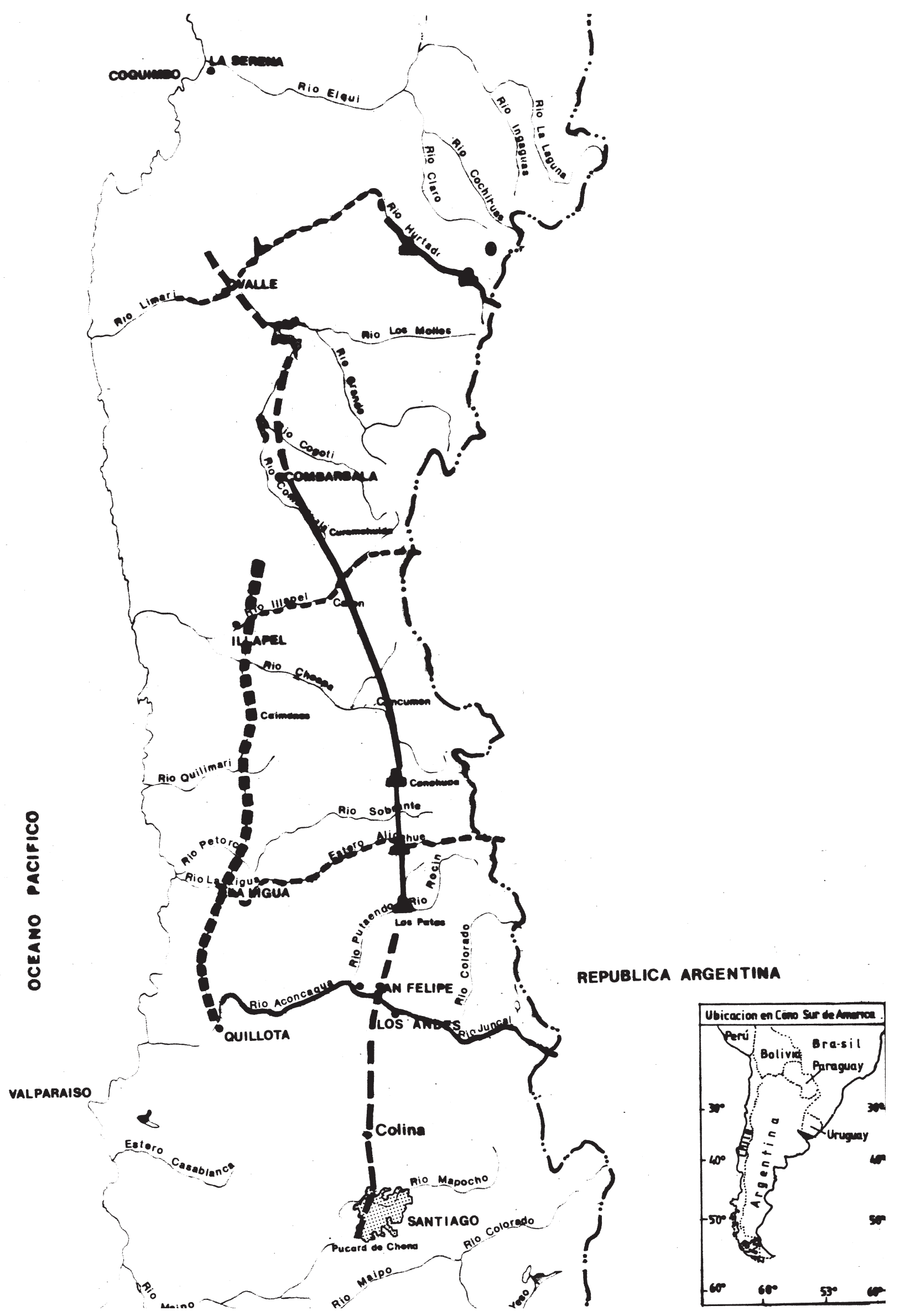

Figura 2. Mapa de las rutas de penetración incásica al Centro de Chile. 


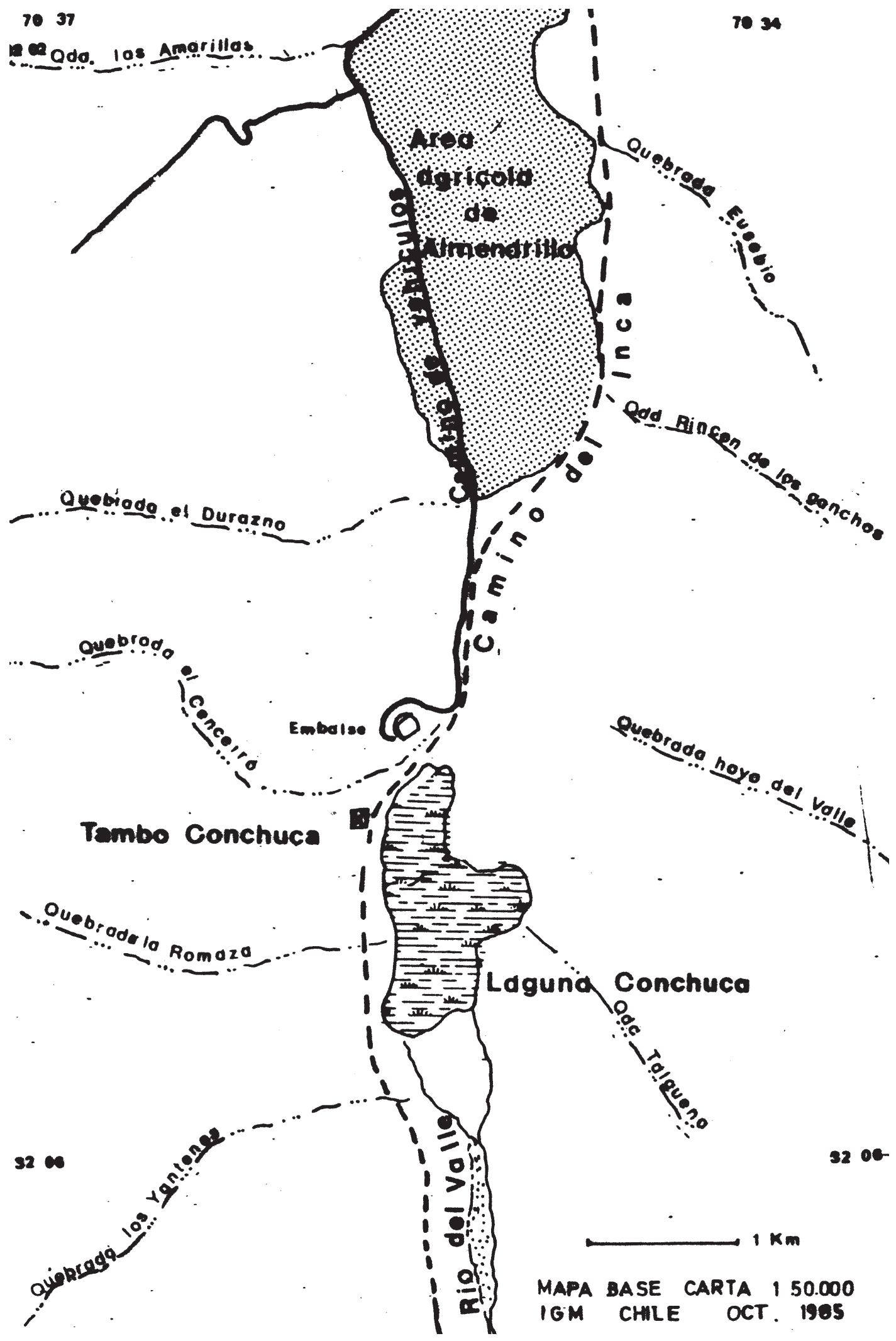

Figura 3. Mapa de la ubicación del Tambo Conchuca. 


\section{Tambo de Conchuca}

El lugar donde se emplazaron las construcciones corresponde a un sector plano a solo $100 \mathrm{~m}$ de la orilla poniente de la vega de ese nombre. Se aprecia a la distancia como un área en la cual se han acumulado una cantidad indeterminada de piedras. Sin embargo, al encontrarse en sus cercanías es posible observar la doble línea de piedras empleadas en la construcción de sus muros. Presenta un evidente patrón constructivo inca-provincial constituído por 3 unidades arquitectónicas separadas exactamente por 3.80 m entre sí y un total de 9 recintos rectangulares (ver Figura 4).

Las excavaciones practicadas en el lugar proporcionaron 659 restos óseos, la totalidad correspondiente a camélidos, una concha de loco Concholepas peruviana Lamarck de procedencia marítima, algunos restos de fogón, 3 puntas de proyectil triangulares pequeñas, una hermosa tortera de combarbalita, material que se encuentra a $100 \mathrm{~km}$ más al norte, un mortero muy desgastado por el uso 37 fragmentos cerámicos diaguitas-incaicos y 3 minibotellitas del mismo material correspondientes a restos del Complejo Cultural Aconcagua de más al sur (Stehberg, Carvajal y Seguel 1985).

Contrasta la clara y abundante presencia de contingentes aculturados diaguitas del norte chileno, con la efímera pero simbólica presencia de elementos procedentes a los territorios templados del sur, lo que indica un fuerte desplazamiento de grupos humanos y rasgos culturales nortinos en esa última dirección.

Los hallazgos arqueológicos de Conchuca permitieron confirmar de manera incuestionable que el sendero asociado reconocido desde Portezuelo Las Mesas hasta Cuncumén efectivamente correspondía a una obra de arquitectura incaica.

Desde el tambo Conchuca hacia el norte el camino sigue por la falda media de la ladera oriental, manteniendo siempre la misma altura hasta la localidad de Almendrillo. Allí, la existencia de un microclima con suelos favorables y abundante agua permite en la actualidad las actividades agrícolas estivales de altura. Existen aproximadamente 600 hectáreas de riego que son intensamente explotadas por los agricultores de Cuncumén y alrededores. Almendrillo exhibe innumerables restos de ocupación preincaica, elementos indicadores de que el lugar jugó un importante rol dentro de la dinámica de desplazamiento prehispánico en la hoya del Choapa. A partir de este punto, el camino debió salvar numerosas quebradas siendo la más importante la del estero El Salto frente a Cerco de Piedra; suponemos que en este lugar debió existir alguna obra de ingeniería que permitiera salvar un acantilado que alcanza unos $50 \mathrm{~m}$. de profundidad. Una vez superado este obstáculo, el camino sigue bordeando la falda de un sector muy pedregoso pero sumamente estable, desde el punto de vista de los materiales, lo que ha facilitado que el tramo en cuestión se mantenga hasta la fecha visible. Esta situación se mantiene hasta frente a la localidad de Batuco cerca de Cuncumen, donde se pierde la evidencia de su trazado (Figura 5).

En el sector de Cuncumén, donde confluyen el estero El Chacay y el estero del Valle dando origen al Río Choapa (1,000 msnm), la falla geológica se interrumpe por un cordón transversal (de aproximadamente $30 \mathrm{~km}$ de ancho) y de 1,800-2,000 m de 


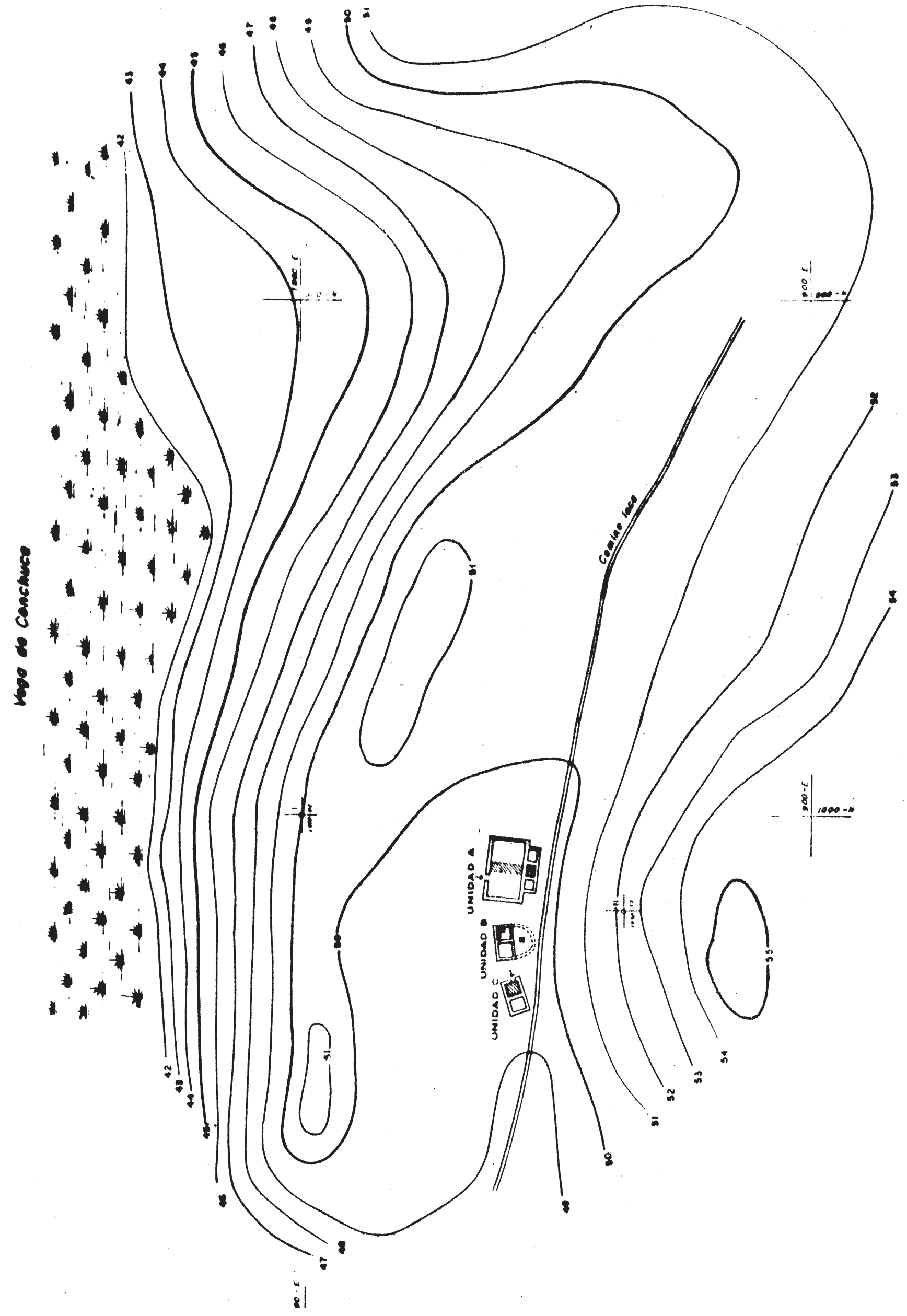

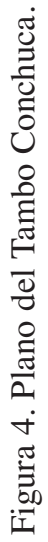



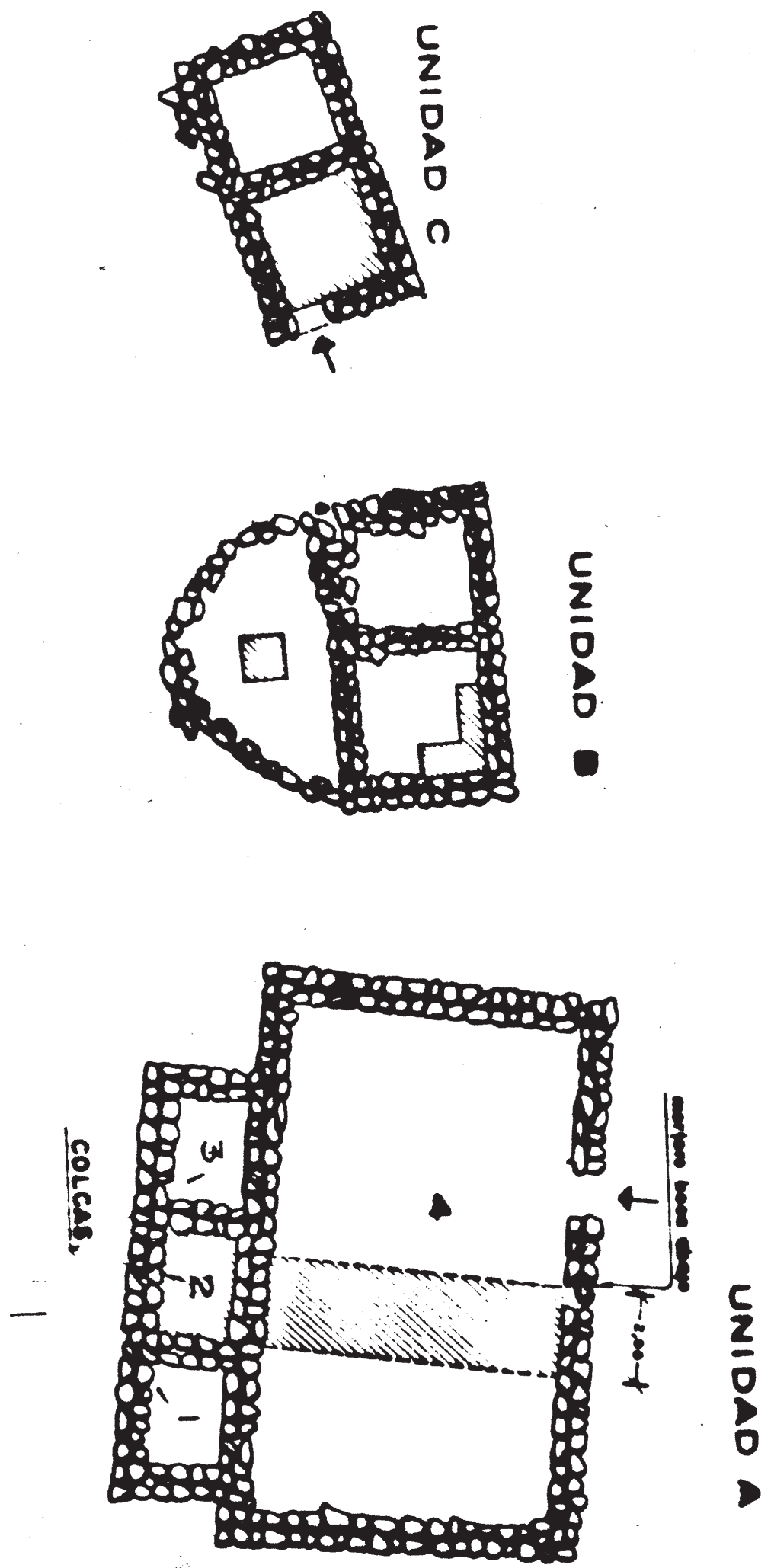
altitud, que alcanza en el Cerro Chiflón del Horno su máxima altura (3,600 msnm), lo que constituye una barrera natural para la continuación del camino; su búsqueda al norte de Cuncumén representó el primer gran problema del proyecto.

Perdimos los rastros del camino incaico poco antes de llegar a sector agrícola de Cuncumén y no disponíamos de evidencias para investigar su continuación a través del cordón transversal, más, el análisis de imagen de satélite nos indicó que los incas dispusieron de dos alternativas para salvar este accidente: desviar el camino hacia alturas superiores a los 3,000 $\mathrm{msnm}$ donde se encuentran planicies favorables al desplazamiento longitudinal, o bajar por el Río Choapa unos 4 ó $5 \mathrm{~km}$ hasta alcanzar pasos cómodos hacia el norte. Como nuestras indagaciones por el potrero El Chacay, ubicado al noreste de Cuncumén, no nos proporcionaron ninguna evidencia se decidió organizar una expedición al interior del Río Chalinga, afluente norte del Río Choapa, para tratar de reconocer el camino al otro lado del cordón transversal (ver Figura 6) y realizar un reconocimiento aéreo del sector. Como resultado se estableció que el Camino del Inca una vez llegado a Cuncumén descendía unos $5 \mathrm{~km}$ aguas abajo del Río Choapa hasta alcanzar una quebrada de dirección norte que aprovechaba para avanzar hacia el Río Manque. En dicho tramo observamos el Camino del Inca desde el aire como una huella tropera marcadamente rectilínea que avanzaba a media falda por la ladera poniente. La ruta continuaba por el Alto de Chillepín, Portezuelo Las Cortaderas, La Palmilla, enseguida remontaba por Quebrada El Peñón y cruzaba Barda, La Cuesta y por la Quebrada El Piche cayendo a Carén en el Río Illapel. En este último sector las actividades agrícolas y ganaderas han borrado los testimonios materiales de su presencia. La ruta incaica continuó su desarrollo por la ladera poniente del cerro Curamávida, en la Cordillera de Fredes, hasta alcanzar una meseta de altura de 2,000 msnm de marcada dirección sur-norte. Poco antes de la laguna El Tome, un pequeño y hermoso "cuerpo de agua" existente en el sector, se encontró el tramo del camino incaico mejor conservado de todos los descubiertos anteriormente por nosotros. En dicho punto, el camino efectúa una pequeña inflexión al oeste para esquivar un morro y acercarse lo más posible a este recurso. Desde allí sigue una línea recta que se reconoce nítidamente desde la distancia, pero que está disectada por numerosas quebradas que han borrado parte de la ruta; cruza la parte alta de la vega de Chépica y sigue al norte, desviándose ligeramente hacia el E para atravesar por las nacientes de la quebrada El Chape y retornar a su dirección habitual perdiéndose de vista poco antes del curso superior de Valle Hermoso.

De todos los sectores prospectados este fue el único tramo de camino que se encontró demarcado a ambos lados por una corrida de grandes bloques rocosos obtenidos directamente del lugar. Los bloques miden entre 0.50 y $1.0 \mathrm{~m}$ de espesor y tienden a confundirse con el resto de las rocas que recubren la ladera del cerro Curamávida. El ancho promedio del camino es de $2.5 \mathrm{~m}$ y su interior no se encuentra despejado de piedras. A la distancia se reconoce como una línea rectilínea de color oscuro que cumple con un típico patrón constructivo inca; este tramo se constituye en el punto más al sur del Kollasuyo donde se ha encontrado este patrón constructivo. En algunos tramos fue posible advertir concentraciones de piedras que pudieron corresponder a pequeños descansos de los chasquis ó a otra función difícil de precisar. 
El camino es inadecuado para el tránsito caballar y es imposible el paso de una carreta o vehículo por su interior; su adscripción al imperio debe fundamentarse en su patrón constructivo y en la tradición oral que lo recuerda como Camino del Inca. No se encontraron restos cerámicos directamente asociados.

\section{El camino inca costero}

Los estudios y prospecciones de terreno se iniciaron en Talagante en el curso medio del valle del Maipo y se extendieron hacia el norte en dirección a Quillota. Su objetivo era confirmar la ruta incaica sugerida por Keller (1959), la cual suponía que el Camino del Inca al sur se dirigía de Quillota por el Portezuelo de San Pedro de Limache a Marga Marga, Lo Orozco, Las Dichas y por el Portezuelo de Ibacache a Talagante. La visita a dichos lugares no proporcionó información relativa a indicios arqueológicos o recuerdos en la tradición oral de la presencia incaica en la zona que confirmaran la hipótesis de Keller. Avanzando al norte cruzamos el Río Margamarga, en cuyas nacientes los incas establecieron un lavadero de oro (Actas del Cabildo de Santiago 1861), proseguimos a Quillota, en el curso inferior del Río Aconcagua, donde los incas establecieron un importante centro administrativo (Keller 1959).

A partir de Quillota al norte, comenzamos a recoger de la tradición oral, reiteradamente, la información acerca del paso de los primeros españoles por la zona, incluso con delimitación precisa de la ruta. Sabemos por las crónicas de la expedición de Diego de Almagro a Chile que éste utilizó en su trayecto el Camino del Inca y vino acompañado por el inca Paullu Topa, hermano del rey Manco Inca (de Herrera 1936:108) y por Huayllullo, indio principal del valle de Chile (Quillota) a quien habían capturado en Tupiza con los presentes que las provincias de Chile enviaban anualmente al Inca (Mariño de Lobera 1936:83). Desde Quillota el camino en cuestión traspasó un cordón montañoso por la Cuesta Vieja hacia el hermoso valle costero de Chilicaquén para proseguir en dirección a La Ligua por el portezuelo de El Melón o por el estero El Cobre. Por más esfuerzos que se desplegaron, no fue posible reconocer restos muebles o inmuebles incaicos antes de La Ligua, ciudad que fue un importante centro incaico y donde se han efectuado hallazgos alfareros inca-locales. En su actual plaza existe una placa recordando el paso de la expedición de Diego de Almagro por el lugar en 1536.

El avance de la ruta hacia el norte representó un nuevo problema, puesto que se planteaba la posibilidad de subir por el Río Ligua para tomar por el estero Las Palmas y avanzar hacia el norte o cruzar el cordón de cerros que separa el Río Ligua del Río Petorca para empalmarse directamente con el estero Las Palmas en el sector de Palquico. Por falta de antecedentes el problema no fue resuelto. A partir de Palquico se reconoció una excelente ruta de dirección norte-sur que cruzaba la cuesta de Las Palmas para llegar a Tilama. Tan favorable se presentó este paso, que el antiguo tramo del ferrocarril longitudinal a Copiapó lo aprovechó en gran parte. Durante todo el trayecto se siguió recogiendo información oral del paso de Diego de Almagro por el sector e incluso del español Diego Calvo de Barrientos, que llegó a la zona de 
Quillota en 1534 huyendo de un castigo físico que se le impuso en Cuzco. De Tilama al norte la tradición oral señala que el Camino Inca Costero pasaba por Ramaditas o Pupío bordeando el Morro Gonzalo y no por el actual pueblo de Caimanes en cuya plaza se exhibe una antigua olla gigante de fierro, atribuída erróneamente a Diego de Almagro. El tramo comprendido entre La Ligua y Caimanes se caracteriza por presentar formas de relieve más bien suaves y en donde los ríos principales se orientan de norte-sur. El sector en general no se presentó pedregoso, excepto en el área de Las Palmas, lo que constituyó una característica favorable para el desplazamiento peatonal. Desde el punto de vista de la vegetación se presenta árido no existiendo cuerpos de agua superficiales.

De Caimanes al norte existe un importante curso de agua denominado estero Limahuida que es afluente del Río Choapa y que se empalma con éste unos $15 \mathrm{~km}$ aguas arriba de Illapel y que seguramente fue la ruta seguida por los conquistadores.

Al llegar al Río Choapa se perdió nuevamente el rastro del camino planteándose el problema de la forma como continuaba el camino hacia el norte. Una posibilidad es que en vez de descender a Illapel, cruzaba el cordón de cerros para tomar el estero Aucó, siguiendo la quebrada de Punquén; de allí pasaba por Yampanguí, Llaimin, Quebrada de Valle Hermoso hasta Combarbalá donde se unió con el camino incaico del interior o andino que describimos anteriormente. Esta posibilidad, que analizada en una carta geográfica e imagen de satélite apareció como muy probable, se vio seriamente restringida en la práctica debido principalmente a las grandes diferencias de niveles existentes para traspasar el portezuelo El Espino $(2,090 \mathrm{msnm})$ y la extrema pobreza de vegetación y recursos hídricos.

La forma y el lugar en que esta ruta siguió hacia el norte hasta empalmar con la ruta andina no fue debidamente investigada pues en aquel momento sosteníamos la hipótesis de que existían dos caminos paralelos y que éste proseguía por la costa. Este vacío deberá ser completado en futuras investigaciones.

Desde Valle Hermoso y Combarbalá aparentemente los caminos continuaban unidos para proseguir seguramente por el Río Guatulame hacia Huana, donde existió un sitio incaico (Niemeyer 1970) y Ovalle, donde estuvo el centro administrativo incaico del valle del Limarí.

El estudio de la ruta alternativa Combarbalá-Punitaque- Ovalle fue descartada como ruta incaica por carecer de evidencias, pese a que fue importante vía en el tránsito colonial.

\section{Ramales transversales trasandinos}

En las prospecciones realizadas en la Cordillera de Los Andes se reconocieron algunos pasos cordilleranos utilizados por el incario para conectar ambas vertientes de la cordillera. A continuación se describirá uno de ellos y se enunciará la existencia de otros tres, cuyo estudio quedará sujeto a futuros reconocimientos en terreno. 


\section{Ramal Ovalle-Hurtado Superior- Quebrada Las Vacas}

Los hallazgos efectuados en el curso superior del Río Hurtado, afluente norte del Río Limarí, pusieron al descubierto la existencia de este importante ramal transversal que unió los asentamientos incaicos del curso medio del Río Limarí (Ovalle, Huana) con los homólogos por descubrir del lado argentino. El destacado arqueólogo argentino Hans Schobinger nos manifestó que aún no se han realizado reconocimientos de este ramal en la vertiente oriental de la cordillera (comunicación personal, 1986) pero que tiene noticias de su existencia.

Nuestros hallazgos se iniciaron en el sector de La Laguna, a unos $20 \mathrm{~km}$ al sureste del pueblo de Hurtado. Allí en la margen sur del Río del mismo nombre, sobre una terraza arenosa del sector El Molino, donde existió antiguamente una laguna, provocada por el derrumbe del cerro de ese nombre, se encontraron los restos bien conservados de un tambo incaico que denominamos "La Laguna". El lugar se encuentra bastante protegido de los vientos, sobre una ladera de solana a unos $500 \mathrm{~m}$ del Río Hurtado.

La construcción consistió en dos conjuntos rectangulares orientados este-oeste dispuestos a $12 \mathrm{~m}$ uno del otro que se divisan a lo lejos como amontonamientos de piedras. A su costado norte pasa la huella tropera actual que suponemos correspondió al antiguo camino incaico.

El primer conjunto "A" emplazado hacia el oriente está formado por un gran recinto de 10x7 m con acceso central por su costado este enfrentando al conjunto "B". Poseía dos muros continuos que se desprendían perpendicularmente de sus esquinas del lado sur y que pudieron corresponder a otros recintos hoy desaparecidos. Por su amplitud fue reutilizado como corral temporal y sus muros están reconstruídos. Por el contrario, el conjunto "B" está completamente desmoronado, siendo difícil la delimitación de sus espacios interiores. A la simple observación se presentó como una $\mathrm{G}$ mayúscula, de lados rectos de $13 \mathrm{~m}$ de largo y $5 \mathrm{~m}$ de ancho de disposición en que parecían distinguirse 4 o más recintos interiores. En la superficie se distinguió gran cantidad de cerámica pintada y decorada de rojo con decoración diaguita- incaica blanco y negro.

La ruta continúa hacia el E bordeando la vega El Cuyano de aproximadamente 1.5 $\mathrm{km}$ de extensión y apenas $50 \mathrm{~m}$ de ancho. En seguida la huella cruza los llanos de Rapel y avanza $3 \mathrm{~km}$ más hasta Quebrada Elqui y tranca El Durazno, lugar muy inestable con muchos derrumbes que se desprendían de ambas laderas. A continuación, el camino se eleva unos 200 m para cruzar La Romazuda, lugar que se caracteriza por sus pequeñas vegas en los sectores donde el río se asienta. De allí el camino sigue por planos inclinados conocidos como El Pije y Vega Seca y continúa subiendo lentamente bordeando el río hasta llegar a Las Vegas de Guandacol. El tambo de este nombre se localiza exactamente a $15.3 \mathrm{~km}$ del tambo de La Laguna y en la margen izquierda del Río Hurtado, poco más abajo de la confluencia con el Río Ternera, sobre el borde sur de Las Vegas de Guandacol, que se destaca por su extensión y la calidad 


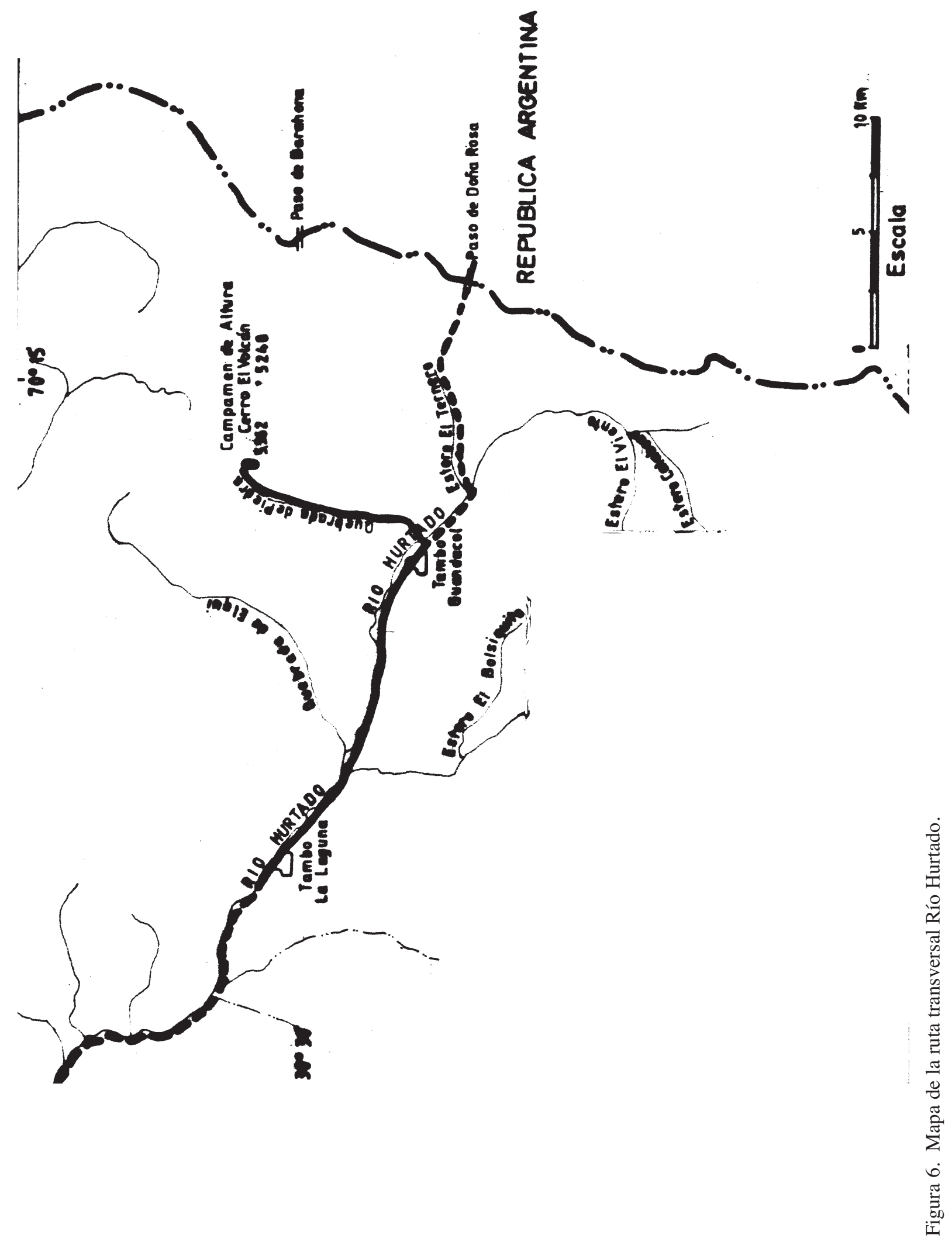


de sus pastos. El tambo mismo está emplazado, al término de una ladera de solifluxión con abundantes acarreos y a unos $10 \mathrm{~m}$ de distancia del camino tropero actual que, sospechamos, correspondió antiguamente al Camino del Inca. Al igual que los otros tambos descubiertos está constituído por dos conjuntos, que se reconocen a la distancia como una gran acumulación de piedras destacando perfectamente del resto del paisaje. A medida que uno se acerca aparecen los muros de doble hilera y los recintos. El conjunto "A", emplazado a escasos $3 \mathrm{~m}$ de altura sobre el borde de la vega, exhibe 8 recintos semirectangulares de $2 \times 2 \mathrm{~m}$ aproximadamente, muros desmoronados, y gran cantidad de restos cerámicos, óseos y líticos (mano y morteros) en superficie. Los restos alfareros presentaban una tipología diaguita-incaica muy semejante a la encontrada en los asentamientos incaicos. El conjunto "B" se compone de 3 recintos rectangulares unidos emplazados a unos $150 \mathrm{~m}$ al suroeste y a unos $50 \mathrm{~m}$ de altura sobre el borde de la vega. Si bien posee un típico patrón constructivo inca-provincial que incluye doble muro, no presentó restos culturales en superficie.

\section{Camino lateral inca, Quebrada de Piedra}

Un importante desvío caminero hacia el norte habilitaron los incas a partir del tambo Guandacol. En efecto, poco más arriba del tambo, donde desemboca el estero Quebrada de Piedra en el Río Hurtado, avanzando por aquel dos horas y media a caballo o sea unos $15 \mathrm{~km}$, llegamos a una rinconada cerrada por cerros de 4,000 m de altitud donde destaca el cerro El Volcán. La rinconada posee una hermosa laguna, muy pedregosa y sin vega, por la cual no presenta aptitudes de veranada. A unos 300 $\mathrm{m}$ al noreste de la laguna descubrimos dos grandes conjuntos arquitectónicos incaicos, que se describen a continuación.

\section{Campamento de altura, Quebrada de Piedra}

Próximo a la laguna Quebrada de Piedra, a unos 200 ó 300 m al noreste y prácticamente al pie del cerro El Volcán (3,500 msnm), se levantaron dos enormes conjuntos arquitectónicos incaicos. El inferior poseía forma rectangular de 8.0x5.5 m y una división interna que lo separa en dos ambientes rectangulares de distintas dimensiones comunicadas por una abertura junto al muro perimetral. Otras divisiones interiores aparecen muy borradas. En la superficie se encontró gran cantidad de cerámica diaguita-incaica decorada con círculos con punto central, recticulado oblicuo e incluso dos grandes pedazos de borde de aríbalo pintado de blanco.

El segundo conjunto se localiza a $100 \mathrm{~m}$ al este, y consiste en un gran recinto rectangular de 10x7.0 m con esquinas semiredondeadas, una gran abertura de acceso en el lado que enfrenta al conjunto "A" y mira hacia la laguna. Posee un pequeño recinto de $3.0 \times 2.5 \mathrm{~m}$ en su esquina sureste y una pequeña abertura de acceso. Si bien en su interior no acusa restos culturales de ningún tipo, a escasos metros de su exterior norte se recogieron varios fragmentos alfareros recubiertos de engobe rojo en ambas caras perteneciente a una misma vasija. El lugar ha sido reutilizado como corral en for- 
ma muy ocasional porque las características pedregosas y sin vegetación de la rinconada lo hacen inhóspito e impiden su aprovechamiento para pastoreo animal.

En relación a la funcionalidad que le cupo al emplazamiento, nos inclinamos a pensar que constituyó un campamento de altura vinculado con un santuario incaico en la cumbre del cerro El Volcán. Una expedición realizada a una de sus cumbres no arrojó resultados positivos. Habrá que continuar los reconocimientos en el sector. El Dr. Hans Schobinger, destacado experto argentino en Santuarios de Altura, nos comunicó que dispone de antecedentes que sugieren que dicho cerro correspondería a un sitio ceremonial del imperio. Como hipótesis alternativa se planteó la posibilidad de que el emplazamiento pudo estar relacionado con actividades mineras, especialmente de extracción de oro, puesto que algunos sectores de la rinconada exhiben antiguos socavones de este metal.

\section{Ruinas en Quebrada El Viento}

A una hora y media a caballo hacia el sureste del tambo de Guandacol, se llega al lugar conocido como Quebrada El Viento donde confluyen los esteros Camino Viejo, que viene del sureste, el estero del Viento y estero Calabozo, conformando un sector de amplias planicies cubiertas de vegas en su mayor parte. El lugar exhibió numerosos vestigios arqueológicos, pero no fue posible determinar su adscripción cultural por carecer de restos diagnósticos en superficie. En la margen izquierda del estero El Viento, a escasos metros y protegidos por un afloramiento rocoso, se reconocieron gran número de pircas viejas y recientes. A unos $500 \mathrm{~m}$ subiendo el estero Camino Viejo, que debe su nombre a un antiguo paso cordillerano, se reconoció un segundo grupo de pircas derruidas que conforman 3 recintos adosados. Finalmente, sobre una loma divisoria de 3,800 $\mathrm{msnm}$ entre el estero El Viento y el Calabozo, con óptima visibilidad hacia todos los puntos incluyendo cerro El Volcán y la actual mina Coipita, se localizaron dos gigantescas estructuras de piedra; la inferior posee forma rectangular de unos $15 \times 10 \mathrm{~m}^{2}$ y está separada $50 \mathrm{~m}$ de la segunda. Esta última presenta forma irregular y según nuestro informante, Sr. Armando Mery, contó que antiguamente disponía de divisiones interiores que han desaparecido.

\section{Otros ramales transversales}

Nuestras observaciones en terreno detectaron la presunta existencia de otros ramales trasandinos. Ellos deberán ser objeto de futuros estudios y prospecciones, pero dada su importancia en la conformación de la red vial incaica los enunciamos someramente a continuación:

\section{Ramal Cuzcuy-Cordillera de Illapel-Las Salinas}

Este ramal trasandino pasaba por Illapel y Cuzcuy, en el curso superior del Río Illapel, se internaba por el río del mismo nombre en dirección este hasta la confluen- 
cia con el estero Carén, donde se cruzaba con el Camino Inca Andino. Se nos presentaron dos posibilidades que deberán ser analizadas en mayor profundidad en el futuro, la primera de ellas, sugirió que la ruta continuaba por el estero Cenicero en dirección noreste empinándose sucesivamente a altitudes de 1,500 msnm hasta llegar en la confluencia con el estero Tambillo $(2,500 \mathrm{msnm})$ donde adoptaba una orientación esteoeste hasta llegar al sector de Los Libros o Latiguillo donde obtuvimos información de la existencia del tambo Los Corralitos del Indio, consistente en un conjunto de estructuras de piedras con restos indígenas en superficie. De allí, existe un paso hacia la Argentina de 4,200 msnm denominado Paso Río Negro que desemboca en el Río Piuquenes en la vertiente oriental de la cordillera. Los "Corralitos del Indio" corresponden a un conjunto de numerosas estructuras de piedras con restos indígenas de superficie, conocido ampliamente por los habitantes del valle.

La otra posibilidad es que la ruta siguiera en dirección E por el Río Carén, el cual después de superar alturas superiores a 2,500 m va a dar al estero La Polcura.

En la confluencia con el Río Pabellón se encontraron restos del tambo de Aletones y posiblemente un tramo del camino incaico. Allí su camino continuaba al Portezuelo Casa de Piedra $(3,849 \mathrm{~m})$.

Este paso conecta con las nacientes del Río Yeso - Las Salinas- Los Piuquenes con una dirección este que los comunicaría directamente con el sector Las Tamberías a unos $20 \mathrm{~km}$ al sur de Calingusta en el lado argentino.

\section{Ramal La Ligua - Alto El Cuzco - Valle Hermoso}

Este ramal que pasaba por el centro incaico de La Ligua, donde se han efectuado hallazgos inca-locales-, seguía el curso del estero de Alicahue, pasando por San Lorenzo y bordeando el cerro Corral de Piedras tomaba el curso del estero de Alicahue, ganando lentamente altura para cruzarse con el Camino Inca Andino en el sector del tambo de Alicahue. Desde allí continuaba ascendiendo por la Quebrada El Cuzco, bordeando los cerros Alto del Cuzco y El Cuzco (3,401 y 3783 msnm respectivamente) hasta llegar a la Quebrada de Videla donde existe un tambo incaico. La ruta continuó ascendiendo por el Río Ricin y Quebrada Tambillos. En esta última localidad, deberán buscarse los restos de un tambo incaico, puesto que poseemos información respecto de su presunta existencia. Desde allí, cruzando la Cordillera de Los Andes, por el paso de Valle Hermoso ( $\left.32^{\circ} 22^{\prime} \mathrm{S}-70^{\circ} 15^{\prime} \mathrm{W}\right)(3,512 \mathrm{msnm})$ en dirección a las Ciénagas de Galguaraz.

\section{Ramal Quillota - Caracoles - Uspallata}

Este ramal siguió el curso del Río Aconcagua desde Quillota hasta San Felipe, Alto del Juncal, cerro Cabeza del Inca, Laguna del Inca y cruzaba por el Cristo Redentor hacia territorio argentino (Schobinger y Bárcena 1972:3). Contrasta los avances alcanzados por los arqueólogos argentinos en relación al tramo oriental de 
esta ruta (Hyslop 1984:190, 196, 198) con la carencia casi absoluta de estudios en el lado occidental chileno, tarea que estimamos urgente de realizar.

\section{INTERPRETACION PRELIMINAR}

Para entender el diseño y trazado del Camino del Inca hacia el límite sur del Kollasuyo por la vertiente occidental de la Cordillera de Los Andes, es conveniente ubicarse en el contexto temporal y espacial de la época y centrarse en los siguientes tres aspectos:

\section{Razón geográfica}

Desde el punto de vista medio ambiental el trazado del camino incaico a través del Desierto de Atacama hasta el valle de Copiapó tuvo la ventaja de avanzar rápido en línea recta con el inconveniente de la extrema aridez, carencia de agua y escasez de recursos alimenticios. De Copiapó al sur en cambio, el problema principal lo constituyó la existencia de numerosas serranías y quebradas semiáridas de pronunciados desniveles que dificultaron el avance. Para resolver estos inconvenientes los incas dispusieron de dos alternativas: primero, dirigirse hacia las cabezadas y nacientes de los ríos donde la profundidad de las quebradas y valles eran menor y en consecuencia el trazado del camino podía conservar una cota más estable (generalmente sobre los 2,000 msnm y bajo la línea de las nieves eternas). Esta alternativa permitía el abastecimiento de recursos hídricos alimenticios y minero-metalúrgicos. Como principal inconveniente estaba el cierre temporal de la ruta producto de nevazones invernales y su relativo alejamiento de los principales centros poblados de la época. La segunda alternativa era optar por descender suavemente hacia las planicies costeras que ofrecían mejores condiciones para el desplazamiento rectilíneo, un clima más favorable con diferencias térmicas menos pronunciadas y tránsito expedito durante todo el año. Es pertinente destacar que entre Los Choros $\left(29^{\circ} \mathrm{LS}-71^{\circ} 10^{\prime} \mathrm{LW}\right)$ y Talinay $\left(30^{\circ}\right.$ $52^{\prime} \mathrm{LS}-71^{\circ} 40^{\prime} \mathrm{LW}$ ) la línea de costa penetra hacia el continente en aproximadamente $20 \mathrm{~km}$ formando la bahía de Coquimbo, lo que permitía que el camino se acercara al litoral sin necesidad de desvíar significativamente su trayectoria. A juzgar por los antecedentes disponibles, los incas utilizaron ambas alternativas al menos hasta el valle de Huasco.

A partir del valle de Elqui por el norte y hasta Combarbalá por el sur, por espacio de unos $120 \mathrm{~km}$ la Cordillera de Los Andes alcanza su mayor proximidad al Océano Pacífico, generando una topografía extremadamente accidentada con quebradas y valles de pronunciada gradiente, lo cual representó un obstáculo que al imperio no interesó resolver. Ello explica porqué en el sector aludido los incas mantuvieron un único camino por tierras bajas que al sur del Río Elqui comienza a internarse lentamente hacia las cabezadas de los valles de Combarbalá.

Fueron razones geográficas las que también explican el porqué la trayectoria del camino no se continúa por la costa al sur de Ovalle. Allí, las planicies costeras 
empiezan a disectarse en numerosas partes, iniciándose a partir de esta área el desarrollo de la Cordillera de la Costa, todo lo cual constituye una barrera natural para el desplazamiento y poblamiento humano.

Sin embargo, al sur del Río Choapa, se aprecia nuevamente una bifurcación del camino, desviándose un ramal hacia tierras bajas en dirección al curso inferior del valle de Aconcagua (Quillota), mientras que el camino principal continúa por las cabezadas de los valles de Alicahue, Sobrante y Putaendo para salir a los cursos medios de los valles de Aconcagua y Maipo en los términos meridionales del Imperio.

\section{Razones Socio-Económicas}

En términos de abastecimiento y poblamiento humano las rutas que se han descrito concuerdan con los requerimientos energéticos del imperio pues, por un lado, unieron los centros agrícolas y poblacionales más desarrollados de la época como lo fueron Copayapó (Copiapó), Guaguingo (Coquimbo), Ovalle, Cocambala (Combarbalá), La Lúa (Ligua), Concumicagua (Quillota) y Mapocho (Santiago). Gracias a ello el inca pudo contar con los recursos humanos y materiales necesarios para construir y mantener en funcionamiento dicho camino. Por otra parte, el trazado del camino por las cabezadas de algunos valles andinos permitió al imperio acceder a recursos hídricos (proximidad a las fuentes de agua), recursos alimenticios (cercanía a varandas y planicies altoandinas de aptitudes ganaderas de hervíboros de consumo humano) y mineros (accesibilidad a yacimientos de oro, cobre y combarbalita). Las limitaciones en uno o más de estos recursos, con el consiguiente despoblamiento humano, característica que se mantiene hasta el presente, explicaron la carencia de un camino andino entre el Río Elqui y Combarbalá y otro Costero entre Limarí y La Ligua.

En relación al diseño y construcción del camino propiamente tal, se pudo constatar la cuidadosa planificación que el incario impuso en su trazado: visibilidad y dominio del valle, protección contra las inclemencias climáticas e inestabilidad del terreno; ruta más expedita y corta entre dos puntos; mantención de una cota estable mediante aprovechamiento de laderas de cerro y unión de portezuelos; emplazamiento de posadas en puntos nodales y favorables, características que garantizaron a sus usuarios, hombre y animales, la rápida recuperación enérgetica y el descanso requerido en sus desplazamientos.

\section{Razones Político-Estratégicas}

Los incas conocieron y analizaron detalladamente la estructura socio-política y económica de los señoríos diaguitas y aconcagua antes de planificar la campaña que condujo a su conquista e incorporación efectiva al imperio. Al momento de su invasión gran parte del área en estudio se encontraba ocupada por poblaciones humanas de tipo aldeano cuya economía descansaba fundamentalmente en la agricultura de quínoa, maíz, calabaza y porotas; ganadería de camélidos; explotación de recursos marinos y en forma restringida caza y recolección. El patrón de poblamien- 
to se organizó principalmente a lo largo de los valles transversales y con una fuerte dinámica vertical que permitió conectar fácilmente ambientes costeros, intermedios, cordilleranos y trasandinos.

Estas sociedades constituyeron un conjunto de señoríos duales cuyas bases se encontraban en la organización de la sociedad en mitades (Ampuero e Hidalgo 1973:104). Así los grandes valles transversales se encontraban divididos en dos parcialidades gobernadas cada una por un señor principal. Una de las mitades correspondió a la costa, otra a la sierra o parte de arriba del valle y aparentemente el señor de esta última tuvo preeminencia sobre el de la mitad interior.

Gerónimo de Bibar (1966), temprano cronista de la conquista hispana de Chile, describe la situación del valle de Aconcagua hacia 1540 de la siguiente manera:

Los señores de este valle son dos. Sus nombres son estos, el uno Tanjalongo, éste manda la mitad del valle a la mar; el otro cacique se dice Hichimalongo, éste manda y selíorea la mitad del valle hacia la sierra. Este ha sido el más temido señor que en todos los valles se ha hallado".

El nivel de desarrollo que habían alcanzado estos señoríos en un marco andino meridional, con capacidad potencial de producir excedentes alimenticios y minerometalúrgicos; la predisposición a reconocer la autoridad señorial y la capacidad de éstos para negociar y concertar acuerdos, constituyeron característicias claves para entender el interés y la rapidez de la conquista incaica. La baja densidad demográfica de estos grupos diaguitas que hacia 1335 se ha estimado en 25,000 habitantes (Hidalgo 1971:4) pudo representar un problema para el incaico. En este contexto, la tendencia imperial de establecer dos arterias paralelas y longitudinales en los territorios semiáridos de Chile la interpretamos tentativamente como un esfuerzo por unir y controlar mediante un camino longitudinal andino las mitades y señoríos de arriba y, mediante otro camino por tierras bajas al interior de la costa, las mitades y señoríos de "la parte del valle a la mar". Esta situación ideal se vió restringida en amplios territorios debido a las condiciones montañosas adversas y baja densidad poblacional que los obligó a habilitar un solo camino. Fue el caso de las tierras comprendidas entre los valles de Elqui, Combarbalá y Choapa que coincidentemente disponen de la menor evidencia etnohistórica de la existencia de señoríos duales.

Es pertinente señalar que este tramo es el único en presentar un desplazamiento de la ruta desde ambientes costeros (Coquimbo), pasando por intermedios (Ovalle) a ambientes andinos (Combarbalá) para retornar mediante un ramal a ambientes intermedios (Quillota). Esta misma trayectoria fue seguida por las expediciones descubridoras de Diego de Almagro (1536) y Pedro de Valdivia (1540) quienes luego de pasar el sector costero de Coquimbo y Limarí se inernaron por este último río y avanzaron por la sierra hasta Combarbalá para descender nuevamente al curso inferior del valle de Aconcagua (Fernández de Oviedo y Valdés 1936:52-56; Bibar 1966: 32, 33, 36).

En relación a la existencia del Camino del Inca Andino o del interior sostenemos una hipótesis alternativa que encuentra justificación en la conveniencia del imperio de ejercer control sobre los desplazamientos trashumánticos de ganado camélido 
entre sectores occidentales y orientales de la Cordillera de Los Andes. Esta actividad representaba la ocupación principal de la población de la mitad de arriba del valle y posiblemente de ahí derivó la preeminencia de su señor por sobre la del cacique de la mitad de abajo. Es así como, se constató una estrecha relación entre los puntos en que los incas establecieron los tambos, con los pasos obligados de ganado trashumante en lo que nos parece constituir una demostración del esfuerzo incaico por controlar estas rutas. En este contexto, se entiende la importancia que el imperio atribuyó a los ramales transversales y se explica la ubicación en puntos nodales de los tambos de Alicahuo y Conchuca, vale decir, en los lugares donde se cruzó el camino longitudinal con el transversal.

A través de la información etnohistórica se dedujo que el camino contó con servicio de posta e incluso de traslado de personajes importantes a través de palanquín. De Góngora Marmolejo $(1862: 3,4)$ señaló que el español Diego Calvo de Barrientos pasó de pueblo en pueblo "y para venir jornada tan larga pidió favor a los indios, entendiendo por las razones que les daba la causa de su peregrinación, la favorecieron y dieron quías que lo llevaron en hamacas a sus hombros hasta ponerlo en el valle de Aconcagua". De ser efectiva esta situación se entiende el interés incaico por unir puntos poblados y se deduce el esfuerzo que significó para las poblaciones locales de baja densidad demográfica la mantención de dicho camino. Asimismo, el uso de la posta e incluso de quipus junto al Camino del Inca tan al sur como Celina y Mpocho están tempranamente documentados por Bibar (1966). Actualmente, parte de la población rural recuerda este camino con la calificación peyorativa de "camino de los cuatreros, de los pavos o de los mañoso".

La conquista incaica de los Andes Meridionales se efectuó por etapas sucesivas. En Chile Semiárido, cada valle transversal está separado unos 100 a $150 \mathrm{~km}$ y su dominio tomó a los incas un período variable de tiempo. Durante ese lapso cada valle representó una frontera transitoria.

Al parecer cada avance por una vertiente de la Cordillera de Los Andes estuvo acompañado por uno igual en la otra vertiente y la expresión material de esta relación estuvo dada por la construcción de un ramal trasandino y la implantación del culto solar en el área.

Schobinger (1986:300) señala al respecto "en donde una senda transversal conectaba ambas vertientes cordilleranas, se buscaba un cerro alto y destacado y se lo elegía para ascensiones rituales que dejaron como vestigios lo que llamamos santuarios de altura". La ocasión en que eran erigidos fue importante y única y "se relacionaba directamente con el dominio sobre un nuevo territorio".

En consecuencia, cada uno de los ramales trasandinos representó un límite que era superado al poco tiempo, por la implantación de uno nuevo, algunos kilómetros más al sur. El estudio de estas fronteras políticas, militares, económicas y religiosas, representa una fértil línea de investigación que vale la pena continuar. 


\section{CONCLUSIÓN}

Los estudios y reconocimientos practidados, en la extensa región comprendida entre los valles de Maipo por el sur y Limarí por el norte permitieron probar arqueológicamente la existencia de los siguientes caminos incaicos:

1. Camino Inca Andino entre Santiago por el sur y nacientes de Valle Hermoso por el norte con descubrimientos de tambos en Laguna Conchuca y Alicachue.

2. Camino Inca Costero entre Quillota y Curso Medio del Río Choapa confirmado indirectamente a través de la información etnohistórica y tradición oral.

3. Fusión de ambos caminos en Combarbalá para proseguir como uno solo hacia el norte, pasando por Huana y Ovalle hacia Coquimbo.

4. Descubrimiento del ramal transversal Ovalle- Río Hurtado- Quebrada Las Vacas con los hallazgos de los tambos de La Laguna y Guandacol. Asimismo, la variante Quebrada de Piedra- Cerro El Volcán con descubrimiento del campamento incaico de altura de Quebrada de Piedra.

5. Hallazgo y enunciado de los ramales transversales de: a) Cuz-Cuz- Cordillera de Illapel- Las Salinas, b) La Ligua- Alto El Cuzco- Valle Hermoso; y c) Quillota- Caracoleo- Uspallata los cuales deberán ser estudiados en el futuro.

6. Descubrimiento de importantes ruinas preincaicas destacando las aldeas aglutinadas de Las Mellacas,y El Durazno y el geoglifo de Las Chilcas.

Los hallazgos en referencia vienen a llenar el vacío de conocimientos que existía en el área y representan un significativo aporte en el conocimiento de la naturaleza de la expansión incaica de Los Andes Meridionales.

\section{AGRADECIMIENTOS}

Nuestra gratitud a las siguientes instituciones y personas que hicieron posible este proyecto: el Honorable Consejo de Monumentos Nacionales; la Dirección de Bibliotecas, Archivos y Museos; el Museo Nacional de Historia Natural; el Centro de Estudios Espaciales de la Universidad de Chile; la National Geographic Society; el Fondo Nacional de Investigación Científico y Tecnológico (FONDECYT); los Carabineros de Chile; la Ilustre Municipalidad de Salamanca; el Círculo de Amigos del Patrimonio Cultural de Chile; Hans Niemeyer F., Conservador Museo Nacional de Historia Natural; Eduardo Díaz, Director, Heinz Martens y Carolos Patillo, Centro de Estudios Especiales de la Universidad de Chile; los arqueológos Eliana Durán, Tom Dillehay, Rodolfo Raffino, John Hyslop, Hans Schobinger, Roberto 
Bárcena, Gustavo Valdivieso y Angel Cabeza; Nicolás Piwonka (fotógrafo), Patricio Sepúlveda (geólogo), Alejo Gajardo (escritor), Andrés Stehberg y Yugen Kunze (pilotos); Samuel Bañados, Manuel Irárrazabal y Familia Carvajal, Pedro Mery y Leonardo Villarroel (informantes); y Directores y profesores de Escuelas Rurales, arrieros e informantes claves, lugareños, campesinos y amigos que por su alto número no podemos enumerar.

\section{BIBLIOGRAFÍA}

Ampuero, Gonzalo

1985 Rutas incaicas (Huellas, senderos y caminosdel Norte Chico.) El Día. La Serena, 28 abril 1985, Chile.

Ampuero, G. y J. Hidalgo

1975 Estructura y proceso en la Prehistoria y Protohistoria del Norte Chico de Chile. Chungará, 5:87-124.

Bibar, Gerónimo

1966 Crónica y relación copiosa y verdaderade los Reinos de Chile (1568). Fondo Histórico y Bibliográfico Jose Toribio Medina. Santiago, Chile.

Cabeza, A. y P. Tudela

1985 Reseña Histórica y Cultural de Pirque y Río Clarillo. Conaf. I. Municipalidad de Pirque. Santiago. Chile.

de Gongora Marmolejo, A.

1862 Historia de Chile desde su descubrimiento hasta el año 1575. Colección Historiadores de Chile. 2:1-212. Chile.

de Herrera, A.

1936 Descripción de las Islas y Tierra Firmedel Mar Oceáno que llamaron Indias Occidentales. Boletín de la Academia Chilena Historia. 4 (7): 106-131. Chile.

Fernández de Oviedo y Valdes

1936 Historia general y natural de las indias, isla y tierra firme del Mar Oceáno. Boletín Academia Chilena Historia. 7 (4): 25-78. Chile.

Gajardo, R. y J. Silva

1970 Notas sobre arqueología de Quillota: Excavaciones en el Estadio. Anales del Museo de Historia Natural. 3:203-236. Chile. 
Hidalgo, J.

1971 Algunos datos sobre la organización dual en las sociedades protohistóricas del Norte Chico de Chile. El testimonio de los cronistas. Noticias Mensuales del Museo Nacional de Historia Natural. 178 (15): 3-10. Chile.

Hidalgo, J.

1972-3Población prehistórica del Norte Chico. Actas del VI Congreso Arqueológico. pp.289-294. Chile.

Hyslop, J.

1984 The Inka Road System. Institute of Andean Research. New York, New York, Estados Unidos.

Iribarrne, J. y A. Bergholz

1972-3El camino del inca en un sector del Norte Chico. Actas VI Congreso de Arqueología Chilena. 1972:229-266. Chile.

Keller, C.

1959 Los orígenes de Quillota. Boletín de la Academia Chilena de Historia. 61. Magallanes, Manuel

1912 El camino del inca. Revista Chilena Historia y Geografía. 3:3-37. Imprenta Universitaria. Chile.

Mariño De Lobera, P.

1936 Crónica del Reino de Chile. Boletín de la Academia de Historia. 4(7): 79105. Chile.

Medina, J.T.

1882 Los aborigenes de Chile. Imprenta Gutemberg. Chile.

Niemeyer, Hans

1970 El yacimiento arqueológico de Huana. Boletín Prehistoria. 2-3:3-63.

Raffino, R.

1981 Los Inkas del Killasuyu. Ramos Americana Editorial. La Plata, Argentina.

Rivera, M. y J. Hyslop

1984 Algunas estrategias para el estudio del Camino del Inca en la Región de Santiago, Chile. Cuadernos de Historia 4:109-130.

Schobinger, J.

1986 La red de santuarios de alta montaña en el Contisuyo y el Collasuyo: Comechingonia. Córdoba. Homenaje al $45^{\circ}$ Congreso Internacional de Americanistas. Bogotá.

Schobinger, J. y R. Barcena

1972-3El tambo incaico de Tambilitos (Prov. Mendoza, Argentina). Actas del VI Congreso Arqueológico Chileno. pp. 397-404. Chile. 
Stehberg, R., N. Carvajal y Roxana Seguel

1985 El tambo Conchuca y su relación con la ruta de penetración inka al centro de Chile. En prensa.

Stehberg, R. y N. Carvajal

1985 Recientes reconocimientos del Camino del Inca en los términos meridionales del Imperio: Tramo Alicahue Adentro-Alto Choapa. Manuscrito inédito.

Strube, L.

1963 Vialidad imperial de los Incas. Universidad Nacional de Córdoba. Córdova, Argentina.

Von Hagen, $\mathrm{H}$.

1958 Los caminos del sol. Editorial Hermes. México-Buenos Aires. 


\title{
LA ACTIVIDAD PREHISPANICA DE LOS INCAS Y SU INFLUENCIA EN LA ARAUCANIA
}

\author{
Tom D. Dillehay \\ Américo Gordon
}

\section{INTRODUCCION}

Se puede afirmar que el estudio de las fronteras de los estados forma parte integral de la comprensión general del crecimiento y expansión dinámica de los estados e imperios. Tales estudios son de particular interés, puesto que las situaciones marginales fronterizas comparadas con las existentes en las áreas internas del estado a menudo requieren diferentes tipos de organización social y económica. Muy poco se conoce respecto a la dinámica de las fronteras externas e internas del estado inca, así como tampoco sobre el impacto que la extensión gradual de sus fronteras ejercía sobre los aspectos políticos, instituciones estatales y las operaciones militares. Asimismo, se sabe muy poco acerca del proceso y tipo de las organizaciones estatales a lo largo de las fronteras y de la influencia del estado sobre las distintas sociedades y culturas que se encuentran en las áreas fronterizas.

El propósito del presente estudio es, por lo tanto, examinar algunos de estos tópicos a la luz de la situación limítrofe que existía en el extremo sur del imperio incaico, es decir en la frontera araucana en la región centro-sur de Chile. En base a evidencias arqueológicas, etnohistóricas, lingüísticas y etnográficas expondremos la siguiente hipótesis. En la región de nuestro interés, existían dos tipos de fronteras incaicas, diferentes pero complementarias: 1) una frontera geopolítica exclusiva y definida, que delimitaba la ocupación territorial en alguna parte del territorio entre la ciudad de Santiago y el Río Maipo o el Río Maule, en cuyas orillas el avance de los incas fue detenido por los araucanos y 2) una frontera geoeconómica inclusiva, militarmente no ocupada y no contenida dentro de las fronteras formalizadas del imperio incaico. Esta región se ubicaba en forma de islas formando un archipiélago de variadas actividades estatales dispersas, al sur de los Ríos Maipo o Maule, en el interior del territorio araucano (ver Figura 1).

La idea central que deseamos desarrollar en el presente estudio se basa en la consideración del límite del estado incaico en su extremo meridional como una "expansión no ocupacional" dirigida hacia el sur, más allá de la frontera geopolítica de corte más claro en Chile Central. La influencia prehispánica de la cultura inca sobre la cultura araucana se inferirá sólamente a medida que los datos lo permitan. Por otro lado, la influencia de esta cultura local sobre las instituciones del estado a lo largo de la frontera sureña solo podrá ser tratada después de realizar estudios más completos. Finalmente, a manera de conclusión, presentaremos algunas ideas respecto al estado incaico y sus fronteras y analizaremos en líneas generales el problema de los límites 
FRONTERA SUR

DE TAWANTINSUYU
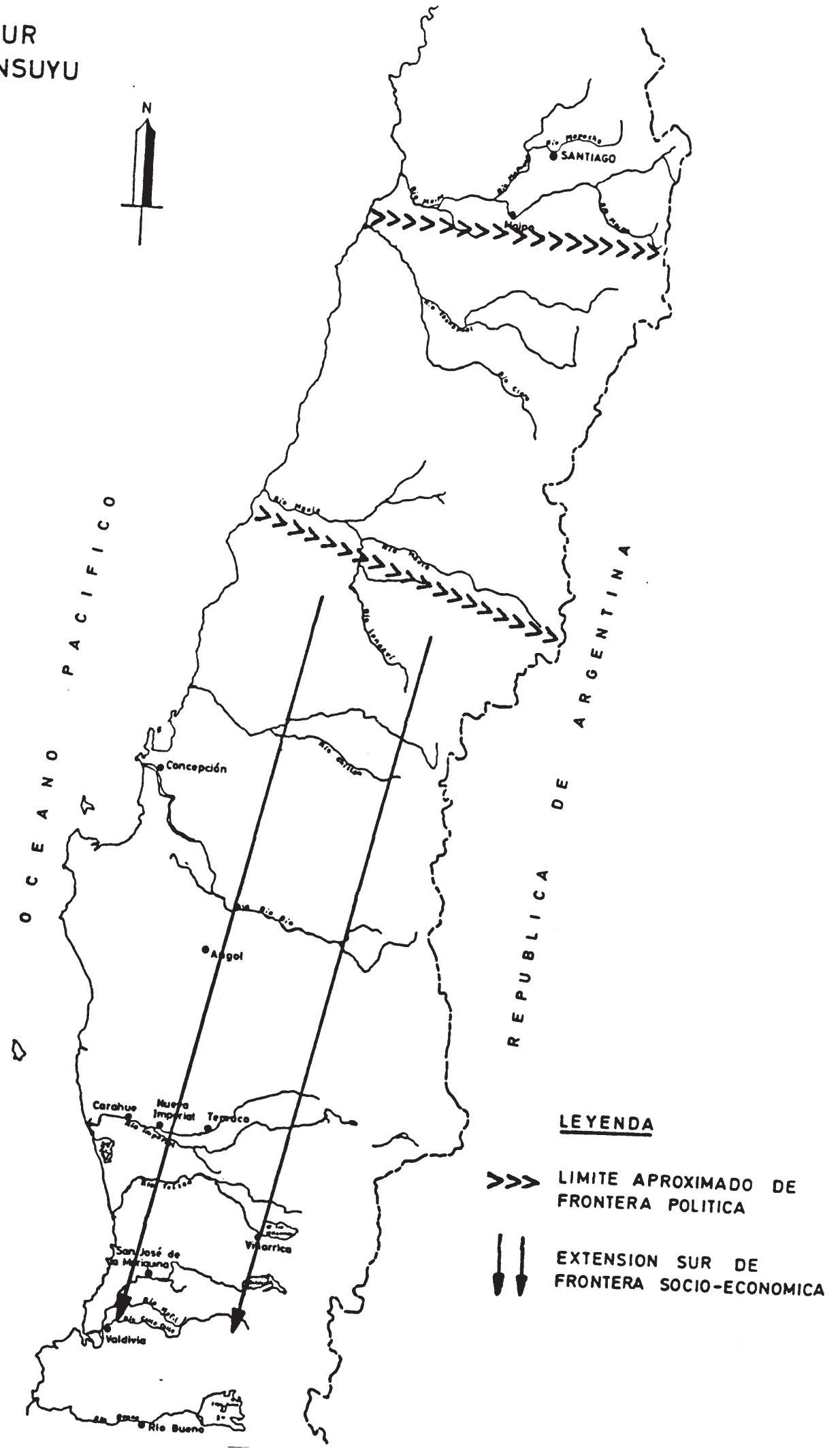

\}$^{5}$

Figura 1. Mapa esquemático de los dos tipos de fronteras del Imperio Incaico en el sur del Chile. 
en el sur. Luego, revisaremos los diversos conjuntos de datos y los discutiremos a la luz de los nuevos elementos considerados.

\section{La frontera araucana: Etnohistoria y arqueología}

Se sabe con certeza que los incas no pudieron vencer militarmente a los araucanos e incluir el centro-sur de Chile en su imperio. Generalmente, se acepta que el estado incaico nunca extendió sus límites más allá del Río Maule, hasta donde llegaron sus ejércitos, tal vez, 50 ó 60 años antes de la llegada de los conquistadores hispánicos a Chile. Los españoles fueron los herederos de esta frontera política incaica. Desde el siglo XVI esta frontera sur limitaba un territorio armado español en donde los habitantes aborígenes fueron obligados a formar parte de la milicia, debido a que las autoridades coloniales no eran capaces de proveerse de tropas regulares. Sin embargo, después del gran levantamiento indígena del año 1598, cuando todas las instalaciones españoles situadas al sur del Río Bío Bío fueron devastadas, las autoridades españolas instituyeron una frontera política a lo largo de dicho río. A partir de 1840 con la incorporación de colonos europeos, los agricultores-ganaderos empezaron a apoderarse de los terrenos indígenas situados al sur del Río Bío Bío; y, finalmente, en la década de los 1880, las autoridades gubernamentales ubicaron a los araucanos en reducciones. Por otra parte, la actividad estatal española, ejercida por medio del comercio, la entrada de misioneros, los casamientos interraciales y la pacificación de algunas comunidades indígenas, demuestran la influencia estatal y una experiencia que iba más allá de la frontera geopolítica desde el primer contacto con los españoles.

Aunque disponemos de varias fuentes etnohistóricas que relatan diferentes versiones de la conquista inca de la región centrosur de Chile, ha sido principalmente la crónica de Garcilaso de la Vega ([1609] 1967)la generalmente aceptada por los historiadores, tal vez, por ser el relato más detallado. Garcilaso afirma que la ocupación inca nunca se extendió más allá del Río Maule, que dista algo más de 200 km hacia el sur de la actual ciudad de Santiago. Otros cronistas delimitaron la extensión del imperio en el sur dentro de diferentes límites, fundamentalmente al norte o al sur del Río Maule. Por ejemplo, los relatos de Cieza de León ([1553]1967) sobre las sucesivas campañas de Topa Inca Yupanqui y Huayna Capac indican que los Incas llegaron mucho más al sur del Río Maule. Otros cronistas, tal como Olavarria ([1594] 1852), ubican el límite del estado en el Río Bío Bío, cerca de la ciudad de Concepción; Rosales [1670] lo localiza también en Concepción y Montesinos ([1682] 1897)lo hace llegar hasta el Estrecho de Magallanes. Por otro lado, Pedro de Valdivia en su carta escrita al emperador el 4 de septiembre de 1545 menciona:

"...y la relación que pude tener fue de cantidad de indios desde este valle de Mapocho hasta Mauli y muchos nombres de caciques; y es que, como éstos nunca han sabido servir, porque el Inga no conquistó más de hasta aqui" (1861:46).

A su vez el compañero de armas de Pedro de Valdivia, el primer cronista de Chile, Gerónimo de Bibar, sostiene: 


\begin{abstract}
"Está este provincia de los Promocaes, que comienza de siete leguas de la ciudad de Santiago que es una angostura y ansi la llaman los españoles estos cerros que lo hacen una angostura. Aqui llegaron los Incas cuando vinieron a conquistar esta tierra, y de aqui adelante no pasaron" ([1558] 1996:137ss).
\end{abstract}

José Toribio Medina subió al Cerro de la Angostura y pudo constatar la existencia de las ruinas de una fortaleza incaica y grandes acumulaciones de piedra rodada para municiones (Medina 1882:83). Santillan ([1563] 1968) ubica el límite del imperio incaico cerca del Río Cachapoal, al sur de Santiago; y Mariño de Lobera ([1580] 1865) marca la frontera sur cerca del Río Maipo. Los cronistas Ovalle ([1646] 1969)y Ercilla ([1569] 1968)ubican la frontera inca también en los alrededores de Santiago, en Chile Central.

Es un tanto curioso que estos datos sean tan discrepantes. Parte de esta situación puede ser explicada por las diferentes experiencias y la fuente de información de los cronistas que escribieron en diferentes épocas. Sin embargo, a pesar de las diferencias observadas, los investigadores modernos están de acuerdo en que existía una frontera estatal con un límite relativamente bien definido en el Río Maipo o Río Maule o cerca de éste. Aparentemente fue Prescott ([1847] 1955) el primer historiador moderno que se interesó por el problema de la extensión meridional del imperio incaico y afirmó como hecho histórico que el "límite permanente" del estado incaico fue el Río Maule. Sin la debida revisión crítica de las fuentes, la mayoría de los investigadores del presente siglo siguieron la línea de Prescott, considerando al Río Maule como el límite del estado en el extremo sur. Algunos investigadores se dedicaron a examinar cuidadosamente los textos de los cronistas surgiendo dudas respecto a la fijación del límite en el Río Maule. Max Uhle, en 1913, afirmó que los incas llegaron mucho más al sur del Río Maule. Otros historiadores, tales como José Toribio Medina (1882) y Osvaldo Silva (1983) sugirieron que fue el Río Maipo, a unos $150 \mathrm{~km}$ al norte del Maule, el límite del estado. Si deseamos sacar una conclusión basada en la documentación etnohistórica, podemos observar que existen entre los cronistas e historiadores modernos, hechos y opiniones diferentes en lo que se refiere a la ubicación del límite de la dominación inca en Chile Central. Sin embargo, sí existe consenso en que la frontera estaba situada en alguna parte entre los Ríos Maipo y Maule.

Según nos parece, existen buenas razones que nos permiten afirmar que la ubicación imprecisa del límite del estado incaico en las crónicas puede, en parte, explicarse por medio de los diferentes criterios utilizados por los redactores para definir los términos geográficos de la actividad del estado y la extensión territorial de sus instalaciones. Algunos cronistas consideraban que el límite del estado estaba determinado por la existencia de fuertes o instalaciones de asentamiento humanos, mientras para otros, estaba marcado por la presencia de un santuario, por una mera actividad estatal sin ocupación o por una manifiesta influencia estatal. Como resultado de estas consideraciones podemos afirmar que existían, de hecho, varios tipos de límites estatales, los que se manifestaban de diferente manera y extendían entre los Ríos Maipo y Maule hasta el Bío Bío y aún más allá. Creemos que los textos diferentes y variados de las crónicas reflejan la realidad existente o sea la presencia de dos tipos de fronte- 
ras, la estatal geopolítica y las fronteras marcadas por los distintos tipos de actividades desarrolladas más allá de aquella, las que se analizarán a continuación.

Pero antes, deseamos referirnos brevemente a los registros arqueológicos, reflejo de la presencia inca en Chile Central y en el centro-sur del país. La información disponible sugiere que 1) la ocupación efectiva del territorio en el sur de parte del imperio incaico se extendía hasta algún lugar entre Santiago y el Río Maule, probablemente en las proximidades de este río. En esta área existen los vestigios de los fuertes, pucarás, en el Cerro Chena (Stehberg 1976), en la Angostura (Bibar [1558] 1966; Rosales [1670] 1897); y, 2) el estilo y la forma de la cerámica tardía del centro-sur de Chile, especialmente los tipos Valdivia y El Vergel (Bullock 1955) presentan influencias incaicas. Por lo tanto, indican algún contacto con la cultura inca. Este contacto se habría producido, tal vez, bajo el dominio de la población inca del norte, que huyó de los consquistadores españoles para evitar ser sometidos a servidumbre o a través de los mismos conquistadores, quienes vinieron acompañados por yanaconas peruanos.

Los primeros cronistas presentan un número de datos que nos informan sobre los distintos tipos de actividades incaicas, tanto en la época prehispánica como también en el período de contacto con los españoles, las cuales se desarrollaron más allá de los límites geopolíticos del Imperio en Chile Central.

El cronista Rosales, al informar sobre la conquista del sur del país realizada por Pedro de Valdivia, menciona:

\footnotetext{
"Pasaron adelante de la Angostura y Maule, como se ve por los memorias que todavía duran de los fuertes que hizieron, y en la promocaes fueron rotos, desbaratados de los indios de Chile, y embiado por más gente al Perú volvieron a proseguir la conquista hasta llegar a Itata, donde ay otros dos fuertes, y en Culacoya, prosiguiendo en su conquista en tierras delgran señor Quincha tipai, cinco leguas de la Concepción tubieron otra fortaleza y allí ay siete piedras a manera de piramides labradasque fueron puestos por los indios del Perú para hacer la ceremonia llamada Calpa Inga, que se hacía para la salud del Rey Inga cada un año". (Rosales (1670] 1877:339).
}

Este relato evidencia una actividad estatal, militar, más otra ceremonial, no militar, al sur del Río Maule. Hemos sido informados por la arqueóloga, Zulema Seguel, que uno de estos fuertes se encontraría en la orilla norte del Río Itata, frente al pueblo de Nipas, en la cima del Cerro Portezuelo.

La transferencia de tecnología mnemotécnica de los incas a los araucanos está evidenciada por el amplio uso de los ñudos o quipus que hacían los indígenas de Chile a la llegada de los españoles. Tanto Pedro de Valdivia como posteriormente Jerónimo de Quiroga mencionan que los araucanos usan nudos para contar las tropas españolas y los caballos, como también para el registro de varios aspectos de su propia economía. Un ejemplo claro es que cuando se convocaba a una junta, el mensajero entregaba al invitado un pequeño cordel con nudos, los cuales indican la cantidad de días por pasar hasta la realización de la reunión. El mismo sistema servía para fijar la fecha de un levantamiento. También es revelante observar como Pedro de Valdivia, en su expedición al sur, se dirigió directamente a los yacimientos de oro, desde Concepción a 
Quilacoya y a la Imperial (actual Carahue). De allí envió a su capitán Alderete a internarse en la precordillera, fundó la Villarrica y luego trabajó las minas de Madre de Dios. La explotación de los yacimientos auríferos de Chile por los incas, antes de la llegada de los españoles, está bien documentada. La expedición de Almagro, en su camino a Chile, se encuentra con una procesión solemne que conduce en andas el oro de Chile para el Inca. Almagro dice:

"Habia llegado a oidos de Almagro -dice Pedro Marino de Lovera- la fama de las grandes riquezas de Chile y de las grandes sumas que se enviaban a Huayna Capac. Este fue uno de los principales motivos de su viaje.

Y por eso, cuando supo de los indios que encontró en Tupiza, que llevaban desde el lejano mediodia aquel tributo en barras de dorados reflejos, clavando los hijares de su caballo, no se detuvo hasta planar sus tiendas en el valle de Chile. (Medina 1882:17).

Es interesante anotar que las barras estaban marcadas con un "pecho de mujer", insignia del Inca. No cabe duda que las minas trabajadas por Pedro de Valdivia no fueron descubiertas por él, sino que se encontraban en explotación antes de su llegada. Pero, ¿cómo sabía el conquistador a dónde dirigirse para encontrar el oro? Pedro de Valdivia envía antes de emprender sus expediciones hacia el sur

...a las provincias de Arauco, por tierra a Francisco Villagra para que tomase lenguas... ([SYS]1861:92).

A través de estos indígenas "tomados" y "atormentados", el conquistador consigue los datos necesarios para conocer la ubicación de las minas y lavaderos de oro en explotación. Gerónimo de Bibar, quien fue testigo ocular, relata:

... yo vi unas minas de oro junto a la Villarrica en un pueblo de un cacique que se decia

Pocurco bien ricas ([1558]1966).

Evidentemente, deben haber sido los yanaconas incas quienes explotaban las vetas auríferas y lavaban oro antes de la llegada de los españoles, puesto que no hay evidencia arqueológica, etnohistórica o etnográfica que indique que los araucanos, alguna vez, hayan explotado minas o trabajado el oro. Por lo anterior, podemos afirmar que el estado incaico realizó a través de mitimas no oficiales actividades religiosas, tecnológicas, de exploración minera y muy probablemente también, transacciones económicas en ciertas áreas seleccionadas de la frontera social y económica situadas más al sur del Río Maule.

\section{Registro arqueológico de los límites del imperio incaico}

La situación de la frontera del imperio incaico en el Río Maule, de acuerdo con datos etnohistóricos, comenzó a evidenciarse recientemente a través de algunos descubrimientos arqueológicos en el área centro-sur de Chile. El registro de puestos fronterizos y santuarios en el extremo sur del imperio se ha incrementado con el hallazgo de los pucarás del Cerro Chena (Stehberg 1976) y de La Angostura (Medina 1882), aproximadamente a 25 y $60 \mathrm{~km}$ al sur de la ciudad de Santiago respectivamente. Las dos fortificaciones en la orilla del Río Itata (Rosales [1670] 1897), una de ellas des- 

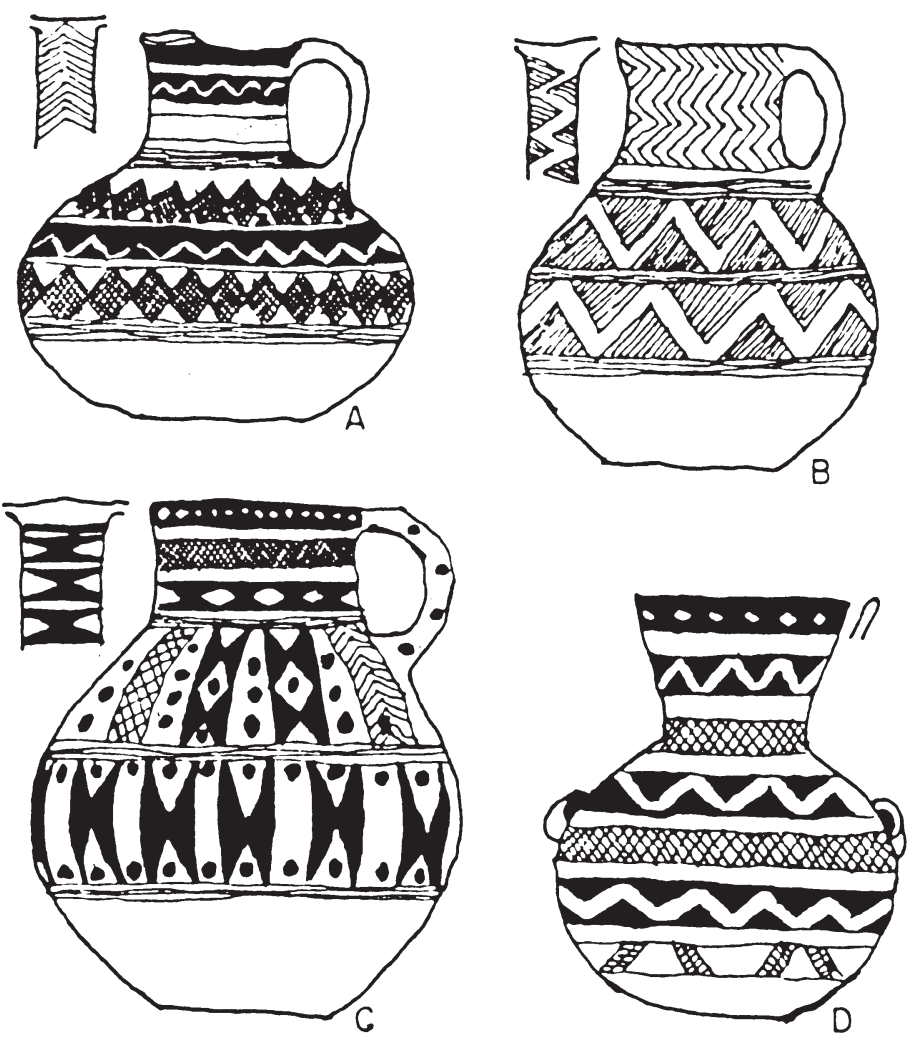

Figura 2. Varios tipos de vasijas del estilo blanco Valdivia.

cubierta por Seguel (Comunicación personal) y la referida "pirámide" inca a "cinco leguas de la actual ciudad de Concepción cerca del pueblo de Ñipas, en el cerro Portezuelo, aproximadamente $130 \mathrm{~km}$ al sur del río Maule" (Rosales [1670] 1897).

Aunque hasta ahora no disponemos de informaciones de la existencia de tambos, de caminos o de instalaciones de poblados, esta carencia de datos puede ser adscrita, eventualmente, a la falta de una investigación detallada en la zona al sur del Río Maule. Sin embargo, existen tipos alfareros de los períodos tardío prehispánico e hispánico temprano que muestran evidentes influencias incaicas. Estas incluyen la cerámica pintada de El Vergel (Angol), hallada aproximadamente a $100 \mathrm{~km}$ hacia el sureste de Concepción y la cerámica blanca pintada del área comprendida entre respectivamente las ciudades de Temuco y Valdivia, localidades que se encuentran a 250 y $450 \mathrm{~km}$ al sur de Concepción. Ambos tipos cerámicos presentan claras influencias incaicas en sus diseños geométricos y sus colores, así como también en algunas de sus formas, específicamente en las tazas, platos y estatuillas Valdivianas. Sin embargo, el tipo blanco Valdivia presenta algunos rasgos europeos en sus formas. En base a esta última característica y a la escasa cronología cerámica construída sobre vasijas excavadas de tumbas, se ha sostenido generalmente que el tipo cerámica Valdivia fue influenciada por los yanaconas incas al servicio de Pedro de Valdivia y que dataría de la primera época de la conquista hispánica. Por otro lado, Guevara (1925) sostiene 
que esta cerámica tuvo su origen en los obrajes instalados en el presidio de Valdivia y que fue producida por soldados peruanos, quienes llegaron acompañados por sus mujeres a mediados del siglo XVII.

Sin embargo, en los últimos 15 años surgieron nuevas evidencias arqueológicas referentes al estilo Valdivia que han contribuido al mejor conocimiento de su origen y ordenamiento cronológico, como también de sus fases de desarrollo. Las excavaciones realizadas por Dillehay, Gordon y Van de Maele en diferentes yacimientos arqueológicos situados entre los Ríos Cautín y Calle Calle han revelado una fase prehispánica tardía, probablemente de afiliación inca, con evidente influencia española, que precede a la bien conocida cerámica blanca Valdivia (ver Figura 2). En los sitios Cocule (comunicación personal de Van de Maele) Pucón (Dillehay 1976; Navarro 1979); Puerto Saavedra, Queule y Colico (Dillehay 1976) se halló cerámica ordinaria con dibujos de color marrón sobre rojo o marrón sobre crema oscuro tipo Valdiviano, en niveles culturales claramente prehispánicos. Se recuperaron fragmentos de vasijas indígenas prehispánicas de formas locales e inca. En uno de estos sitios, la clásica cerámica blanca, que muestra la influencia española, se encuentra en el nivel cultural que se superpone a aquella que contiene la primera cerámica Valdivia de aspecto más burdo, de color crema o rojo.

La estratigrafía cerámica y cultural en tres sitios: Pucón, Puerto Saavedra y Carilafquén está bien definida: a la cerámica burda tipo Valdivia se superponen depósitos culturalmente estériles, los que a su vez, están cubiertos por alfarería blanca clásica de tipo Valdivia. Aún más información suministra la excavación actual del fuerte de Carilafquén, situado a 10km de Pitrufquén hacia Villarrica, que data de la época temprana de la conquista hispánica. Directamente asociado al fortín, existe un sitio habitacional indígena. Las excavaciones en el sitio ocupacional produjeron en los niveles más profundos fragmentos de cerámica ordinaria de tipo Valdivia, superpuestos por una capa culturalmente estéril que correspondería a la permanencia española en el fuerte. Luego, el estrato superior corresponde a la época que sigue a la destrucción de la fortaleza y a la ocupación indígena de ambos sitios. Se hace claramente evidente, la existencia de una cerámica burda y decorada, anterior a la clásica blanca Valdivia. La excavación en Carilafquén (Gordon sf) se encuentra en su fase inicial y se espera que futuras excavaciones suministrarán antecedentes más precisos referentes a la alfarería de tipo precedente a Valdivia. Además, disponemos también de dos fechas radiocarbónicas que confirman la ubicación cronológica y cultural preinca de la cerámica Valdivia. En la Isla Quiriquina $\left(36^{\circ} 38^{\prime} \mathrm{S}, 73^{\circ} 04^{\prime} \mathrm{W}\right)$, en el sitio Punta Arenas, el arqueólogo Víctor Bustos de la Universidad de Concepción halló cerámica decorada con los típicos dibujos de triángulos que en su interior presentan líneas paralelas a uno de los vértices. Ambas fechas coinciden con el ordenamiento cronológico inferido a través de la estratigrafía cerámica:

Sector I $\quad 800+60$ años A.P. 1150 d.C.

Sector II $\quad 840+60$ años A.P. 1110 d.C.

(Comunicación personal de V. Bustos) 
Uno de los problemas que presenta la cerámica Valdiviana, tanto la decorada con motivos incaicos como la pintada, es el establecer si es realmente prehispánica y está relacionada con la presencia inca o si llegó con los yanaconas desde Perú en épocas poshispánicas. En el cementerio de Cocule parecen presentarse evidencias sobre el ordenamiento cultural de la alfarería valdiviana. En dicho sitio, esta cerámica se encuentra representada por platos, tazas y estatuillas cerámicas de evidente origen incaico. Adicionalmente, un tiesto de cerámica amarilla del tipo clásico Inca Imperial Cuzco (Fernández 1971), que seguramente no es de origen local, ha sido recuperado en un nivel prehispánico en Puerto Saavedra. Tampoco son de origen local los fragmentos de cabeza con los lóbulos de la oreja perforados (Colección Rivas) encontrados en las cercanías de Chol Chol ni el fragmento representando la cabeza de un tucán hallado por Chodovwicky en un fondo cerca de Villa Los Boldos al sur del Río Tolten (Cedido a A.Gordon). En tercer lugar la investigación arqueológica en la región centrosur de Chile confirmó que todos los diseños de la cerámica valdiviana conocidos hasta el presente son de origen inca (compárese Fernández 1971: Fig. 37, 170, 184, 202, 346). No existen formas ni diseños similares de épocas tempranas en ningún tipo de cerámica local de la región, por ejemplo Pitrense, ni de áreas situadas en el norte inmediato.

Además de los datos cerámicos, existen otras dos líneas de evidencia arqueológica especialmente relevantes. En el cementerio de Cocule se encontraron, junto a los esqueletos humanos, aros de cobre similares a los usados por los incas y tupus de estilo incaico puro asociados a la ordinaria cerámica temprana Valdiviana (M.Van de Maele, comunicación personal). Entre las formas de las vasijas se encontraron tazas, platos y estatuillas de origen inca. Por otro lado, se han recuperado algunos fragmentos de cerámica ordinaria Valdivia en pozos de sondeo asociados a construcciones de piedra cerca de la localidad Madre de Dios (Ciruelos, Provincia de Valdivia). Se debe destacar que en el lugar no se halló ningún resto de origen español.

Para concluir con la parte arqueológica, debemos puntualizar que los sitios arqueológicos que arrojaron artefactos relacionados con la cultura inca están situados generalmente a lo largo de las vías fluviales, bahías, lagos, cerros y en las cercanías de antiguos yacimientos auríferos. Aunque se nos presentan problemas de muestreo, existe una difusa presencia de materiales arqueológicos de origen inca en el centrosur de Chile. La situación geográfica de este tipo de sitios arqueológicos tiende a sugerir la selección de áreas específicas y refleja contactos o una penetración pacífica del estado incaico de la Araucania en Chile.

\section{Datos etnohistóricos y la arquelogía}

Al visualizar los datos del pasado desde la doble perspectiva de la documentación etnohistórica y del registro arqueológico esperamos encontrar suficiente información para inferir que la influencia y la actividad incaica en la época prehispánica se extendía hasta áreas situadas mucho más al sur del Río Maule. Sin embargo, no se considera que la actividad o la influencia está asociada a instalaciones permanentes incai- 
cas (asentamientos habitacionales). Aunque el registro arqueológico es escaso hasta el presente, el patrón de la actividad incaica parece más bien representar una serie de islas de actividad social y económica dispersa entre las diferentes poblaciones en contacto con los incas, formando así una especie de archipiélago. Lamentablemente, se conoce muy poco acerca de la forma como operaba el estado más allá de sus instalaciones fijas, en el límite político del Río Maule. Considerando incluso el hecho histórico que los araucanos detuvieron el avance inca a través del Río Maule, evidentemente había grupos de indígenas pacíficos más al sur que estaban dispuestos a recibir y/o cooperar con los incas.

Este patrón se observa también en las relaciones que existían entre los españoles e "indios amigos". Los españoles, aún en constante conflicto con los araucanos durante 340 años fundaron fuertes e instalaron poblados dispersos, aislados y distantes, más de $100 \mathrm{~km}$ entre sí, a lo largo de bahías, ríos y lagos, dando lugar a una ocupación a manera de un archipiélago en el interior del territorio araucano. Existen inclusive testimonios sobre que algunos españoles se establecieron individualmente entre la población autóctona, enseñándoles nuevas tecnologías, el modo de vida europeo y que, además, participaron en la guerra al lado de los indígenas y contra sus propios compatriotas.

Este tipo de contacto y patrón se vislumbra con respecto a la presencia inca en el área que denominamos el segundo límite, es decir, el límite socioeconómico. Este límite se extendió unos $500 \mathrm{~km}$ más al sur de la frontera geopolítica formalizada, situada en alguna parte del centro-sur de Chile. Creemos importante considerar la consecuencia geográfica y cultural de estos dos tipos de límite del estado incaico y la manera en que éstos podrían haber impactado tanto las instituciones del estado como las instituciones de las culturas autóctonas. Futuros estudios deberán realizarse para analizar el impacto de estas situaciones sobre las partes involucradas. A pesar del escaso material a nuestra disposición, podemos obtener una idea básica acerca de la influencia que los límites socioeconómicos, geográficamente extendidos, ejercieron sobre la cultura araucana.

\section{Los límites socioeconómicos geográficamente extendidos}

Los primeros cronistas suministran algunos pocos datos básicos referentes al tipo de organización estatal, social y a las actividades individuales que se realizaron al sur de los límites geopolíticos. Estas actividades fueron tanto oficiales como no oficiales. Oficiales, en el sentido que el estado probablemente envió emisarios en misión diplomática, como también de yanaconas trabajadores y cateadores mineros para la explotación de los recursos naturales. No oficiales, en el sentido que probablemente vivían entre los araucanos numerosos indígenas incas o hablantes de quechua, desertores y refugiados, quienes enseñaron a sus hospederos nuevas tecnologías o mejoraron las ya existentes.

En el campo de la transferencia de tecnología, a partir de los primeros documentos escritos y de datos etnográficos contemporáneos, podemos determinar que ciertas 
técnicas del tejido, diseños textiles, implementos agrícolas, la explotación de minas de plata y la organización del trabajo probablemente fueron adquiridas de los incas. Un caso particularmente bien conocido es el sistema mapuche de trabajo comunitario entre familias relacionadas entre sí. En mapudungun o lengua mapuche este sistema recibe el nombre de mingaco, mientras en lengua quechua se dice minga.

La extensión del presente estudio no permite un listado amplio de palabras quechuas en la lengua araucana, pero se pueden citar algunos ejemplos:

\begin{tabular}{lll}
\hline Qechua & Araucana & Español \\
\hline charqui & carne seca \\
(hua) & wa-(hua) & maíz \\
(huacho) & wacho & hijo ilegítimo, huérfano \\
(huima) & ñachi & sangre cuajada que se come cruda \\
(huima) & waina & mozo, joven \\
\hline
\end{tabular}

La lingüista Mary Ritchie Key y otros han publicado estudios sobre este tópico. De su trabajo podemos concluir que los mapuches en la actualidad empleen más de 100 palabras quechuas. Lo que parece ser relevante es que la mayoría de estas expresiones se relaciona con aspectos tecnológicos o con estructuras de la organización social y económica. En el idioma mapuche no conocemos palabras prestadas del quechua relacionadas con armas o acciones militares. Sin embargo, nos parece que la honda como arma de ataque a distancia fue adoptada durante la época de la conquista. Pedro de Valdivia ([1861]1978:155) en una de sus cartas anota como fenómeno digno de mención: "No pelean con piedras." Guaman Poma de Ayala ilustra el enfretamiento del ejército incaico, blandiendo hondas, a los "indios de Chile" sin hondas. Sin embargo, los datos históricos del siglo XVII (Quiroga [1690] 1979) indican el empleo de esta arma en el ataque contra los fortines españoles. Su uso queda ampliamente documentado en el fortín de Carilafquén (Gordon sf). En el área de la religión, la influencia atribuible a los incas es aparentemente ínfima, si es que existe alguna. Los araucanos, principalmente horticultores y agricultores, adoraban al sol. La palabra para indicar "sol" en mapudungun es antu, supuestamente derivada de la palabra quechua inti. Sin embargo, ésto no es suficiente evidencia como para llegar a una conclusión sobre afiliaciones religiosas.

El problema principal en este conjunto de rasgos culturales influenciados por la cultura inca reside en la cuestión temporal, lo mismo que ocurre con la alfarería de tipo Valdivia. ¿Llega esta influencia antes o durante la conquista hispana? En el caso de los datos lingüísticos y etnográficos, tal vez, nunca lo sabremos con certeza. No obstante, según los registros arqueológicos, está claro que hubo contactos prehispánicos entre incas y araucanos en el sur del territorio del estado; lo que estamos sugirien- 
do es que las relaciones se centraban en torno a actividades sociales y económicas, similares al tipo de las que se manifiestan en los registros lingüísticos y etnográficos mencionados.

\section{CONCLUSIONES}

En base a los datos y argumentos expuestos, se puede postular que existían dos tipos de límite del estado en el área del extremo sur del imperio incaico. Uno de estos límites estaba formado por una exclusiva línea limítrofe fortificada que cercaba una población indígena relativamente densa en el centro de Chile. La ocupación militar y la soberanía del estado incaico no se extendió más allá de este límite, como tampoco existió ningún control o actividad formalizada por parte del estado. El otro límite fue el resultado de una política calculada de penetración pacífica no formalizada, pero expansiva, que iba conduciendo (y habría conducido a la postre) al dominio territorial. Esta segunda frontera, evidentemente no estaba delimitada por una línea, límite o proceso unilateral de ocupación, sino que formaba más bien una frontera inclusiva de intenciones múltiples y complejas transacciones sociales y económicas y de adaptación. Esta situación se desarrollaba tanto por parte del estado como de los individuos de origen inca, quienes actuaban ejerciendo su oficio en calidad extraoficial. Es muy probable que la influencia cultural inca en la cultura araucana temprana y moderna haya sido lograda por medios indirectos como un tipo de "imperio no formalizado" o de una influencia extendida a manera de islas formando un archipiélago a través del territorio sureño. Probablemente, la atracción de la plata y del oro fue lo que más intensamente motivó a los incas para penetrar en los bosques sureños y entender su frontera de actividades sociales y económicas. Ya mencionamos algunos de los puntos en que la cultura inca hizo impacto sobre la Araucania. La influencia que estas experiencias fronterizas ejercieron sobre el estado incaico no ha sido aún explorada. Sin embargo, a partir de los trabajos de algunos investigadores sabemos que en la interacción en las regiones fronterizas, entre las lejanas instalaciones del estado y las etnias locales se basó la dinámica inca de expansión de los límites del imperio. El fracaso en el control de ciertos límites y los tipos de frontera muy extendidos, como a las que se hace referencia en el presente estudio, debe haber legado un patrimonio de estructurados desequilibrios además de un desproporcionado crecimiento estatal que podría ser denominado un "colonialismo interno". En consecuencia, deberá realizarse una investigación más analítica y detallada sobre los tipos de conexiones e impulsos para establecer una coherencia entre los límites étnicos y la ideología política del estado. El problema que se refiere a la expansión del estado incaico deberá ser abordado en futuros estudios para establecer estas conexiones e impulsos con mayor precisión. 


\section{BIBLIOGRAFIA}

Bibar, Gerónimo de

[1558] Crónica y Relación copiosa y verdadera de los Reynos de Chile.

1966 (MDLVIII). Fondo Histórico y Bibliográfico José Toribio Medina.

Santiago.

Bullock, Dillman

1955 Urnas funerarias prehistóricas de la región de Angol. Boletín del Museo Nacional de Historia Natural. 26(5):93-154.

Cieza de León, Pedro

[1553] El señorío de los Incas. Instituto de Estudios Peruanos. Lima. 1977

Dillehay, Tom D.

1976 Informe sobre trabajo antropológico en la Provincia de Cautín. Universidad Católica de Chile. Banco Interamericano de Desarrollo. Panamá.

Ercilla y Zúñiza, Alonso de

[1568] La Araucana. Editorial Aguilar. Madrid.

1968

Fernández Baca, Jenaro

1971 Motivos de ornamentación de la cerámica Inca Cuzco. Librería Studium, S.A. Lima.

Garcilaso de la Vega, Inca

1967 Comentarios reales que tratan del origen de los Yncas. Editorial [1609] Universitaria. Lima.

Gordon, Américo

sf El fortín Carilafquén de la temprana época de la Conquista. (Inédito, 1985).

Guevara, Tomás

1925 Historia de Chile: Chile Prehispánico. Tomo 2. pp. 260-270. Santiago.

Mariño de Lobera, Pedro

[1580] Crónica del Reyno de Chile. Colección Historiadores de Chile. Imprenta 1865 del Ferrocarril. Santiago.

Medina, José Toribio

1882 Los aborígenes de Chile. Imprenta Gutenberg. Santiago.

Montecinos, Fernando

[1682] Memorias antiguas y políticas del Perú. Marcos Jiménez de la Espada,

1882 ed. Colección de libros españoles raros y curiosos. 16:1-76. Madrid. 
Navarro, Ximena

1979 Arqueología de un yacimiento precordillero en el sur de Chile (Pucon, IX: Región). Universidad Austral de Chile. Valdivia.

Olavarria, Miguel de

[1594] Informe de Don Miguel de Olavarria sobre el Reyno de Chile, sus indios 1852 y sus guerras. Documentos sobre la historia, la estadística y la geografía de Chile. C.Gay. Tomo 2, compilado por C. Gay, pp. 13-54. Santiago.

Ovalle, Alonso de

[1646] Histórica relación del Reyno de Chile. Editorial Universitaria, S.A. 1969 Santiago.

Prescott, William

[1847] Historia de la conquista del Perú. Ediciones Imán. Buenos Aires. 1955

Quiroga, Gerónimo de

[1690] Memorias de los sucesos de la guerra de Chile. Editorial Andrés Bello.

1847 Santiago.

Rosales, Pedro Diego de

[1670] Historia General del Reyno de Chile. El Mercurio. Valparaíso, Chile. 1897

Santillan, Hernando de

[1563] Relación del origen, descendencia, política y gobierno de los incas.

1968 Biblioteca de Autores Españoles. Tomo 209. pp. 97-149. Ediciones Atlas. Madrid.

Silva, Osvaldo

1983 ¿Detuvo la batalla del Maule la expansión inca? Cuadernos de Historia 3:7-26.

Stehberg, Ruben L.

1974 Fortaleza "La Muralla". Noticiario Mensual 219:3-5. Museo Nacional de Historia Natural. Santiago.

Stehberg, Ruben L.

1976 La Fortaleza de Chena y su relación con la ocupación incaica de Chile Central. Publicación Ocasional del Museo Nacional de Historia Natural, 23. Santiago.

Uhle, Max

1913 La esfera de influencia del país de los Incas. Trabajos del IV Congreso Científico. Tomo 12. pp. 260-281.

Valdivia, Pedro de

[1861] Cartas de relación de la conquista de Chile. Editorial Universitaria S.A. 1978 Santiago. 


\title{
LOS DIAGUITAS Y EL TAWANTINSUYU: UNA HIPOTESIS DE CONFLICTO
}

\author{
Ana María Lorandi
}

En el debate suscitado durante las sesiones de este simposium, los comentaristas John Murra y Richard Schaedel expresaron su asombro frente al hecho de que no se hubiese definido el concepto de frontera del Tawantinsuyu. El tema no se había discutido, en efecto, y fue muchas veces ignorado. De allí que, al redactar la versión definitiva de la ponencia presentada en este XLV Congreso Internacional de Americanistas, se dedicará especial atención a este problema.

Tal como muchos lo hicimos, la "frontera" parecía definida por la perspectiva de la distancia entre la región estudiada y el centro nuclear del estado inca, es decir, de acuerdo a su condición de relativa marginalidad geográfica, en nuestro caso acrecentada debido a que no suscitó el mismo interés que la frontera norte, donde Tumipampa tuvo las pretensiones de ser otro Cuzco.

No obstante lo anterior creo que el área diaguita y el Tucumán pueden ser vistos como una "frontera" y no solo por razones geográficas. Vayamos por partes.

Las relaciones culturales entre los Andes Centrales y el noroeste argentino, que integraba la mayor parte de la jurisdicción política del Tucumán colonial (que incluía también a Córdoba), se remontan a los tiempos iniciales de la ocupación humana en el territorio. Sin embargo, esta área sufrió procesos particulares que la distinguen de la zona nuclear. Es una región abierta a la penetración cultural y étnica proveniente de las tierras bajas chaqueñas y presenta una ecología que, en términos generales, es menos rica y variada que la frontera norte. Si bien incluye sectores muy fértiles, existen otros casi desérticos y no puede "competir" con el norte del Ecuador y el sur de Colombia donde la variedad de cultivos y la riqueza en oro ofrecían señuelos tentadores a las apetencias del Cuzco. Además, la frontera norte lo ponía en contacto con zonas más densamente pobladas que la nuestra y de manera especial con recursos, en casos inexistentes en los Andes Centrales. Incluso, desde el punto de vista minero, se pueden haber tenido buenas expectativas en el noroeste argentino, aún cuando los resultados, sin duda, no fueron espectaculares.

Para comprender la problemática vinculada a la frontera sur del Tawantinsuyu es necesario tener un panorama de la distribución étnica de la región. En publicaciones anteriores (Lorandi 1980, 1984) ya planteamos parcialmente este tema, en especial el que se refiere a la identificación de lo que fue el Tucumán prehispánico con referencia al posterior Tucumán colonial. Para una mejor aproximación a esta problemática, deberemos identificar primero los principales sectores en los cuales puede subdividirse el noroeste argentino, sobretodo aquellos que son necesarios conocer para los fines de esta presentación. Para el caso nos interesa distinguir las siguientes regiones étnicas: 


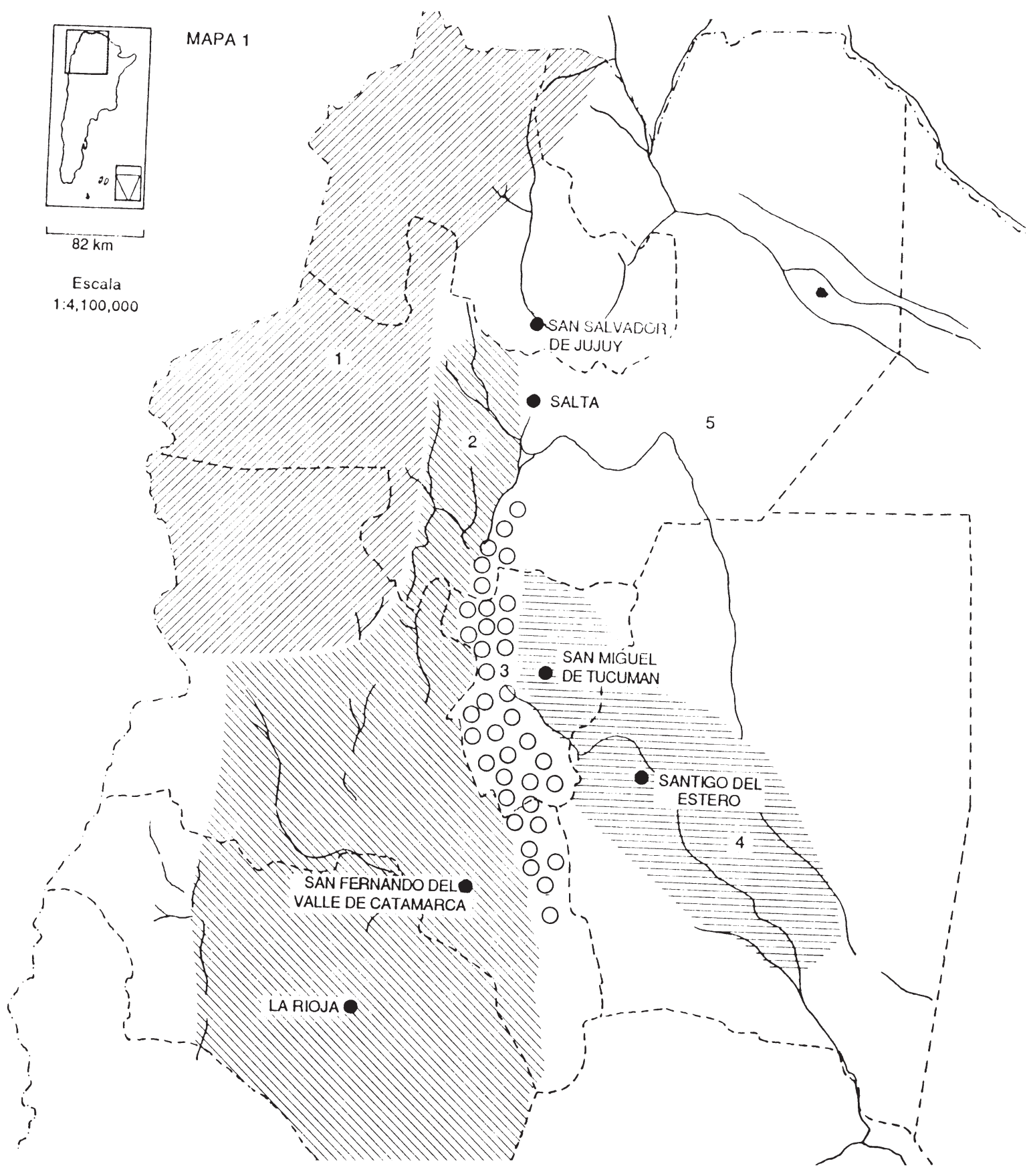

Figura 1. Puna 2. Valliserrana Central. 3. Tucumán Prehispánico. 4. Chaoc San Tiagueña. 5. Chaco. La presente publicación se ajusta a la cartografía oficial establecida por el Poder Ejecutivo Nacional a través del IGM, Ley 22963 y fue aprobada por Expdte.Na.G.G.6 4020/19 de fecha 21 de abril de 1986. 
I. El sector Noroeste Andino (NOA) está ocupado por la prolongación meridional del altiplano, es decir, la llamada puna argentina. La caracterización étnica de este sector en las fuentes relativas a las primeras entradas es nula o vaga, puesto que, en general, es considerado como parte del altiplano y no se le describe. Hay pocas menciones sobre sus habitantes, excepto las de los pueblos de Casavindo y Cochinoca, sin asignación étnica general. Por el momento, para los fines de esta discusión, no interesa internarnos en este problema. (Para más datos sobre este punto, ver Krapovickas 1978). En el mapa adjunto lo hemos indicado como Zona 1. (Figura 1)

II. El área valliserrana central (Zona 2 del mapa) comprende diversos valles y pampas, abiertos entre cadenas montañosas que se escalonan a lo largo de las Provincias de Salta, Catamarca y La Rioja y el oeste de Tucumán. Toda el área fue ocupada por una gran unidad étnico-lingüística denominada diaguita, de habla kakana ("serrano" en quichua). Dentro de este amplio territorio y del conjunto diaguita podemos distinguir diversos grupos étnicos o parcialidades. Si bien en las primeras entradas todos estos indios fueron designados como diaguitas, con el tiempo los pueblos que ocupaban los actuales Valles de Calchaquí y Santa María (o Valles Calchaquíes como denominación general) empezaron a ser identificados como calchaquí. Este apelativo es una hispanización proveniente de la extensión del "apellido" de un líder de la resistencia indígena llamado Juan Calchaquí.

Las investigaciones etnohistóricas demuestran que más tarde, a medida que los diversos grupos que habitaban estos valles pudieron ser individualizados con mayor precisión, el gentilicio calchaquí no aparece como autodesignación de ningún grupo étnico en particular. No obstante, se generalizó su uso para señalar en general a todos los habitantes de los Valles Calchaquíes. En consecuencia, cuando debamos referirnos a las poblaciones del valle en el sentido de "todos los habitantes del valle", usaremos también esta designación por razones de comodidad expresiva.

Por el momento conocemos la existencia de un cierto número de grupos étnicos o parcialidades que presentan una relativa coherencia política interna, así como de otros grupos sobre los cuales desconocemos sus relaciones o su más amplia filiación.

A los efectos de esta presentación parece oportuno mencionar solo las unidades étnico-políticas más importantes que deberemos incluir en el análisis del tema. Estos grupos se distribuyen de norte a sur de la siguiente manera:

1. En la originalmente llamada "provincia de Chicoana" (Valle Calchaquí propiamente dicho en sus sectores alto y medio) hallamos un grupo llamado pular que controla un amplio territorio en el valle y también fuera de él en el Valle de Salta (ubicado al este del Calchaquí).

2. El extremo sur del Valle Calchaquí y norte del actual Santa María fue habitado por diversas parcialidades, erróneamente denominadas calchaquíes, entre las cuales debemos mencionar en especial a los tolombón, colalao y paccioca.

3. En el centro del Valle de Santa María encontramos una unidad muy bien localizada "que tienen 11 pueblos" cuyos habitantes son llamados quilme. 
4. En el sur del valle hallamos a los yocabil "con 10 pueblos", la mayoría recostados en las laderas del Aconquija y en la banda opuesta a los ingamana.

5. Hacia el sur, en los actuales Valles de Hualfín y en Andalgalá, hallamos a los malfin en el primero y a éstos y los andalgalá en el segundo.

6. En el Valle de Abaucán, próximo a la cordillera que nos separa de Chile, a los abaucán.

7. En el centro de la Provincia de Catamarca hay diversas parcialidades de estructura política más segmentada que las anteriores, aunque en general todas lo son.

8. En el norte de La Rioja hallamos a los sanagasta y otras parcialidades de menor importancia política y demográfica.

En suma, éstas eran las principales etnias del área central.

III. Hacia el este, ocupando las pampas altas y las vertientes orientales de las cadenas que forman el límite del Noroeste Argentina, hallamos la antigua provincia prehispánica del Tucumán. Estas sierras son: Aconquija, parte del Ambato, Alto, Ancasti y algunos cordones paralelos que descienden hacia la llanura tucumano-santiagueña.

El Tucumán Prehispánico fue habitado por diversos grupos con menor coherencia política que los del área diaguita y, en general, presentan características culturales mixtas, entre andinas y chaqueñas. En las primeras épocas de la ocupación hispana, esta región fue identificada como la tierra del cacique Tucma o Tucuman. Sin embargo, compartiendo el territorio con ellos hallaron los conquistadores hispanos a los juríes, designación genérica que significa "los que se visten con plumas de avestruz" (ñandú), las cuales fueron consideradas como behetrías y de hábitos semisedentarios. No obstante ésto, los indios del Tucumán propiamente dicho se distinguen de estos otros por un mayor nivel cultural y político, pero nunca se logra una identificación étnica precisa de los vasallos del cacique Tucma o Tucuman.

Los juríes que comparten el territorio con los de Tucumán fueron luego llamados por nombre étnicos precisos tales como lule, solco y tonocoté. Para la región de Tucumán nos restan entonces otros dos grupos: los aconquija y los tafí que habitaban las pampas altas de las sierras y que confinaban con los diaguitas de los valles centrales.

IV. En la llanura interfluvial de Santiago del Estero habitaban, al menos, dos pueblos sedentarios, identificables por las claras diferencias en sus tradiciones cerámicas aunque participaban de un patrón de poblamiento común. Estos grupos eran los tonocoté y posiblemente los lule. Una de las tradiciones alfareras de Santiago se expande hacia el oeste y penetra la región tucumana. Ese es uno de los indicadores de las relaciones étnicas que podrían haber mantenido ambas subregiones del noroeste. Lo cierto es que la llanura santiagueña no formaba parte del Tawantinsuyu cuyo límite oriental pasaba por la frontera del territorio de Tucuman. 
En términos generales, dejando fuera de consideración el área puneña, las tres grandes regiones étnicas quedan identificadas con el nombre que los españoles dieron a esta nueva provincia, es decir, de tucumán y de juríes y diaguitas.

Si insistimos en dilucidar este punto, que ya hemos tratado en trabajos anteriores, es porque el mismo se torna imprescindible para evaluar los informes referentes a la conquista de la región por parte de los incas, dado que es necesario hacer compatibles las opiniones de diversos autores que han tratado el tema.

Por ejemplo, Garcilaso sostiene que los indios del Tucumán ofrecieron voluntariamente su vasallaje al Inca. A su vez, Lozano afirma que los calchaquíes resistieron ferozmente esa conquista. Si se engloba a las dos regiones, la de los diaguitas y Tucumán, en una misma unidad estas afirmaciones parecen contradictorias, puesto que consenso o incluso alianza y luego coherción parecen incompatibles. Si consideramos, en cambio, que cada sector tuvo una historia prehispánica independiente, en ese caso merecen un análisis diferente.

Respecto a las fuentes, lo primero que nos ha llamado la atención es la escasez de datos relativos a nuestra zona en las obras de los cronistas peruanos. Para ésto hay razones históricas vinculadas al tipo de ocupación hispánica que expondremos más adelante, pero lo cierto es que las noticias sobre la conquista inca son muy vagas en cuanto a detalles o a las particularidades que tomó su dominio en esta región. La resistencia opuesta a los españoles por los indígenas del noroeste y la ausencia de riquezas que justificara el arribo de gran número de conquistadores son todos hechos que determinan que no existan crónicas tempranas escritas por testigos establecidos en la tierra. Los datos de Cieza, Garcilazo, Montesinos, Santa Cruz Pachacuti, entre otros, son indirectos y casi circunstanciales. Esto también determina, sin duda, la imagen de marginalidad dada a la región.

Cieza de León nos habla del Tucumán como de una "frontera" en tiempos incas. Refiriéndose a los nativos de la zona dice:

"...fácilmente los pudieron los orejones atraer a que se dieran por vasallos del Rey Inca e concertaron que su amistad fuese perpetua, e ellos obligados a no mas de aguardar aquella frontera que no entrase ninguna gente por alli a dar la guerra a su Señor como esta paz fue hecha..." (Cieza [1553] 1947:Cap.XVI).

En trabajos anteriores (Lorandi 1980, 1983) interpreté que Cieza se refiere a la "frontera" oriental, que debió ser defendida de los ataques de los lulu, nómadas que presionaban hacia la sierra desde las tierras bajas del chaco-santiagueño. Ahora bien, reflexionando sobre la conducta colonial de los diaguitas, en especial la de las poblaciones que habitaban los Valles de Santa María y Calchaquí que resistieron al dominio español durante 130 años, este concepto limitado de "frontera", circunscrito a la porción oriental del territorio incorporado al Tawantinsuyu, me parece insuficiente.

El jesuíta Pedro Lozano insiste en señalar el hecho de la resistencia calchaquí ante la invasión incaica. Opinión que mucho más tarde comparte el arqueólogo Juan B. 
Ambrosetti poniendo en duda la incorporación de la zona al imperio. Posteriormente, la arqueología ha demostrado que tal propuesta no corresponde a los hechos, dado que la ocupación inca está ampliamente documentada. No obstante, la cita de Pedro Lozano merece ser transcrita en su integridad porque ofrece matices que no han sido explorados en su justa medida. Pedro Lozano escribe:

"Otros finalmente, empeñados en introducir por cualquier camino el Imperio de los Ingas en Tucumán, dicen ahora, haber sido tradición entre los indios tucumanos que las milicias peruanas entraron por la parte de Salta, y prueban su dicho, lo primero por el lugar que en el valle de Calchaquí hasta hoy preserva, con el nombre de Tambo del Inga, y lo segundo con el pueblo y asiento que llamande Chicoana... porque para seguridad de esta conquista, mandó el Inga poner en aquel paraje... un fuerte presidio, cuya guarnición venía a sus tiempos, desde el valle de Chicoana, cercano a su corte del Cuzco, remudándose unos en lugar de otros y todos naturales de aquel valle por ser de los más fieles, y por esta razón llamaron a aquel sitio el Asiento de Chicoana en memoria de su patria..." (Lozano 1874,IV:8).

Pedro Lozano, a su vez, reproduce la opinión del padre Diego Lozano quien rechaza la idea de tal conquista. Sostiene este último que los calchaquíes eran indios indómitos. Nuestro autor, que se adhiere en general a esta tesis, la refuerza al señalar que:

...Los cuzqueños temblaban de solo el nombre de los Calchaquí, como que sabían, era gente indómita, fiera por extremo y caribes..." (Lozano 1874:IV,10).

Ahora bien, en otro libro del jesuíta, Historia de la Compañía de Jesús, menos citado, insiste en el tema y confirma los matices del texto precedente:

El poder amplísimo de los Ingas jamás domó el orgullo de los naturales de este valle y los españoles nunca pudieron rendir las duras cervices en más de cien años, si bien los tuvieron a raya, para que no embarazacen las Conquistas de otras Naciones, como también los Ingas procuraron tenerlos enfrenados... (Lozano 1754:I,Cap.X,p. 47).

Se ha desconfiado de las informaciones de este cronista por considerárselas tardías e indirectas. Sin embargo, su trabajo fue el de un verdadero historiador que buceaba en los documentos y, sin duda, dispuso de datos fehacientes, muchos actualmente no localizables.

Una vez más, la arqueología puede venir en nuestro auxilio para ayudarnos a comprender estos matices de los textos de Pedro Lozano. Pues bien, el sector del área ocupada por grupos diaguitas que comprende el sur del Valle Calchaquí, Santa María, Hualfín, Andalgalá y el centro de Catamarca presenta una particular modalidad en la ocupación inca. En todos los asentamientos estatales siempre está presente la cerámica que proviene del territorio que hoy consideramos el Tucumán Prehispánico. Si descartamos que esta alfarería, extraña a la región diaguita, no proviene de intercambios y nos ajustamos al modelo general andino, lo más probable es que dicha cerámica haya sido elaborada in situ por mitmakuna traídos a esa frontera oriental. En trabajos anteriores ya hemos avanzado esta hipótesis y los argumentos que la sostienen (Lorandi 1980,1983,1984b). Resumiendo, podemos decir que la misma plantea la po- 
sibilidad que los indios del Tucumán, acosados por los lule nómadas, se protegieran bajo el "paraguas" imperial. Estos nativos fieles fueron también instalados en la zona de los valles centrales como mitmakuna, una de cuyas funciones fue la de contener a los "bárbaros" del este. Esas funciones pudieron estar acompañadas del disfrute de ciertos privilegios tales como el vestir a la usanza peruana y aprender su idioma, otorgados como parte del sistema de reciprocidad obligada del estado. Más tarde, habiendo regresado estos mitmakuna a su antiguo natural luego de la caída del Cuzco, fueron los que expandieron el quichua en los llanos de Tucumán y Santiago del Estero, subregión que nunca fue incorporada al Tawantinsuyu pero que en tiempos preincas había sido su hábitat como lo muestra la arqueología.

No obstante, a la luz de la cita de Pedro Lozano también el texto de Cieza transcrito arriba adquiere otro carácter. En suma, la frontera no sería exclusivamente la oriental que, sin duda, debió ser defendida. La rebeldía diaguita de aceptar el dominio inca los obligó a soportar que su territorio fuera ocupado por grandes masas de mitmakuna fieles, instalados allí con el propósito de "tenerlos enfrenados", según la expresión de Pedro Lozano. Es decir, que además de las prestaciones agrícolas o artesanales que pudieron cumplir, como lo demuestra la arqueología (Lorandi 1984; Williams y Lorandi 1985), debieron agregárseles también funciones de contención y guarda de las poblaciones difíciles de dominar.

Sin embargo, fuera de los datos de Pedro Lozano y de las evidencias arqueológicas, pocos son los informes que ayudan a aclarar este tema. Al principio de este trabajo mencionamos la escasez de datos en las crónicas tempranas. Muchas veces, aparentemente se engloba a Chile y al Tucumán en un solo conjunto. Cuando Guaman Poma enuncia las conquistas de los reyes incas, menciona que Pachacuti:

\footnotetext{
...conquistó ...la provincia de Chile, Chacllla, Chinchay, Cocha... (Guaman Poma [1615]1980:89).
}

Del mismo modo, al ilustrar sobre las conquistas del octavo capitán Apo Camoc Inga, Guaman Poma nos dice:

Y ance este baleroso capitan fue a Chile llevando cincoenta mil yndios soldados a la conquista... Y dicen que mató cien mil chilenos... (Guaman Poma [1615] 1980:137).

En ningún momento hay referencias concretas a la conquista del Tucumán ni de los diaguitas, si bien Tucumán es mencionado en otras páginas como parte del Tawantinsuyu. Otros cronistas, en cambio, traen algunas referencias. Por caso, Santa Cruz Pachacuti Yampqui consigna que en épocas de Tupa Inca los

...Chiles hazian gente de guerra para contra el Inga y entonces despacha a un capitán con veinte mil hombres y otros a los Guarmeoaucas y Chilles y Tucuma, muy bién, trayéndoles mucho oro; los enemigos no hacen tanto daño en los de acá, antes con fazelidad fueron sujetados y los Guarmeoaucas lo mesmo (Santa Cruz Pachacuti Yampqui [1613] 1950).

Del mismo modo, Montesinos sostiene que hubo diversas batallas y conflictos antes de lograr la paz (citado en Leviller 1926). Garcilaso, en cambio, presenta el asun- 
to como una relación de vasallaje espontáneo ofrecido a los incas por los indios del Tucumán. En prueba de esta amistad entregaron:

...mucha ropa de algodón, mucha miel muy buena, cara [maíz] y otras mieses y legumbres de aquella tierra ...no trujeron oro ni plata porque no la tenían los indios ni hasta ahora por mucho que ha sido la diligencia de los que la han buscado, han podido descubrirla... (Garcilaso de la Vega [1609] 1960:V,Cap.25).

La enumeración de presentes corresponde, sobretodo por la miel, a productos propios de zonas boscosas. Pero ésto puede corresponder a una versión oral recogida por Garcilaso en su juventud o a un relato donde se combinan informes originados en su conocimiento general de la región, dado que también comenta, como se desprende de la cita, que los incas no encontraron oro ni había sido hallado "hasta ahora", es decir en la época colonial.

Por otra parte, el vasallaje ofrecido en la forma descrita pudo ser tanto una reconstrucción tomada del modelo español, como una manifestación del acto final de paz, siempre revestido de ruegos y dones, propio del mundo andino. Finalmente, pudo tratarse de una estrategia de los indios del Tucumán para protegerse de los ataques de los nómadas chaqueños. Las tres hipótesis deben ser puestas en la balanza en el momento de considerar los problemas que nos ocupan.

En estas informaciones sobre el Tucumán o Chile no se incorpora expresamente el área diaguita, ni se la diferencia como zona particular. Ahora bien, si los cronistas peruanos no nos ayudan en esta tarea, la documentación originada en la zona es más explícita, como ya lo señalamos y la arqueología colabora ofreciendo datos importantes.

La existencia de mitmakuna está probada. Sabemos que ésta fue una política que tuvo especial énfasis en todo el altiplano meridional, donde las funciones de estos colonos estatales fueron primordialmente productivas (Wachtel 1980-81; del Río y Presta 1984). Al mismo tiempo, muchos de ellos estaban obligados a prestaciones militares en la defensa de la "frontera de los chiriguanos". Todo el arco suroriental del altiplano está salpicado de guarniciones que se prolongan por el sur hasta el Pucará de Aconquija.

Ahora bien, salvo estas referencias de Pedro Lozano, los datos históricos más precisos para basar nuestra hipótesis de conflicto se encuentran en el proceso colonial posterior.

Llama la atención que dentro del territorio diaguita existían tres asentamientos designados con el nombre de Tucumangasta (o Tucumanaho). Uno de ellos, ubicado al norte de la actual localidad de San Carlos, en el Valle Calchaquí; el otro, al sur del Valle de Santa María en un lugar impreciso (tal vez Ingenio del Arenal) y el tercero, al sur de Andalgalá en el borde del actual Salar de Pipanaco. Sobretodo, el caso del primer Tucumangasta que hemos citado ha sido uno de los argumentos usados para sostener que los Valles Calchaquíes eran parte del Tucumán Prehispánico. Sin embargo, una cita de Herrera arroja cierta luz sobre este problema. 
...entra (Diego de) Rojas al Tucumán y en Tucumano halla buena acogida como es natural, porque el español había heredado los derechos del Inca (Herrera [1601-15] 1934: Década VII, libro IV Cap.II).

Herrera incluye al Valle Calchaquí en Tucumán, pero hace hincapié en la obediencia de los indios, fundado en el traspaso de poder del Inca a los españoles. Sabemos que sus informes son indirectos y que no se puede avanzar en interpretaciones sutiles usando estos datos. Pero, como lo afirma Pedro Lozano, si Chicoana lleva tal nombre en memoria del lugar de origen de los mitmakuna ¿no puede ser que Tucumangasta también haya sido designado así en memoria de la procedencia de otros mitmakuna? Es decir, pueblos de gente del Tucumán instalados en territorio diaguita. En ambos casos, asentamientos de indios amigos del Inca.

Entre 1658 y 1659, los ingamanas, posiblemente antiguos mitmakuna estatales que habitaban el sur del Valle de Santa María en Punta de Gualasto (actualmente Punta de Balasto), mantuvieron una conducta ambigua en la guerra contra los españoles y finalizan por colaborar con ellos, perjudicando a las restantes poblaciones del valle. ${ }^{2}$

Estos ingamanas se mostraron amigos de los españoles y a su vez, reclamaban derechos sobre tierras en Andalgalá y en Hualfín donde habitaban "sus parientes y amigos", como se dice en fuentes diversas (Autos, Charcas 58, $2^{\circ}$ cuad.,ff.58-59. 1658). Los estudios recientes en el asentamiento inca de Potrero-Chaquiago en la zona de Andalgalá demuestran que hubo densa ocupación de mitmakuna provenientes del Tucumán Prehispánico, seguramente dedicados a explotar extensos predios agrícolas y a labores artesanales diversas (Lorandi 1983, 1984; Williams y Lorandi 1985). Lo mismo sucede en Ingenio del Arenal (Marquez Miranda y Cigliano 1961). Veamos un poco la relación espacial de estos asentamientos, probables localizaciones de colonos imperiales.

El primer Tucumangasta al que hiciéramos referencia está ubicado próximo al actual San Carlos, tal vez en la frontera entre los pulares y diaguitas. Desde allí se podía controlar el límite norte de las parcialidades calchaquíes. En el sur, en el Valle de Santa María originalmente llamado de Yocavil, tendríamos: al oeste, al pie de la Sierra del Cajón, a Punta de Gualasto (Gualasto: esquina) desde donde se supervisa el paso hacia el Valle de Hualfín (Carrara, Lorandi et al. 1960). Al mismo tiempo, este asiento permite vigilar el paso hacia el Valle del Cajón, acceso a la puna meridional.

A su vez, recostado sobre la ladera occidental del Aconquija, siempre al sur del Valle de Yocavil, encontramos el Ingenio del Arenal Médanos desde donde se controla el paso hacia el sur por la sierra de Capillitas a cuyo pie, a pocos kilómetros de Andalgalá, se encuentra el establecimiento Potrero-Chaquiago. Al mismo tiempo, por su ubicación el Ingenio del Arenal controla el acceso al Aconquija y a los establecimientos de Las Pavas y Pucará.

Finalmente, el tercer Tucumangasta se encuentra al borde del Salar de Pipanaco, que pudo tener esa ubicación original o ser un traslado colonial. De todas maneras, 
si lo primero fuera cierto, pudo estar ligado a la explotación del saladar y controlar al mismo tiempo el camino hacia Tinogasta y el Valle de Catamarca.

Sin considerar otros posibles asentamientos de colonos estatales, con los ejemplos mencionados podemos comprobar el valor estratégico de cada uno de ellos. Además, incorporando indios amigos en territorio conflictivo, se aseguraban las explotaciones apetecidas y, asimismo, se colaboraba en la administración de las prestaciones rotativas asignadas a los diaguitas, poco propensos a cumplirlas.

Debemos considerar que cuando se instalaban mitmakuna se les concedían tierras para su propia manutención. Estos terrenos en muchos casos pasaron a manos de sus usuarios, sobretodo en estas regiones donde la colonización hispana fue escasa o nula. Después de 130 años sería muy difícil negar los derechos adquiridos. Por otra parte, sabemos que la recomposición de las comunidades a partir de componentes multiétnicos es un fenómeno frecuente que se constata a lo largo de todo el mundo andino. En la región tenemos el ejemplo del pueblo de Culumpí, donde se consigna una parcialidad Tucumangasta. ¿Se trata de una mitad o de un ayllu de tucumanos que quedó integrada dentro de un grupo étnico local? No lo sabemos, puesto que no se aclara en la fuente que otras parcialidades integraban la unidad. (Autos Charcas 58, 1658, $1^{\circ}$ cuad.,f.23v). Pero es un caso que llama a reflexión, puesto que situaciones como ésta pudieron estar en el origen de los conflictos por tierras entre los ingamanas y los pobladores del Valle de Hualfín, conflictos que se perciben confusamente a mediados de 1600 .

Si nuestra hipótesis es correcta, en toda la región se habrían incorporado colonos traídos de otras regiones. En el norte, en lo que Pedro Lozano llama el "presidio" de Chicoana, (posiblemente Potrero de Payogasta o la Quebrada de Luracatao con su fuerte llamado Elencot), adonde venían los indios por "sus tiempos", habían mitmakuna cuzqueños o, al menos, provenientes del altiplano. Esto explicaría la existencia arqueológica del estilo cerámico mixto denominado Inca-Paya y la influencia de otros estilos, visible no solo en el Valle Calchaquí sino también más al norte, en la puna y Quebrada de Humahuaca (Krapovickas 1981-82). En todo el cuadrante septentrional del noroeste los establecimientos estatales incaicos tienen alfarería con rasgos del altiplano. El sector central del área, aquel que muestra relaciones entre los sitios inca y la cerámica de origen tucumano-santiagueño, habría sido controlado por mitmakuna del Tucumán mediante la instalación de guarniciones, algunas de las cuales fueron luego identificadas con el nombre de Tucumangasta. En el sur del área diaguita, en La Rioja y San Juan, lo mismo que en Mendoza (no diaguita) se habrían instalado colonos del altiplano (en Viluco) y chilenos. Solo de esta manera, los incas habrían podido controlar y mantener en paz una región que mostró tantos síntomas de rebeldía durante la época hispánica y, más aún, que muestra tantos indicadores arqueológicos de que la situación en tiempos imperiales no fue diferente.

Por lo que vimos hasta ahora, tendríamos dos argumentos para juzgar que la región, considerada globalmente, debió ser una frontera. Uno de ellos sería su relativa pobreza y marginalidad. El otro es la hipótesis del conflicto interno. En un trabajo 
reciente, Franklin Pease (1982) discute dos casos similares. Uno de ellos es el Reino Chimor y el otro Chachapoyas, este último en la Sierra. Como lo demuestra este autor, la sola hipótesis de conflicto, el caso Chimor, no es suficiente para que un grupo étnico de una región pueda ser considerada como frontera. La situación de Chachapoyas se aproxima más a nuestro caso. Pease la considera marginal, entre otras cosas, por la ausencia de datos sobre los tributos debidos al Inca. Hasta el momento, nosotros no tenemos ninguna información sobre ese punto, excepto una noticia aislada sobre caravanas de oro llevadas hacia el Cuzco, pero no sabemos si se obtenía por prestaciones de los diaguitas o de los mitmakuna, siendo esta última, tal vez, la variable más correcta. Por supuesto, demás está decirlo, no tenemos nada similar a las visitas de Huánuco o a las de los lupacas.

En Chimor y en Chachapoyas, y como veremos más adelante en el área diaguita también, el grado de desestructuración sociopolítica fue mayor en aquellas zonas adonde, como entre los lupacas, el consenso para aceptar la dominación inca fue mayor. Es más, en cuanto a los chachapoyas, Espinosa Soriano afirma que: "Entre los chachas cada ayllu y pueblo o grupo de ayllus o pueblos vivían independientes unos de otros. Cada ayllu se desenvolvía libremente en su pueblo y en su marca o parcialidad.... Los curacas de ayllu no estaban sujetos a nadie". Más adelante agrega, "...tenían una cultura uniforme y hablaban la misma lengua y tenían el mismo dios... nunca constituyeron un estado unificado..." (Espinosa Soriano 1966:233,235, citado en Pease 1982). Pease a su vez sugiere, basándose en Fortes y Evans-Pritchard, que puede tratarse de un caso de estructuras sociales enteramente independientes, pero con autoridades interrelacionadas (1982:189). Los comentarios del colega peruano respecto al papel del Tawantinsuyu y sus efectos, en los cambios que produjo en cada grupo étnico, resultan muy valiosos para entender nuestro problema. En este caso, al aportar un nuevo ejemplo que, a su vez, presenta variables particulares, pretendemos hacer un pequeño aporte a la teoría general sobre la política del Tawantinsuyu y sus efectos en las estructuras sociales de los grupos dominados.

Es evidente que los diaguitas y en especial, los calchaquíes, no debieron ser presa fácil para los incas. Esta hipótesis de conflicto se sustenta, como ya dijimos, en la situación colonial, época durante la cual a pesar de las constantes luchas internas entre las distintas unidades étnicas, supieron conservar una política de solidaridad generalizada respecto al invasor. La jurisdicción española se hizo efectiva en los Valles Calchaquíes apenas en 1665 (Autos Charcas 58,78 $1^{\circ}$ cuad.,f.34). En el sector sur del área diaguita, en Andalgalá, Hualfín, Catamarca y La Rioja, la ocupación hispana comienza precariamente y sujeta a muchas incertidumbres desde fines del siglo XVI. No obstante, en 1630 se produjo un levantamiento general y todos los diaguitas se aliaron tras el objetivo de expulsar a los españoles. La ciudad de La Rioja se salvó a duras penas y la conmoción fue general. Hacia 1643 esta situación quedó bajo control en el sur, pero los Valles Calchaquíes continuaron incólumes en su resistencia. Solo después de una guerra sin cuartel, llevada a cabo en dos campañas, una en 1659 y la otra en 1664, así como con la posterior desnaturalización de todos los indios del valle (los quilme fueron llevados hasta Buenos Aires), se logra pacificar el Tucumán colonial y obtener la tan apetecida mano de obra que se les había escamoteado a los 
españoles por más de un siglo. Mano de obra, de todas maneras, notablemente disminuída por los efectos de las epidemias y, sobretodo, de las guerras. El proceso de despoblación ha sido, en líneas generales, irreversible hasta la presente.

Si las apreciaciones anteriores se ajustan a la realidad, serían la base para considerar que la región central del Noroeste Argentina fue, en efecto, una frontera que durante el período incaico tenía dos frentes de conflicto. Uno externo, hacia las tierras bajas desde donde los lule asolaban al Tawantinsuyu y otro interno, adonde era necesario controlar a los diaguitas, que no dieron muestras de consenso para aceptar su incorporación al estado inca. La región debió interesar a los cuzqueños por sus posibles riquezas mineras, si bien este es un punto controvertido. En una carta del padre León, jesuita que evangelizaba en los Valles Calchaquíes en 1658, se afirma que:

... Cada año pasaban por este valle de renta al Inga quatrocientos carneros cargados de oro, la renta del Inga de estos quatrocientos enterraron en este valle quando oyeron que le avían muerto... (Autos Charcas 122).

Esta información es tardía e imprecisa, ligada al interés de los misioneros por conservar en los valles a Pedro Bohorquez quien comanda el último episodio de rebelión. En toda su extensión, la carta del Padre León, por su parte, muestra la ansiedad por hallar minas cuya localización, según los españoles, ocultaron los indios durante el largo período de resistencia. Pedro Bohorquez, según ellos, sería el encargado de develar esos secretos.

Además del oro, debemos considerar que la otra gran apetencia cuzqueña era la mano de obra. Si bien esta región no tuvo la misma densidad demográfica que el altiplano, no sería nada despreciable. No obstante que no hay información sobre traslados de diaguitas fuera del territorio, no sería improbable que los hayan enviado a Chile donde la riqueza minera era mayor. En el sur de Bolivia encontramos juríes, puestos allí por el Inca, para defender esa frontera de los ataques chiriguanos y donde permanecieron hasta fines del siglo XVI (del Rio y Presta 1984:241-242). Ahora bien, hay que tener en cuenta que estos juríes eran pobladores del Tucumán prehispánico y no del área diaguita, por lo tanto eran fieles al Inca. Es difícil pensar que se les pudieran confiar obligaciones similares a indios de dudosa lealtad. Lo más probable entonces es que la mayor parte de las prestaciones diaguitas se hayan cumplido dentro de su propio "país".

Finalmente, hay que tener en cuenta que la región era el paso obligado en el camino hacia Chile si, como lo haría Diego de Almagro más tarde, se deseaba evitar la travesía del desierto de Atacama. Por lo tanto, controlando el noroeste argentino se aseguraba esa ruta y además se cuidaban las espaldas de Chile.

Hechas estas consideraciones, ahora podemos preguntarnos sobre las posibilidades de realizar estudios que nos aclaren algo más acerca de esta "frontera" meridional del Tawantinsuyu. Para ello, debemos evaluar la calidad de la información contenida en las fuentes en relación con la situación colonial; solo después podremos plantearnos los problemas etnológicos que deberíamos dilucidar. 
En general, el estudio etnohistórico en el Noreste argentina se hace más difícil que en los Andes Centrales. Veamos las razones:

1. La penetración española encuentra grandes dificultades. Diego de Almagro la atraviesa solo en su viaje de ida a Chile en 1535. Diego de Rojas y su gente la recorren entre 1543 y 1545, en una expedición que, si bien duró tres años, fue azarosa y de la cual no obtienen ningún rédito económico. Este será un factor clave para comprender el resto del problema.

2. A partir de 1550, la ocupación española comienza a hacerse efectiva con los sucesivos intentos de fundar la ciudad del Barco que culminan con el establecimiento de Santiago del Estero en 1553 por obra de Francisco de Aguirre. Durante años, todos los esfuerzos para ocupar la zona más rica, es decir el interior de los Valles Calchaquíes, se estrellan contra una feroz resistencia indígena. Resistencia que solo permitirá la instalación de ciudades en el cinturón exterior de los valles, desde donde se ejerce una jurisdicción solo teórica sobre los mismos. Tan es así, que las encomiendas calchaquíes que se reparten nunca se hacen efectivas y sus depositarios no disfrutan de las prestaciones esperadas.

Tenemos así un factor de perturbación que marca una diferencia sustancial entre la colonización del Tucumán y la de los Andes Centrales. No existen relaciones económicas estables entre los diaguitas de los Valles Calchaquíes y los españoles y, en consecuencia, los datos etnológicos son escasos y fragmentarios. Disponemos de informes que relatan las "entradas" para pacificarlos o de escasas cartas producidas por los misioneros jesuítas, de las cuales la más extensa, aún así no demasiado rica en datos etnológicos, es la del padre Torreblanca, escrita en razón del último episodio de resistencia comandado por Pedro Bohorquez (Torreblanca [1696] 1984). Sin embargo, esa carta, que es una larga crónica de los sucesos fue escrita después de concluida la guerra ya lejos de su escenario y, además, tenía un objetivo concreto: limpiar la imagen de Pedro Bohorquez y la de la Compañía de Jesús, respecto a dicho episodio. Por lo mismo, los datos etnológicos son solo los necesarios para dar coherencia al relato.

Los primeros asentamientos hispanos entre los juríes (Santiago del Estero) y en Tucumán (San Miguel de Tucumán, Salta), pasaron por años de miseria e incertidumbre. Estaban relativamente aislados y poco comunicados con el Alto Perú. Más tarde, se logra completar el cerco con las fundaciones de La Rioja en 1591 y Jujuy en 1593. Pero como vemos, ésto se produce 50 años más tarde de la llegada de Pizarro al Perú. A pesar de las dificultades, los españoles continuaron interesados en ocupar la región. La razón debemos buscarla, sobretodo, en el descubrimiento de Potosí en 1545. Desde ese momento, la búsqueda de un puerto sobre el Atlántico para enviar la plata a España se convierte en una obsesión de los sucesivos gobernantes.

Hacia 1570 el Virrey Toledo bombardeará con cartas y órdenes a los gobernadores del Tucumán para que completen las fundaciones. El famoso itinerario de Matienzo, que marca la ruta del camino inca y sus tambos, no se hace sin duda por su curiosidad arqueológica sino para facilitar la información sobre el mejor cami- 
no hacia el sur. Es más, la fundación de Córdoba en 1573 cobra significación en este contexto de enlace con Buenos Aires.

4. Ahora bien, esta situación de inestabilidad de las ciudades, la carencia de minas locales de importancia que convocaran masas considerables de mano de obra y atrajeran a la población europea, la ausencia de grandes centros de poder político y económico (tanto prehispánicos como coloniales), son factores relevantes que explican la falta de crónicas de importancia. Ninguna se dedica en especial y exclusivamente a Tucumán. Ninguna nos ofrece relatos concretos y confiables acerca de los tipos de estructuración del poder político o social de las poblaciones de la región o acerca de la forma de articulación entre el estado inca y esas sociedades. Las que lo hacen, pongamos por caso a Cieza o Garcilaso, como ya lo comentamos arriba, incorporan relatos indirectos, generales y poco precisos, de escaso valor testimonial. Nadie que haya convivido con nuestros indígenas se ocupó de relatar pormenorizadamente sus hábitos y las formas concretas de su vida social o de su ideología. Tenemos, eso sí, otros tipos de documentos: las probanzas de méritos o relaciones generales, documentos administrativos, militares o jurídicos y también religiosos, pero que presentan menos información etnológica que sus equivalentes en los Andes Centrales.

De todas maneras, y a pesar de lo dicho, la información aunque fragmentada existe y es susceptible de ser explotada. Simplemente es más difícil extraerla y seguramente menos rica que la de las áreas nucleares. Aquí no se realizan las visitas de la época toledana; la de Francisco de Alfaro de 1611 no ha sido hallada. Hay otras más tardías, pero con escasos detalles etnológicos.

5. Aún más, todo el sistema de encomiendas en la zona difiere del que se aplica en el Perú aunque legalmente es el mismo. En la práctica, es una forma encubierta de servicio personal. Las causas de este problema provienen de factores diversos. En primer lugar, las comunidades que pudieron ser incorporadas al sistema colonial a medida que se realizaban las fundaciones carecían en general de excedentes que permitieran una renta atractiva a los encomenderos. Los indígenas eran desplazados hacia las haciendas y estancias de los españoles o bien éstos se apoderaban de sus tierras y los hacían trabajar en ellas como operarios agrícolas o ganaderos, y sus mujeres eran obligadas a hilar y tejer mantas de algodón, "la moneda de la tierra".

Resumiendo desde los puntos de vista historiográfico y etnológico el hecho de la relación conflictiva entre españoles e indios, la no perduración de las comunidades en sus establecimientos originales, los contactos casi exclusivamente bélicos con los calchaquíes, entre otros factores, oscurecen el tipo y la calidad de la información que puede ser hallada en los papeles coloniales. De todas maneras, el trabajo está apenas comenzado y, tal vez, cuando lo intensifiquemos podamos decir que estas apreciaciones han sido exageradas.

En este momento interesa establecer la posibilidad de responder a preguntas claves, generadas en el modelo andino. Una de estas preguntas se refiere a la naturaleza del sistema político preincaico. Durante el período colonial nos hallamos con cu- 
racazgos de poder relativamente atomizado. Ya hemos discutido en otros trabajos los casos de Juan Calchaquí (en torno a 1560) y Viltipoco en la Quebrada de Humanhuaca a fines del mismo siglo (Lorandi 1984b).

¿Responde esta situación colonial a la realidad prehispánica? ¿En qué medida la acción de los incas, al menos en el área diaguita, no colaboró en desarticular los señoríos de mayor envergadura? Muy bien pudo suceder, si nuestra hipótesis de conflicto es correcta, que se aplicara en la zona una política de derrocamiento de jefaturas o de subdivisión de poder, independizando "mitades" o desarticulando confederaciones que anteriormente formaban una unidad étnica o política, como sucedió en el Reino Chimor (Netherly 1984; Pease 1982). La existencia de un sistema dual, similar al andino, aparece fragmentariamente expresado en las fuentes, pero nunca se aplican términos como hanan o hurín. Hay, como ya lo citamos, curacas que comandan varias parcialidades. Pero también hay curacas que comandan una sola parcialidad, como el caso del cacique Culumpí de la parcialidad Tucumangasta, del pueblo de Culumpí (ver Autos Charcas 58). No conocemos cuál es la otra mitad, ni cuál es el curaca de la unidad étnica. ¿Es solo una situación colonial o era un pueblo multiétnico conformado por mitmakuna tucumanos y diaguitas? La interrogante queda sin resolver.

Lo más frecuente es que cuando se menciona a Viltipoco o a Juan Calchaquí como a "caciques principales" en sus respectivos valles, se haga referencia más bien a líderes capaces de amplias convocatorias y no a curacas que disfrutaban de un poder real y que gobernaban a una base tributaria que incluía a todas las poblaciones de sus respectivos valles.

En uno de los documentos incorporados a los Autos del proceso a Pedro Bohorquez se dice claramente:

...decimos que aunque algunos caciques e yndios del valle de pulares vinieran a la Ciudad de Salta a dar la paz en compañía del dicho Don Pedro Bohorquez y dicho Señor Oydor la aceptó, a ninguna persona de experiencia y conocimiento del natural de dichos yndios pareció de fundamento porque como es notorio todos savemos en esta provincia los dichos yndios no obedecen ni respetan a sus caciques y el que entre ellosse muestra más alentado y tiene más séquito ese se alza con el gobierno y se hace temer y respetar por causa de ellos... (Autos Charcas $58,3^{\circ}$ cuad.f.66).

De todas maneras, sabemos muy poco sobre el grado de poder efectivo del curaca principal en los grandes reinos o en confederaciones como la de los charcas. Esta situación del Noroeste argentino se asemeja mucho a la descrita para los Chachapoyas. Valen también aquí las observaciones de Fortes y Evans-Pritchard comentadas por Pease (1982).

Ya hemos avanzado algo respecto al sistema económico. Probamos la presencia del "control vertical" en la Quebrada de Humanhuaca (Lorandi 1984b) y es probable que exista otro caso fácil de analizar entre comunidades del Valle de Tafí (Tucumán actual y Tucumán prehispánico) y el Valle de Santa María. De esta forma, el área diaguita y el Tucumán no serían compartimientos estancos, sino vinculados por este sis- 
tema de control vertical. ¿En qué medida este mecanismo confundió a los observadores, cuando trataban de delimitar territorialidad?

Llegamos así a un punto donde el control vertical, resistencia diaguita y la definición de los límites del Tucumán prehispánico se vinculan en una problemática común. Tal vez, partiendo de este nudo podamos ver más claro en el futuro sobre la etnología regional y, como consecuencia, convalidar o rechazar nuestra hipótesis de conflicto para explicar la existencia de una frontera interior en el noroeste argentino.

\section{NOTAS}

1 Investigadora del CONICET. Directora del Instituto de Ciencias Antropológicas, Facultad de Filosofía y Letras. Universidad de Buenos Aires.

2 (Autos del proceso a Pedro Bohórquez, Legajo Charchas 58, 2o cuaderno, folio 25, del 12 de mayo de 1658 y folios 58 y 59 del 14 de junio de 1658, 3o cuaderno, folio 108 a 114 del 8 de julio de 1659, Autos, Charcas 58, ff 25, 58-59, ff, R-114). 


\section{BIBLIOGRAFIA}

Carrara, María T. y .A.M.Lorandi, et al.

1960 Punta de Balasto. Investigaciones arqueológicas en el valle de Santa María. Instituto de Antropología, Facultad de Filosofía y Letras. Universidad del Litoral 4:13-43. Rosario, Argentina.

Cieza de León, Pedro

1947 Guerras Civiles del Perú. Biblioteca de Autores Españoles. Ediciones [1553] Atlas. Madrid.

del Río, Mercedes y A.M. Presta

1984 Un estudio etnohistórico en los corregimientos de Tomina y Yamparaes: casos de multietnicidad. Runa. XIV:221-147. Buenos Aires.

Garcilaso de la Vega Inca

[1609] Los comentarios reales de los incas. Biblioteca de Autores Españoles. 1960 Ediciones Atlas. Madrid.

Krapovickas, Pedro

1978 Los indios de la Puna en el siglo XVI. Relaciones de la Sociedad Argentina de Antropología. XII:71-93. Buenos Aires.

1981-82 Hallazgos incaicos en Tilcara y Yacoraite (Una reinterpretación). Relaciones de la Sociedad Argentina de Antropología. XIV(2):67-81. Buenos Aires.

Leviller, Roberto

[1550-1602] La gobernación de Tucumán. Probanzas de méritos y servicios de

1919 los conquistadores. Documentos del Archivo de Indias. 2 Tomos

1920 (1550-1602). Madrid.

1926 Nueva crónica de la conquista del Tucumán. Madrid.

Lorandi, Ana María

1980 La frontera oriental de Tawantinsuyu: el Umasuyu y el Tucumán. Una hipótesis de trabajo. Relaciones de la Sociedad Argentina de Antropología. XIV(1):147-164. Buenos Aires.

1983 Mitayos y mitmaqkuna en el Tawantinsuyu meridional. Histórica. VII(1):3-50. Lima.

1984a Soñocamayoc. Los olleros del inka en los centros manufactureros del Tucumán. Revista del Museo de La Plata. VIII,62:303-327. La Plata, Argentina.

1984b Pleito de Juan Ochoa de Zárate por la posesión de los indios ocloyas. Un caso de verticalidad étnica o un relicto de archipiélago estatal? Runa. XIV:125-145. Buenos Aires.

sf Los trabajos y las rebeliones. Buenos Aires. 1986. 
Lozano, Pedro

1754 Historia de la Compañía de Jesús en la Provincia del Paraguay. T.I. Imprenta de la Viuda de Manuel Fernández. Madrid.

1874 Historia de la conquista del Paraguay. Colección de Obras y documentos y Noticias Inéditas o poco conocidas. Andrés Lamas, compilador. Buenos Aires.

Márquez Miranda, Fernando y E.M. Cigliano

1961 Problemas arqueológicos en la zona de Ingenio del Arenal (Provincia de Catamarca, Rep. Argentina). Revista del Museo de La Plata. Sec.Antrop.V. La Plata, Argentina.

Netherly, Patricia

1984 The Management of Late Andean Irrigation Systems on the North Coast of Peru. American Antiquity 49(2):227-254.

Pease, Franklin

1982 The formation of Tawantinsuyu: Mechanisms of colonization and relationships with ethnic groups". The Inca and Aztec States 1400-1800. Academic Press. New York.

Santa Cruz Pachacuti Yampqui, Joan de

[1613] Relación de antiguedades de este reyno del Pyru. Tres relaciones de 1950 antigüedades peruanas. Ediciones Guaranía. Asunción.

Torreblanca, Hernando

[1696] Relación histórica de Calchaquí. Biblioteca Nacional de Río de Janeiro. 1984 Colección de Angelis. Ediciones Culturales Argentinas. Edición Libre de T. Piossek Prebish. Buenos Aires.

Wachtel, Nathan

1980-81 Les mitimas de la vallée de Cochabamba. La politique de colonisation de Huayna Cápac. Journal de la Societé des Américanistes 67:297-327. París.

Williams, Verónica y A.M.Lorandi

1985 Evidencias funcionales de un establecimiento incaico del noroeste argentino. Ponencia presentada al 45 Congreso Internacional de Americanistas. Bogotá. 


\title{
COMENTARIO: LAS FRONTERAS DEL ESTADO INCA
}

\author{
Richard Schaedel
}

\begin{abstract}
Las fronteras externas del Tawantinsuyu estaban también en una correlación aproximada con la etnoecología andina aún cuando en el norte, parecen haber estado [los incas] más preocupados en el establecimiento de una frontera viable y defendible que restringidos por la dificultad de incorporar progresivamente más bosques de tierra alta en la economía del estado. Al este, el macronicho de las tierras bajas tropicales parece no haber desempeñado un papel en su léxico estratégico. Ya sea por lo costoso del esfuerzo o por fracasado intento (los incas nunca tuvieron éxito en desarrollar una estrategia de mobilización para penetrar la selva), ya sea debido a las tradiciones etnoecológicas establecidas desde hacía mucho tiempo, [los incas] sabían que los patrones de sedentarismo y de establecida transhumancia son intercambiables y que, por lo tanto, podían ser incorporados o vinculados a los Andes, pero que necesitaban ser reajustados totalmente en las tierras bajas a un ciclo de estaciones y periodicidad radicalmente diferentes. El haber intentado esta [campaña] hubiera arriesgado el desmembramiento de un elaborado y complejo sistema de coordinadas técnicas de explotación que ellos habían desarrollado, sin ninguna garantía de que la nueva conquista contribuiría de manera significativa al bienestar del estado. Del mismo modo, los densos bosques de la parte sur de Chile Central, planteaban problemas prácticos en cuanto a la extensión del sistema de caminos y hubieran arrojado una pobre proporción de costos y beneficios en términos del potencial ecológico. Aún cuando los incas examinaron la frontera occidental, parecen haber abandonado rápidamente el imaginativo concepto de volverse "lo marítimo", dejando ese potencial ecológico en las manos de la Provincia de Chincha como una concesión especial (Rostworoski en Schaedel 1978a:122-3).
\end{abstract}

La primera observación tiene que ver con la falta de una buena definición de consenso o, por lo menos, operativa de "frontera" entre los participantes del simposio. En primer lugar, existe una confusión entre el concepto "frontera", el cual, desde nuestro punto de vista, es casi por definición un concepto referente a un aparato estatal desarrollado, y el concepto de límites o linderos que es un concepto previo a la formación del estado, muy vinculado al concepto universal de territorialidad. Así, desde el punto de vista de los pueblos tribales en la periferia del estado inca, el problema se podría explicar en términos del mantenimiento, reajuste o redefinición de sus límites (por ejemplo, el caso de las tribus y los pueblos del Ecuador). Sin embargo, visto el asunto desde el interior del Tawantinsuyu debería ser definido como el principio para establecer una frontera que mantuviera la estabilidad y la seguridad de la repúbli$c a$. Nos referimos principalmente a una de las dos fases del segundo tema; aquí, observamos que lo que interesa es la presentación de datos sobre las diversas fronteras del Tawantinsuyu que nos permitan reconstruir los principios del gobierno inca que guiaban su "política de fronteras". Desafortunadamente, solo se trataron estos temas en forma marginal en algunos de los trabajos.

El primer y obvio obstáculo para una reconstrucción de la política inca de fronteras tiene que ver con algunas hipótesis expresamente presentadas como nuestra afirmación que para la época de Huayna Capac, la política consistía en "apuntalar" o es- 
tabilizar las fronteras. Otras hipótesis presentadas en forma implícita incluyen la hipótesis frecuentemente citada, pero enormemente exagerada, de Conrad (1984: 84151) sobre el "patrimonio dividido", según la cual el imperio seguía una política de expansión continua de sus fronteras. ¿Estaba el imperio incaico en proceso de expandirse, estabilizarse o, tal vez, reducirse?

Nosotros interpretaríamos la mayor parte de la evidencia citada en las colaboraciones, en particular las que tratan de la frontera sur, en apoyo de una política inca de consolidación. Dillehay y Gordon desarrollan el concepto de la frontera formalizada contra la no formalizada, lo cual interpretamos como los extremos establecidos, definibles y colonizables del imperio. La formalizada, en este caso, alcanza el área de Santiago hasta el Maipú; la no formalizada se refiere a un territorio de puestos de avanzada, dentro de una especie de zona de amortiguamiento político o una gran tierra de nadie, cuya función política era absorber la hostilidad esporádica y su función económica fue la creación de condiciones que permitieran el comercio externo. En el caso de Chile, incluiría el área al sur del Maipú, en la vecindad del Bío Bío e incluso hasta Chiloé.

Hyslop básicamente refuerza la proposición hecha por Dillehay y Gordon, distinguiendo entre las fronteras formalizadas y no formalizadas en todos los puntos cardinales aunque no ofrece una terminología para distinguir entre los límites que los incas protegieron e incorporaron y aquellos que se encontraban dentro de su "esfera de influencia".

Este mismo paradigma se podría aplicar a la frontera norte, sino fuera por la dificultad de delimitar el término "formalizado", tanto a lo largo de la costa como de las tierras altas. Tenemos la impresión de que Idrovo indicaba que en su área (la región marítima ecuatoriana y su traspaíso hinterland), la "frontera no formalizada" era de carácter operativo. Hyslop rechaza rotundamente que el grupo costero se encontrara dentro de la frontera formalizada. En cuanto a ésto quisiéramos citar dos breves artículos de Quilter (1982) y Mathewson (1982) que apoyan la posición de Hyslop y (suponemos también) la de Idrovo.

El artículo de Idrovo confirma el concepto de que la frontera noreste fue estabilizada en época temprana por una serie de fortalezas. Esta proposición acerca de como las fronteras orientales del Tawantinsuyu fueron defendidas, fue planteada por Hyslop, quien aboga por el fechamiento y examen arqueológico de las fortalezas a lo largo de toda la frontera oriental. Idrovo presenta en forma convincente que la serie de fortalezas desde "Gualaceo-Chordeleg-Sigsig y más hacia el este", representaron la frontera defensiva del noreste inca contra los jívaros shuar y las tribus del bosque tropical.

Idrovo confirma que tanto Ingapirca como Tomebamba eran capitales de provincia, pero que Tomebamba era evidentemente la más importante. Una importante pregunta, la cual deberíamos dilucidar utilizando los datos sobre la frontera ecuatoriana, es ¿Cuál era el estatus de Quito? 
Salomon, cuyo trabajo añade una nueva dimensión al estudio de la política inca de fronteras, parece confirmar que Quito ciertamente estaba "formalizadamente" emancipado como una provincia de primera magnitud. La débil base arqueológica para justificar esta afirmación no puede ser solamente atribuida al vandalismo español o a que los restos permanecen aún soterrados, sino más bien a un supuesto estado de inconclusión de los principales edificios y rasgos característicos. Nos atrevemos a especular que la contienda sobre la inversión asignada para la construcción de una impresionante capital provincial fue una de las razones para la guerra civil entre Atahualpa y Huascar, y que la depredación causada por la guerra misma ocasionó que el trabajo en la obra quedara inconcluso.

El ensayo de Morris tiende a presentar un andamiaje más bien frágil para sostener la superestructura gubernamental inca (la cual probablemente podría apoyar una noción de "ausencia de una política de fronteras" o en el mejor de los casos de una política $a d h o c$ ), que para nosotros entra en conflicto con las implicaciones generales de los otros trabajos. Morris informa acerca de los resultados preliminares de sus investigaciones en Chincha y sobre la operación de la concesión para el comercio foráneo, un mecanismo inca para tratar con las relaciones económicas más allá de la frontera noroeste del Tawantinsuyu por medio de la Provincia de Chincha. Sus datos deberían haber sido relacionados, de alguna manera, con el estudio de Marcos sobre la región costera ecuatoriana en la época inca. De toda la información que tenemos sobre la costa ecuatoriana (arqueológica, etnohistórica e histórica), es evidente que ésta era una zona de libre comercio y confrontación multiétnica. Parece que Chincha tenía la base infraestructural necesaria para llevar a cabo el comercio extranjero regular, así como garantizar al estado el suministro constante de mullu. Así, el mantenimiento de esta frontera no formalizada parece formar parte de la política inca de consolidación (la hipótesis que particularmente defendemos). Los incas emanciparon a Chincha y le garantizaron un trato especial para facilitar el transporte rápido entre el puerto de entrada, La Centinela y la capital, Cuzco.

De haber sido la política de expansión de los incas (como Morris correctamente conjetura) una actitud deliberada de "manos quedas", la costa ecuatoriana no tendría sentido y se esperaría un despliegue considerable de tropas en las campañas ecuatorianas de las regiones costeras.

Parece haber poco apoyo para la conjetura original de Morris sobre la "heterogeneidad demostrada del Tawantinsuyu" (en enfasis nuestra). Si acaso, su caso apoya el punto de vista de una política de fronteras única y homogénea, lo cual está contenido en el párrafo citado al comienzo de esta discusión.

El trabajo de Lorandi es de más difícil discusión. Sin embargo, parece que Tucumán, como región al sureste, podría ser comparada con Chile en el sur, en cuanto a que ambos tienen una zona formalizada de frontera y otra zona no formalizada. Lo que crea más bien confusión en el escrito de Lorandi es el uso liberal del término mitima aplicado a la frontera suroriental. Se nos ocurre que el gobierno inca se distinguía por su genialidad conceptual, la enunciación de su política y la uniformidad en 
su ejecución. Múltiples evidencias provenientes de más de cien años de estudio de las fuentes históricas y etnohistóricas sobre los Andes, justifican ampliamente el concepto bifuncional de mitima como lo explicó Espinosa (1969-70:10ff): 1) de seguridad y contra insurección y, 2) económico.

El ensayo de Lorandi deja la impresión que grupos de las provincias recién conquistadas estaban siendo establecidos como mitimas en la última provincia conquistada. En el tratamiento que Rex González (1982) da al problema, habría habido solamente un grupo especial de mitimas hablante de aymara, desde luego no originarios de lo que ahora constituye el noroeste de Argentina desempeñando ese papel protector a lo largo de la frontera inca suroriental. Las provincias incas, según Rex González, son de norte a sur: 1) Humahuaca (con capital Pucara de Tilcara); 2) Chicoana (con capital La Paya); 3) Quiri-quiri (con capital Tolombón) y, 4) una al sur cuya frontera meridional podría estar cerca del actual Mendoza y cuya capital podría haber sido Chilecito.

Es de lamentar que Lorandi no haga ninguna referencia al trabajo de Rex González o a la igualmente importante contribución arqueológica de Raffino (1981), en la clarificación de la frontera suroriental del Tawantinsuyu.

También, lamentamos que los colegas argentinos no se pongan de acuerdo en cuanto a los puntos sobre los que discrepan, al menos, para ofrecernos designaciones equivalentes para los grupos étnicos que diferencian. Así, el título del trabajo de Lorandi se refiere a los diaguitas, un término que Rex González no utiliza, pero sobre el que está claro que corresponde a los naturales de su provincia de Quiri-quiri. Además, los diaguitas también pueden ser equivalentes con otra clasificación étnica, los calchaquíes.

El punto que Lorandi solo sugiere (es decir, ¿A qué hace referencia Tucumán dentro de las designaciones del Tawantinsuyu?) es aludido bastante claramente en el estudio de Rex González o sea que representa una macroregión que se asemeja mucho a la implicada en el término Collao y (como supondríamos) también Chile, término bajo el cual una serie de provincias fueron incluidas pero nunca definidas expresamente.

A pesar de que felicitamos a Dillehay y Gordon por la valiosa distinción conceptual entre las fronteras geopolíticas y económicas (formalizadas y no formalizadas, como preferimos), se puede poner en tela de juicio su interpretación de que la frontera meridional (chilena) proporciona evidencias en apoyo de la idea de una política expansionista de fronteras. Permítasenos citar lo que parece querer dar a entender como el propósito de la frontera no formalizada.

"El otro límite fue el resultado de una política calculada de penetración pacífica, no formalizada, pero expansiva, que iba conduciendo (y habría conducido a la postre) al dominio territorial." (Este tomo p, 194). (El énfasis es nuestro).

En primer lugar, las actividades del estado más allá de la frontera formalizada parecen estar limitadas a la búsqueda de recursos minerales y al establecimiento de for- 
talezas, no tanto como avanzadas defendibles sino como sitios para albergar a los destacamentos de los pocos empleados del estado, encargados de la tarea de explotación del mineral. De haber sido el objetivo la expansión del imperio, tendrían que haber indicios que señalen fines económicos, distintos de las actividades mineras. Hacia donde los incas se expandieron, colonizaron, es decir, tomaron nuevas tierras bajo cultivo (ésto está indicado en los antiguos canales cerca de La Chena y en la provincia más meridional de la Argentina). Parece bastante claro que al sur del Maipú, el cambio ecológico hizo perder el atractivo para la intensificación del cultivo o, por lo menos (dados los problemas del desmonte), impidió que fuera rentable económicamente.

La evidencia etnohistórica indica que la "penetración pacífica no formalizada", no era pacífica (Poma de Ayala [1615] 1980:136). La evidencia arqueológica es la que indica que después del establecimiento de la frontera las cosas se desarrollaron más pacíficamente, lo cual sugeriría que ambos lados coexistían en paz cuando los españoles llegaron y no en base a un "desequilibrio estructurado" como los autores quieren hacernos creer.

Los otros trabajos que se refieren a Chile padecen del defecto general que aqueja a este simposio, es decir, que no nos dicen mucho sobre las fronteras, sino que discuten el tipo de ocupación inca entre los lejanos grupos étnicos y su conversión en "provincias". Stehberg y Carvajal informan sobre el camino inca que vinculaba lo que sería la hipotética provincia de La Serena-Copiapó (diaguitas chilenos) con la provincia fronteriza de Santiago. Niemeyer y Schiappacasse extienden la presentación sobre el camino y provincias chilenas a un área tan distante como Arica. Parecieran (aunque los autores no llegan tan lejos como Rex González en su publicación sobre las provincias incas argentinas) querer identificar a Saguare II, en el piedemonte de la minúscula Quebrada Camarones, como la capital provincial de la zona agrícola en el extremo norte (Schaedel 1957). De la misma manera, confirman la identificación de Catarpe hecha por la Paige como la capital provincial de la región atacameña, la provincia más próxima al sur. Resumiendo, de las contribuciones chilenas y argentinas a este simposio, podemos afirmar que en la última década se ha avanzado considerablemente en la definición de las unidades provinciales incas y, aunque ésto no fuera el tema principal de esta reunión, ha servido para enfocar la atención en estos nuevos descubrimientos. Sería muy valioso llegar a un consenso sobre las provincias propuestas.

Uno de los aspectos del trabajo de Netherly que, a juzgar por el título, esperábamos se tratara fue la reconstrucción de la política chimú de fronteras, puesto que ya nos habíamos aventurado a expresar una hipótesis en cuanto a que la suya era una política de tipo "Línea Maginot" (Schaedel 1978b:42). Teniendo en cuenta que la autora se limitó a discutir cómo los incas incorporaron al Reino Chimor al Tawuantinsu$\mathrm{yu}$, asunto que, en nuestra opinión, estaba al margen del tema de este simposio, quisiéramos debatir algunos puntos comparando la política chimú de fronteras con la inca. Por una parte, ambas tenían en común una técnica para definir las fronteras estatales y provinciales (véase "amojonadores" en Poma 1980:324-5). Las avanzadas no formalizadas de guarniciones incas son el equivalente de los muros de defensa (Línea Maginot) de los chimús. Los muros de la frontera occidental se extendían completa- 
mente a través del alto chaupiyunga. Hasta ahora, no se han encontrado demarcaciones fronterizas norte-sur (aunque el paralelismo de los límites extremos aboga por un período de, quizás, una generación para el establecimiento de los límites de Tumbez y Carabayllo. Aquí vale la pena examinar la función de Paramonga dentro de todo este esquema, puesto que le ha sido atribuido tanto a los incas como a los chimús. Parece estar bastante claro que existe una notable falta de evidencia arqueológica para identificarlo con una ocupación chimú o con la primera construcción. Se cuenta con evidencia para una tardía ocupación y remodelación inca que parecen tener una naturaleza más ritual que funcional (Langlois 1938:42; Wiener 1880:495). Es concebible que fuera restaurado por los incas durante su campaña sur-norte vía la costa como un baluarte fronterizo, mientras reagrupaban sus fuerzas para atacar Chimor por el norte y este. De todos modos, parece que el edificio fue originalmente construido en época preinca como parte de un complejo del Período Intermedio Tardío bastante extenso y, por lo visto, fue conquistado por los chimús sin que llegaran a utilizarlo.

Pasando a las diferencias en la estrategia de fronteras chimú e inca, se puede deducir que los chimús, ciertamente, tenían una "mentalidad de Línea Maginot" y que ésto se fundamentaba en consideraciones ecológicas. Obviamente, desde el punto de vista estratégico, se encontraban en una situación de desventaja con respecto a los grupos en la sierra. Por ello, preferían una política de alianzas del tipo de "defensa mutua", parecida a la puesta en práctica por los incas al comienzo de su expansión, cuando se aliaron con los distantes Lupacas contra la posición intermedia de los Collaos, para apaciguar a los potencialmente explosivos serranos. Tampoco creaban disturbios en la frontera de Tumbez. Parecería que su política de consesiones frente al "comercio extranjero" citado por Calancha, podría haber sido utilizado en el extremo norte del Perú y, tal vez en la costa central. Se sabe muy poco acerca del carácter de la expansión chimú, pero, sin duda, sus técnicas no eran del tipo de Blitzkrieg inca. La expansión chimú parece más bien haber sido cimentada con alianzas matrimoniales y coparticipación en Chan Chan de los cabezas de linaje provinciales recientemente incorporados que por medio del robustecimiento de las élites provinciales en sus propios territorios una vez que su lealtad parecía segura.

En cuanto a la política inca frente a Chimor que trata Netherly, vale la pena observar que aquí, en contraste con las fronteras de la sierra, es de presumir que las guarniciones apostadas por los incas no eran insignificantes (sostendríamos que Cinto-Patapo y Cerro Corbacho en Zaña podrían haber sido dos puntos potenciales de guarnición inca en la costa) para mantener la nueva y bastante prolongada frontera occidental que heredaron de Minchancaman. Así, prefirieron adoptar una política tripartita de: 1) despoblación o reducción de la densidad demográfica enviando gran cantidad de mitimas chimús a otras partes (en algunos casos mezclando la población de valles contiguos); 2) utilización de puntos de control en la sierra para recolectar y redistribuir el "tributo", un punto que enfatizan tanto Netherly como Susan Ramírez en varias publicaciones; 3) una política "balcánica" (enunciada anteriormente). Nadie está muy seguro de cómo las provincias incas fueron sobrepuestas a la estructura Chimor pero nuestra hipótesis es que había por lo menos ocho (Schaedel 1985:452-3). 
Esto parece ser razonable, desde el punto de vista demográfico, si asumimos una población mínima de 1,000,000 para Chimor.

Se pueden hacer conjeturas acerca de la paradoja que resulta de comparar esta política de fronteras con los eventos reales de la conquista española, en cuanto al porqué ésta fue tan fácil de efectuar, dada la increíble desproporción de fuerzas militares, de haber sido los incas (como hemos dicho) tan astutos en el diseño de su política de fronteras. Es evidente que la frontera de más fácil defensa militarmente era la noroccidental. Parecería que no existía una fuerte amenaza de parte de las beligerantes tribus o señoríos marítimos de la costa ecuatoriana, y que los señoríos débilmente defendidos y no belicosos que habían sido moldeados dentro del estado chimú, se separaron en unidades provinciales incas independientes relativamente dóciles. ¿Dónde radicaba entonces el peligro? En esencia los incas tenían una política adecuada y pragmática en la frontera norte, dejando el riesgo a los vasallos de Tumbez y a los comerciantes marinos de Chincha. Toda la costa septentrional fue dejada en un estado de benigno abandono. De todas maneras, en nuestro análisis de la política inca de fronteras, hay razón para comprender el establecimiento de fronteras en el noroccidente donde aquella no podía alcanzar su capacidad cohesiva, exactamente como sucedió en el noreste, sur y sureste. El que los incas se hayan esforzado muy poco en la "consolidación" del noroeste, se puede atribuir al hecho que ya había sido consolidado hasta Tumbez por los chimús.

Para finalizar, unas palabras de felicitación a los organizadores de este simposio por haber reunido a la mayoría de los investigadores dedicados al estudio de las fronteras del Tawantinsuyu. Cabe agregar que de las únicas áreas que fueron dejadas al margen, la extendida frontera de los Chachapoyas fue recientemente sujeto de serias investigaciones por parte de Lerche (1986) y Schjellerup (1984). Por otra parte, sobre el sureste de Bolivia (desde Cochabamba hasta la frontera argentina), del Río y Presta (1984) realizaron un interesante estudio etnohistórico. 


\section{BIBLIOGRAFÍA}

Conrad, Geoffrey y Arthur Demarest

1984 Religion and Empire: The Dynamics of Aztec and Inca Expansionism. Cambridge University Press. New York.

Del Río, María de las Mercedes y Ana María Presta

1984 Un estudio etnohistórico en los corregimientos de tomima y amparaez: casos de multietnicidad. Runa. 14:221-246. Buenos Aires.

Espinoza Soriano, Waldemar

1969-70 Los mitmas yungas de Collique en Cajamarca, siglos XV, XVI, XVII. Revista del Museo Nacional. 36:9-59. Lima.

Fernández, Jorge

1978 Los chichas, los lipes y un posible enclave de la cultura de San Pedro de Atacama en el zona limítrofe argentino-boliviana. Estudios Atacameños. 6:19-35 Antofagasta, Chile.

Langlois, Louis

1938 Paramonga. Revista del Museo Nacional. 7:1:21-52. Lima.

Lerche, Peter

1986 Hauptlingstum Jalca: Bevolkerung und Resourcen bei den vorspanischen Chachapoya, Peru. Dietrich Reimer Verlag. Berlin.

Mathewson, Kent

1982 Bridging the Guayas River Gap: Legend and Landscape Archaeology in Coastal Ecuador. Andean Perspective Newsletter 4:15-20. Austin.

Meyers, Albert

1976 Die Inka in Ekuador. Bonner Amerikanische Studien. Bonn.

Netherly, Patricia J.

1977 Local Level Lords on the North Coast of Peru. Tesis Doctoral inédita. Department of Anthropology, Cornell University. University Microfilms International. Ann Arbor, Michigan, Estados Unidos.

Poma de Ayala, Felipe Guamán

1980 El primer nueva crónica y buen gobierno. Edición crítica de John V. Murra y Rolena Adorno. Siglo Veintiuno. México.

Quilter, Jeffrey

1982 Why the Inca Coastal Road Stopped at Tumbes. Andean Perspective Newsletter. 4:10-14. Austin, TX, Estados Unidos.

Raffino, Rodolfo A.

1989 Los inkas de Illasuyu. Ramos Americana Editores. La Plata, Argentina. 
Ramírez, Susan

1985 Social Frontiers and theTerritorial Base of Curacazgos. Andean Ecology and Civilization. Shozo Asuda, Izumi Shimada y Craig Morris, compiladores. pp. 423-442. University of Tokyo Press. Tokyo.

Rex González, Alberto

1982 Las "provincias" inca del antiguo Tucumán. Revista del Museo Nacional. Lima. 46:317-380.

Rex González, Alberto

1986 Inca Settlement Patterns in a Marginal Province of the Empire. Sociocultural Implications Symposium. pp.337-360. Burg Wartenstein.

Schaedel, Richard P.

1957 Informe general sobre la expedición a la zona comprendida entre Arica y La Serena. En Arqueología Chilena 1:5-42. Santiago.

1978a Formation of the Inca State. En El hombre y la cultura andina. Ramiro Matos, compilador. 1:112-156. Lima.

1978b The City and the Origin of the State in America. En Urbanization in the Americas from its Beginning to the Present. Richard P. Schaedel, Jorge E. Hardoy y Nora Scott Kinzer, compiladores. Pág.31-49. Mouton Press. La Haya, Paíse Bajos.

1985 Coast-highland Interrelationships and Ethnic groups in Northern Peru (500 B.C.-A.D.1980). En Andean Ecology and Civilization. S.Masuda, I.Shimada, y C.Morris, compiladores, Pág.443-474. University of Tokyo. Tokyo.

Salomon, Frank

1980 Los señores étnicos de Quito en la época de los incas. Instituto Otavaleño de Antropología. Serie Pendoneros. No.10. Otavalo, Ecuador.

Schjellerup, Inge

1984 Cochabamba - an Incaic Administrative Center in the Rebellious Province of Chachapoyas. En Current Archaeological Projects in the Central Andes. Ann, Kendall, compliadora. B.A.R. Oxford, Inglaterra.

Wiener, Charles

1880 Pérou et Bolivie. París. 


\title{
EPILOGO
}

\author{
Tom Dillehay \\ Patricia Netherly
}

La diversidad de tópicos tratados a lo largo del simposio ejemplifica los avances y problemas que ofrece el estudio del tema sobre los límites fronterizos del imperio inca. Pudo notarse, también, la ausencia virtual de información sobre las áreas correspondientes a Colombia y Bolivia, lo mismo la falta de un marco teórico que permitiese el tratamiento de una información tan diversa como la presentada en las reuniones de Bogotá. Si bien todos los participantes compartían el interés general por el tema de los estados fronterizos, el tratamiento del problema, los enfoques y el cuerpo de datos varió de investigador a investigador. Con la sola excepción del trabajo presentado por Hyslop, quien analizaba el problema en relación al territorio imperial en su conjunto, las demás ponencias son de carácter regional. Obviamente, los estudios locales son importantes para el entendimiento del problema general; sin embargo, no alcanza a suplir la necesidad de un cuerpo teórico que coadyuve al análisis del conjunto de conclusiones obtenidas en cada estudio.

A pesar de estas limitaciones, el simposio fue exitoso en cuanto se informó a los participantes y al público interesado del estado de las investigaciones. De mayor importancia fue aún el reconocimiento de una serie de problemas vinculados al estudio de los estados de frontera. Uno de ellos fue la percepción de distintos tipos de límites fronterizos: límites firmemente controlados; sectores de expansión o recientemente sometidos; límites de frontera trazados paralelos o incluyendo grupos étnicos asentados con anterioridad a la llegada de los incas; límites en disputa y la diferencia entre las fronteras formalizadas y no formalizadas. También tenemos la consideración presentada por Morris sobre la conveniencia de asumir que un estado debe conceptualizarse como las relaciones que mantienen sus partes, más que como una unidad definida por sus límites externos. Adicionalmente, adquirimos el conocimiento que los estados fronterizos definidos por la documentación histórica deben ser confirmados por la evidencia arqueológica. La presencia de cerámica inca u otros materiales culturales no es siempre sinónimo de la existencia de una frontera formalizada, dado que dichos restos pueden ser solamente la evidencia de actividad comercial o de un contacto esporádico. Estos problemas de verificación y de empleo del material arqueológico para el tratamiento de este problema es también aplicable a otros estados prehispánicos de los Andes Centrales, como por ejemplo el estado norteño de Chimor. Nuestra tarea es ahora la de reconocer y entender los diferentes tipos de instituciones estatales, la interacción con los grupos locales y los cambios sociales y económicos ocurridos a consecuencia de dicho contacto. En otras palabras, qué tipo de factores fronterizos (sociales, políticos, económicos, geográficos, etc.) determinaron el contexto donde se moldeó y desarrolló el control del estado inca.

Este simposio ha ofrecido una de las pocas oportunidades en que los investigadores especializados en el área andina se han reunido para encontrar una explicación al 
problema de los estados fronterizos durante el Período Inca. En los últimos años se han realizado significativos avances en el estudio arqueológico y etnohistórico del imperio inca. Numerosos proyectos arqueológicos, no necesariamente concentrados en el tema sobre los límites territoriales, han incrementado materialmente nuestro conocimiento sobre la amplitud e intensidad de la ocupación inca en los Andes. Además, en años recientes se ha avanzado mucho en el conocimiento de la estructura de los asentamientos incas, vale decir: la división espacial, funcional y jerárquica de sus componentes; la complejidad de la organización local y regional inca; el significado de la presencia de determinadas estructuras arquitectónicas; el objetivo y naturaleza de las redes de caminos y del sistema de riego; la interacción entre las instituciones locales y las impuestas por el estado vencedor y la naturaleza del contacto cultural entre el grupo dominante y el dominado.

No obstante, existen numerosos problemas que afectan al estudio arqueológico de la cultura inca. Uno de esos problemas es la relativa escasez de estudios arqueológicos que se hayan dedicado exhaustivamente a la descripción de los sitios ubicados en los Andes. Esta situación podría solucionarse realizando investigaciones que se ocupen del tema sobre los límites territoriales del estado expansionista. Algunos avances se han realizado en los años pasados, pero aún queda mucho por hacer, en particular en relación a la ubicación geográfica de los estados fronterizos y la especificación de la naturaleza de las instituciones establecidas por el grupo gobernante. En cierta medida, nuestra habilidad para entender el desarrollo del estado inca está restringida por la escasez de información sobre las poblaciones locales. Es claro que la elaboración de cualquier modelo nunca habrá de estar completo, sin que se profundice la investigación en la zona oriental del imperio. Es interesante mencionar que todas las áreas del imperio inca, internas o externas, fueron algunas veces fronteras de este estado en continuo proceso de expansión. De esta manera, es posible afirmar que el principal problema por resolver es la cronología inca. Hasta que no se entiendan claramente los límites de las fronteras internas y no se hayan ordenado cronológicamente, será muy difícil relacionar el desarrollo de las diversas instituciones creadas por el Tawantinsuyo a lo largo de su territorio, con el proceso de evolución y cambio del estado mismo.

Todo lo anterior hace evidente la necesidad que los etnohistoriadores trabajen en estrecha vinculación con los arqueólogos en la determinación de la extensión del estado y del tipo de límites establecidos por ese grupo en las diferentes regiones de los Andes. Aunque, la evidencia histórica puede ayudar en la detección de detalles específicos sobre la localización y relación de los distintos grupos establecidos a lo largo de las fronteras, solamente la arqueología tiene los elementos para verificar la presencia del estado dominante y, tal vez, establecer la naturaleza y el grado de la forma de ocupación. Aún cuando en las últimas décadas los etnohistoriadores han intentado comprobar una serie de hipótesis, elaboradas en base a documentos, utilizando el material cultural de un grupo étnico específico y la distribución espacial y características arquitectónicas de ciertos complejos arqueológicos, quedan una serie de detalles culturales como son la cerámica, los restos líticos, los metales, etc., que no dan lugar para ser empleados por dichos investigadores. Es obvio, que todos esos 
aspectos no pueden ser incluidos en una síntesis etnohistórica, sin embargo, constituyen un área donde los arqueólogos podrían elaborar un valioso cuerpo de información que podría compararse con los rasgos de distribución espacial y arquitectónica. Por otro lado, son estos aspectos de la cultura material que ayudan a los arqueólogos a estudiar los procesos sociales y económicos que llevaron a un determinado grupo a desarrollar un gobierno por un estado. La cerámica, por ejemplo, ha sido usada en la determinación de jerarquías sociales, especialización económica y la caracterización de la producción y el consumo, todo lo cual ayuda a entender el proceso de control social y político.

La necesidad de realizar esta colaboración para obtener una mejor comprensión del estado inca, se ve limitada por la carencia de material arqueológico que proporcione una base sólida para ese intercambio metodológico y temático. La ausencia de una cooperación constante entre etnohistoriadores y arqueólogos está ejemplificada en la extrema diversidad de datos y temas presentados en este simposio, lo cual es, también, la lógica consecuencia de la falta de criterios adecuados de evaluación de los temas a investigar. La extrema dispersión de intereses y datos necesita hacerse explícita para integrarla, con el objeto de disponer de un marco teórico que facilite la formulación de investigaciones multidisciplinarias. Creemos que puede finalizarse esta exposición sumaria del simposio sobre las "Fronteras del estado inca", indicando que queda mucho trabajo por realizar como paso previo para llegar a un mejor entendimiento del fenómeno de los límites territoriales y el estado inca. 


\section{PUBLICACIONES DE LA FUNDACION \\ ALEXANDER VON HUMBOLDT}

\section{FRONTERAS DE INVESTIGACION}

\section{Año 1 No. 1}

\section{Artículos}

Costanza Di Capua

J. Stephen Athens

Patricia Netherly

Arthur Rostoker

Warren DeBoer

Eduardo Almeida Reyes

Tom D. Dillehay
Una atribución cultural controvertida

Paleoambiente del Oriente ecuatoriano

Loma y ribera: Patrones de asentamiento prehistóricos en la Amazonía ecuatoriana

Provincias alfareras en la prehistoria del Oriente ecuatoriano

Discusión para el simposium: La Amazonía occidental

Los roperos de La Calera en la comunidad campesina de Rumicucho

Sobre el poblamiento inicial de Sudamérica

\section{Informes}

Shuichi Odairea

Mirador de Moyepungo: Un sitio incaico en el sur de la Provincia de Azuay

Jorge Arellano

Loma Pucareá: Un asentamiento del Formativo Tardío en el Valle de Cehadas, Sierra Central del Ecuador.

Números sueltos disponibles.

Precio al Exterior US $\$ 15.00$ mas $\$ 5.00$ franquicia

Precio nacional: S/.30,000.

Pedidos a la Fundación Alexander von Humboldt, Casilla 17-21-1202, Quito, Ecuador 


\section{FRONTERAS DE INVESTIGACION}

Año 1 No. 2

\section{Artículos}

Deborah Truhan,

El cinabriuo en el mundo andino

James H. Burton

y Karen Olsen Bruhns

David O. Brown

La venganza de los apus: Patrones de asentamiento inka en la Sierra Central del Ecuador

Patricia J. Netherly y

La dualidad en la arquitectura Tom D. Dillehay pública en el Valle Alto del Zaña

Cristóbal Campana

Una deidad antropomorfa en el Formativo andino

Alberto Di Capua

Malaspina en el Ecuador

Irina Xomchuk

Las obligaciones teributarias y otros haberes de los indígenas de la antigua provincia de Guayaquil en el período colonial

\section{Informes:}

J. Stephen Athens

Cronología cultural y agricultura prehistórica: Investigaciones arqueológicas en la Sierra Norte del Ecuador, 1989, 1994, y 1997

César Veinteimilla

Análsis de opal-fitolitos en camellones del sector Puntiachil, Canton Cayambe, Provincia de Pichincha

Números sueltos disponibles.

Precio al Exterior US $\$ 15.00$ mas $\$ 5.00$ franquicia

Precio nacional: $\mathrm{S} / .30,000$.

Pedidos a la Fundación Alexander von Humboldt,

Casilla 17-21-1202, Quito, Ecuador 